\title{
Teaching and learning New Zealand's difficult history of colonisation in secondary school contexts
}

\author{
Michael Edward Harcourt
}

A thesis submitted to the Victoria University of Wellington in fulfilment of the requirements for the degree of Doctor of Philosophy in Education

2020

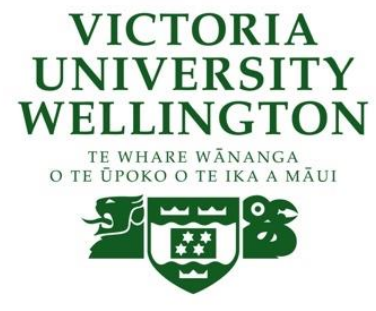



Will people step up now and take the time to learn, know and feel the history of the places they call home?

Rachel Buchanan, Ko Taranaki Te Maunga (2018, p. 103)

I feel like when you are at Parihaka, you can't at all say to yourself that the past doesn't matter

Carolin Hamblin, student, Western College 



\begin{abstract}
In recent years, awareness of New Zealand's history of colonial injustice has grown in national consciousness. This awareness has led to much questioning of history education, particularly New Zealand's high autonomy curriculum and its capacity to ensure that all young people encounter these 'difficult' aspects of the past. Yet little is known about the experiences of secondary school teachers and students during lessons on New Zealand's history of colonisation. This study aimed to explore how teachers and students engaged with the history of colonisation, including how a sample of effective teachers and their students confronted the challenges and complexities of these pedagogical encounters. The importance of understanding this became even more significant when in 2019, the government surprised many by announcing that New Zealand history will become a compulsory feature of the curriculum at all levels of school from 2022. This thesis contributes to the new challenge of implementing compulsory curriculum content by developing a deeper understanding of the complexities currently experienced by teachers and students during lessons on colonisation.
\end{abstract}

History education that focuses on historical forms of violence and its representation in curriculum is commonly referred to as the study of 'difficult history' (Epstein \& Peck, 2018). In New Zealand, the early European colonists acquired land from the Indigenous Māori people resulting in inter-generational forms of suffering, trauma and oppression. In such a 'settler society' the history of one's own nation and its instances of colonial injustice present challenges because the descendants of the early colonists remain, owning the majority of land and controlling to a large extent political systems and institutions, including schools. This thesis extends the research on difficult history by focusing on the challenges of teaching and learning the history of colonisation in New Zealand, particularly as it relates to the power dynamics of a settler society. It plays close attention to the pedagogical complexities of place and emotion and is situated within a broad framework of critical theory which seeks to explicitly acknowledge the significance of Indigenous systems of knowledge.

Using a mixed method approach, this study presents findings drawn from a survey of teachers $(n=298)$ and students $(n=1889)$ and a multiple-site case study using qualitative approaches at four schools. In addition to classrooom based research, the study also investigated students' 
experiences during field trips to places of colonial violence. Data gathering methods included interviews, semi-structured focus groups, classroom and field trip observations and a studentled photography task.

Analysis of the data showed that history and social studies teachers overwhelmingly expressed critical views about the nature of colonisation and recognised that, for example, colonisation reverberates in the present and that its consequences were destructive, primarily for Māori. Teachers also comprehensively endorsed inquiry-led and discussion-based pedagogical approaches that were attentive to the conventions of the discipline of history. Some dominant conceptions, however, revealed barriers that prevented teachers' collective ability to engage more deeply with this history, especially Māori perspectives. Students also expressed critical views about colonisation, but many still understood this process as a discrete 'event' found only in the past, reducing their ability to consider the implications of the past for today. Furthermore, while the majority of students were receptive to learning the history of colonisation, a significant proportion were not. The ethnographic component of the study revealed a number of complexities that hindered deeper engagement with the past. This included dealing with discomfort and resistance to histories of colonisation and the challenges teachers faced in forming relationships with iwi and hapū. The ethnographic component also showed that school field trips to sites of colonial violence held potential to operate as place-based 'counter narratives' that could transform students' prior conceptions and deepen their engagement with difficult histories of place.

The study concludes that two key 'patterns of engagement' shaped teachers' and students' encounters with New Zealand's history of colonisation. In the first, many teachers struggled to engage pedagogically with Māori perspectives and approaches to the past, which made the curriculum goal of acknowledging and validating Indigenous systems of knowledge less likely. In the second, students' emotional discomfort functioned as a complex and everpresent dynamic that potentially deepened but at times reduced their engagement with difficult histories of colonisation. Collectively these findings have implications for classroom practice and policy reform that take on a renewed urgency with New Zealand's move toward compulsory teaching of New Zealand history. 


\section{ACKNOWLEDGEMENTS AND DEDICATION}

Very early on in my teaching career, the now departed Jim Neyland put me on to the academic pathway of completing a PhD. For his teaching and mentorship, I continue to be grateful.

Over the course of this thesis and in the years prior to it, I have enjoyed enormous friendship, generosity, hospitality and academic support from Terrie Epstein, Keith Barton, Alison Kitson, Richard Manning, Andrea Milligan, Robin Cohen, Lisa Purcell and Katharine Burn. I also owe a debt of gratitude to Peter Adds and Michael Johnston from Victoria University and Tom Roa from the University of Waikato for providing much needed advice at various stages of this thesis. Bridget Williams, Tom Rennie and Vincent O'Malley have also been supportive and encouraging.

Doug Mason and Andrew Savage have been outstanding friends to have alongside me during this journey. Over three years of study, I have also benefitted from the friendship and encouragement of a number of fellow PhD students: Rachel Tallon, Kevin Haunui, Liana Macdonald, Ethel Renata, Amy Austin, Liwei Liu and Hine Funaki.

Without the Victoria University Doctoral Scholarship, I simply could not have written this thesis. To the Quaker Education Fund Committee also, I am extremely grateful for the provision of such a generous grant.

I continue to be in awe of Caitlin, Hannah, Sarah and Peter, the teachers who let me sit in their classrooms, talk to them and participate in field trips. Their powerful teaching is an inspiration. Their students, who I started to get to know during the fieldwork stage, were also exceptionally generous with their time and comments.

I could not have asked for better supervisors in Mark Sheehan and Bronwyn Wood. I learned an extraordinary amount from their mentorship and scholarly approach to education and research. Like my earlier supervision from Jim Neyland, theirs will reverberate in my life for decades to come. 
I cannot thank enough my parents, Tony and Elizabeth Harcourt, and my parents-in-law, Pat and Marie-Ann Quin for the invaluable encouragement and support they have given me with childcare, random meals, accommodation, providing quiet spaces for study, to name only a handful of things.

Finally, to my wife Esther. Your support has been unwavering from beginning to end. So many people helped to make this thesis possible, but you were the keystone. 
For my two children, Leah and Thomas. 


\section{TABLE OF CONTENTS}

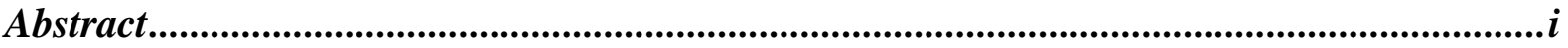

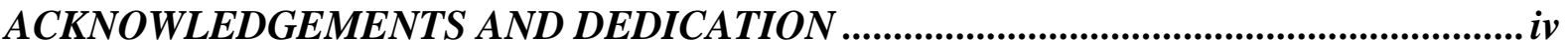

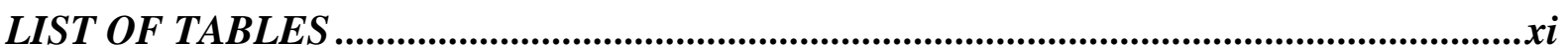

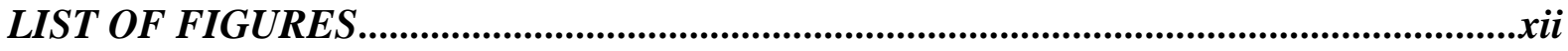

GLOSSARY OF TERMS AND NOTES ON LANGUAGE ......................................... xiii

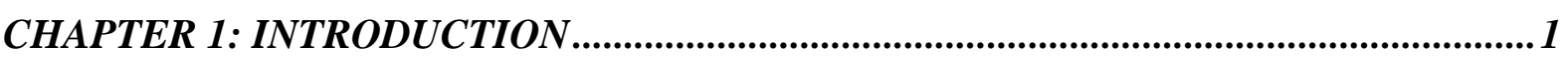

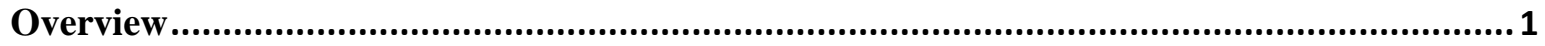

Research problem and the curriculum context of this study.................................................. 1

The personal and social significance of this study ............................................................ 5

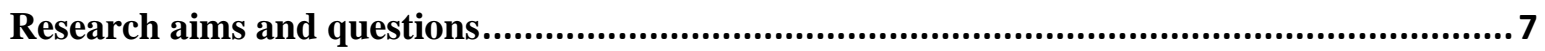

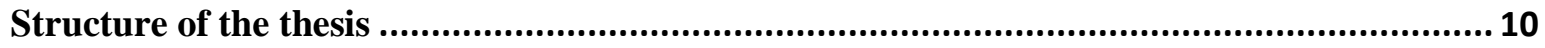

CHAPTER 2: A REVIEW OF THE LITERATURE - KEY DEBATES AND

PERSPECTIVES ON TEACHING AND LEARNING DIFFICULT HISTORIES OF

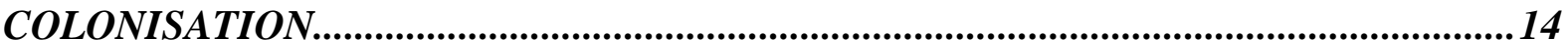

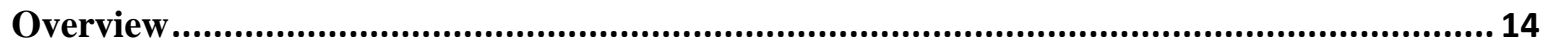

Teaching and learning difficult history in settler colonial contexts .................................... 14

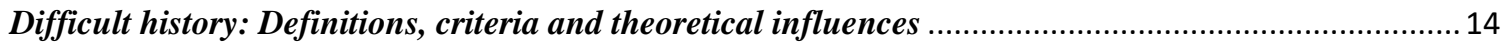

Settler colonialism and history education ..................................................................................... 17

Existing studies on history education and teaching about colonisation in New Zealand, Australia and

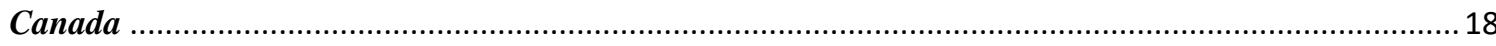

Navigating settler and Indigenous epistemological traditions within history education ......................... 24

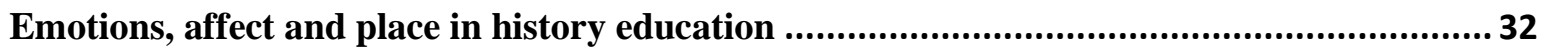

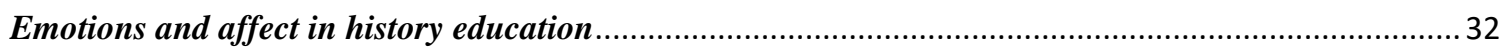

History field trips to sacred sites and places of violence and suffering ................................................. 35

Pedagogies for engaging with difficult histories of colonisation ............................................. 38

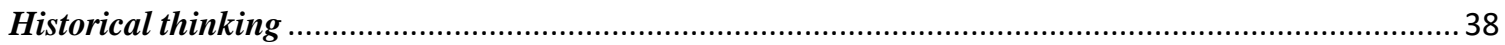

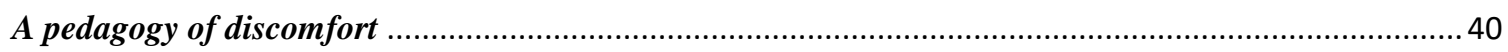

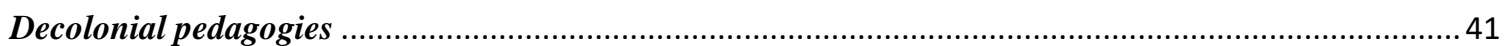

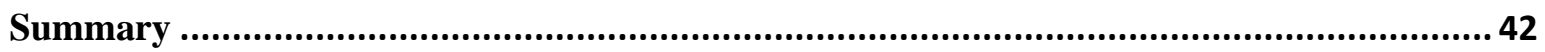

CHAPTER 3: A THEORETICAL AND CONCEPTUAL FRAMEWORK FOR

EXAMINING THE TEACHING AND LEARNING OF COLONISATION IN NEW

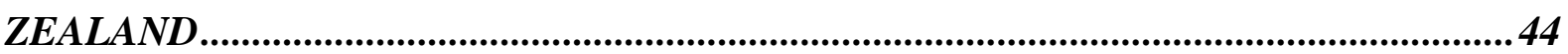

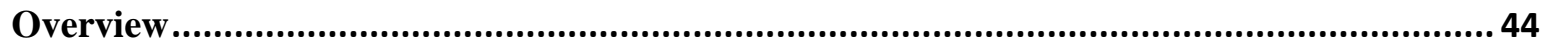

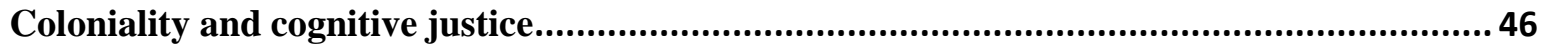

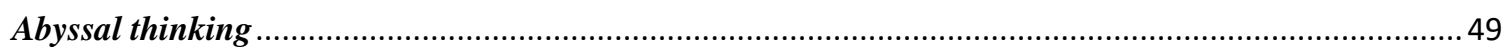

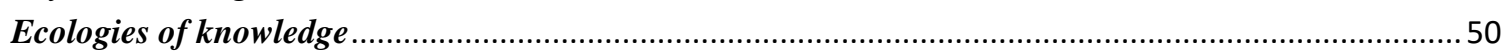

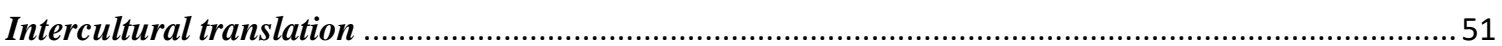


Critical theory

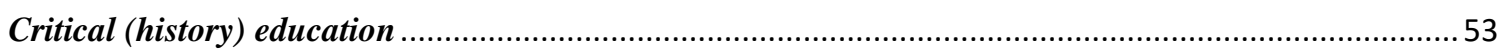

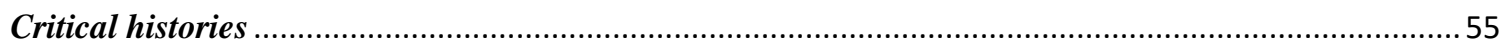

Pedagogical encounters with New Zealand's history of colonisation ......................................56

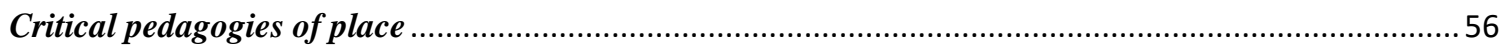

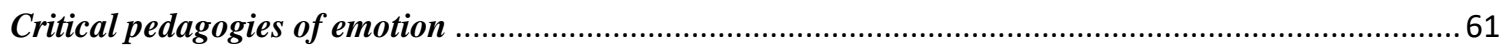

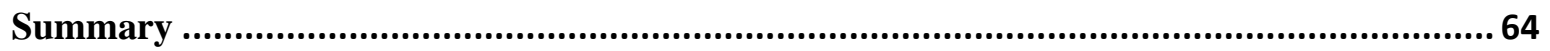

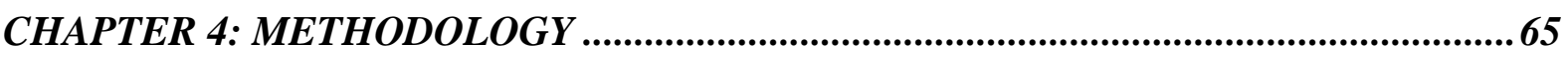

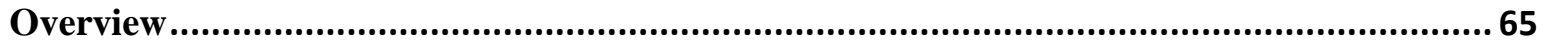

A critical and place-conscious stance toward research in education ......................................65

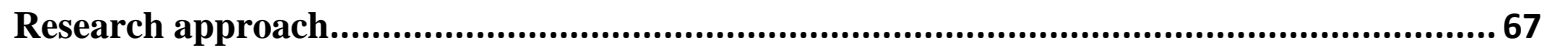

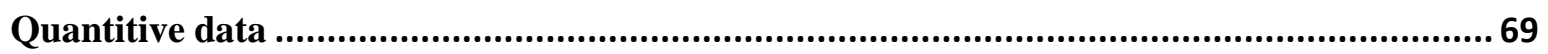

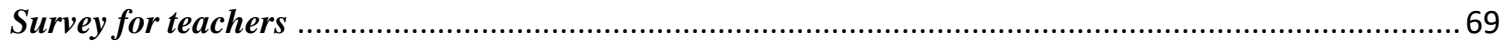

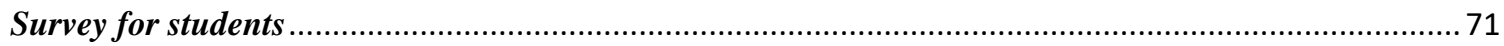

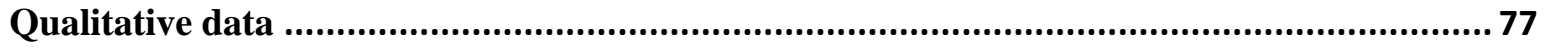

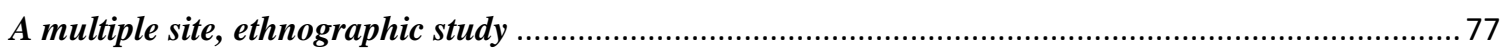

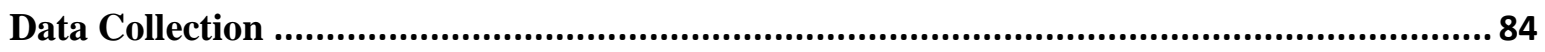

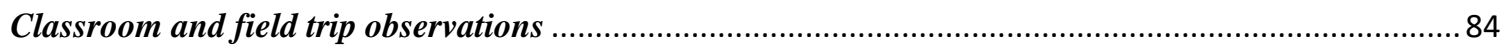

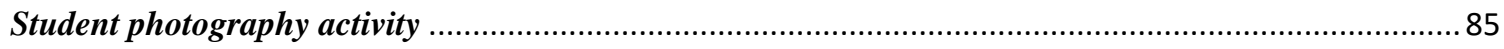

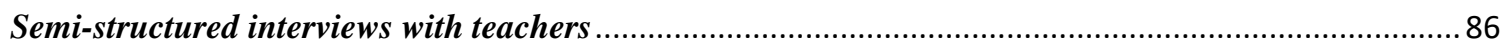

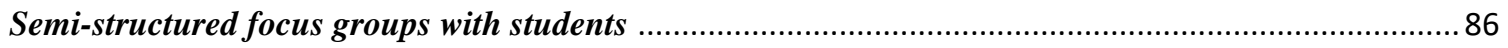

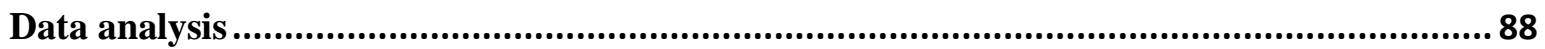

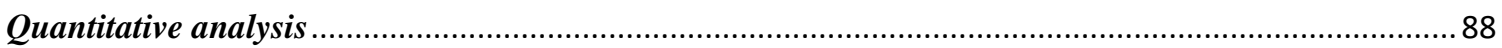

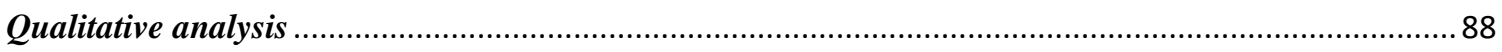

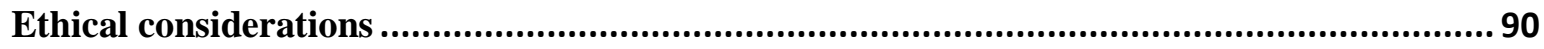

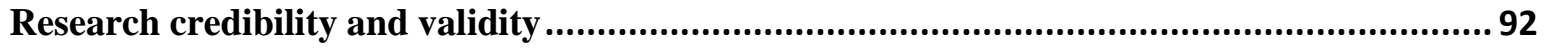

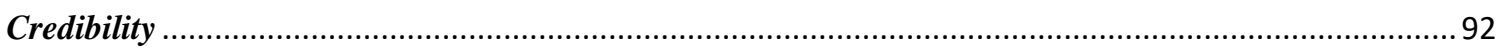

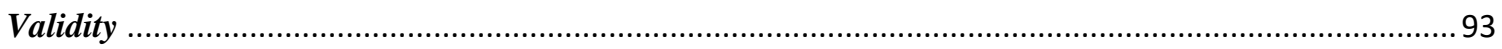

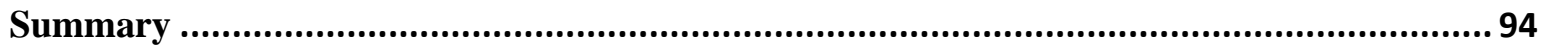

CHAPTER 5: TEACHER AND STUDENT CONCEPTIONS OF COLONISATION IN

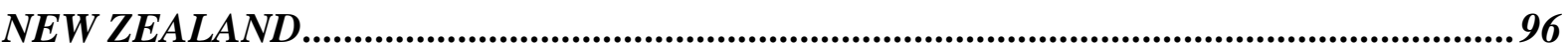

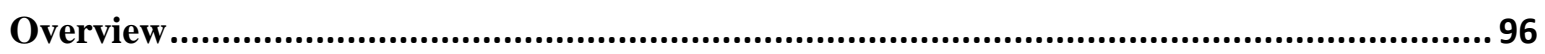

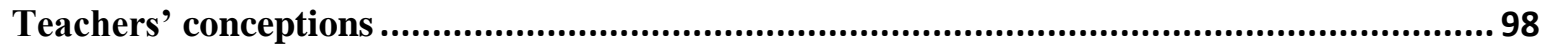

Critical views about the nature of colonisation and how to teach it....................................................... 98

Perceptual barriers to deeper pedagogical engagement with colonisation ........................................... 104

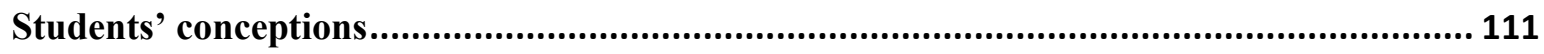

Views on the nature of colonisation, especially past/present relations .................................................. 111

Students' receptivity to learning New Zealand's history of colonisation ............................................... 117

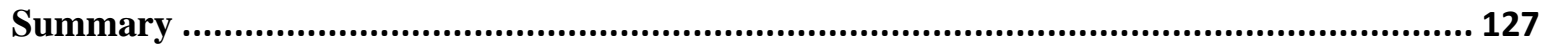


Overview.

The socio-political context of history curriculum in New Zealand today .............................. 130

The complexities of teaching New Zealand's history of colonisation................................... 132

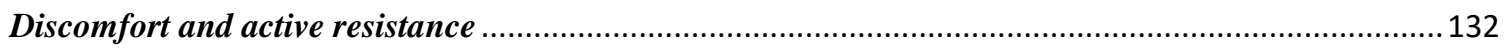

Forming relationships with iwi and hap $\bar{u}$ and navigating cultural spaces ......................................... 134

The difficulty of articulating and implementing critical approaches to past/present relationships ....... 138

The complexities of learning New Zealand's history of colonisation .................................... 140

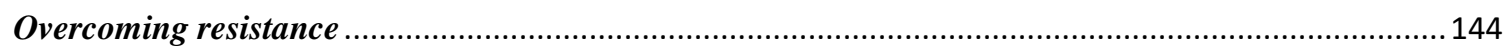

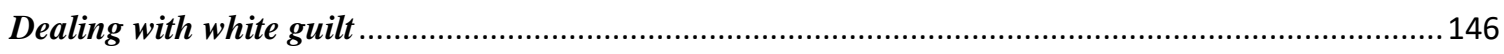

Grappling with limited historical knowledge and understanding ................................................... 150

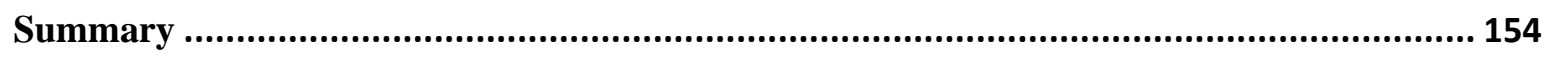

CHAPTER 7: YOUNG PEOPLE AND THEIR ENCOUNTERS WITH COLONIAL

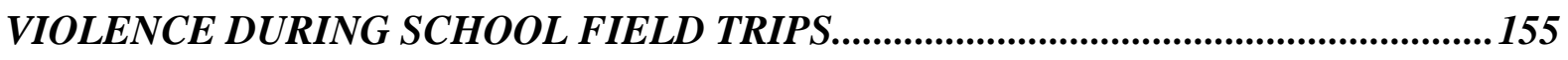

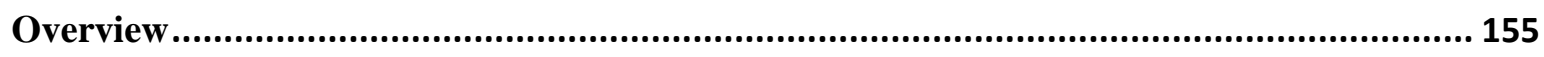

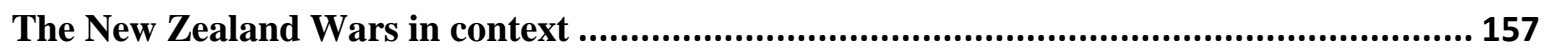

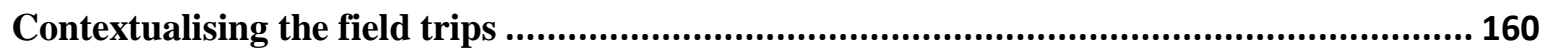

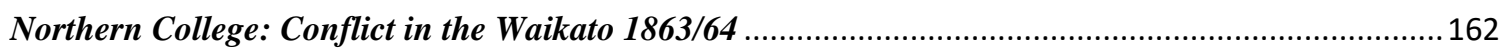

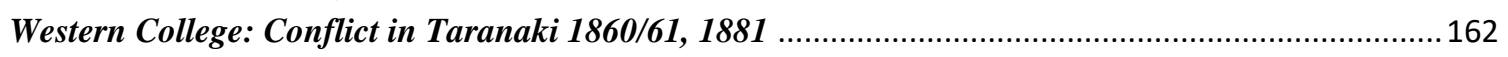

Eastern College: Conflict and colonisation in the Hutt Valley, Porirua, 1840s .................................... 163

The pedagogically transformative features of school field trips......................................... 163

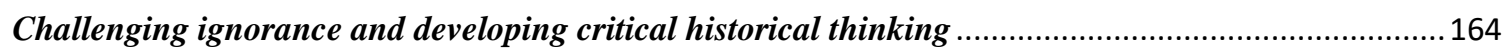

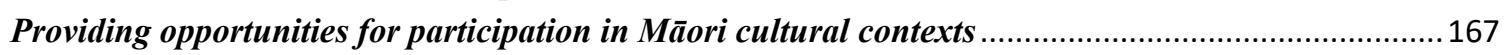

Occasioning opportunities for emotional and affective engagements with place-based history ............. 169

The pedagogically constraining features of school field trips............................................. 174

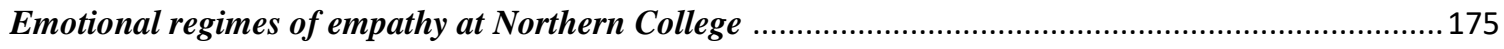

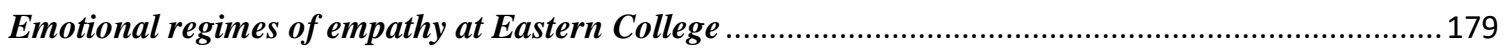

Feelings of disconnection at key sites at Western College ................................................................... 182

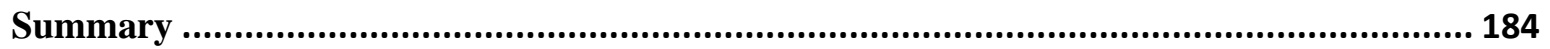

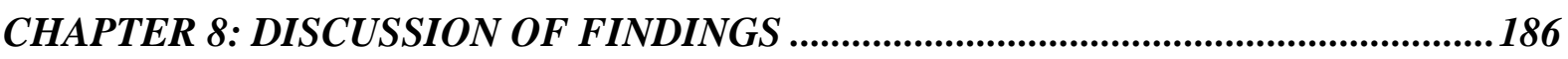

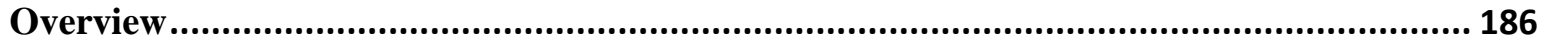

Teachers' pedagogical efforts to engage with Māori communities and history .................... 187

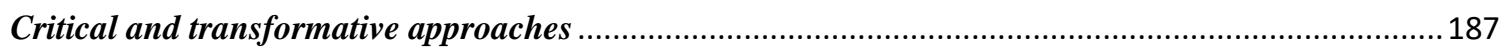

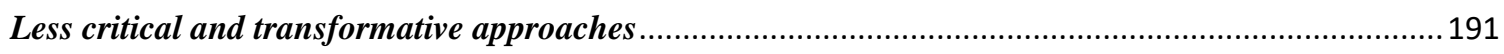

Students' emotional discomfort when learning the history of colonisation ........................... 192

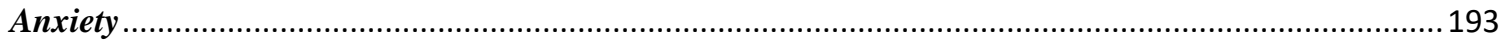

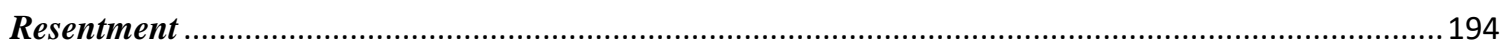

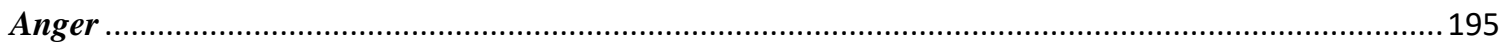

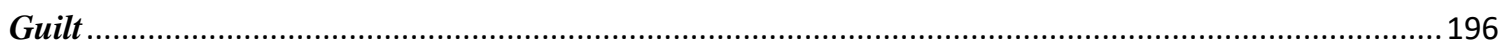


Implications of findings: why these patterns of engagement are important ......................... 199

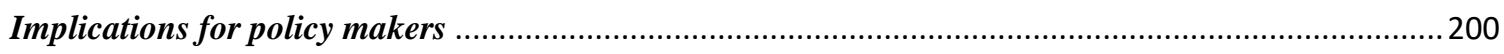

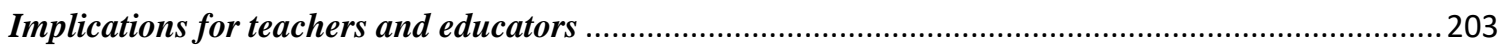

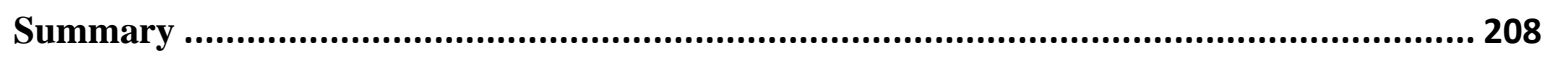

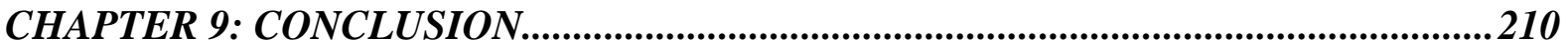

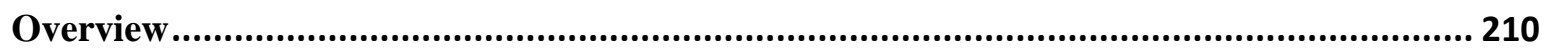

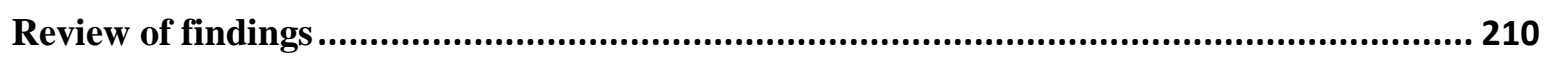

Limitations of this study and avenues for future research ................................................. 213

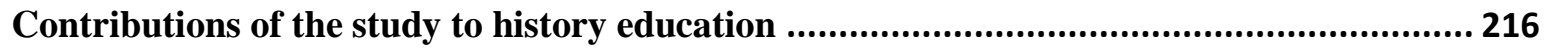

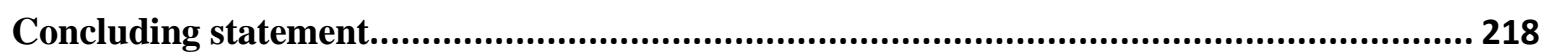

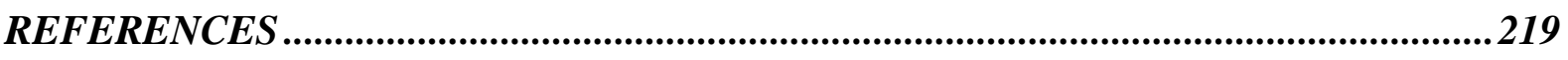

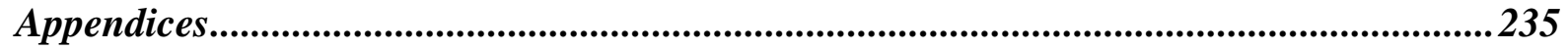

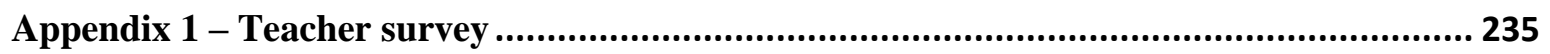

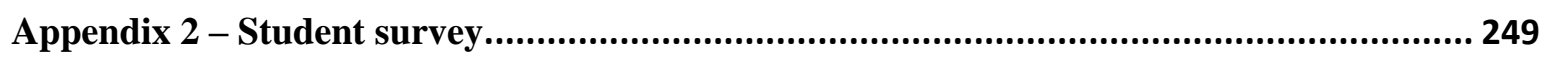

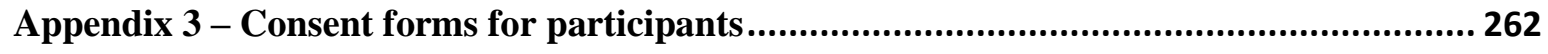

Appendix 4 - Information sheets for survey participants .................................................... 272

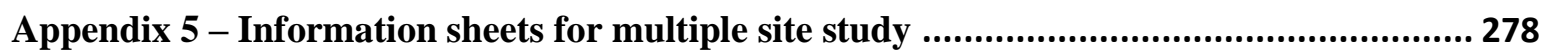

Appendix 6 - Information sheet and consent for field trip photograph task....................... 288

Appendix 7 - Exemplar summary report for schools that administered the survey ............. 292 


\section{LIST OF TABLES}

Table 1.1: Terms used to describe New Zealand's history of colonisation ......................................................

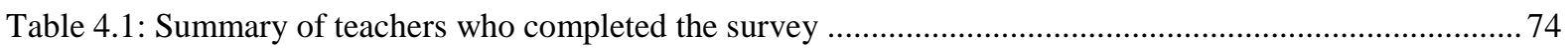

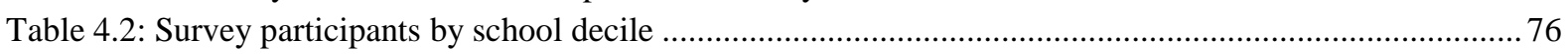

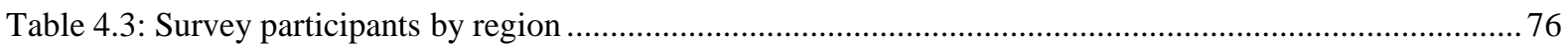

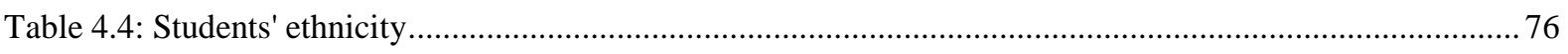

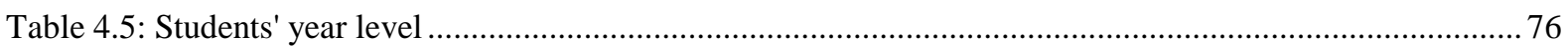

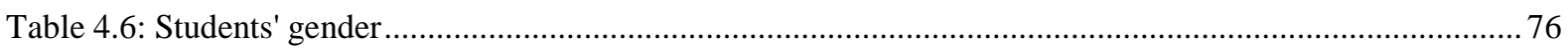

Table 4.7: Summary characteristics of each participating college ............................................................. 80

Table 4.8: Similarities and differences of the research process according to site ......................................... 81

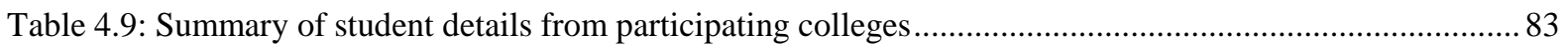

Table 4.9.1: Sample questions to support close-coding data in a critical thematic analysis .............................90

Table 7.1: Key information for three Year 13 history school field trips................................................... 161

Table 8.1: Conceptual frameworks for teaching difficult, place-based histories of colonisation in New Zealand 


\section{LIST OF FIGURES}

Figure 2.1: A continuum of positions in history education regarding the compatibility of Indigenous and

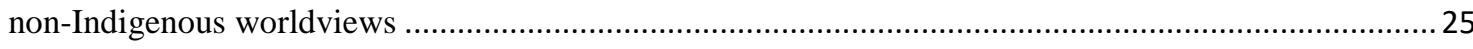

Figure 3.1: A visual representation of my theoretical and conceptual framework .............................. 45

Figure 4.1: Photography prompt card used by students during field trips ............................................86

Figure 5.1: Teachers' views on whether colonisation has consequences today .....................................98

Figure 5.2: History and social studies teachers' views on the nature of colonisation ............................99

Figure 5.3: Teachers' views on the importance of teaching New Zealand's history of colonisation .........99

Figure 5.4: Teachers' views on the importance of connecting past and present................................. 100

Figure 5.5: Teachers' views on the social effects of learning about settler/Indigenous conflict. ............ 101

Figure 5.6: Approaches teachers report using when teaching controversial aspects of colonisation ...... 102

Figure 5.7: Teachers' views on how well their profession prioritises colonisation ................................ 105

Figure 5.8: Teachers' views on the significance of particular challenges when teaching New Zealand's

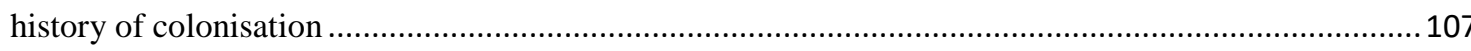

Figure 5.9: Students' responses to a question about the relationship between past conflict and the present 112

Figure 5.9.1: Students' views about the relationship between past conflict and violence and the present according to year level. ................................................................................................................ 113

Figure 5.9.3: Views about learning New Zealand's history of colonisation according to year level...... 119

Figure 5.9.4: Students' views on the controversial nature of colonisation. ............................................ 125

Figure 5.9.5: Teachers' views on the controversial nature of colonisation ........................................ 126

Figure 7.1: Gravestone at St Mary's Church settler cemetery. Photo by Bella Forbes ......................... 167

Figure 7.2: Parihaka from the top of Purepō. Photo (taken with permission) by Caroline Hamblin ....... 168

Figure 7.3: Individual gravestones of European soldiers killed during the invasion of the Waikato at

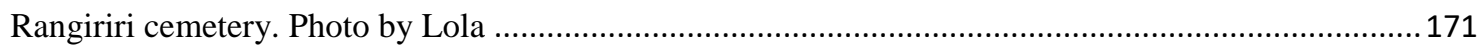

Figure 7.5: Rangiaowhia Anglican church. Photo by Gspicemoo................................................... 172

Figure 7.6: Official sign reinterpreted at Ōrākau. Photo by Gspicemoo. ............................................. 174

Figure 7.7: Ministry for Culture and Heritage historical display sign at Rangiriri. Photo by Shannon

Haunui-Thompson and courtesy of RNZ. ............................................................................ 178

Figure 7.8: Memorial to the soldiers killed at Boulcotts Farm, May 1846. Photo by Gary

Lewis/NZHistory ................................................................................................................ 181

Figure 8.2: Ōrākau battle and massacre site. Photo by Margaret Marks/NZHistory ............................. 206 


\section{GLOSSARY OF TERMS AND NOTES ON LANGUAGE}

This glossary is provided to help the reader, particularly with Māori words. Macrons are used over some Māori vowels, which indicates an elongated sound. Use of macrons in modern Māori is relatively new and it postdates some scholars' use of them. In keeping with the original text, I have not added them where it would otherwise be written today. When teachers and students use Māori words in a transcript, I add macrons in appropriate places, but when my survey participants write words without them, I leave it as they have written.

When a Māori word is used for the first time, I provide a brief in-text translation, unless a longer explanation is needed in which case it can be found in a footnote. All Māori words and phrases used are also written below, for the most part with more extensive translations and explanations. Unless otherwise noted, definitions come directly from the website: https://maoridictionary.co.nz. Translations of words from one language to another do not always capture the full complexity of a concept's meaning and the translations provided here may have meanings that not all speakers of Māori agree with. Nevertheless, they provide a starting point for readers unfamiliar with the terms.

The word 'Indigenous' is written with a capital ' $\mathrm{I}$ ' to differentiate it from other meanings of the word. For example, in their book on writing ethnographic field notes, Emerson and colleagues (2011) refer to 'indigenous meanings', or the perspectives of the people under ethnographic observation. Like Sundberg (2014), I follow Shaw, Herman and Dobbs' (2006) usage of the term Indigenous. They use this word to describe "groups with ancestral and often spiritual ties to particular land, and whose ancestors held that land prior to colonization by outside powers, and whose nations remain submerged within the states created by those powers" (p. 268). Like these scholars I am aware that terms like Indigenous are contested, suggesting a commonality of experience across nations that may not reflect the specific realities of different Indigenous nations.

Key terms

Hap $\overline{\mathbf{u}}$ - kinship group, clan, tribe, subtribe - section of a large kinship group and the primary political unit in traditional Māori society. 
Hīkoi - step, march, hike, trek, tramp, trip, journey

Iwi - extended kinship group, tribe, nation, people, nationality, race - often refers to a large group of people descended from a common ancestor and associated with a distinct territory.

Kāinga - home, address, residence, village, settlement, habitation, habitat, dwelling.

Kaitiaki - trustee, minder, guard, custodian, guardian, caregiver, keeper, steward.

Karakia - incantation, ritual chant, chant, intoned incantation, charm, spell - a set form of words to state or make effective a ritual activity.

Karanga - formal call, ceremonial call, welcome call, call - a ceremonial call of welcome to visitors onto a marae, or equivalent venue, at the start of a pōwhiri.

Kaumātua - adult, elder, elderly man, elderly woman, old man - a person of status within the whānau.

Kīngitanga - King Movement - a movement which developed in the 1850s, culminating in the anointing of Pōtatau Te Wherowhero as King. Established to stop the loss of land to the colonists, to maintain law and order, and to promote traditional values and culture.

Mamae - Ache, pain, injury, wound.

Marae - courtyard - the open area in front of the wharenui, where formal greetings and discussions take place. Often also used to include the complex of buildings around the marae. Mana - prestige, authority, control, power, influence, status, spiritual power, charisma - mana is a supernatural force in a person, place or object. Mana goes hand in hand with tapu, one affecting the other. The more prestigious the event, person or object, the more it is surrounded by tapu and mana.

Manaakitanga - hospitality, kindness, generosity, support - the process of showing respect, generosity and care for others.

Mana whenua - territorial rights, power from the land, authority over land or territory, jurisdiction over land or territory - power associated with possession and occupation of tribal land

Ngāi Tahu - A prominent South Island iwi (my definition)

Ngāti Tama - According to their website (https://ngatitama.nz/who-are-we/our-history/), Ngāti Tama are a people who migrated to the Wellington and Upper South Island region in the 1820 s.

Noa - To be free from the extensions of tapu, ordinary, unrestricted, void 
Pasifika - According to the document Tapasā: Cultural competencies framework for teachers of Pacific learners (2018), the term Pasifika or (Pasifika peoples) "are umbrella terms used to categorise trans-culturally diverse peoples from the Pacific region who now live in New Zealand but continue to have family and cultural connections to Pacific Island nations" (p. 5).

$\mathbf{P} \overline{\mathbf{a}}$ - fortified village, fort, stockade, screen, blockade, city (especially a fortified one). Pahuatanga - The sacking, often used in reference to the destruction of the village at Parihaka by the Armed Constabulary and volunteer settlers in 1881 (my explanation). Pākehā - English, foreign, European, exotic - introduced from or originating in a foreign country.

Pōwhiri - invitation, rituals of encounter, welcome ceremony on a marae, welcome.

Rangatira - chief (male or female), chieftain, chieftainess, master, mistress, boss, supervisor, employer, landlord, owner, proprietor - qualities of a leader is a concern for the integrity and prosperity of the people, the land, the language and other cultural treasures (e.g. oratory and song poetry), and an aggressive and sustained response to outside forces that may threaten these.

Raupatu - conquered, confiscated.

Tapu - be sacred, prohibited, restricted, set apart, forbidden, under atua protection Te Tiriti o Waitangi - The name given to the Māori text of the Treaty of Waitangi, signed in 1840 and which was the version debated and signed by the majority of chiefs (my explanation).

Tīkanga - correct procedure, custom, habit, lore, method, manner, rule, way, code, meaning, plan, practice, convention, protocol - the customary system of values and practices that have developed over time and are deeply embedded in the social context

Tīpuna - ancestor, grandparent, grandfather, grandmother - singular form of tīpuna and the eastern dialect variation of tupuna.

Taniwha - water spirit, monster, dangerous water creature, powerful creature, chief, powerful leader, something or someone awesome - taniwha take many forms from logs to reptiles and whales and often live in lakes, rivers or the sea. They are often regarded as guardians by the people who live in their territory, but may also have a malign influence on human beings.

Te Ao Māori - The Māori world (my translation) 
Te Reo Māori - The Māori language (my translation)

Urup $\overline{\mathbf{a}}$ - burial ground, cemetery, graveyard.

Wāhi tapu - sacred place, sacred site - a place subject to long-term ritual restrictions on access or use, e.g. a burial ground, a battle site or a place where tapu objects were placed.

Whānau - extended family, family group, a familiar term of address to a number of people the primary economic unit of traditional Māori society 


\section{CHAPTER 1: INTRODUCTION}

When history goes unexamined, when its victors cherish its spoils, and when its victims remain victimized, difficult histories bequeath conflict.

Simone Schweber (2019, p. xii)

\section{Overview}

In the wake of the 2019 terrorist attack on a mosque in Christchurch, some Māori leaders reminded a stunned nation that racially influenced atrocities had previously taken place in this country. ${ }^{1}$ These leaders did not want to minimise the tragedy in Christchurch, but they could not let claims that 'this is not us' or that New Zealand had 'lost its innocence' go unchallenged; only those with short historical memories could proclaim this position. With notable exceptions, secondary schools in New Zealand have not been very successful at developing the kinds of knowledge and understanding young people need to gain the longer historical perspective often held by Māori communities, a perspective that might disrupt the "intergenerational cycles of ignorance" about colonisation that continue to affect this nation (O'Malley, 2019b). In this mixed methods study, I address the wider issue of how teachers and students engage with New Zealand's difficult history of colonisation, exploring their conceptions of colonisation and the multitude of challenges and opportunities encountered in classrooms and during field trips to sites of colonial violence. In this chapter, I start by naming the research problem and establishing the broad context of curriculum from which this thesis was written, followed by the personal and social significance of the study. My research aims and questions, some notes on terminology and finally the structure of the thesis follow on from this.

\section{Research problem and the curriculum context of this study}

The history of colonisation in New Zealand permeates the present, yet little is known about how teachers and students of history and social studies engage with their own nation's difficult history of colonial injustice. Without a detailed understanding of what happens in schools during these pedagogical encounters with violence, suffering and oppression, educational reform at local and national levels is unlikely to proceed in an informed manner.

\footnotetext{
${ }^{1}$ See, for example: https://www.rnz.co.nz/news/national/385226/christchurch-mosque-attacks-maori-leaderssay-acts-of-terror-nothing-new-in-new-zealand.
} 
In recent years, the need for nuanced accounts of the challenges teachers and students face during history lessons on colonisation has become especially urgent because teachers and schools have been criticised for not adequately ensuring Māori perspectives form a part of their history curriculum. ${ }^{2}$ As an experienced history teacher I have considerable sympathy for these critiques of the teaching profession, but I also recognise that it is much easier to name the problem than to explore solutions. Without a thorough understanding of the challenges that affect teachers' capacity to engage with tribal histories (and other complexities associated with teaching New Zealand's difficult history of colonisation) such solutions are hard to develop. New ventures such as the (2019) announcement for compulsory teaching of New Zealand history will likely result only in increased frustration from all sides unless changes are informed by a research base that carefully examines what occurs in schools. This thesis responds to this problem by presenting conceptions and pictures of practice that illustrate the challenges of teaching and learning difficult history in a settler society. It proceeds from the assumption that research in education is validated by the extent to which it can improve the outcomes and experiences of students.

Improving the educational outcomes of students in history and social studies education presents educational leaders in New Zealand with some unique challenges. Schools in this country operate within a broad, outcomes-based framework that allows for high levels of curriculum autonomy (Sinnema, 2015). In its current form, the official history and social studies curriculum neither prescribes a celebratory narrative accommodating to those in power, nor guides teachers to focus on specific historical contexts that might provide young people with "an informed understanding of the causes and legacies of violence and injustice" (Benetravato, et al. 2016, p. 19). Instead, history and social studies teachers are given the responsibility to select all content and design their programmes with minimal involvement (or professional support) from the Ministry of Education (Sheehan, 2010, Ormond, 2017). Furthermore, history is an elective subject that for most students is an option only in the final three years of their schooling. Prior to this, students take the compulsory subject of social studies, an integrated subject often taught by non-specialists that includes some history. The combination of a high autonomy curriculum with no prescribed content, and history as an

\footnotetext{
${ }^{2}$ See for example, the interview at this site: https://www.newshub.co.nz/home/new-zealand/2019/10/howshould-new-zealand-remember-the-land-wars.html and the portrayal of history teachers in this article: https://www.stuff.co.nz/national/education/107206925/new-zealands-schooltaught-colonial-history-is-racistand-needs-changing--say-teachers. (Both accessed in January 2020)
} 
elective subject in the senior secondary school is an approach only taken by few modern, democratic nations, with Scotland being one other case (Smith, 2019).

In recent years, a number of commentators have queried this high-autonomy approach, particularly as awareness of New Zealand's history of colonial injustice has grown in national consciousness. In fact, the writing of this thesis has intersected with a period of widespread and sometimes heated public debate about the value of New Zealanders learning their own nations' troubling past and the role of school curriculum in this. For example, in October 2017 (my first year of $\mathrm{PhD}$ study), the first officially recognised commemoration of the nineteenth century New Zealand Wars (see Chapter 7) took place. These commemorations were largely the result of a 2015 petition to Parliament led by students from Ōtorohanga College, who in their petition also called for compulsory teaching of the New Zealand Wars. ${ }^{3}$ This push for compulsory teaching of New Zealand's difficult history continued in 2018 when a range of experts presented to the Māori Affairs Select Committee as part of Parliament's "Briefing on the teaching of New Zealand's colonial history in schools". These presentations contributed to rigorous discussion about the challenges of teaching history in New Zealand (Biddle \& Redmond, 2018; Long, 2018). ${ }^{4}$ In early 2019, the digital advocacy group ActionStations led a petition that was submitted to Parliament calling for better education of New Zealand's history, particularly the Treaty of Waitangi and iwi (tribal) and hapū (sub-tribal) histories. ${ }^{5}$ In the same year a mainstream online media outlet led a campaign called Time to Tell Our Story, and another petition, submitted this time by the New Zealand History Teachers' Association (NZHTA), called for the compulsory teaching of New Zealand history in the school curriculum. ${ }^{6}$ Finally, in late 2019, the Prime Minister responded to these pressures and announced that New Zealand history would be compulsory in primary, intermediate and secondary schools from 2022.

\footnotetext{
${ }^{3}$ See, for example: https://www.stuff.co.nz/waikato-times/news/74876330/otorohanga-college-students-deliverland-wars-petition-to-parliament

${ }^{4}$ See the terms of the petition at: https://www.parliament.nz/en/pb/sc/business-beforecommittees/document/BRF 78167/briefing-on-the-teaching-of-new-zealands-colonial-history

${ }^{5}$ See, for example:

https://www.waateanews.com/waateanews/x_news/MjEwNTU/Breakfast\%20with\%20Dale/Petition-for-treatyhistory-in-all-schools

${ }^{6}$ See the terms of the petition at: https://www.parliament.nz/en/pb/petitions/document/PET 83795/petition-ofgraeme-ball-on-behalf-of-the-new-zealand-history
} 
This announcement signals a significant reversal in official education policy and some major changes for teachers and schools as they begin to grapple with the implications of prescribed content. The announcement also highlights the significance of this study's focus on the pedagogical complexities of teaching difficult history in a settler society. In the early stages of this thesis, I was more interested in curriculum questions, especially learning more about what teachers currently include in their programmes. My interest in the question of what is taught (or not taught) shifted as it became increasingly clear that within the context of a high autonomy curriculum it was extremely difficult to establish with any real certainty the content of school history and social studies programmes across the nation. Many teachers, for example, are agile in their ability to change topics according to their own and their students' interests. I have also observed in larger school departments that individual teachers often have considerable freedom to choose their contexts, so what one teacher is covering may be quite different to the teacher in the adjacent classroom. In several schools I have also observed a history curriculum formed entirely through student choice with the teacher facilitating only the development of historical skills.

The difficulties associated with establishing what history students learn in New Zealand schools does not mean some broad patterns cannot be detected. Existing studies, for example, clearly highlight that many teachers struggle to teach the history of colonisation in depth (Bargas, 2005; Derbyshire, 2004; Fountain, 2012; Harcourt, 2020; Hunter \& Farthing, 2004; Manning, 2017; Sheehan, 2010). More specifically, research indicates a consistent tendency by many social sciences departments to minimise, avoid and neglect New Zealand's difficult history of colonisation (see Chapter 2). Despite this situation, my earlier goal for this study shifted away from researching the profession's failings to incorporate more diverse curriculum content. Instead, I chose to focus more explicitly on pedagogy, and the nature of the encounter with New Zealand's difficult history of colonisation, particularly as experienced by effective teachers and their students. This pushed me toward a mixed methods approach that sought to understand as extensively as possible the perspectives of teachers and students, an approach that revealed an enormously rich and complex set of challenges. These are challenges that a mandate from central government is unlikely to solve, at least not without extensive, high quality (and costly) professional development and resourcing. This study highlights that even the best and most committed teachers nevertheless grappled with 
the challenges of teaching about colonisation and wanted more sophisticated forms of support than to be told they must teach what they already prioritise and care about deeply.

\section{The personal and social significance of this study}

This study is the result of many practical challenges I experienced inside and outside the classroom after more than a decade of teaching history and social studies in two secondary schools. At the classroom level, I often encountered Pākehā (New Zealanders of European descent) students who deeply resented having to learn New Zealand's history of colonisation, a resentment that seemed at times contagious as otherwise open-minded students mobilised behind them. Others were passionate about the opportunities afforded from learning about colonisation and expressed surprise at their peers' resistance or ambivalent attitudes. For the most part, my predominantly Pākehā students could be convinced of the value to come from learning New Zealand history. Nevertheless, without me working hard to persuade them, they usually preferred to learn about distant instances of racism and human rights abuses. ${ }^{7}$

Also informing this study were the challenges I experienced as a teacher when planning and carrying out field trips to sites of colonial violence. Sometimes these outdoor experiences overcame students' resistance to learning New Zealand history, but at other times they reinforced views about the perceived benign or 'boring' nature of colonisation. It was a constant challenge to successfully curate rich and coherent outdoor experiences that prioritised Māori histories through collaboration with local iwi and hapū. Despite these difficulties, and the mixed nature of my success, chance encounters with former students attest that these field trips generated powerful learning experiences. This fact made me curious about the role history field trips could play in history education.

A final challenge I encountered as a teacher and that informed this study was the manner in which structures of schooling constantly thwarted my ability to work alongside iwi, and to embed Māori histories into the curriculum in ways that illustrated for students how "indigenous historical narratives are intimately tied to the ecologies of places" (Manning \&

\footnotetext{
${ }^{7}$ Linda Levstik (2001) found a similar pattern in students' thinking in Auckland schools nearly two decades ago.
} 
Harrison, 2018, p. 59). While enjoying some limited success at one stage of my career, ${ }^{8}$ collectively these experiences inside and outside the classroom imprinted a lasting desire and sense of obligation to explore in greater depth the complexities associated with teaching and learning New Zealand's difficult history of colonisation.

As a Pākehā, or white New Zealander, this sense of obligation comes from the fact that I still benefit from the decisions of my ancestors to sail to New Zealand from England and Scotland in the mid nineteenth century, acquire land that belonged to Māori and start new lives in a colony they ultimately intended to rule. Some of those ancestors were on New Zealand's first settler ship, the Aurora, which arrived in Wellington Harbour on January $22^{\text {nd }}, 1840$. John Howard Wallace, my great, great, great grandfather became a prominent member of colonial society and authored one of the first New Zealand history textbooks for children. Another ancestor, James Macandrew, was the superintendent of the province of Otago, a key player in establishing the University of Otago and Minister of Public Works during the Vogel ministry of the 1870s (Bunce, 2018). Unsurprisingly, less is known about the women in my family. But they, and their husbands, were people who believed passionately in the benefits and inevitability of colonisation. This historical process reaped huge and intergenerational rewards for settlers, resulting in the enormous loss of Indigenous land, the transferral of power away from Māori and ongoing breaches of the promises established in 1840 with the signing of Te Tiriti o Waitangi/Treaty of Waitangi (see Chapter 7). Understanding the way in which my family history is implicated in the processes of settler colonialism presents a constant motivation to deepen my knowledge of history and history education.

Beyond the personal significance of this study, it also has a broader social significance. As stated above, in New Zealand the history of colonisation permeates contemporary New Zealand society. From the dominance of the English language to many of the beliefs that underpin common ideas about the environment, history and identity, colonisation is a central aspect of New Zealand's past and present (Buchanan, 2009; Gibbons, 2003; Mikaere, 2011; Park, 1995). Frequent media stories on key social issues point to further examples of colonisation's deep influence. Some of these include: the inequality between Māori and Pākehā in a number of social indices, ongoing land disputes, the uplifting of Māori children

\footnotetext{
${ }^{8}$ See for example: https://www.rnz.co.nz/news/te-manu-korihi/135073/iwi-and-school-launch-history-sharingproject
} 
and their placement into state care, consistent evidence of institutionalised racism in schools, the police force, and the justice and health systems, the ecological dilemma of polluted waterways, and political debates about Māori representation in Parliament and on council boards. Contemporary issues like these are rooted in New Zealand's history of colonisation, yet are often framed and discussed in terms of present-day concerns, devoid of historical context. The contemporary significance of colonisation highlights the need to find out more about what currently takes place in schools during history and social studies lessons.

\section{Research aims and questions}

As mentioned earlier, we have little detailed, empirical evidence of the nature of teachers' and students' engagement with history. In particular, we know little about what they are teaching, how they teach or the challenges of dealing with emotional climates generated during lessons on colonisation. This is problematic because the ongoing, 'structural' nature of colonisation, manifesting itself in continuing forms of racism, inequality, grievance and resentment makes teaching and learning its history an uncomfortable, even traumatic endeavour (Buchanan, 2018; Kunowski, 2005; Levstik, 2001; Pihama et al., 2014). This situation necessarily drew my attention to studies in emotion and affect, shaping the direction of this thesis in important ways. Due to the paucity of existing research and the emotionally challenging nature of New Zealand's history of colonisation, my aim was to extend the New Zealand literature and contribute to a broader empirical basis from which to develop critical, transformative forms of history education for a settler society. 'Critical and transformative' are terms I use frequently throughout this thesis, and their meaning needs clarification. In this study, a critical and transformative history education for a settler society like New Zealand is one that includes the following features:

- Teachers support students to build the knowledge needed to recognise colonial narratives and the historical basis of contemporary New Zealand settler society, particularly the relationship between the past and the 'settler-colonial present' (Veracini, 2015).

- Teachers engage with, and support students' engagement with Indigenous epistemological traditions and Indigenous peoples' stories of place, told on their terms (Rey \& Harrison, 2018).

- Teachers explore their own, and encourage their students to explore their emotional responses to historical injustice in ways that ask probing questions about the roots of 
their "values and cherished beliefs" (Boler, 1999, p. 176). This includes their attachment to these responses and the role of these emotions in maintaining or challenging (settler-colonial) relations of power (Zembylas \& McGlynn, 2012).

- Teachers develop in themselves and their students "a critical understanding of the conflictual past through the cultivation of historical thinking, empathy, an overcoming of ethnocentric narratives and the promotion of multiperspectivity" (Psaltis, et al, 2017, p. vi).

In addition to contributing to the New Zealand literature base, another aim of this study is to extend international conversations about teaching difficult history, particularly in the context of settler societies like New Zealand. My hope is that empirically grounded research into the current nature of teachers' and students' engagement with the history of colonisation will inform policy, pre-service teacher training, in-service professional development and classroom pedagogies. To meet these research aims, I framed the current study around the following questions:

\section{Primary research question:}

- How do teachers and students in secondary school social studies and history classes engage with New Zealand's history of colonisation?

\section{Sub questions:}

1. How do teachers and students conceptualise the issue of colonisation in New Zealand?

2. What complexities do history teachers and their students contend with during lessons on New Zealand's history of colonisation?

3. What role do field-trips to sites of colonial aggression play in shaping students' encounters with the past?

\section{A note on terminology}

For the most part, I refer in this thesis to 'New Zealand's difficult history of colonisation' and 'New Zealand's history of colonisation'. A number of other terms exist which I illustrate on a continuum in Table1.1. 
Table 1.1: Terms used to describe New Zealand's history of colonisation

\begin{tabular}{|c|c|c|}
\hline \multicolumn{3}{|c|}{ New Zealand's difficult history of colonisation } \\
\hline $\begin{array}{c}\text { Terms that prioritise Māori } \\
\text { perspectives, knowledge and } \\
\text { epistemology }\end{array}$ & $\longleftrightarrow$ & $\begin{array}{c}\text { Terms that prioritise Pākehā } \\
\text { perspectives, knowledge and } \\
\text { epistemology }\end{array}$ \\
\hline Māori history/histories & \multirow{2}{*}{$\begin{array}{c}\text { New Zealand history/New } \\
\text { Zealand histories }\end{array}$} & New Zealand's colonial past \\
\hline $\begin{array}{c}\text { Indigenous narratives of the } \\
\text { land }\end{array}$ & & $\begin{array}{l}\text { New Zealand's colonial } \\
\text { history/colonial histories }\end{array}$ \\
\hline & \multirow{2}{*}{$\begin{array}{c}\text { New Zealand's contested } \\
\text { national history }\end{array}$} & \\
\hline Māori/tribal histories of place & & Colonial histories of Māori \\
\hline $\begin{array}{l}\text { Māori perspectives on } \\
\text { colonisation }\end{array}$ & \multirow[t]{2}{*}{$\begin{array}{l}\text { New Zealand's difficult } \\
\text { histories of place }\end{array}$} & \\
\hline Indigenous history/histories & & \\
\hline
\end{tabular}

Some of these terms, such as 'New Zealand's colonial past/history' (on the right hand side of the table) have connotations of a Pākehā-centric approach to history, which locates colonisation in the past, downplaying its structural, ongoing nature. The New Zealand History Teachers' Association has used variations of this term in their otherwise staunch advocacy, in recent years, for greater attention to difficult histories of colonisation. ${ }^{9}$ 'Colonial histories of Māori' very much indicates a Eurocentric perspective by making Māori the subject of a colonial gaze (Keenan, 2012). Other phrases in this table (on the left hand side) more deliberately foreground Indigenous historical experiences and epistemologies. I decided on 'New Zealand's (difficult) history of colonisation' because it was generic enough to capture place-based, Māori histories and perspectives from my participants that might reflect more Eurocentric attitudes to the past. 'New Zealand's difficult history of colonisation' also explicitly connects my work to the international literature on difficult history (Epstein \& Peck, 2018; Gross \& Terra, 2019b; Zembylas, 2017d).

I also sought terms to describe the nature of New Zealand society's relationship with its history of historical injustices. A substantial literature explores the complexities of teaching history in 'post-conflict' and '(deeply) divided societies,' terms often used synonymously

\footnotetext{
${ }^{9}$ See, for example: https://www.parliament.nz/resource/enNZ/52SCMA_EVI 78167_848/c9c58d91526a8caf587720d38fa73aa55be691b3.
} 
(Bekerman \& Zembylas, 2012; Bentrovato, Korostelina, \& Schulze, 2016; McCully, 2012; Paulson, 2015; Psaltis, Carretero, \& Čehajić-Clancy, 2017). Scholarship written in this field of history education looks for ways in which history teaching can be used toward peacebuilding and reconciliation in the aftermath of recent conflict. In one sense, New Zealand could also be characterised as a 'post-conflict' society but this would not recognise the fundamental differences that exist between "long established democratic societies" (Epstein $\&$ Peck, 2018) and those emerging from violence such as Rwanda, Cyprus or Northern Ireland (p. 9). Nevertheless, as the title of Danny Keenan's book Wars Without End (2009) suggests, the wars, conflict over land and histories of colonisation from the nineteenth century onwards continue to be felt in ways not captured by the temporal delineation of a 'post-conflict' society. Ross' (2009) definition of a divided society is more applicable to New Zealand. For him, divided societies are those that experience cultural divisions over the symbolic landscape. He argues that cultural contestation "is about inclusion and exclusion from a society's symbolic landscape and that such inclusion or exclusion tells us about the politics of acceptance, rejection, and access to a society's resources and opportunities (p. 1)". Despite Ross' broader definition, and in keeping with most literature, I chose to avoid descriptions of New Zealand society as either divided or post-conflict. Instead, New Zealand is best characterised as a settler society, one in which colonisation is a materially and symbolically violent structure that continues to make its presence felt (see Chapter 2 for a more detailed discussion). This term enabled me to position my study within the particular power dynamics of history education in white settler societies (Bell, 2006; Dion, 2008; Gibson \& Case, 2019; Keynes, 2018; Shear \& Krutka, 2019; Tupper, 2011).

\section{Structure of the thesis}

This thesis has nine chapters. In chapters two to four I review the literature, introduce my theoretical position, and outline my methodological approach. This is followed by three findings chapters and a discussion of common themes across these chapters. The thesis ends with a short conclusion.

Chapter 2 outlines the competing definitions and theoretical influences of 'difficult history' and defines in more detail the terms settler colonialism and settler society. I summarise relevant studies in history education from three commonwealth settler societies similar to New Zealand and show that relatively few explicitly acknowledge their settler colonial 
context, or explore the complexities of teaching and learning difficult histories of colonisation. Chapter 2 also summarises key debates over the challenges of negotiating the tensions, contradictions and overlaps of Indigenous and Western systems of knowledge, and it situates my position within these arguments. It then outlines the literature on place and emotion, two key themes in this thesis and both central to teaching and learning difficult histories of colonisation. The chapter concludes by describing three different pedagogical approaches (each with their own strengths and weaknesses) for engaging with challenging histories of colonial injustice.

In Chapter 3, I provide a theoretical framework for interpreting how teachers and students engage with New Zealand's history of colonisation. I draw on a critical paradigm, but extend critical theory in ways that acknowledge the value of Indigenous knowledge. To achieve this, I turn particularly to Santos' (2014) notion of cognitive justice. Cognitive justice provides the theoretical basis for a history education informed by Indigenous history and critical-historical methodologies. Together these approaches can disrupt settler colonialism and give substance to interpretations of Te Tiriti o Waitangi (the Treaty of Waitangi) that advance the ability of all people in New Zealand to live socially and ecologically just lives.

In Chapter 4 I describe my critical, place-conscious research stance, which informed the design of my 'transformative mixed methods' study. I outline my research design, which included surveys of teachers $(n=298)$ and students $(n=1889)$ and a multiple-site study using critical ethnography. In this chapter, I explain my use of critical thematic analysis to analyse and interpret key findings drawn from qualitative survey responses, focus groups, interviews and field notes. Ethical considerations are discussed, particularly in relation to students taking photographs at sacred sites of suffering and violence. The chapter concludes with a discussion about my study's credibility and validity, particularly in the context of research that openly acknowledges a transformative agenda.

Chapter $\mathbf{5}$ is the first of three main findings chapters. I start by presenting data from the national survey that shows how teachers $(n=298)$ conceptualise the issue of colonisation. I explain that with few exceptions, teachers' respond in ways that can be characterised as critical and pedagogically progressive, providing a sound platform for history education in New Zealand. However, these responses also reveal a number of barriers that will likely 
make it difficult for the profession to enact transformative pedagogies capable of disrupting the dynamics of settler colonialism. This chapter also outlines students' $(n=1889)$ conceptions about colonisation. It highlights a number of broad trends including their reactions to learning about colonisation and the reasons they give for these responses. Chapter 5 shows that although most students are receptive to learning more about New Zealand's history of colonisation, many are not, revealing a complex emotional and affective terrain for teachers to navigate during history and social studies lessons.

Chapter 6 draws primarily on classroom-based observations and interviews/focus groups to explore in finer detail the complexities of teaching and learning about colonisation. Using the concept of cognitive justice as a lens, this chapter focuses on the experiences of four teachers and their students $(n=48)$ in different secondary schools. I begin by presenting an overview of the socio-political context of the history curriculum in New Zealand today, followed by a description of the multiple complexities teachers and students contend with during history lessons on colonisation. This chapter shows the varied ways that teachers deal with active resistance and discomfort, the complexities of forming relationships with iwi and hapu and the difficulty of articulating and implementing critical approaches to exploring past/present relationships. For students, it highlights the challenges of overcoming resistance, dealing with white guilt and grappling with limited historical knowledge and understanding.

In Chapter 7, I describe students' experiences during field trips to different North Island sites of colonial violence. After presenting a broad history of the New Zealand Wars and a summary of each school's itinerary, I describe the transformative features of field-trips. This included the teachers' ability to use these outdoor experiences as 'counter narratives', challenging students' prior ignorance of major events in New Zealand's history and developing their historical understanding. Field trips also provided opportunities for participation in Māori cultural contexts, including hearing Māori historical perspectives directly from Māori. Finally, field trips occasioned opportunities for emotional and affective engagements with place-based histories of historical injustice. In this chapter I also describe the pedagogically constraining features of school field trips. Using the concept of an 'emotional regime' I argue that for two schools, emotional regimes of empathy constrained the critical and transformative potential of field trips. For another school, the major challenge was students' feelings of disconnection at key historical sites. 
In Chapter 8 I draw together major strands from the previous three chapters, focussing on two key 'patterns of engagement' with New Zealand's history of colonisation. In the first, I discuss teachers' pedagogical efforts to connect with Māori communities and history. Some of these efforts resulted in productive engagements with difficult histories of colonisation; others revealed key areas where teachers need more support. The second pattern of engagement concerns students' emotional discomfort with historical injustices of colonisation and the extent to which these emotions operated as bridges or barriers to deeper historical understanding. The chapter outlines a range of particular emotions, which students struggled with to different degrees. I conclude by explaining why these two dominant patterns of engagement are important for history education, outlining the implications for policy makers, teachers and educators.

Chapter 9 concludes the thesis. In this chapter, I review my findings in light of my research questions and describe some of the limitations of this study. I also suggest some avenues for future researchers to take forward and summarise several core contributions this thesis makes to the field of history education.

\section{Summary}

In this chapter, I established the curriculum context of this thesis. I outlined the personal and social significance of my topic and explained my goal to contribute to a broader empirical basis from which to develop a more critical and transformative form of history education. I also clarified some key terms, concluding with the structure of the thesis. In the next chapter, I present the key debates and perspectives on teaching and learning difficult histories of colonisation. 


\section{CHAPTER 2: A REVIEW OF THE LITERATURE - KEY DEBATES AND PERSPECTIVES ON TEACHING AND LEARNING DIFFICULT HISTORIES OF COLONISATION}

No one likes the way history is taught.

Keith Barton and Linda Levstik (2004, p.1)

\section{Overview}

The purpose of this chapter is to present a review of prior research in order to position my study of how teachers and students engage with New Zealand's difficult history of colonisation. Divided into three main parts, it begins by outlining key definitions, criteria and theoretical influences concerning 'difficult history' before summarising the nature of settler colonialism and its significance to history education. This section then outlines the strengths and limitations of existing research in three similar settler societies, including debates about history stemming from Indigenous and European knowledge traditions. I also comment, where appropriate, on methodologies as this emerged as a key consideration for the setting up of my own study. In the second section, I outline research on emotions, affect and place in history education, illustrating that effective teaching about difficult histories of colonisation acknowledges these interrelated themes. In the final section, I present three key, mutually compatible pedagogies for engaging with difficult histories of colonisation, and suggest that together they provide teachers a powerful framework for addressing histories of colonisation with young people.

\section{Teaching and learning difficult history in settler colonial contexts}

\section{Difficult history: Definitions, criteria and theoretical influences}

In recent years, scholarly attention in the social sciences has drawn attention to the specific challenges of teaching and learning about human violence, suffering and oppression. Terms for this history include the dark past (Ahonen, 2012), the violent past (Cole, 2007), hard history (Shuster, 2018) and sensitive pasts (Savenije, van Boxtel, \& Grever, 2014). As Gross and Terra (2019b) argue, "this variety of terms and definitions, sometimes used interchangeably, indicates the complexity of the matter at hand" (p. 3). Despite this variety, the phrases difficult history or difficult pasts have proven resilient, forming the titles of a 
range of theses, published articles, chapters, and edited book collections (Epstein \& Peck, 2018; Goldberg, 2018; Gross, 2014; Gross \& Terra, 2019b; Sheppard, 2010; Stoddard, Marcus, \& Hicks, 2017). 'Difficult history' owes its lineage to the notion of difficult knowledge, an idea first coined more than two decades ago by Deborah Britzman (1998) . Difficult knowledge "signifies both representations of social traumas in curriculum and the individual's encounters with them in pedagogy" (Pitt \& Britzman, 2003, p. 755). Throughout this thesis, I use the term difficult history because, like Pitt and Britzman (2003), I am interested in the interplay of historical representations of (colonial) violence and conflict and the manner of teachers' and students' pedagogical engagement with this content.

Some scholars in history education use criteria to help determine what counts as difficult history. For example, Maia Sheppard's (2010) framework for determining what historical topics were 'difficult' developed from months of observing a single history teacher and her students. Sheppard (2010) found that only two history topics were 'co-constructed' by the teacher and students as difficult history; slavery and westward expansion. These topics incorporated "(a) content centred on traumatic events; (b) a sense of identification between those studying the history and those represented in history; and (c) a moral response to these events" (Sheppard, 2010, p. iii). Sheppard's study is also useful for its demonstration of ethnography, which she used to illustrate how 'difficulty' is not inherent in a topic but dependent on the nature of teachers' and students' engagement with the past, and that this engagement often has a moral component to it. Unlike my study, Sheppard (2010) did not focus deeply on the process of colonisation, or draw explicitly from a perspective informed by settler colonial studies (see below). The depth of Sheppard's (2010) ethnography also meant her study focussed on one school, instead of comparing multiple sites.

Gross and Terra (2019) identify five different characteristics of difficult history, presenting a framework for explaining why some topics can "[cause] emotional pain or trauma" (p. 4) and thus be considered difficult. For them, difficult histories:

1. are central to a nation's history (whether or not they are so recognised by political elites);

2. tend to refute broadly accepted versions of the past or stated national values;

3. may connect with questions or problems facing us in the present; 
4. involve violence, usually collective and sanctioned by the state...[which] may be committed by citizens of good social standing;

5. create disequilibria that challenge existing historical understanding. (Gross \& Terra, 2019, pp. 4-5).

These criteria are useful to settler colonial contexts for their more explicit recognition of power than those suggested by Sheppard's (2010) framework. However, unlike Sheppard's empirical and methodological contribution, it is unclear how Gross and Terra's (2019) criteria were developed and their application in schooling contexts has not been tested.

Difficult histories are also informed by a range of theoretical influences. Tsafir Goldberg (2017), for example, comments on the theoretical basis of Sheppard's (2010) criteria. For him, these criteria are limited due to their grounding in the "psychoanalytic notion of trauma as unworked-through experience of injury, haunting the individual" (p. 145). While not entirely discrediting this psychoanalytic position, Goldberg (2017) nonetheless argues that such approaches cannot sufficiently transfer to the collective level "in which historical trauma is a culturally mediated memory, not a relived experience" (p. 146). Instead, he calls for greater attention to social psychological perspectives, which consider "historical events as difficult due to educators' and learners' perception of threat to group image" (p. 350). In addition to the theoretical influences of psychoanalysis and social psychology, Zembylas (2017b) also identifies sociological influences to explore and analyse difficult history. From this perspective, the focus turns to "the bodies and the troubled knowledge they carry - as it is embedded in social structures and ideologies" (p. 663).

Scholars that employ the concept of difficult history frequently focus on one of three broad contexts. In the first, they look at places emerging from recent conflict such as Israel or Ireland, where the memories of violence are still remembered by many in society and the future remains uncertain (see, for example, Barton \& McCully, 2005; Bekerman \& Zembylas, 2012). In the second, research in difficult history explores the history of democratic and peaceful societies like the United Kingdom or the Netherlands but where some topics remain controversial or emotional (see, for example, Savenije et al., 2014; Spalding, 2011). Thirdly, (and underrepresented in the literature) some scholars focus on difficult history in settler colonial contexts. These may be democratically established societies but ones in which the legacies and trauma of colonisation are ongoing, creating considerable uncertainly for 
Indigenous people (see, for example, Keynes, 2018; Tupper, 2014). It is into this latter context that my research fits. The next section, therefore, describes in more detail the nature of a 'settler society' and describes some common trends in such societies' relationships to their own history of colonisation, trends that frequently shape perceptions of what counts as 'difficult history'.

\section{Settler colonialism and history education}

New Zealand's status as a settler society is central to understanding New Zealanders' engagement with their history of colonisation. Settler societies "build new societies independent of their countries of origin and institute political institutions that maintain settler rule over the Indigenous peoples they displace" (Calderon, 2014b, p. 317). They include nations such as New Zealand, Australia, Canada and the United States and have at their centre "the [legitimation of] settler territorial acquisition through physical and ideological dispossession of Indigenous inhabitants and co-optation of nativeness by settlers" (Calderon, 2014b, p. 314). Settler colonialism, therefore, is not an 'era' in the past, but rather an ongoing mode of domination within settler societies that manifests itself across multiple aspects of society including schools (Calderon, 2014b; Kidman, Ormond, \& MacDonald, 2018; Tupper, 2011).

Settler societies are characterized by a denial, sanitization and 'cultural forgetting' of their own violent histories of colonisation and invasion of Indigenous lands (Gahman, 2016; Kidman, 2018; Veracini, 2008). Attwood (2017) explains that it is especially difficult for settler societies to deal with their own history because "their very foundations lie in the dispossession, destruction and displacement of aboriginal peoples" (p. 24). Educational researchers interested in settler colonialism often seek to uncover and interrograte the "grammers" (Calderon, 2014b) of settler society as found in the relatively static artefacts of curriculum such as official text books and mandated curriculum standards. These scholars frequently concentrate on the ways in which curriculum validates Eurocentric master narratives (Anderson, 2012; Calderon, 2014b; Journell, 2009; Shear, Knowles, Soden, \& Castro, 2015; Stanton, 2012). They seek to expose how offically mandated curricula represent the values of people in power at the expense of Indigenous people and the potential of these standards or resources to influence what happens in classrooms. 
For my study, I have found useful sociologist Paul Spoonley's (2015) categorisation of New Zealand, Australia and Canada as particular types of settler society. Spoonley explains that all three commonwealth nations have Indigenous communities that were colonized by Europe in the 1700s and 1800s, particularly by Britain (though also France in the case of Canada). All have experienced "the establishment of British hegemony" and all have similar approaches to immigration today with annual targets "that equate to approximately $1 \%$ of the national population" (p. 651). Spoonley argues that while the historical experiences and contemporary realities of these three nations are not uniform, in all three of them "the politics of indigeneity are reconfiguring political contours in ways unimaginable just a generation ago" (Maaka and Fleras, 2005, p.9, cited in Spoonley, p. 652). Furthermore, an important and central characteristic of these settler societies is resistance by the white majority population to acknowledging the traumas associated with colonial dispossession of Indigenous peoples (Spoonley, 2015, p. 652).

\section{Existing studies on history education and teaching about colonisation in New Zealand, Australia and Canada}

One consistent pattern highlighted by much of the New Zealand-based research is the lack of curriculum focus given to New Zealand's histories of colonisation or Māori historical perspectives and experiences (Bargas, 2005; Derbyshire, 2004; Hunter \& Farthing, 2004; Manning, 2017; Sheehan, 2010). ${ }^{10}$ To illustrate further, Hunter and Farthing (2004) published a wide-ranging report in the broader Waikato region with approximately $70 \%$ of the total history teaching cohort. They interviewed ten teachers from different schools and surveyed an additional group of history teachers $(n=51)$ on a range of issues pertaining to their perceptions of history curriculum. Hunter and Farthing (2004) found that teachers of Year 11 history students mostly taught international topics. Of the five most popular topics in Year 12, none included a New Zealand context, and in Year 13, they reported a roughly even split of teachers choosing between the broad survey courses of New Zealand in the Nineteenth Century and England 1558-1667 (though the figures slightly favoured the latter context (pp. 64-66)). Hunter and Farthing (2004) concluded that

\footnotetext{
${ }^{10}$ A substantial body of literature also exists detailing the nature of settler colonialism (Belich, 1996; Byrnes, 2001; Patterson, Hill, \& Patterson, 2016), constitutional arrangements and the Treaty of Waitangi (Mulholland \& Tawhai, 2010; O'Sullivan, 2007; Ward, 1999) and the challenges Māori face within the context of a neoliberal state (Bargh, 2007; Howard-Wagner, Bargh, \& Altamirano-Jiménez, 2018). I acknowledge the significance of these works of scholarship, and accept that a similar body of work exists in other settler-colonial nation states. In this section, however, I focus only on key literature from history education.
} 
Teachers' topic selections emphasise European and conflict histories. There is a serious lack of New Zealand histories, and New Zealand history topics selected in years 11 and 12 reflect traditional monocultural contexts and approaches. Bicultural, Maori histories and gendered histories are not represented in research findings. (p. 68) This is an important, albeit dated case study. The area in which the report was written was also invaded by a large colonial army in the 1860s (see Chapter 7). This invasion affected the ability of Māori to ensure their histories are included in curriculum. While Hunter and Farthing's (2004) report is not contextualised within this broader history of settler colonialism, it nonetheless illustrates the historical lack of attention to diverse New Zealand histories. Through interviewing and surveying teachers, it is one of the few mixed methods studies in New Zealand history education, reaching a wide group of teachers and providing a valuable region-specific study. ${ }^{11}$

In addition to highlighting New Zealand's narrow, internationally focussed history curriculum, researchers have also illustrated a lack of engagement specifically with Māori history. Manning's (2009) doctoral research in the Wellington area involved interviewing nine, primarily Pākehā, senior history teachers and comparing these interviews with the views of local tribal experts. He found that teachers were disconnected from local iwi (tribes) and (consequently) had weak knowledge of local tribal history and historical perspectives. Manning (2009) also reported that "teachers agreed that Māori content was often avoided because it would require Pakeha students, parents and teachers to address a contested past" (p. 12). This study implicitly recognised the nature of settler society and illustrated why young people in schools around Wellington Harbour are unlikely to encounter tribal histories of place. Conceptually, Manning's (2009) study draws heavily on notions of place and the central manner in which Indigenous histories are often embedded in the land instead of document-based materials or Pākehā teachers' knowledge. It is one of the few research projects to produce empirical findings about Māori history within the context of history education. Although Manning (2009) interviews his teacher-participants, his study does not investigate the complexities presented to teachers or students in real-life teaching situations, an approach particularly suited to ethnographic research methods.

\footnotetext{
${ }^{11}$ Hunter and Farthings' (2004) findings are also corroborated by several surveys carried out by the New Zealand History Teachers association from 2002-2015 and Manning's (2009b) similar analysis of curriculum in Wellington based schools. See Harcourt, (2020 (forthcoming)) for a more specific summary of these statistics.
} 
Myra Kunowski's (2005) doctoral thesis is one of the few studies that focuses on New Zealand social studies teachers' approach to historical topics. Kunowski (2005) observed, recorded and interviewed four teachers in the Canterbury area that were teaching their junior students about the Treaty of Waitangi. She found that teacher's disciplinary knowledge had a big impact on their confidence and ability to engage with contested narratives of colonisation. Weak disciplinary knowledge, she reported, led to "instances of misrepresentation of content and to some information errors" (p. 138). The teachers in her study who did not report confidence in their content knowledge "expressed concern about parental and community opinion, "not becoming too controversial", and "avoiding politicizing the topic"" (p. 139). Kunowski's (2005) findings are useful because they highlight the essential role of teachers' knowledge in their ability to teach contested and sensitive histories of colonisation in the context of a compulsory school subject. Like Manning (2009), she hints at the issue of teacher avoidance of controversial topics but the small-scale, qualitative nature of her research limits the degree to which generalisations or comparisons can be drawn across different sites.

Until recently, relatively few New Zealand studies have explored the nature of students' engagement with New Zealand's history of colonisation. An early and influential example is visiting United States academic Linda Levstik's (2001) study of 49 students in four Auckland schools. This study is similar to my own for the almost identical number of schools and students (see Chapter 4). Although her chosen sites were relatively diverse, they were all regionally contained. Levstik did not focus on the issue of colonisation, or theorise her research within the context of settler colonialism. Nevertheless, her empirical contribution to New Zealand's history education is significant. Levstik found that despite her participants' ability to entertain complex historical perspectives from people and places far away, her Pākehā respondents were more reluctant to engage with difficult historical issues concerning local Māori land rights (pp. 82-83). She found that for Pākehā students, the act of considering local historical topics and their contemporary significance required taking a perspective that challenged students' ethnic identity, making it an uncomfortable and therefore a less likely cognitive act (Levstik, 2001, p. 89).

Two recent studies by Epstein \& Harcourt (2019) and Sheehan, Epstein \& Harcourt (2018) focus particularly on the Treaty of Waitangi and explore in further detail students' 
conceptions of colonisation and the role of students' social identity in shaping these views. Sheehan's et al. (2018) study builds on Levstik's (2001) earlier work but more explicitly explored attributions of significance given to the Treaty of Waitangi among adolescents of different ethnicities. Unlike most previous research, this study was large in scale, and analysed the short qualitative responses of a large sample of students $(n=500)$. The authors found that "the vast majority of students from all ethnic groups considered the Treaty a significant symbol or event to contemporary New Zealanders" (p. 117). These findings suggest that young people largely affirm New Zealand's official position of the Treaty as the nation's founding document. However, Pākehā students were considerably less likely to consider the Treaty as a source of conflict or controversy when compared to their Māori, Asian and Pasifika counterparts. Māori students were also "much more likely to emphasize a sense of personal or familial loss and ongoing grievance over broken Treaty promises and what these continue to mean for Māori today" (p. 118).

Epstein and Harcourt's (2018) research was similar, though substantially smaller in scale, with the first author interviewing groups of students in a majority Māori and Pasifika population school and in a majority Pākehā school. This study found fewer similarities in student interpretations of the Treaty's contemporary significance and it asked more specific questions, such as whether the Treaty of Waitangi should be celebrated or commemorated, or whether the Treaty is a healing or divisive document. The authors found considerable differences in the ways that students of different ethnicities responded to these questions. For example, Māori described Waitangi Day (the annual commemoration of the signing of the Treaty) in terms of invasion and Pākehā hegemony whereas Pākehā saw it as "just a day off from school" (p. 173). While both of these recent studies make important contributions to our understanding of the role ethnic identity plays in shaping students' historical understanding, neither explicitly frame their findings within the context of a settler society.

To summarise, the New Zealand literature about the teaching and learning of difficult histories of colonisation tends to be small-scale, mostly qualtitative studies limited to particular regions and without the benefit of inter-regional, cross-site comparison. It is also inclined toward the experiences and perceptions of teachers or students, and around a relatively limited range of topics, especially the Treaty of Waitangi. Few studies explicitly position their work within the context of settler colonialism or international literature on 
difficult histories. Some of Manning's (2009) participants discuss the importance of history lessons occurring outside the classroom, but this was not a topic explored in depth, at least not with teachers and their students. Collectively the New Zealand based research paints an important, albeit incomplete picture of how teachers and students engage with the difficult history of colonisation in secondary schooling contexts.

Educational research investigating teachers' and students' engagement with Australian histories of colonisation is not as extensive as one might expect. Studies tend to discuss the challenges of working with pre-service teachers to teach Aboriginal perspectives and a few explore similar issues with in-service teachers (Hart, Whatman, McLaughlin, \& SharmaBrymer, 2012; McKnight, 2015). For example, Harrison and Greenfield's (2011) research with primary teachers and school management in 12 different locations around Sydney explicitly encouraged participants to develop learning that affirmed Indigenous epistemological traditions. Staff at these schools were taught to recognise Aboriginal knowledge "as that which is always grounded in place and only meaningful in the context in which it was produced" (p. 66). This study did not, however, provide an ethnographic description of the learning that took place and the challenges teachers found in supporting the stance toward Indigenous knowledge encouraged by the authors of this study.

One Australian study stands out for its sustained attention to practising history teachers and their secondary school students, particularly their views on Australia's history of colonisation and Indigenous history. Anna Clark $(2008,2018)$ investigated the attitudes of 182 high school students and 43 teachers, explicitly focussing on students' connection with the past. From her interviews, she concluded, "it is Indigenous history in particular that stands out as one of the most scorned areas of Australian history" (Clark, 2018, p. 82). Clark asked her participants extensively about their experiences with teaching and learning Indigenous history. The teachers in this study, for example, while generally not hostile to Indigenous history were lacking in confidence and uncomfortable about how to go about presenting it to their students. One argued that "a lot of the kids come from redneck backgrounds and I feel that's in one way why we've steered clear from doing straight units on Indigenous history because there does get a bit of antagonism" (Clark, 2018, p. 87). Australia's history of colonisation, however, featured as only one part of Clark's broader study and history curriculum in Australia was not theorised specifically as taking place within the context of a 
settler society. Clark's research remains significant because it is one of the few large-scale investigations within the three commonwealth settler societies to directly consider teachers' and students' engagement with Australia's history of colonisation.

Canadian research into how teachers and students engage with histories of colonisation appears more diverse than in Australia or New Zealand and studies often acknowledge Canada's status as a settler society. For example, Tupper (2014) explicitly foregrounds "difficult historical knowledge" within the context of ongoing processes of colonialism in contemporary Canadian society (p. 476). In one study, Tupper and Capello (2008) model an action research approach with four researchers and six teachers who worked together to “implement best practices for teaching treaties" (p. 563). Tupper and Capello (2008) write that "a central focus of the research was to explore what students across grade levels understood, knew and felt about treaties, about First Nation peoples and about the relationships between First Nations and non-First nations people in Saskatchewan" (p. 564). Students were surveyed before and after a teaching episode in order to evaluate its effectiveness. This study established that prior to the intervention, a number of white students held highly problematic views about Indigenous people and Canada's history of treaties. These views shifted slightly after closer attention to local histories of treaties between settlers and Indigenous people. Methodologically, there are few examples of research that match this study's use of action research to disrupt racist settler narratives of history. Its use of interviews and surveys across a range of different schools also ensured a high level of detail about classroom contexts during lessons on colonisation.

Two further useful studies prioritise the views and classroom practices specifically of exemplary teachers. Yatta Kanu's (2005) research used an ethnographic approach to investigate "teachers' perceptions of the integration of Aboriginal culture into the regular school curriculum" (p. 51). This investigation focussed on ten teachers and drew on data from classroom observations, teachers journals and interviews. Kanu (2005) found that "although there was an expressed openness among teachers to include Aboriginal perspectives in the school curriculum, in practice little headway was being made except for a few unique cases" (p. 57). Kanu's study is significant for its focus on a range of exemplary teachers and her use of an ethnographic methodology to reveal their views and practices. She highlights that a simple willingness to teach Indigenous history is often not enough to disrupt practices that 
maintain settler narratives of history. Similarly, Susan Dion's (2008) study, Braiding Histories also prioritised the views and practices of two exemplary non-Indigenous teachers. Her research highlights how even teachers committed to teaching Indigenous history and perspectives remain constrained by their cultural positioning and the ideologies of schooling that determine what counts as good practice.

In the next section, I focus on scholarly debates about the challenge of navigating settler and Indigenous epistemological traditions within history education. This is an issue specific to settler societies and is largely unexplored in the wider scholarship on difficult histories.

\section{Navigating settler and Indigenous epistemological traditions within history education}

Scholars from diverse academic fields have explored the intersections and overlaps between Indigenous and non-Indigenous systems of knowledge (Basso, 1996; Beck \& Somerville, 2005; Bell, 2017; Berkes, Colding, \& Folke, 2000; Carlson, 2010; Johnson \& Murton, 2007; Macfarlane, Macfarlane, \& Gillon, 2015; Salmond, 2017). Within education, the issue has also received attention with critics concerned about the ability of mainstream education to recognise this knowledge in appropriate ways (Aikenhead, 2001; Barnhardt, 2005; Carter, 2006; Somerville \& Perkins, 2010). Drilling down further, there is a debate among history educationalists in Canada, Australia and to a lesser extent New Zealand about the compatibility of Indigenous and Western ways of knowing. The issue is a unique, yet underexplored aspect of the literature on difficult history that nations such as Germany, France or the United Kingdom do not have to contend with when designing and enacting history curriculum. It is a significant issue for history education in settler societies because, as Sidney Stephen (2000) argues, "exploration of a topic through multiple knowledge systems can only enrich perspective and create thoughtful dialogue" (pp. 10-11). In this section I outline the scholarly debates and explain my position within them. I also show that with few exceptions, the arguments are theoretical with minimal empirical data revealing actions and practices of teachers and students.

Little consensus exists within history education over the extent to which Indigenous approaches to the past are compatible with those rooted in Western traditions. For the most part, arguments appear to fall along a continuum (see Figure 2.1) of compatibility between 
knowledge systems. Some scholars recognise that while there may be significant differences (even contradictions), a middle ground is nevertheless possible.

\section{Navigating settler and Indigenous epistemological traditions in history education}

\section{Emphasis on incompatibility between traditions}

\section{Emphasis on compatibility between traditions}

Middle ground

Figure 2.1: A continuum of positions in history education regarding the compatibility of Indigenous and non-Indigenous worldviews

An emphasis on the incompatibility of traditions is exemplified by a scholarly dispute between two Canadian educationalists. Michael Marker (2011) explains that for Aboriginal students "history courses in Canadian schools are probably the most difficult" (p. 97). This is not because there is no Aboriginal content in Canadian classrooms but that "the deeper perspectives of Aboriginal peoples in regard to their understandings of the processes of time and the principles of their knowledge systems are usually missing" (p. 97). Marker (2011) identifies four Indigenous themes that he believes "are difficult to integrate into the conventions of Western historiographies" (p. 98). These themes are:

1. The circular nature of time and the way oral traditions is integrated with recurring events;

2. The often central theme of relationships with landscape and non-humans;

3. An emphasis on the local landscape as containing the meaning of both time and place rather than on analyses of global social and political change;

4. Indigenous narratives and perspectives on the histories of colonization that have attempted to displace and replace indigenous knowledge. (Marker, 2011, p. 98)

Peter Seixas' (2012) critiques this work by making clear that Marker is making a: Claim to a distinct "way of knowing," an indigenous epistemology, a non-European, non-Enlightenment sense of the relationship between past, present and future that puts 
the understanding of history on an entirely different ground from that developed by

English, French, Dutch and German historical thinkers". (p. 126)

He poses the question: "is all historical consciousness to be measured against a standard set by modern Europe?” (p. 128).

For the most part arguing in the affirmative to this question, Seixas uses six historical thinking concepts as yard sticks for measuring their compatibility with Marker's (2011) Aboriginal themes, mostly finding areas of contention. ${ }^{12}$ For example, he claims there are irreconcilable differences with the Indigenous understanding of ownership and authority in the telling of stories because "some stories, for spiritual reasons, can only be told at certain times by certain people" whereby "the credibility of an account rests upon the identity of the teller" (Seixas, 2012, p. 129). Seixas explains that in the European tradition all historians are equally open to challenge with their authority to make claims about the past deriving from their conformity to disciplinary norms. Nevertheless, the 'ethical dimension' is one of six primary historical thinking concepts from the Historical Thinking Project that Seixas believes has genuine compatibility with an Indigenous approach to the past. He suggests, "Western and First Nations historiography have a chance to come together around debts of memory, and obligations for reparations and restitution" (p. 135). Seixas (2012) concludes his analysis of Marker's four indigenous themes with the question "once indigenous ways of knowing are actually part of the textbook's way of knowing, then who will be able to object to histories based on Islamic cosmology, Biblical fundamentalism and Haitian voodoo?” (p. 136). ${ }^{13}$

Another Canadian scholar, Samantha Cutrara (2018), has recently articulated a sharp critique of Seixas' position, arguing that his historical thinking reforms in Canada "[impose] a settler

\footnotetext{
12 These concepts are historical significance, primary source evidence, continuity and change, cause and consequences, historical perspective-taking and the 'ethical dimension'. They broadly align with the historical thinking concepts embedded within the New Zealand Curriculum's history strand. While no longer active, the details of the original Canadian project can be found here: https://historicalthinking.ca/

${ }^{13}$ Some Indigenous and allied scholars challenge the idea that it is possible for Indigenous ways of knowing to be represented in a textbook because aboriginal knowledge is "alive, performative and reflective of the place where it is produced" (Harrison and Greenfield, 2011, p. 72). In other work, Marker (2019) also makes it clear that Indigenous epistemologies are not comparable with individually held religious 'beliefs'. I agree with Marker that Indigenous epistemologies are not the same as individual (and especially fundamentalist) religious beliefs. I also recognise that some branches of Christianity - such as the Fransciscan friars - acknowledge the ecological nature of reality and the divine nature of all things. The cosmology of mystical Christianity, which dates back millennia to the desert fathers and mothers of Egypt, seeks a unitive relationship with all things and all people in ways that closely resemble, (although in entirely different cultural contexts) important aspects of Indigenous knowledge.
} 
grammar over the study of the past" which, she explains, makes reconciliation between Indigenous and non-Indigenous Canadians more difficult (p. 251). I place Cutrara on the end of the continuum that emphasises the incompatibility of traditions due to her contention that historical thinking "[denies] the presence of Indigenous epistemologies as legitimate ways for understanding the past" (p. 257). She uses the same logic as Seixas by using one set of ideas as the lens for commenting on another entirely different set. Compared to Seixas (2012), she inverts this logic and uses Indigenous ideas as the yard stick for critiquing historical thinking concepts, concluding that,

Historical thinking starts and ends with a disciplinary approach to history not designed for fluidity and respect for multiple understandings of the past - multiple interpretations of history based on historical evidence, yes; but not different ways of seeing and being able to see into the past. (p. 266)

While both of these accounts set up an either/or approach between Indigenous and Western traditions, Gibson and Case (2019) argue for a middle line, holding that historical thinking plays an important role in challenging settler narratives of colonisation and promoting reconciliation. These authors argue against Cutrara (2018), explaining, "the legitimate opposition to Eurocentric dominance of the history curriculum can be redressed without the wholesale dismissal of the discipline of history and its methods" (p. 254). Gibson and Case (2019) lay out a number of ways in which historical thinking can work to promote reconciliation in Canada, such as a greater inclusion of "Indigenous events, developments and people", presenting "nuanced portrayals of Indigenous people" and "[showcasing] Indigenous sources of historical evidence" (pp. 256-257). McGregor (2017), another Canadian educator, also seeks to reconcile how Canadian history teachers might navigate different epistemological traditions. She (2017) explains, “answers to complex and sometimes incommensurable challenges will likely be developed on a case-by-case basis, responding to particular learning contexts places and relationships" (p. 3). Like Gibson and Case (2019), McGregor (2017) looks for a middle ground in ways that are largely absent in Cutrara's (2019) and Seixas' (2012) work and less obvious in Marker's (2011) scholarship.

The studies described above are entirely theoretical but one Canadian project that makes an empirical contribution to the debate and which also seeks to find a middle ground as illustrated in Figure 2.1 is Jennifer Tinkham's (2018) work with Mi'kmaw students. Using a "decolonising approach where participants played an active role in interpreting the data" (p. 
124), Tinkham worked with 13 Indigenous students across two sites. She found that in one "band-controlled school”, Mi'kmaw students report feeling no pressure to "choose between two knowledge systems" (p. 125). Tinkham (2018) concluded:

A negotiated partnership between Indigenous and Western knowledge would represent what Lipka et al. describe as a "third reality" where cultures in contact are represented not by an either/or approach but rather both/and, lessening the struggle over whose knowledge is of most worth. (p. 134)

Tinkham's (2018) study is one of the few empirical research projects in history education secondary school classrooms that draws on 'border zone theories' such as third reality, the cultural interface (Nakata, 2004), or in New Zealand, He Awa Whiria (Macfarlane et al., 2015), all approaches to knowledge that are firmly placed on the middle of the continuum presented above. ${ }^{14}$

Some Australian scholars also debate the compatibility of western and Indigenous knowledge systems, illustrating how this issue transcends the borders of white settler societies. Neil Harrison (2013) for example, disagrees with a conclusion drawn by Clark's (2008) largescale research project described in the previous section. Clark argued that young people feel disconnected from learning Australian (Indigenous) history because their teachers do not employ active pedagogies that engage students with the disciplinary features of the subject. Harrison counters this by explaining instead that disciplinary features (historical thinking concepts) represent an "epistemology that produces knowledge as disembodied and placeless" (p. 215). He claims that "all students need to know how to interpret and explain, but they also need to recognise that conceptual knowledge will not make their historical studies any more interesting, intriguing or engaging" (p. 218). According to Harrison, students need a history curriculum that is linked to place and which connects deeply with students' lived experiences and prior knowledge. Like Cutrara (2019), Harrison sees little hope in educational reform stemming from critical historical thinking, which he believes "privileges a western epistemology that relies on the production of knowledge as disembodied, and employs concepts which are culturally bound, for example, cause and consequence, empathy, evidence, and linear sequencing" (p. 218). Harrison's solution is for schools to work directly with Aboriginal communities and he explains that teachers need to

\footnotetext{
${ }^{14}$ See Chapter 8 for a fuller discussion of He Awa Whiria as a potential model for history education.
} 
understand that learning history involves "[reading] oneself in country" (p. 221). From this perspective, to leave history in books and documents only "[ensures] that children become further divorced from the place in which they live" (p. 222). These arguments place Harrison on the end of the continuum that emphasises the incompatibility of Indigenous approaches to the past and those drawn from European traditions of historical thinking.

In a similar paradigm to Harrison, another Australian scholar, Keynes (2018), suggests that modernist assumptions about the nature of time inherent to the discipline of history make it difficult for history education to recognise ongoing structural violence, thereby reducing the subject's contribution to reconciliation and transitional justice in settler societies. Keynes critiques the approach to history education that draws on a disciplinary framework. This framework prioritises historicisation, which she argues is "deeply problematic for reconciliation efforts in Australia" (pp. 126-127). Historicisation "[emphasises] the differences between a past and the present" and is a cognitive act that "has typically been perceived as a positive, even ethical dimension of an historian's work" (Keynes, 2018, p. 127). Historicisation sits at the heart of the discipline of history and Keynes' critique of this notion is a profound conceptual challenge to the forms of historical thinking that underpin curriculum in nations such as New Zealand, Australia, Canada and the United Kingdom. She argues that:

By demarcating the apparent distinctions between a past and present, victims of injustice, including Indigenous persons and groups that do not want to, or cannot, leave their past behind - for the very reason that it is not past or for other cultural reasons - are only further marginalized. (Keynes, 2018, p. 128, italics in original) History education, from this perspective, tends to "put a past in its proper time" (Bevernage, cited in Keynes, 2018, p. 115). Historical theorist Bevernage (2010) explains that the containing of the past, present and future into discrete temporal 'packages' emerged as a "distinctively modernist (and Western) concept of time" (p. 125). It is argued that historicism, and the modernist theories of time that give it conceptual integrity, ring fence or label as deviant alternative conceptions of time such as Indigenous temporalities (Keynes, 2018). I agree that a conception of time that renders Indigenous temporalities as deviant is problematic for a history education committed to cognitive justice (see Chapter 3). Unlike Keynes (2018), I am not convinced that the logic of historical thinking "[makes] it possible for students to recognize and validate only particular pasts and particular presents, while 
others are rendered illegitimate and unrecognizable" (p. 131). While this is always a danger to which educators needs to be attentive, in the following chapter I outline in more detail an approach to knowledge that seeks to push beyond this kind of either/or thinking about history education.

As mentioned in the previous section, in New Zealand, Manning's research (2009, 2011, 2017 ) is the largest body of scholarship to explore the tensions between Indigenous and nonIndigenous historical traditions in secondary school contexts. More recently, Manning and his Australian colleague Neil Harrison (2018) have collaborated, arguing for the inclusion of more Indigenous narratives of place and land in teacher education. However, this latest study does not present any new findings from New Zealand nor does it explore current challenges faced by practising teachers and their students. The overall limited scale of the conversation in New Zealand history education stands in contrast to that of many Māori scholars who discuss the meaning of the concept of 'Māori history' and the differences, similarities and compatibility of Māori and traditionally European approaches to history (Buchanan, 2018; Keenan, 2012; O'Regan, 2014; Penetito, 2009; Tau, 2001; Williams, 2014).

Some of these Māori scholars have commented explicitly on history education and not all see European and Māori approaches to history as incompatible. For example, in an interview for the Māori History Project, scholar Piri Sciascia expressed views that suggest he is looking for a middle ground between knowledge systems. Sciascia argued that Māori history requires a different way of thinking about the past than some traditional Western perspectives: "Māori history is more reflective, may contain several viewpoints and have no single version of the truth. It encourages questioning of who is telling the story and who is the intended audience. Māori history presents a less certain world". ${ }^{15}$ These views very much reflect the values of historical thinking which also explicitly rejects the unproblematic delivery of single narratives, seeking instead an "informed provisional uncertainty" (Brett, 2016, p. 41). For Sciascia, Māori history also reflects some of aspects of Marker's (2011) 'four pathways' described earlier. For him, Māori history is place-based and told from a Māori viewpoint. To illustrate this, Sciascia argues that it might involve investigating an event that happened in the paddock next door, or the exchanges that took place between two iwi in a local valley near a

\footnotetext{
${ }^{15}$ Interview accessed July, 2019: http://maorihistory.tki.org.nz/en/why-teach-maori-history/
} 
school. Sciascia emphasizes the Treaty of Waitangi as a lens for understanding Māori history in schools. For Sciascia, local iwi should handle and guard Māori history and schools need to connect with tribal structures in their area to access these stories.

The descriptions and definitions offered by Sciascia do not suggest an intractable relationship between Māori history and historical thinking, placing him more in the middle of the continuum in Figure 2.1. Historian Danny Keenan (2012) is another scholar who seeks a middle ground. He begins by arguing that "colonial histories of Māori made very little reference to whānau, hapū or tribal groups and the interrelationships they had with each other" (p. xv). In doing so he establishes the deep connection of Māori history to whakapapa (genealogy) which is always grounded in place and landscape. For Keenan, New Zealand's dominant historical narratives overlooked "essential elements of Te Ao Māori such as history, legitimacy and mana whenua, specifically grounded within tribal areas" (p. xv). Keenan's emphasis on the tribal and place-based nature of Māori history, however, does not discount the value of historical thinking. He argues that "since the advent of the "indigenous revolution', native peoples have 'strategically employed non-indigenous discourses and theory' when insisting upon redressing the wrongs of colonisation” (p. xxxi). Similar to the arguments of Gibson and Case (2019), Keenan recognises the potential value of historical thinking in challenging narratives that sustain settler-colonial systems of power. Keenan's additional emphasis on the role of whakapapa and its connection to place and landscape in Māori history place him as a scholar searching for a middle ground between Indigenous and western approaches to the past.

To summarise this chapter so far, existing studies in history education that explore the teaching and learning of histories of colonisation do not always acknowledge their settler colonial context. Moreover, few studies examine in depth the experiences of both teachers and students during lessons on the contested process of colonisation. Instead, particular events (such as the Treaty of Waitangi in New Zealand) receive attention, or the more general challenges of prioritising Indigenous knowledge and perspectives within Eurocentric schooling contexts. While a number of scholars now explore the compatibility of different epistemological perspectives, there is little explicit analysis of the complexities of navigating Indigenous and western systems of knowledge by teachers and students. Where this does exist, it is frequently removed from real-life school contexts and with a tendency either to 
overstate the power of historical thinking or to reject its conceptual apparatus as inherently 'colonial'.

In the next section, I explore the literature on place and emotion. These are two important themes in this thesis because teaching and learning difficult histories of colonisation is by nature about land and places that are contested, and to which Māori, Pākehā and other nonIndigenous New Zealanders feel a deep sense of belonging. When made an explicit focus of study for students (especially when teachers attempt to explore multiple perspectives, draw past and present connections and acknowledge historical injustices), feelings of hurt, resentment and anger from many different sides can emerge. These challenges of teaching history in a settler society drew my attention to a body of literature on the role of emotions and place in history education.

\section{Emotions, affect and place in history education}

\section{Emotions and affect in history education}

Scholars in education are increasingly interested in the nature and role of emotions and their implications for teaching about contemporary and historical forms of injustice (Bekerman \& Zembylas, 2012; Bermudez, 2012; Goldberg, 2018). Megan Boler's early and seminal work in this field, while not focussing on any one example of injustice, explained how emotions function as a site of social control and a mode of political resistance (Boler, 1999). She argued that "we need pedagogical recognition of how emotions shape our classroom interactions" (p. xv). For Boler (1999), recognising the emotional rules that operate in classroom contexts can help teachers to "challenge rigid patterns of thinking that perpetuate injustice and instead encourage flexible analytical skills, which include the ability to selfreflectively evaluate the complex relations of power and emotion" (p. 157). Similarly, referring to social studies, Sheppard and colleagues (2015) explain, "what is needed is an ability to see [emotions], to trace their movements, and to consider how they are or are not supporting learning (p. 166)”. Bekerman and Zembylas (2016) also advise teachers to "acknowledge and explore disturbing feelings" using a pedagogy that "[deals] with open wounds without reproducing the status quo" (cited in Epstein \& Peck, 2018, p. 6). These educators agree that education should help break down dichotomous categories such as 'us and them', categories that are maintained through "emotional and affective forces" (Helmsing, 2014, p. 128). 
Although many scholars in the social sciences agree that emotions are an important focus of inquiry, there are fundamentally different perspectives about how to conceptualise them. Zembylas (2007) makes these perspectives explicit in his framework of three contrasting approaches. ${ }^{16}$ In the first approach, emotions are an individual, biologically determined, and universal experience where there is "little interest in the details of sociocultural context in which the meanings of emotions are developed, including such aspects as power relations, or historical and cultural conditions" (p. 60). In the second approach, emotions are a sociocultural experience, "determined not only or even primarily by internal individual (intrapersonal) characteristics, but rather by relationships" (p. 62). In the final 'interactionist' approach, "emotions are crucial to the processes in which the psychological and the social are produced" (p. 63).

When looked at from an interactionist perspective, emotions and emotional expressions are highly political. They flow or "stick" to bodies according to rules of inclusion and exclusion, rules that are always embedded within broader relations of power that exceed invividual feelings (Ahmed, 2004). Put differently, emotions "do not come from inside us as a reaction, but are produced in and circulated between others and ourselves as actions or practices (Bekerman \& Zembylas, 2012, pp. 116, parentheses in original). Sheppard et al. (2015) use Zembylas' (2007) framework to assess literature in the social sciences and they conclude that very few studies explicitly theorise emotions or reflect this third interpretation of emotions and their nature, the interpretation that also informs this study. Highlighting the significance of further research on emotions, Sheppard (2015) and her colleagues conclude that democratic education needs "social studies researchers and educators [to] examine emotions' role in how students engage with difficult and controversial issues" (p. 167).

Directly related to the issue of difficult and controversial issues are debates about how far emotions serve as a resource or a barrier to teaching and learning history. Goldberg and Schwarz (2016) argue that "rather than attempting to foster positive emotion only or to avoid emotions altogether, we should look at ways of engaging with emotion in history teaching"

\footnotetext{
${ }^{16}$ Zembylas (2017c) also defines emotions as "the socially agreed names people give to how they feel" (p. 665). Emotions however, are not synonymous with 'affect'. Miles (2019) describes affect succinctly as "an embodied experience of intensity that is only later consciously interpreted or registered as an emotion or feeling" (p. 478).
} 
(p. 7). They contrast this approach to those who consider disciplinary thinking as a useful conceptual apparatus for constraining emotional responses that lead to bias, presentism and identity-based controversy in the classroom (Davis, Yeager, \& Foster, 2001). Goldberg \& Schwarz (2016) are particularly critical of suggestions that teachers avoid controversial and emotive issues and teach instead distant events "in order to allow learners to better focus on disciplinary practices" (p. 8). These scholars have helped inform my approach to emotions and suggest that:

We should start looking at emotions as promoters, factors and even as desirable outcomes of learning in history. This does not mean, of course, that we should ignore the inhibiting role of emotions in some cases, and that we should eliminate from class activity a detached critical-disciplinary approach. Our message is that emotions are precious resources for history education, but that teachers should learn when and how to capitalize on them. (pp. 16-17)

Closely related to the concept of emotion is the idea of empathy, referred to by Helmsing (2014) as "one predominant marker of affect" (p.130). Empathy is an enormously contested concept in history education (Endacott \& Brooks, 2018). One major point of disagreement is the tension between scholars who see empathy as a primarily cognitive process or outcome, and those who recognise that "dispassionate analysis of history is not superior to inquiry in which affective considerations are involved" (Endacott \& Brook, 2018, p. 207). Two authors, Barton \& Levstik (2004), have proven particularly influential in articulating this latter approach to empathy, commonly understood as the beliefs, motivations and actions of those in the past. For them, history education cannot afford to disregard students' feelings about the historical people they encounter. They emphasise the importance of students personally caring about, and holding as relevant, the people they study during history lessons. Inevitably, this approach to empathy invites an emotional response, the very thing, they argue, that makes history relevant and provides the motivation needed to do the cognitive work of critical historical thinking (Barton \& Levstik, 2004). Applying these ideas about the significance of engaging with students' affective responses to history, my study took a particular interest in the emotional 'climates' generated when learning centred on instances of colonial injustice and the significance of emotion when visiting sites of trauma. However, as stated above, pedagogies that turn to the affective dimensions of learning local or national histories of colonisation remain incomplete if separated from place and land. In the next 
section, I explore the literature on the physical engagement with places and their histories beyond the classroom.

\section{History field trips to sacred sites and places of violence and suffering}

The manner in which humans use and interact with historical sites of violence and suffering has been extensively theorised by scholars in a wide range of academic fields (Kenneth Foote, 1997; Landsberg, 2004; Lehrer, Milton, \& Patterson, 2011; Lennon, 2017; Schramm, 2011a). Comparatively few of these studies, however, focus on young people's pedagogical encounters with these difficult histories of place in secondary school contexts. This is despite the growth of tourism to sites of former atrocities ${ }^{17}$ and travel companies that support schools to run such excursions. ${ }^{18}$ Nevertheless, existing scholarship, even when not directly linked to secondary schooling contexts, still informs this study in important ways. For example, in heritage and museum studies, Lehrer, Milton and Patterson's (2011) edited volume Curating Difficult Knowledge: Violent Pasts in Public Places investigates curatorial practices of difficult history at museums, memorials and historical sites. For them, a key question driving their research is "What is our responsibility to stories of suffering that we inherit?" (p. 4), a question relevant to all teachers of history who run field trips to sites of colonial violence. Geographer Matthew Cook (2015) more specifically examined the experiences of visitors at a plantation house in the American South. Although not a settler/Indigenous context, Cook visited three plantation sites converted into museums that specifically try to disrupt common assumptions about slavery through the presentation of 'counter narratives'. The concept of a counter narrative is one explored in greater detail in Chapter 7, and is defined by educationalists Goldberg and colleagues (2006) as a narrative that focuses on "groups underrepresented or excluded from the official institutions or the official narrative" (p. 323). Using an ethnographic methodological approach Cook pays attention to how museum staff curate each site during guided tours. He concludes that the guides' well-intentioned attempts to cultivate empathy for the enslaved did not provoke critical thinking about racism and privilege and "may preclude important activism and greater solidarity between racial groups" (p. 290). Modlin Jr and colleagues (2011) explore more closely the role of affect when audiences follow guides at a plantation site. These scholars carefully considered how the built environment was used to promote certain historical narratives and affective experiences.

\footnotetext{
17 See, for example: https://www.tourism-review.com/dark-tourism-includes-various-niches-news10368

${ }^{18}$ See for example: https://www.voyagerschooltravel.com/
} 
They concluded that tour guides create "emotionally evocative accounts" about the planter class but at the expense of the enslaved (p. 3). For these researchers, this generates an "affective inequality" that is "created and reproduced through specific spatial and narrative practices" (p. 3). While neither of these geographic studies focus on schooling contexts or colonial landscapes of violence, they both highlight the value ethnographic methodologies can have when exploring the affective consequences of place-based encounters with pain and suffering and both helped to shape the approach taken in this study (see Chapter 4).

Existing literature on students' engagement with sites of suffering is mostly found within education studies, particulary history education (Burgard \& Boucher, 2016; Feldman, 2002; Freeman, 2014; McKernan, 2017; Rose, 2016; Spalding, 2011; Trofanenko, 2011). These studies of youth recognise in varying detail the impact that visits to historical sites and museums can have on young people's historical understanding and affective responses to difficult history. Four studies, however, stand out for their contributions to theorising emotion, place and difficult history. These helped me to develop my conceptual and methodological approach when framing sections of my research around difficult histories of place. The first is Jackie Feldman's (2002) ethnographic research into Israeli students' journeys to Poland to commemorate the Holocaust. Feldman showed how the journeys to Poland were deliberately curated to generate an affective attachment to the state of Israel ( $\mathrm{p}$. 85). Field trips in this study were highly political and succeeded in creating a clear distinction between Israeli Jews and Polish gentiles, an approach which "[essentialized] group differences" (p. 107). Drawing on a Levinasian ethics, Feldman concluded that instead of promoting notions of 'us versus them', field trips could instead "provoke us to engage in dialogue with the other, and [evoke] in us our sense of responsibility for him (sic)" (p. 109). From this perspective, the purpose of field trips moves beyond developing historical understanding as the ultimate purpose of history education to include promoting bonds of solidarity among diverse groups of young people.

In the second study, Peter Brett (2016) argues, "mainstream approaches to both history and teacher education have little to say about emotions, affectivity and feelings" (p. 39). Using the Port Arthur penal settlement in Tasmania, Brett draws together ideas of place, emotion and what he calls "traumatic sites of memory" (p. 39). For this author, it matters deeply what students feel at sites of suffering and trauma. He does not suggest that history teachers should 
prompt a particular kind of emotional response, but argues they should support students to "make meaning from their affective experience at a site of suffering" (p. 34). Brett looks for ways in which affective experiences at places of deep suffering and trauma can support students to think historically, "[engaging] young people in a dialogical and participatory process of historical interpretation" (p. 36).

In a further study that deals more specifically with a settler-colonial context, Michael Marker (2019) describes his work with a small group of Indigenous youth and their field trip to a local sacred site, placing this journey in the broader context of Canadian settler society and its long legacies of colonial injustice. Marker uses the field trip to support theorising an Indigenous historical consciousness which he argues "include realities beyond what Western minds consider to be historical truth" (p. 185). Marker's purpose is to illustrate that "history not only contains multiple accounts and interpretations of events, but also multiple forms of consciousness for experiencing the reality of events" (p. 185). He highlights the significance of learning history within certain locations, the interdisciplinary nature of history and the circular nature of time from his Coast Salish Indigenous perspective. For Marker, the "light of Indigenous wisdom" (p. 196) can help students today consider new ways of thinking and being that are directly conducive to planetary survival in a world threatened by climate change.

In the final study that drew together emotion, place and difficult history, Harper Keenan (2018), also addresses the history of colonisation, though with less explicit attention to Indigenous epistemology than Marker's study above. Keenan uses the concept of a 'counterstory' to theorise how a 4th grade school field trip to a Catholic Mission can disrupt the processes of settler colonialism. Keenan participates in a school field trip and describes the way two Indigenous guides narrate their tribal histories within a particular location as a story of Indigenous agency and presence. He describes how these guides highlight for students the message that "we are still here. Our language is Chochenyo" (italics in original, p. 18). Harper argues that it was more than simply going on the field trip that provided students with a powerful experience but rather the "meaningful engagement with contemporary Indigenous knowledge, history and counterstory about the place where we live" (p. 18). He argues that such an experience is not possible within classroom walls, explaining, "sometimes, the school is not well-suited to the learning we need to do" (p. 17). 
Nevertheless, Harper acknowledges that, "leaving [the classroom] could also be symbolic" (p. 18) if teachers drew on Indigenous material in classroom contexts. A key element of Keenan's counterstory is that encountering Indigenous perspectives provided students a point of reference with which to compare and critique settler narratives, such as those found in state mandated textbooks.

These four studies illustrate the power (for good and ill) of emotions and affective experiences at sites of deep trauma, the role of field trips in developing historical understanding and the educative potential of teaching students to make sense of their feelings and to challenge settler narratives of the past. Harper (2018) and Marker (2019) also highlight the opportunities and challenges to come from acknowledging Indigenous forms of historical consciousness. Putting these dimensions together into a pedagogy, however, is no easy task. In the final section, I outline several pedagogical approaches and evaluate their usefulness for engaging with New Zealand's difficult history of colonisation.

\section{Pedagogies for engaging with difficult histories of colonisation}

\section{Historical thinking}

In recent decades, a number of democratic and settler-colonial nations (such as New Zealand, Australia and Canada) have attempted to reform history curriculum through embedding 'historical thinking' into official curriculum design. Historical thinking seeks to recontextualise the discipline of history into the school subject through foregrounding key 'second-order' or 'procedural' concepts such as historical significance, evidence, and causation. These work in tandem with 'first order' or 'substantive' content-based concepts such as empire, slavery or democracy. A key proponent of this movement is the Canadianbased scholar Peter Seixas (introduced earlier), who argues that the second-order concepts function as "problems, tensions, or difficulties that demand comprehension, negotiation and, ultimately, an accommodation that is never a complete solution" (Seixas, 2017b, p. 597). By focussing on the rational, critical and disciplinary features of the discipline, proponents of historical thinking argue that it provides an important alternative to 'monumental' forms of history education, forms which "[serve] the function of legitimizing the ruling regime and developing loyalty among the younger generation” (Bentrovato et al., 2016, p. 290). 
As discussed in a section above, historical thinking is far from an uncontested field. Aside from critiques arguing that historical thinking forms an extension of settler colonialism and is inherently antagonistic to an Indigenous world view, others react to school reforms based on historical thinking in different ways. For example, Barton (2009) argues that a curriculum focused on the disciplinary nature of history "carries with it the danger of discounting students' perspectives on history, and as a result, the subject may become increasingly meaningless to them" (p. 265). Barton acknowledges that the critical, inquiry-based approach of reforms based on historical thinking has valuable impacts on learning and is a useful alternative to students memorising nationalistic narratives. However, he also warns that "we may replace one meaningless version of history with another that is equally meaningless even if it is better grounded in the academic discipline" (p. 266). Barton is primarily concerned that a focus on the nature of the discipline will result in students' perspectives being rejected, a process he sees occuring through a "chronological presentation of history", "ignoring issues of identity" and educators "neglecting to help students understand the myriad ways in which the past is used in contemporary society" (p. 266).

In another critique of historical thinking, Zembylas (2017c) warns that educators need to constantly consider the way pedagogies based on rational, evidence-based attention to the discipline (an historical thinking approach) might

Contribute to [sustaining] hegemonic norms of understanding trauma and loss by ignoring the affective dimensions of transformation and by simply attempting to change students' or teachers' rational understandings through replacing faith with reason and belief with knowledge. (p. 663)

Like Barton's (2009) scholarship, Zembylas' work does not discount the significance of historical understanding based on disciplinary norms. Both, however, see the purpose of teaching history in 'extrinsic' rather than 'intrinsic terms'. Intrinsic approaches are "those aims that remain within the confines of history as a discipline" whereas extrinsic aims are “those broader educational objectives that seek to identify history's potential contribution to wider societal change" (McCully, 2018, p. 161). One pedagogy different to historical thinking that aligns with an extrinsic perspective is a pedagogy of discomfort. 


\section{A pedagogy of discomfort}

Megan Boler (1999) initially coined the term 'pedagogy of discomfort' as an orientation toward education which starts by "inviting educators and students to engage in critical inquiry regarding values and cherished beliefs" (p. 176). Boler pushed well beyond instrumentalist interpretations of pedagogy that reduce the concept to techniques and strategies. Recogising how power operates to regulate our emotional responses, a pedagogy of discomfort "aims to invite students and educators to examine how our modes of seeing have been shaped specifically by the dominant culture of the historical moment" (p. 179). One key idea that Boler draws attention to is the difference between spectating and witnessing and the significance of learning to tell the difference. The former suggests a voyeuristic approach to learning about the lives of others which "[allows] oneself to inhabit a position of distance and separation...and abdicate any possible responsibility" (p. 184). Witnessing, in contrast, "is a process in which we do not have the luxury of seeing a static truth or fixed certainty" (p. 186). She continues by saying that "as a witness we undertake our historical responsibilities and co-implication" (p. 186). Witnessing suggests that it is not enough to feel what Boler criticizes as "passive empathy" at the suffering and injustice in the world because "passive empathy produces no action toward justice" (p. 159).

Boler (1999) also explains that learning to recognise our values and cherished beliefs and differentiate between 'spectating' and 'witnessing' is likely to result in resistance which teachers and students need to navigate together, especially when our emotional attachments are implicated in systems of privilege. She argues that "a pedagogy of discomfort invites students and educators to engage in collective self-reflection regarding the reasons for our emotions" (p. 192). For Boler, teachers can only operate from this perspective through invitation, not through coercion. She also argues that a pedagogy of discomfort should centre mutual exploration rather than confrontation. Boler hopes that at a minimum her students "examine their values, and analyze how they came to hold those values" (p. 199). Ultimately, this is directed toward the goal of "greater clarity of our emotional investments and the ability to account historically for our values and their effects on others" (p. 199).

One challenge associated with a pedagogy of discomfort is 'safely' exposing students' deeply held beliefs in classroom contexts that can never fully escape dynamics of power (Jones, 
1999). How, for example, does a teacher productively wrestle with her privileged students' feelings of guilt, resentment or shame when the systems of inequality that generate that privilege are the topic of learning? Zembylas and Papamichael (2017) acknowledge that "in practice it is not always easy or productive for the teacher or teacher educator to navigate through such feelings" (p. 14). These (and other) scholars recommend the use of "strategic empathy" which involves the teacher empathising with students' disturbing views in order to establish the kind of empathy and relational bond required for transformation (Lindquist, 2004; Zembylas, 2012; Zembylas \& Papamichael, 2017). One challenge, however, that teachers face when they strategically empathise with racist, homophobic or sexist views in classrooms is the risk of some students reading that empathy as (tacit) agreement. Barbara Applebaum (2017) is also critical of strategically empathising with white students who become upset when their privilege is challenged. She argues that such empathy may be interpreted as the comforting of white feelings of discomfort. She asks how educators can "support white students to stay with rather than flee from the discomfort that is necessary for learning” (p. 864, italic in original).

\section{Decolonial pedagogies}

Unlike the two pedagogies described above, decolonial approaches explicitly engage with the consequences of colonisation in education. Framing the schooling project firmly within the violent and genocidal history of global settler colonialism, Gaztambide-Fernández (2012) argues that educators are

Called upon to play a central role in constructing the conditions for a different kind of encounter, an encounter that both opposes ongoing colonization and that seeks to heal the social, cultural, and spiritual ravages of colonial history". (p. 42)

Extending this relational understanding of decolonial pedagogies, (similar in important ways to pedagogies of discomfort) one key distinction in the literature concerns learning 'about' Indigenous knowledge, history and perspectives versus learning 'with' and 'from' local Indigenous people and their lands (den Heyer, 2009; Harrison, 2012; Harrison \& Greenfield, 2011; Hart et al., 2012; McKnight, 2015; Weuffen, Cahir, \& Pickford, 2016). These latter 
approaches typically involve learning outside the classroom, alongside Indigenous communities and extending purely cognitive notions of historical understanding. ${ }^{19}$

The literature on decolonisation and decolonial pedagogies is vast but New Zealand scholars Melinda Webber and Kapua O’Connor (2019) underscore the important point of Māori youth hearing "narratives of Māori success, identity, and thriving" (p. 4). They argue that

Decolonisation starts to occur when children understand that even though centuries of colonial education have methodically disparaged and interrupted Māori ways of seeing, being and interacting with the world, we can still live and learn 'as Māori'”. (p. 2)

Highlighting the fact that Māori students have been profoundly underserved by systems of schooling, they suggest Māori students learn about their tribal leaders and the successes with which they "adapted, took advantage of opportunities, and thrived in the face of change" (p. 5). Webber and O'Connor (2019) further argue for the importance of Māori students learning the ways in which their ancestors were "tenacious, determined, entrepreneurial, competitive, peacemakers, political, navigators, explorers, forward-thinking, tactical, and innovative" (p. 6). Their main purpose is to advocate for the importance of using Māori students' whakapapa (genealogy) as a 'pedagogical tool'. Their argument implicitly highlights the significance of history education doing more than calling students' attention to instances of colonial brutality or critiquing misrepresentations of Indigenous peoples, knowledge and history. While these might contribute to the broader goals of decolonisation, they do not necessarily highlight "strengths-based stories" which are needed if Māori students are to feel a sense of belonging in history lessons (Webber \& O’Connor, 2019, p. 2).

\section{Summary}

In this chapter I have drawn together notions of difficult history, emotion and place, particularly within a settler-colonial context. In the first section I outlined different interpretations of 'difficult history' and described the nature of a settler society. Using this as the framework I then outlined some key literature regarding the teaching of colonisation in three similar settler societies including New Zealand. I showed that although teaching and

\footnotetext{
${ }^{19}$ In Chapter 3, I discuss in more depth the role of place and land in decolonial pedagogies, particularly as it pertains to a 'critical pedagogy of place'.
} 
learning about colonisation is a topic of international interest, rarely are the themes of place, emotion and difficult history brought together in a secondary school context and explored from the perspectives of teachers and students. In this section I also described international debates about the (in)compatability of Indigenous and Western systems of knowledge that bears some important similarities across state boundaries. In the second section I summarised literature on emotions and affect, particularly a smaller field of interest in the relationship between emotions and place, especially at sacred sites and places of violence and suffering. In the final section of this chapter I described what I argue are three mutually compatible resources for teachers to draw from when they and their students engage with difficult histories of colonisation. Not all, however, would agree in their compatibility, and in the next chapter I present a theoretical framework that allows for different systems of knowledge to exist in relation to each other without one tradition dominating the other. 


\section{CHAPTER 3: A THEORETICAL AND CONCEPTUAL FRAMEWORK FOR EXAMINING THE TEACHING AND LEARNING OF COLONISATION IN NEW ZEALAND}

The sense of history conveyed by [Indigenous] approaches is not the same thing as the
discipline of history, and so our accounts collide, crash into each other.

Linda Tuhiwai Smith (1999, p. 28)

\section{Overview}

In this chapter I present a theoretical and conceptual framework for examining how teachers and students engage with New Zealand's history of colonisation in classrooms and at sites of colonial violence. In particular, I establish the significance of using theory that is attentive to the pedagogical complexities of place and emotion. Theorising place and emotion during lessons on difficult histories of colonisation is central to this study for two key reasons. First, all lessons concerning the history of colonisation in New Zealand occur within the specific context of a settler society. This situation is critical for understanding and explaining the practices of ignorance, denial and 'cultural forgetting' of historical injustices common to settler colonial nation-states and many of its citizens (see Chapter 2). Writing within this context of settler colonialism, the New Zealand author Rachel Buchanan (2018) asks "will people step up now and take the time to learn, know and feel the history of the places they call home?" (p. 103). As demonstrated in later chapters, 'stepping up' to learn, know and feel the difficult histories of colonisation is often an emotionally challenging exercise. This is especially the case when prior beliefs of an unproblematic past are disrupted, unsettling our understanding of the places to which we feel a deep sense of belonging. Furthermore, emotions, as some geographers argue, are inseperable from the places in which our lives unfold. Smith et al, (2009) argue that "emotions are vital (living) aspects of who we are and of our situational engagement with the world; they compose, decompose, and recompose the geographies of our lives" (p. 10).

A second reason for choosing a theoretical and conceptual framework attentive to place and emotion is because in settler societies, all education takes place on Indigenous land in which history is also said to be embedded (Basso, 1996; Harrison, 2013; Howse, 2019; Moeahu, 2019; Penetito, 2009). In this sense, where history is taught matters deeply, requiring theory 
that can account for Indigenous approaches to history that may, at times, diverge from traditions that have their epistemological roots in the abstract and universalist rationality of European modernity. Teaching the history of colonisation from Māori perspectives and in ways that validate Māori epistemological standpoints cannot, therefore, only take place in a classroom (Keenan, 2018; Manning, 2017; Marker, 2019). Such a framework is especially useful for this study due to my interest in field trips and how students engage directly with 'landscapes of violence' (Schramm, 2011). From this perspective, field trips and the close encounters with the land they enable are not optional extras, but instead foundational pedagogies to learning the multiple, complex, emotionally-laden and place-based histories of colonisation. In Figure 3.1, I present a visual summary of this theoretical and conceptual approach:

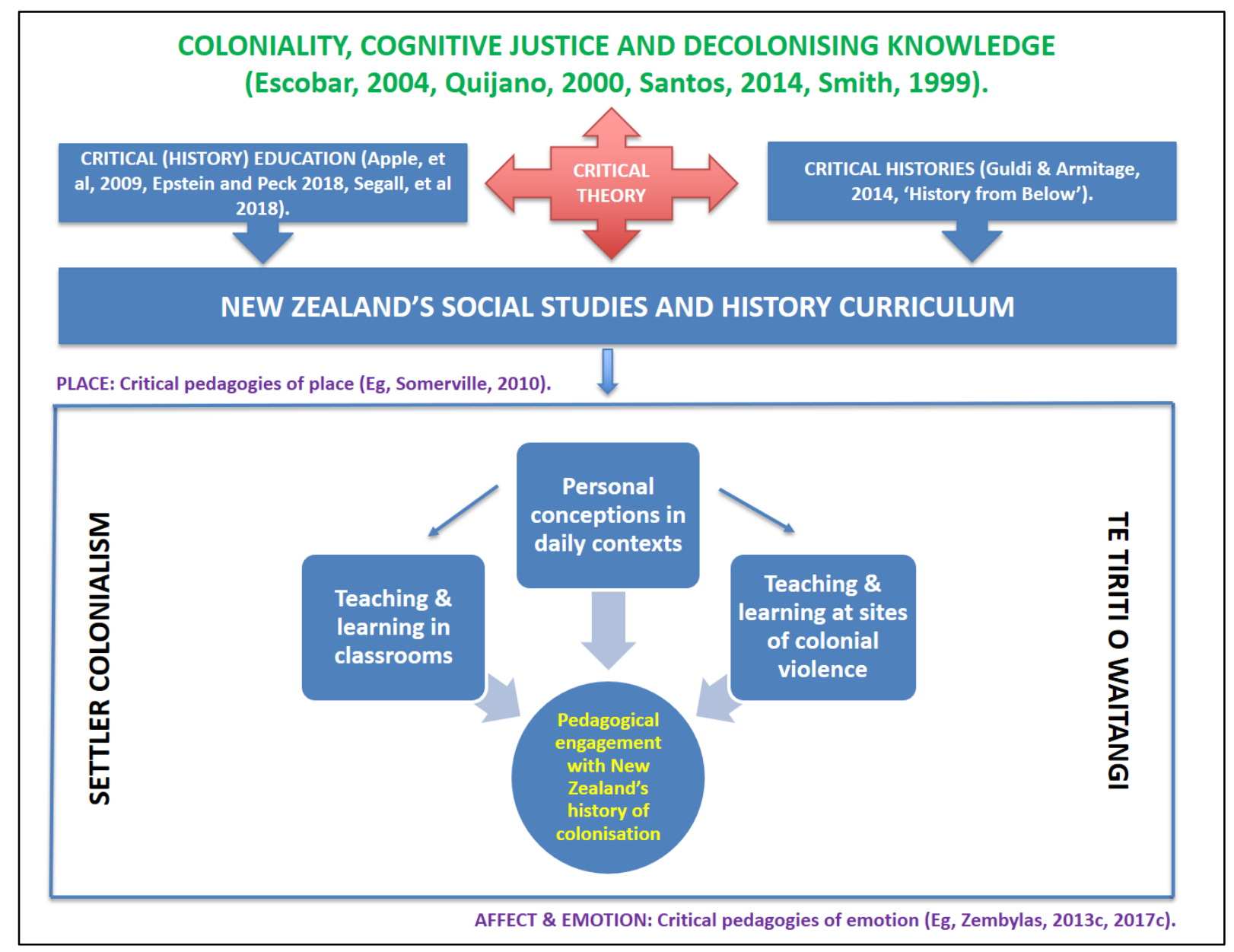

Figure 3.1: A visual representation of my theoretical and conceptual framework 
Figure 3.1 shows how the different components of my theoretical and conceptual framework relate to each other, converging in the bottom circle to my primary interest in pedagogical engagement with New Zealand's history of colonisation. The diagram also provides the organisational outline of this chapter, with an initial examination of coloniality and cognitive justice.

\section{Coloniality and cognitive justice}

I begin this chapter by positioning my central concern - the quality of pedagogical encounters with New Zealand's history of colonisation - within a broader context of what Peruvian sociologist Anibal Quijano (2000) refers to as the 'coloniality of power'. According to Andreotti (2011), the coloniality of power is "a global hegemonic model of power in place since the conquest of the Americas that articulated race and labour, space and peoples, according to the needs of capital and to the benefit of white European peoples" (p. 383). Similarly, the Columbian Anthropologist Arturo Escobar (2004) describes what he calls 'global coloniality' as referring to the "heightened marginalisation and suppression of the knowledge and culture of subaltern groups" (p. 207). The concepts of (global) coloniality and the coloniality of power have been taken up by a range of critical educators (Eg, Andreotti, 2011; Rudolph, Sriprakash, \& Gerrard, 2018; Zembylas, 2017a). The writings of these educational theorists have distinct resonance with this study's analysis of history education in New Zealand and my interest in cognitive justice as a curriculum goal. Cognitive justice is the opposite of coloniality because it rejects patterns of thinking which assume the superiority of dominant Western knowledge, its criterion of truth and the systems of validation by which new knowledge is generated (Santos, 2014). For Santos, the world's social and ecological problems are too intractable to be solved by any one system of knowledge. Cognitive justice, therefore, is a concept highly relevant to the world's current planetary crisis of humaninduced climate change and the social injustices that stem from coloniality.

Educationalists influenced by studies in coloniality reject the idea that Western ways of knowing are inherently the most powerful and valid, a belief that some scholars refer to as 'epistemic violence' (Maldonado-Torres, 2004). Andreotti (2011), for example, explains that under coloniality "non-European epistemologies and ontologies are translated into universalised European epistemological parameters as inferior, less evolved, primitive, erronous or eccentric 'culturally tainted' derivatives" (p. 385). Significantly, educationalists 
writing in this field do not totally reject modernity and the education systems and forms of knowledge it has produced. To illustrate, in Andreotti's (2011) discussion of the coloniality of power, including its epistemic reproduction of western ways of knowing, she still seeks to "move discussions away from the uncritical and wholesale embrace or rejection of modernity" (p. 382).

The ability to hold seemingly paradoxical positions in productive tension with each other without retreating to a binary either/or positon is a challenging but essential task for history education. As already summarised in greater depth in Chapter 2, one such tension centres on arguments about the compatibility of Indigenous approaches to the past and the disciplinary procedures central to historical thinking. History education, however, has not produced a large scholarship that "engages with the co-existence of multiple bodies of knowledge and ontologies" (Bell, 2017, p. 19). Furthermore, as scholars often warn, highlighting the existence of 'two world views' in opposition can be problematic. New Zealand anthropologist Anne Salmond (2012) argues that within this framework, “"Māori' and 'modernist' ontologies, or 'relational' and 'objective' styles are likely to be treated as mutually exclusive and in opposition to each other" (p. 125). Salmond continues by saying that

Ontologies based on reciprocity are not the exclusive preserve of particular groups of people, and 'Westerners' also operate relationally, at least some of the time. Similarly, many 'Māori' proceed on the basis of modernist assumptions, although not necessarily all the time. (p. 125)

Keeping in mind the dangers of applying an essentialist, dualistic and colonial logic onto distinct ontological and epistemological realities, a history education capable of overcoming the 'coloniality of power' must also recognise what Sami scholar Rauna Kuokkanen calls “multiepistemic literacy" (cited in Sundberg, 2014, p. 34). The notion of multiepistemic literacy implies the recognition of important differences between broadly western and Indigenous ways of knowing. For the geographer Juanita Sundberg (2014), an orientation to the world that recognises the validity of Indigenous ontologies is a key component of decolonisation, which she summarises as a process of "exposing the ontological violence authorised by Eurocentric epistemologies both in scholarship and everyday life" (p. 34). 
In summary, to subvert the ongoing presence of coloniality in official curriculum and the pedagogies enacted in classrooms, teachers and students need support to recognise the validity, overlaps, contradictions and tensions of distinct ways of knowing and being. Subverting coloniality like this demands a careful approach, grounded in humility and the recognition that what teachers learn in their university courses may not be the full story. This reality was highlighted to me in 2018 when I was a delegate at a New Zealand History Teachers' Association conference. The conference committee worked hard to recognise the centrality of land and place to history within a Māori worldview. That included taking all 150 conference attendees on a whole day field trip to key sites associated with the invasion of the Waikato in 1863. At the battle site of Rangiriri, our tribal expert, Moko Tauariki, addressed us with the following challenge. He asked: "Who among you is an ecologist?......You are ALL ecologists. You have a kaitiaki [guardian] role to play on this land" (Field notes, April, 2018). For Tauariki, history education demands an ethic of care for the land. In this statement, he appears to be calling for a relational ontology between humans, the land and the more-than-human world (Harrison, Bodkin, Bodkin-Andrews, \& Mackinlay, 2017). New Zealand sociologist Avril Bell (2017) articulates this challenge (particularly for Pākehā teachers who comprise the majority of the profession $)^{20}$ when she claims, "we need to develop an ability to be in relation with other ontologies rather than to be in charge" (p. 20). For Bell (2017), as with many other scholars, this means an orientation that learns from, not merely about Indigenous knowledge (p. 20). Drawing on a Levinasian approach to ethical relations, Bell (2017) suggests that,

The ethical Pākehā response to the presence of Māori ontology is to allow our own ontological presuppositions to be unsettled/affected by it, to bring our western, science-based ontology into question, to be prepared to think (and be) differently, to think of our path of becoming in relation to it. (p. 20)

History education that encourages its participants to exist in relation to diverse ontologies is an education committed to cognitive justice, an idea that demands educators take seriously the implications of Tauariki's challenge to history teachers at Rangiriri and Bell's (2017) "ethical response" (p. 20) to Māori ontologies. In the sections below I draw on the writing of Portuguese scholar Boaventura de Sousa Santos (2014) to further illustrate the nature of cognitive justice and its value for history education in a settler society.

\footnotetext{
${ }^{20}$ For example, quantitative data gathered from my survey of $(n=298)$ history and social studies teachers indicated that over $80 \%$ of teachers surveyed identified as Pākehā (see Chapter 4).
} 


\section{Abyssal thinking}

The nature of cognitive justice is revealed in greater clarity through what Santos (2014) calls abyssal thinking, by which he means a mode of thinking that establishes a set of visible and invisible lines "[dividing] reality into two realms" (p. 118). These realms of reality cannot speak to each other because one realm, as Santos explains, "vanishes as a reality, becomes nonexistent, and is indeed produced as nonexistent” (p. 118). For Andreotti (2011), abyssal thinking and abyssal lines are useful metaphors that "make the coloniality of power more visible and accessible to those who have not engaged with these ideas before" (p. 389). In a New Zealand context, Linda Smith's (1999) discussion about the ways in which the discipline of history is used to render Māori epistemologies as subservient to Western historical methods is very similar Santos' notion of an abyssal line and it can help teachers and educators recognise when they are moving away from an approach that might lead to cognitive justice (pp. 28-29).

To illustrate further the notion of abyssal thinking, Santos (2014) argues that Western epistemologies that produce knowledge about the law, history and medicine, dominate on one side of the abyssal line whereas on the other "there is no real knowledge: there are beliefs, opinions, intuitions and subjective understandings" (p. 120). It is worth quoting in length Santos' explanation of abyssal thinking, because it helps to establish in greater depth the implications for authentic engagement with Māori history within history curriculum in New Zealand:

The division is such that "the other side of the line" vanishes as reality, becomes nonexistent, and is indeed produced as non-existent. Nonexistent means not existing in any relevant or comprehensible way of being. Whatever is produced as nonexistent is radically excluded because it lies beyond the realm of what the accepted conception of inclusion considers to be its other. What most fundamentally characterizes abyssal thinking is thus the impossibility of the co-presence of the two sides of the line. To the extent that it prevails, this side of the line only prevails by exhausting the field of relevant reality. Beyond it, there is only nonexistence, invisibility, non-dialectical absence. (Santos, 2007, p. 2)

For history education in a settler society, abyssal thinking is highly problematic if it places Indigenous history on one side of the abyssal line, or domesticates it so much that 'Māori history' is simply added to the pantheon of topics in a school's programme and 
recontextualised into a traditional school subject. To further the project of cognitive justice, Santos defines two primary 'procedures' which he calls ecologies of knowledge and intercultural translation (p. 188). Below I provide a brief summary of these ideas and their significance for history education.

\section{Ecologies of knowledge}

Santo's (2014) notion of ecologies of knowledge provides a vocabulary to describe the nature and value of epistemological diversity, extending our ability to theorise history education. For example, recognizing ecologies of knowledge does not mean abandoning historical thinking drawn from the scholarly traditions of the university and familiar to many history teachers. Instead, it means giving up the belief that historical truths produced through the disciplinary procedures of the academy are always and automatically the most useful for intervening in a world marked by social injustice and ecological degradation. For Santos (2014), all knowledges are incomplete and limited, so it makes no sense that one should dominate, especially to the extent that historically subjugated knowledges are erased from consideration. Santos explains that knowledge should be assessed according to the way "it leads a certain practice to overcome a certain ignorance" (p. 189). From this perspective, "the credibility of cognitive construction is measured by the type of intervention in the world it provides, assists or hinders" (p. 207). He elaborates that:

The point is not to ascribe the same validity to every kind of knowledge, but rather to allow for a pragmatic discussion among alternative, valid criteria without immediately disqualifying whatever does not fit the epistemological canon of modern science. (p. 190)

Finally, for Santos (2014) an ecology of knowledges also assumes that "history is an intense, constitutive part of the present" (p. 209). The history of colonisation is evidence of how abyssal thinking has attempted to erase Indigenous knowledge with enormous contemporary consequences (Smith, 1999). Ecologies of knowledge, therefore, are well positioned to respond to the inequities of colonisation and modernity including what Santos (2014) calls the "epistemicide" (p. 92) of diverse, non-western systems of knowledge. 


\section{Intercultural translation}

The second key 'procedure' of cognitive justice resonates with educational literature calling for teachers and educators to recognise a 'third space' between (seemingly) incommensurable knowledge systems (Barnhardt, 2005; Macfarlane et al., 2015; Nakata, 2012). Santos (2014) summarises intercultural translation as "a procedure that allows for mutual intelligibility among the experiences of the world" (p. 403). In Santos' words, intercultural translation offers a way forward from assimilation and destruction, the two pathways traditionally taken by western modernity in regards to non-western and Indigenous cultures (p. 212). He argues that:

Intercultural translation consists of searching for isomorphic concerns and underlying assumptions among cultures, identifying differences and similarities, and developing, whenever appropriate, new hybrid forms of cultural understanding and intercommunication that may be useful in favoring interactions and strengthening alliances among social movements fighting, in different cultural contexts, against capitalism, colonialism, and patriarchy and for social justice, human dignity, or human decency. (2014, p. 212)

In a later chapter, I explore this idea of intercultural translation within the particular context of history teaching. The concept of cognitive justice, though, (including its derivative terms) provides a powerful conceptual apparatus for exploring the challenges and opportunities associated with teaching difficult histories of colonisation in a settler society. In the next section, I argue that cognitive justice is also strengthened through disciplined historical thinking when it deliberately pays attention to power.

\section{Critical theory}

As illustrated in Figure 3.1, critical theory is central to this thesis. The roots of critical theory lie in the social and historical context of twentieth century Europe after the continent was brutalised by fascism and Stalinism and confronted with the banality of capitialist cultural life. Critical theory is also an approach to knowledge and society committed first and foremost to cultural critique (Prasad, 2005, p. 136). Critical theorists respond to oppressive forces by "systematically rejecting a value neutral position, and they conduct research that aims openly at meeting the goals of human liberation and social justice" (Prasad, 2005, p. 139). In addition to beginning from the position that no knowledge is neutral, theorists from 
this paradigm argue that all knowledge is connected to individual and broader societal interests (Prasad, 2005, p. 141).

Critical theory, however, can sit uneasily alongside the notion of cognitive justice and its call to recognise Indigenous systems of knowledge. Santos (2014) even suggests the need to "create a distance from the Eurocentric critical tradition" that for him "[provides] only weak answers for the strong questions confronting us in our time" (p. 20). Nevertheless, Santos also argues that "keeping a distance does not mean discarding the rich Eurocentric critical tradition and throwing it into the dustbin of history, thereby ignoring the historical possibilities of social emancipation in Western modernity" (p. 44). Instead, Santos rightly argues that the 'global North' needs to learn from the "anti-imperial South", instituting intercultural dialogue as a means to navigate "among different critical knowledges and practices" (p. 42). When employed carefully, I see critical theory's critique of power working with, rather than against Indigenous and decolonising approaches to knowledge.

In addition to recognising differences between 'western' and 'Indigenous' world views without becoming too rigid in these distinctions, in this thesis I also subscribe to versions of critical theory that recognise the potential dangers of reifying the categories of oppressed/oppressor, colonised/coloniser, settler/Indigenous or Māori/Pākehā, even though these might be strategically employed in certain situations. This complex middle position is captured well by the New Zealand educationalist Te Kawehau Hoskins (2017). She critiques structuralist analyses of power that place an emphasis on "oppositional politics" (p. 98). These critical analyses of power, while responding to the superficiality of cultural-additive approaches to raising Māori achievement in schools, are, for Hoskins, "too deterministic, often asserting a simplistic view that, for example, 'they' (for instance, the coloniser) have all the power and 'we' have none" (p. 98). Hoskins is doubtful that the view "schools oppress Māori and benefit Pākehā" will progress "far more nuanced, radical analyses that consider both the benefits and problems of schools for Māori” (pp. 98-99). Such nuanced and radical analysis, Hoskins explains, are more likely to draw deeper attention to, and result in a greater agency to deal with entrenched societal inequalities of settler colonialism manifest in schooling systems. Hoskins (2017) summarises her position by arguing against "[using] binary oppositional categories or [trying] to develop more complex ones" (p. 100, italics in original). For her, both approaches are useful and "it is necessary to both evoke and refuse 
the binary" (p. 100, italics in original). It is this kind of non-dualistic thinking exemplified by Hoskins that needs to underpin a critical and transformative history education.

\section{Critical (history) education}

When applied specifically to education, critical theory asks questions about the relationship between dominant education practices and the reproduction of inequalities in society. In regards to my interest in secondary schooling, critical education generates questions about what curriculum is taught and why, what kinds of knowledge (both formal and informal) are validated, what pedagogies dominate and with what effect and whose interests are most served by the official, enacted and hidden curricula (Eisner, 1985). Similar to those using critical theory in fields outside of education, secondary school teachers who operate from a critical paradigm are committed to cultural critique and making visible the systems of power that are normalised and taken for granted within the education sector. For Apple et al (2009), critical educators embody a "commitment toward social transformation and a break with the comforting illusions that the ways in which our societies and their educational apparatuses are organized currently can lead to social justice" (p. 3). These scholars explain that "critical education' and 'critical pedagogy' refer to the recognition of "multiple dynamics underpinning the relations of exploitation and domination in our socieities" (p. 3). Tying these ideas explicitly to history teaching, Segal et al. (2018) explain further that "history education informed by critical theory is interested in the relationship among power, knowledge, the ways of knowing underlying history and its education, and the social identities, and subjectivities they help foster" (p. 283). Critical approaches to history education, therefore, provide a useful lens with which to interpret and analyse how the school subject of history either interrupts or reinforces the power dynamics that maintain settler colonialism within and beyond classroom settings.

Critical educators draw on multiple traditions that loosely conform to broader notions of critical theory. For example, Avner Segal and colleagues (2018), in a recent and helpful review of critical theories explains that their use of the term 'critical' "invokes education or scholarship that uses the lenses of postmodernism, poststructuralism, postcolonialism, thirdwave feminism, race-based theories, psychoanalytic theories, and critical pedagogy" (p. 284). The latter source of intellectual inspiration in this list, 'critical pedagogy' remains arguably one of the most well-recognised manifestations of critical education and sits at the heart of 
my pedagogical interpretations of classroom and field trip-based encounters with difficult history (as illustrated by the purple font in Figure 3.1). A useful starting point for defining critical pedagogy is Sandy Grande's (2007) assertion that “critical pedgogy is first and foremost an approach to schooling (i.e., teaching, policy making, curriculum production) that emphasises the political nature of education" (p. 317). As an Indigenous academic influenced by Brazilian scholar Paulo Freire, Grande (2013) reframes critical pedagogy and extends it into a "critical Indigenous theory" (p. 184). For Grande, critical pedagogy's focus on becoming more critically conscious of the oppressive elements of reality and resisting a "banking metaphor" (Freire, 1993) of education does not adequately address the nature and reality of settler colonialism. She argues that any theoretical framework that claims to be useful for Indigenous education must recognise that modern settler nation states are founded on the dispossesion of Indigenous people, a process that needs be understood as a persistent, ongoing structure and not a discrete historical event confined to the past. Educational projects such as critical pedagogy, therefore, need to "go beyond resisting oppression...and work instead to interrogate, disrupt, and replace the epistemological underpinnings of the settler world order" (Grande, 2013, p. 191). This is a world order, however, in which critical historical thinking can also help disrupt, even when recognising the complicity of scientific thinking within European expansion and settler colonialism.

History education scholars frequently describe how disciplinary thinking can be a powerful and transformative tool for reconciliation, peace-building and critical participation in democratic society (Barton \& Levstik, 2004; Epstein \& Peck, 2017; Gross \& Terra, 2019; McCully, 2012). In their volume History can Bite: History Education in Divided and Postwar Societies, Bentrovato and colleagues (2016) illustrate in particularly powerful ways the transformative potential of disciplined historical inquiry across multiple nations afflicted by war and conflict. They describe the frequency with which history curriculum is mobilised by powerful groups in society to bolster their legitimacy to rule, a process achieved through "emphasizing the uniqueness of the in-group and its fundamental difference from significant Others, while at the same time suppressing internal diversity by masking the existence and experience of subgroups" (p. 18). For these authors, history education characterised by critical-historical methodologies is well placed to challenge powerful groups who would wield versions of the past in destructive ways. The conceptual tools of historical thinking (such as the use of evidence to understand multiple historical causes and the perspectives of 
historical actors) can help young people to engage with the legacies of the violent past and to "deconstruct single truths and negative images of the Other and to critically confront and navigate divergent narratives of conflict" (p. 21). History teachers who use the conceptual tools of their discipline to address issues of power to "deconstruct single truths" (p. 21) are not alone and walk in the footsteps of many critically minded professional historians.

\section{Critical histories}

Some historians explicitly employ their craft to challenge popular historical myths and speak truth to power, while maintaining the integrity of their discipline. For example, during the turbulent decade of the 1960s a field of history known as 'history from below' became a popular area of scholarly interest. In contrast to traditional histories that explored the rise and fall of nations and empires and their oscillations between diplomacy and war, history from below focussed more on the "'lived' experiences of ordinary people, i.e., on the actions, practices, habits, values, beliefs, mentalities, and feelings of the oppressed, excluded, pauperized, and marginalized" (Port, 2015, p. 108). This new approach explicitly tried to rescue historical actors from broad, impersonal and oppressive forces that denied individuals historical agency and focussed too much on (male) Europeans' historical experiences (Port, 2015, pp. 109,110). In recent decades “history from below' has formed the intellectual milieu of many New Zealand historians who employ historical skills and new sources of evidence to challenge Pākehā centric narratives of New Zealand history (Anderson, Binney, \& Harris, 2014; Ballantyne, 2012; Belich, 1996; Byrnes, 2001). Historian Andrew Port (2015) argues that the emergence of peoples' history and history from below in the $1960 \mathrm{~s}$ "reflected the political turmoil, social upheaval, and critical atmosphere of that decade" (p. 112). In the same manner, one can clearly see contemporary concerns shaping another form of history that sees for itself a role beyond the intrinsically valuable production of new knowledge.

For historians Jo Guldi and David Armitage (2014), global inequality and climate change present humanity with their greatest challenges. Drawing on the Annales school of historical thought that emphasises the "vibrations of deeper time", Guldi and Armitage (2014) argue that historians can make a contribution to society by thinking big and rejecting what they call "short termism" (p. 9). For these scholars, humanity needs to understand broad patterns of time - five hundred years for example - as a planning horizon. Thinking big, they argue, can help citizens and their governments to recognise the relationship between past and future, 
enabling them to "imagine alternative possibilities for the future" (p. 10). At the centre of Guldi and Armitage's (2014) argument are three "modes of thinking" inherent in history:

It looks at processes that take a long time to unfold; it engages false myths about the future and talks about where the data come from; and it looks to many different kinds and sources of data for multiple perspectives on how past and future were and may yet be experienced by a variety of different actors. (p. 12)

These two examples, looking at history from below and taking a much longer temporal view, highlight some of the way in which historians use their craft to address contemporary issues of power in our society including colonial injustices. In the next section, I shift to a more explicit theorisation of the type of pedagogy which could deal effectively with difficult histories.

\section{Pedagogical encounters with New Zealand's history of colonisation}

The content of the history curriculum - what to teach - is a central yet highly contested and deeply politicised component of curriculum reform (Taylor \& Guyver, 2011). Yet beyond the important concerns of what to teach remain important questions of how to teach, or pedagogy. Even the most powerful counternarratives and previously marginalised histories of colonial injustice can be made part of the official curriculum but then lose their critical and transformative potential through weak and unsupported pedagogies. Zembylas (2014a), however, makes an important observation that the term 'pedagogies' does not "signify classroom pedagogical practices" (p. 14). Instead, pedagogies are "the relational encounters among people through which unpredictable possibilities of connectedness, solidarity and action are created" (p. 14). With this relational interpretation of pedagogy in mind, in the following sections I draw on two conceptual domains within critical education that resonate strongly with the context of my study: critical pedagogies of place and critical pedagogies of emotion (see purple font in Figure 3.1).

\section{Critical pedagogies of place}

Critical pedagogies of place combine concerns with oppression and ecological crisis into one conceptual framework. First articulated in a seminal article by David Gruenewald (now Greenwood), (2003), critical pedagogies of place draw heavily from the Freirean tradition of critical pedagogy. They are also influenced by environmental education which seeks to 
disrupt humanity's increasingly exploitative relationship with the earth. Of particular concern for educators working from this perspective is the role of schools in producing curriculum that alienates young people from the social and ecological places they inhabit. Theorists frequently posit the goals of decolonisation and reinhabitation (see below) as the primary objectives of a critical pedagogy of place (Gruenewald, 2003; Johnson, 2012; Somerville, 2010). Greenwood (2010) makes explicit the value of history curriculum to these goals when he explains that "a fundamental component of a critical, place-based inquiry must be acknowledging the contested history of colonization with respect to land (environment) and homeland (culture)" (p. 351).

Critical pedagogies of place have been challenged by some Indigenous scholars who argue that while "a step in the right direction", they generally do not go far enough (Calderon, 2014a, p. 26). For these scholars, pedagogies of place tend to inadequately foreground two core situations: i) the centrality of land to Indigenous cultural, spiritual and economic wellbeing and ii) the paramount goal of settler colonialism in acquiring and maintaining control over that land through combinations of genocide, war, treaty-making/breaking, assimilationist social policies and settler mythmaking (Bang et al., 2014; Calderon, 2014a; Tuck, McKenzie, \& McCoy, 2014; Turner, 1999). With these challenges to the theory in mind, in the next section I describe three key ideas that animate my understanding of a critical pedagogy of place: place, decolonisation, and reinhabitation. Collectively, these ideas form a core component of my conceptual framework for interpreting how teachers' and students' engage with New Zealand's history of colonisation.

\section{Place}

Place(s) can function as a meeting ground between diverse epistemological and ontological realities and multiple contested stories (Beck \& Somerville, 2005; Somerville, 2007; Somerville, 2010). Somerville (2010) argues that "place [provides] a site for the intersection of multiple and contested stories [and] is especially significant in the relationship between indigenous, and other subjugated knowledges, and Western academic thought" (p. 338). She discusses the importance of holding different perspectives of place in "productive tension" ( $p$. 338). These "contact zones", as Somerville (2010) terms them, could become sites of coexistence between different knowledge systems, such as the western-oriented disciplinary thinking and Māori histories rooted in the topographies of land. 
In addition to place mediating diverse ways of knowing and being, cultural geographers Alderman and Inwood (2013) suggest two metaphors that support the navigation of multiple contested stories within what they call 'landscapes of memory'. They suggest the metaphor of narrative leads to questions such as "What is said and not said about the past? Whose history is remembered or forgotten? What does the differential treatment of histories and identities tell us about power relations and patterns of inequality within historical and contemporary societies?" (p. 190). In contrast, the metaphor of the arena operates differently, focussing instead:

On the capacity of memorials and heritage locations to serve as sites for social groups, with varying levels of power and social resources, to actively interpret and debate the meaning of the past as part of larger struggles over recognition and the legacies of discrimination and dispossession. (Alderman \& Inwood, 2013, p. 193)

Alderman and Inwood (2013) endorse both metaphors, although for them an arena demands a more interactive engagement with places and the contested interpretations and meanings that are attached to, and produced within landscapes of memory such as those visited by the teachers and students in this study (see Chapter 7).

A critical pedagogy of place also holds that places are pedagogical; that is, they can transform human understanding of the world and lead to ethical action (Basso, 1996; Greenwood, 2009; Hoskins, 2010; Johnson \& Larsen, 2017). For this to happen, places needs to be interpreted as dynamic, open and even alive, allowing us to become 'enfolded' or 'entangled' in them. This challenges conceptions of place as a surface which a history teacher might use as an interesting backdrop to narrate a story. Instead, we need to recognise the 'agency of place' which requires an "ontologically oriented capacity" and runs contrary to dominant desires to control places through critical, rational, detached historical inquiry (Lewin, cited in Davis, 1996, p. 44). Treating places as if they have agency is also a radical departure from settler traditions of land as static and inanimate (Burow, Brock, \& Dove, 2018; Country et al., 2016; Hoskins \& Jones, 2017). It asks history educators to consider the possibility that land-based experiences such as fieldtrips might have a purpose beyond developing purely cognitive historical understanding. For example, Larson and Johnson (2017) describe the agency of place as the "call of place" (p. 2). They explain that 
Because place is a more-than-human-engagement, its call is unusual - it is not like calling to a faith or profession, but rather a summons to encounter, dialogue, and relationship among the humans and nonhumans who share the landscape. (p.2) From an Indigenous perspective, places also have an agentic capacity through their role as holders and teachers of knowledge and wisdom (Basso, 1996; Country et al.; Marker, 2019; "The Ngai Tahu Atlas," 2019). The pedagogical implications of an inseparability between place, knowing and being within Indigenous world views is an emerging field led to a large extent by Australian scholars (see for example, Harrison et al., 2017; Harrison, Page, \& Tobin, 2015; Rey \& Harrison, 2018). The approach of these educators is to move beyond learning 'about' a place in ways that only prioritise critical, cognitive thinking to an engagement with place that requires a non-representational pedagogy of affective engagement with 'Country', where the senses matter and learning is performed through the relationships between people and the land (Harrison et al., 2017). The place-based, experiential and relational understanding of learning described here creates openings for students to encounter Indigenous histories on Indigenous terms, counteracting stereotypical representations of Indigenous people, places and histories.

\section{Decolonisation}

Decolonisation, as an extrinsic, educational goal for history education attempts to challenge, critique and to undo settler colonialism, especially as it operates within the official, intended and enacted forms of curriculum (Tuck \& Gaztambide-Fernandez, 2013). A key priority for teachers, therefore, is to challenge assumptions about the superiority of western modes of historical inquiry over Indigenous epistemological traditions (Bell, 2009; Johnson, 2012). A key decolonising strategy also involves teaching young people the history of settler colonialism especially its processes of acquisition, retention and exploitation of Indigenous territory. This aspect of decolonisation can be implemented effectively through an evidencebased framework of critical historical thinking, an approach that provides a powerful context for transformative dialogue about difficult histories of colonisation and their connection to the present. A further dimension of decolonisation in history education involves uncovering historical narratives that maintain and reproduce settler colonialism (Calderon, 2014a, 2014b; Keenan, 2018; Shear, 2018; Tupper, 2014). Somerville's (2010) description of 'storylines' is useful here and it connects the concept of settler narratives to specific places. She explains that storylines involve uncovering destructive stories and "[seeking] out previously invisible 
place stories or [generating] new stories about place" (p. 336). Storylines, for Somerville, can "be used deconstructively to analyse how stories function to shape places" (p. 336).

Decolonisation, however, tends to prioritise critical thinking and needs supplementing with the additional concept of reinhabitation, an idea which connects more to the heart, body and earth.

\section{Reinhabitation}

Reinhabiting a place involves "learning to live well socially and ecologically in places that have been disrupted and injured" (Gruenewald, 2003, p. 9). For Somerville (2010) reinhabitation is "place learning" that "is necessarily embodied and local" (Somerville, 2010, p. 336). This element of Somerville's (2010) 'place inquiry' is “the most radical, transformative, and challenging" (p. 336). It is also the hardest to explain because it draws from a different set of ontological and epistemological assumptions that are counterintuitive to the Western mind's tendency to separate mind and body (B. Davis, Sumara, \& LuceKapler, 2008). ${ }^{21}$ Becoming open to the embodied intimacy of being-in-place cannot be done at the level of intellectual theorising and critical historical thinking. Somerville explains that as a non-Aboriginal woman working closely with Aboriginal people on their land, she had to "open [herself] to the materiality of places, as well as their stories" (p. 338). It was the intimacy of this experience that allowed her to learn from the land, a learning that "demands an attentiveness to place from the whole body" (p. 338). Reinhabitation, therefore, depends on the expansive, dynamic and open interpretation of place described earlier. Some Indigenous scholars, however, express concern that notions of reinhabitation serve to legitimate settler claims to Indigeneity, reinscribing settler colonialism at the expense of Indigenous expressions of sovereignty and land repatriation (Calderon, 2014a; Paperson, 2014; Tuck et al., 2014). They suggest the more expansive idea of a 'decolonised reinhabitation of place' which explicitly shows the interrelationship between place, decolonisation and reinhabitation (Calderon, 2014a).

In sum, critical pedagogies of place can act as a powerful source of theory for teachers wishing to engage more deeply with the land, its history and people. However, such theories provide inadequate direction for those wanting to theorise the emotional struggles of learning

${ }^{21}$ See Chapter 8 for an illustration of what this might look like in a history teaching context. 
difficult histories. In order to deepen my analysis of teaching and learning New Zealand's history of colonisation, I now turn to a critical pedagogy of emotion as a means to enrich and extend the place-based pedagogies described above through an explicit focus on affect and emotion. This combined approach provides the interpretive heft needed to understand and respond to complex issues such as resistance to learning settler-colonial histories and the ignorance and denial of colonial history that characterise settler societies (Attwood, 2017; Turner, 1999; Veracini, 2008).

\section{Critical pedagogies of emotion}

Pedagogical encounters with the history and historical injustices of colonisation invite complex emotional responses from teachers, students and communities in New Zealand (Buchanan, 2018; Huygens, 2018; Kidman \& O’Malley, 2018; Kunowski, 2005; Sheehan, 2017). Research in history education must account for these complexities due to the ideological nature of emotions and the ways they can be mobilised for political purposes, shaping, (in)validating and maintaining certain historical narratives, collective memories and social identities. As Zembylas (2013c) reminds us, classrooms are "deeply divided places where contested narratives are steeped in the politics of emotion to create complex emotional and intellectual challenges for teachers" (p. 181). At a broader level, societal injustice may even be maintained, at least in part, by the strong emotional attachments to certain contested historical narratives and the legitimacy they give to institutional norms (Zembylas \& McGlynn, 2012).

A 'critical pedagogy of emotion' is my term that draws together a set of ideas about the nature, significance and consequences of emotions, particularly in the context of teaching and learning unresolved histories of violence, suffering and exploitation. While drawing from a range of theorists, I am principally indebted to the writing of Cypriot scholar Michalinos Zembylas for this concept. The aim of this approach is to engender a deeper acknowledgement of the nature and purpose of emotions in teaching contexts. From this perspective, paying closer attention to emotions can enrich critical approaches to education and support teaching practices that might dislodge essentialised beliefs and rigid notions of 'Us' and 'Them' (Jansen, 2009; Zembylas, 2013c). Such pedagogical approaches draw on what is know as the "affective turn" (Clough, 2007). For Zembylas, the affective turn, or 'affect theory' 
Marks a shift in thought in critical theory through an exploration of the complex interrelations of discursive practices, the human body, social and cultural forces, and individually experienced but historically situated emotions and affects (2014b, p. 397) In this section I present two concepts central to my interpretation of a critical pedagogy of emotion and the broader idea of affect theory. The first, emotional regimes, is useful for investigating the 'rules' of emotion and the nature of their movement in the context of history lessons concerning New Zealand's history of colonisation. The second concept, mutual vulnerability, is useful for challenging emotional rules that do not support the aims of a critical and transformative history education.

Emotional regimes are "the discursive practices and power relations prescribing specific 'emotional rules', ideals, rituals and vocabularies" (Zembylas, 2017d, p. 501). Originally developed by historians who study the history of emotions, the concept of an emotional regime is used to understand the emotional rules that govern, and give stability to a political entity (Plamper, 2010, p. 242). Educationalists have taken this idea and applied it to pedagogical situations. Depending on the context, some emotional regimes may be more dominant than others and they are often described in terms of their capacity to be shaped, evoked, used or established (Zembylas, 2016). Emotional regimes are always mobilised to serve a purpose, highlighting Bekerman and Zembylas' (2012) observation that "power relations are at the core of emotional practices in the classroom" and, indeed, wider in society (p. 121). For example, in some classrooms, learning difficult histories of colonisation might evoke regimes of resentment, even hatred, and in other places regimes of pity or empathy might be established. Whatever the dominant emotional regime, it is maintained through certain unwritten rules and anchored in wider discourses of power that constrain what can be spoken about and what cannot during a history lesson.

Simply identifying and characterising dominant emotional regimes does little to shift conceptions of the past that sustain ongoing practices of settler colonialism. For this reason, the concept of mutual vulnerability is useful because it acknowledges that all humans possess the common capacity to suffer and inflict pain on others, a recognition that "creates important openings for friendship, responsibility and solidarity" (Zembylas, 2017d, p. 504). Far from being a weakness, our vulnerabilities, which are always asymetrically embedded within relations of power, can in fact operate as a powerful resource for teachers. Concerning the 
teaching of difficult history, an ignorance of vulnerability "may be produced and maintained in schools, especially in the context of pedagogial engagement with difficult histories" (Zembylas, 2017d, p. 500). For Zembylas, one major task for teaching difficult histories is the 'unmaking' of 'regimes of ignorance' that disavow the vulnerability of others. Disrupting ignorance cannot be achieved through the mere provision of information about, for example, the New Zealand Wars, because ignorance is not due only to an absence of knowledge. Instead, ignorance is "actively produced and maintained throught the reinforcement of unknowing about inconvenient and discomforting truths" (Zembylas, 2017d, p. 499). Furthermore, ignorance "[acquires] an emotional as well cognitive content, and it sustains a specific set of power relationships within particular socio-political settings" (p. 504). Ignorance of vulnerability makes it harder to recogise the Others' full humanity, that they too suffer and are vulnerable to feelings of pain, grief, joy and hope. Zembylas (2017d) theorises this production of ignorance further through the notion of emotional regimes. He explains that the failure to recognise the full humanity of the Other invokes and shapes emotional regimes that recursively perpetuate and reproduce an ignorance of vulnerability.

Zembylas (2017d) suggests a range of questions that history educators might ask to help dismantle regimes of ignorance. These questions may help to design curriculum that dissolves, or at least minimises essentialised categories of Us and Them:

- Whose difficult histories are being recognised?

- Are there any difficult histories that are ignored?

- How are vulnerabilities symetrical or asymetrical for different individuals or groups featured in difficult histories?

- In what ways could individuals or groups be complicit to others' suffering and trauma without knowing it?

- What can be done to understand oneself as both vulnerable and complicit? (Zembylas, 2017, p. 510).

To conclude this section, the concept of mutual vulnerability is foundational to opening pedagogical spaces in schooling contexts that might otherwise be shaped by dominant emotional regimes that work to maintain settler-colonial historical narratives. For my study this meant paying close attention to the emotional climates of teaching situations, particularly during the field work stage of the research, including looking for the emotional 'rules' that might be collectively established and occasionally challenged in teaching situations. I needed 
to also look for openings, potential and real where teachers and students might transcend binary labels, critically recogising each other's mutual vulnerability, albeit within the context of a settler society within which exists deeply engrained forms of inequality.

\section{Summary}

In this chapter, I provided a theoretical framework for interpreting how teachers and students engage with New Zealand's history of colonisation. My central concern was to develop a theory expansive enough to account for specific pedagogical encounters in diverse learning contexts. To achieve this, I drew on a critical paradigm (see Figure 3.1). Critical theory highlights the political and contested nature of all knowledge and speaks consistently and reflexively to questions of power in society. As a theoretical standpoint, critical theory achieves much and has been frequently and productively employed by educationalists to critique and improve schooling, including in history education. For the context of this study, I needed to extend a purely critical approach and acknowledge the value of Indigenous knowledge originating from traditions outside European epistemic frameworks. For this reason, I turned particularly to Santos' (2014) notion of cognitive justice. Cognitive justice recognises the validity of 'Southern' epistemological positions without allowing 'Northern' traditions to dominate. History education informed by notions of cognitive justice acknowledges Indigenous history and critical-historical methodologies.

In this chapter, I also described two different frameworks for thinking about pedagogical encounters with difficult histories of colonisation. In the first, a critical pedagogy of place, I outlined the concepts of place, decolonisation ad reinhabitation. Collectively, these help draw attention to the politics of place in a settler society, the significance of experiencing a place's material reality, and the pedagogical value in learning from, and not just about the sites in which New Zealand's history of colonisation unfolded. In the second, I introduced a critical pedagogy of emotion, which gave me a framework from which to more explicitly theorise emotions, their nature and power when learning difficult histories of colonisation. Put together, my theoretical and conceptual framework from Figure 3.1 presents a specific lens for my study, drawing together key ideas of place, emotion and difficult history in a settler colonial context. In the next chapter, I outline my methodology, including how it reflects the theoretical and conceptual framework described here. 


\section{CHAPTER 4: METHODOLOGY}

Whereas traditional researchers cling to the guard rail of neutrality, critical researchers frequently announce their partisanship in the struggle for a better world.

Joe Kinchloe and Peter McLaren (2005, p. 305)

\section{Overview}

In this chapter, I begin by outlining the broad paradigm from which this research stems including my positionality within that framework. The main purpose of this chapter, however, is to provide the rationale for my research design and the selection of my methods. I show how I used these methods to generate data to answer my three research questions outlined in Chapter 1, and how that data was analysed. A key objective of this chapter is to make transparent the decision-making processes that led to my findings and the conclusions drawn from them. Inevitably, gathering and interpreting data from schools was an untidy process. I also explain, therefore, the difficulties and problems I encountered and the limitations these presented for my findings. The methods I employed were also necessarily selective with ethical decision-making "[permeating] every phase of the research process" (Denzin \& Lincoln, 2003, p. 30). I conclude the chapter by discussing in more depth the ethical challenges encountered and the processes I used to ensure credibility and validity in the research process.

\section{A critical and place-conscious stance toward research in education}

As explained in the previous chapter, this thesis draws from a critical paradigm, one in which researchers "announce their partisanship in the struggle for a better world" (Kinchloe and McLaren, 2005, p. 305). In their book Place in Research: Theory, Methodology, and Methods, scholars Eve Tuck and Marcia McKenzie (2015) take this idea further and argue more specifically that researchers investigating critical questions should use methods and methodological approaches "informed by the embeddedness of social life in and with places" (p. 2). They continue that these approaches should aim to "be a form of action in responding to critical place issues such as those of globalization and neoliberalism, settler colonialism, and environmental degradation" (p. 2). In making these points, Tuck and Mackenzie (2015) establish the significance of researchers in fields such as history education recognising and 
responding to the social locatedness of their topic of investigation within broader historical, economic and political systems.

In New Zealand, the ongoing presence of settler colonialism forms the backdrop to all history education research. However, simply acknowledging that New Zealand is a settler society and announcing a desire to respond to that reality does little, on its own, to change the status quo. Tuck and Mackenzie (2015) make the even stronger point that, "[the] social sciences, when not cognizant of settler colonial structures, can replicate some of the epistemic violence of settler colonialism and exhibit some of the tendencies of that structure" (p. xvi). The dangers of replicating settler colonial systems, structures or ideologies within my own research practices - while trying to do precisely the opposite - dawned on me relatively slowly during this thesis and it continues to prompt reflection. The issue highlights the importance of a taking a continually critical and reflexive stance on the research process, and accepting the inevitable stumbles and 'ethical violence' that occurs during complex engagements with the world such as social sciences research (Zembylas, 2015).

Further to this, the benefits I accrue from being a middle class, male, cisgendered and ablebodied Pākehā researcher generally makes me less inclined toward the kind of reflection and critique needed for research that 'speaks back' to, and transforms the oppressive elements of settler society. As Simon and Dippo (1986) elaborate,

We should turn to a consideration of how the discourse we use to talk with others and through which we write and think silences as well as articulates. This is especially important for us white males who have long acquired the cultural capital of those who control our institutions. (p. 201)

Through engaging with literature on settler colonialism and related studies on the nature of whiteness I find myself increasingly sensitive to the multiple dangers of silencing others and perpetuating the processes of settler colonialism through research practices. Furthermore, if the process of decolonising scholarship involves promoting the validity and significance of non-western epistemic systems, I have much 'homework' to do. Citing Spivak, the geographer Juanita Sundberg (2014) explains "homework entails a self-reflexive analysis of one's own epistemological and ontological assumptions" (p. 39). In one sense, this whole thesis has been an exercise in such 'homework'. For example, at first, I wanted to know more about the challenges of teaching difficult histories of colonisation, largely unaware of settler 
colonialism and its mode of operation as an ongoing process, especially within curriculum and schooling structures. Settler colonialism became an increasingly necessary frame for thinking about history education because the challenge of teaching and learning histories of colonisation cannot be separated from the histories of colonisation themselves.

At the same time as I was learning to look at history education through a critical lens of settler colonialism I also came to appreciate the dangers of an approach that too quickly drew binary distinctions between the coloniser and colonised or settler and Indigenous. Influenced also by a range of critical educators who sought to uncover and actively respond to the emotional basis of racism, nationalism, xenophobia and sexism as expressed within classrooms, I wanted to explore ideas of settler colonialism in ways that also acknowledged how "all human beings are vulnerable, yet not in the same manner" (Zembylas, 2017d, p. 510). In the latter stages of this study, this concern coincided with further questions about my methodological approach. Shear and Krutka (2019), for example, ask "[are there] methodological ways non-Indigenous scholars can unlearn, disrupt, and relearn qualitative inquiry in the support of resistance and refusal?" (p. 39). This question continues to resonate with me, though I am encouraged by Barton's (2019) notion of a “dynamic research tradition" that he says "would investigate concrete efforts to change how history is taught and learned" (p. 13). While inevitably limited and developing, I am confident that my critical and place-conscious stance toward research has revealed findings that will ultimately be useful for history educators with flow-on effects for their students.

\section{Research approach}

This thesis utilises what Donna Mertens (2012) terms a 'transformative mixed methods' approach, a methodology that uses quantitative and qualitative methods, providing a broader and more detailed picture of my research questions. Transformative mixed methods generate findings that are "conducive to social change" and thus consistent with the theoretical and conceptual framework outlined in the previous chapter (Mertens, 2012, p. 801). Definitions of mixed methods, however, are generally "contested, multiple and blurred" (Charmaz, 2012, p. 125). One frequently cited definition explains that this approach "mixes or combines quantitative and qualitative research techniques, methods, approaches, and concepts of language into a single study" (Johnson \& Onwuegbuzie, 2004, p. 17). While not the conclusive definition of mixed methods, it comfortably describes my study. 
Some scholars suggest that mixed methods studies "[have] one method serve as a core component and another method as a supplementary component" (Charmaz, 2012, p. 133).

Because my research questions demanded the use of methods that illustrated the perspectives, experiences and contexts of participants, qualitative data generated the bulk of my findings. The quantitative data in this study is a relatively simple (although no less quantitative) form of descriptive statistics, gathered through surveys. It was critical to obtain this data to make any broad generalisations about teachers' and students' conceptions of colonisation, data which could not have come from more qualitative methods that provide nuanced pictures of practice, but do not produce generalisations.

Consistent with the critical paradigm of this research and a transformative approach to mixed methods, this study uses a critical ethnographic methodology for its qualitative components. Critical ethnography extends a purely interpretive form of ethnographic research. According to Simon and Deppo (1986), the goal of critical ethnography is to "[seek] to transform the relations of power that constrict people's lives" (p. 196). As Madison (2012) puts it, "critical ethnography begins with an ethical responsibility to address processes of unfairness or injustice within a particular lived domain" (p. 5). As a research stance, however, critical ethnography's interest in power does not mean compromising its interpretive aspects. It still involves "the study of groups and people as they go about their everyday lives" (Emerson et al., 2011, p. 1). I chose a critical ethnographic methodology because I was interested in learning more about the challenges and opportunities encountered by teachers and students during lessons on colonisation. Ethnography, with its emphasis on "being there" (Murchison, 2010) provided insight into the pedagogical complexities and nature of engagement with colonisation in ways that other methods simply could not achieve (p.12, bold in original).

As a part of my ethnographic approach I encouraged students to take photographs during the field trips, which I then printed and used as an elicitation tool during focus groups (see below). Using photographs with young people has a number of advantages. First, it actively involves young people in a key part of the research and supports them to interpret and make meaning from their built environments in a democratic fashion (Leonard \& McKnight, 2014, p. 2). As an elicitation tool, photographs are also more "linguistically flexible" than interviews because they can "pave the way for a wider dialogue on aspects of social life that it may represent to them" (Leonard \& McKnight, 2014, p. 4). Photographs call students' 
attention to the specificities of a place once they are back in from the field, allowing researchers to prompt reflections about the affective experiences and cognitive understanding that emerged from being at an historical site.

To conclude this section, the type of mixed methods approach employed in this study most closely resembled an 'explanatory sequential' mixed methods approach, where quantitative data is gathered first before proceeding to qualitative data gathering (Creswell, 2014). Although there was overlap in both phases of data collection, by gathering significant proportions of data from surveys, I was able to use this to refine the kinds of questions I asked during focus groups and interviews. Gathering data that revealed broad trends in teachers' and students' conceptions about the issue of colonisation also highlighted areas I could look for during classroom and field trip observations.

\section{Quantitive data}

My mixed methods study began with a quantitative survey of as many history and social studies teachers and students as I could access from different parts of New Zealand. In the next section, I outline the process of carrying out these surveys.

\section{Survey for teachers}

My choice to administer a large-scale survey about the issue of colonisation related to my interest in understanding broad patterns in teachers' conceptions of this issue, patterns that I could not gain from a small qualitative study and that had not been gathered before in New Zealand. Prior to distributing an online survey to teachers, I administered a pilot survey to some of my former colleagues in a Wellington secondary school. A small group of history and social studies teachers completed this survey and provided feedback on the questions. I provided a voucher for a local café as recompense for their time and advice. Only minor changes were made. For example, Question 10 (Appendix 1), which asked participants to make a judgement on the statement Colonisation in New Zealand was a benign process, was changed slightly and the adjectives good, kindly, and humane were added as synonyms for the word 'benign'. After making changes to the survey (designed with the programme Qualtrics), I used a volunteer sampling method to find participants. This method is used when "it is necessary to rely on those who are willing to answer requests to provide data" (Jupp, 2006, p. 2) 
Initial invitations to teachers were delivered by three key methods. The first involved the chairperson of the New Zealand History Teachers Association (NZHTA) distributing a link of the questionnaire to all of its member schools. I then posted a link to two private and frequently used Facebook forums: New Zealand History Teachers and New Zealand Social Studies Teachers. The final, more laborious method involved contacting the teachers in each school. I attempted to invite all New Zealand history and social studies teachers working in a school with a roll of more than 250 students. The one exception was Māori medium schools. Most of these schools are small, but I wanted to ensure that teachers from Māori medium contexts received an invitation to complete the survey. The minimum roll size of 250 was chosen as a broad indicator of the number of teachers working at any one school, schools which included state, state integrated, private secondary and composite schools (Years 1-15).

In many cases, I personally contacted schools and their teaching staff through the details on a school website. For example, some include the names and email addresses of all staff, which made it a relatively easy process to invite individual teachers within an entire social sciences faculty or department to complete the questionnaire (see Appendix 1). Other school websites only included the email addresses of teachers in key leadership positions. In this case, I contacted this person and requested that they forward the link to the survey to all of their staff that teach history or social studies. Many school websites did not include the details of any teachers, which necessitated calling the school administration staff and asking for the name and email address for the lead social sciences teacher. In these ways, I contacted a total of 341 schools, making direct contact with 526 individual teachers and 204 heads of department. Only one school refused to complete the survey or allow any staff to do so.

Although these methods ensured that a large number of teachers were invited to complete the survey, there are a number of reasons why a teacher may not have received the link to participate. For example, using the Ministry of Education's website Education Counts, ${ }^{22}$ I made the database of schools and their details before the summer holidays began toward the end of 2017. Many of the teachers emailed directly were not contacted until the beginning of the new school year in late January and early February 2018. During that time some teachers had shifted schools, retired or left the profession, and therefore would not have received the

22 https://www.educationcounts.govt.nz/home 
email. If it was a Head of Department who left, it is possible that none of the teachers in that school were alerted to the survey. Additionally, staff lists on a school website with individual email addresses for social sciences teachers may not have been fully up to date or $100 \%$ accurate.

For many schools I relied on the Head of Faculty or Head of Department to distribute the survey to their staff. For a handful of schools, I also I relied on the school administration staff forwarding the survey link to the head teacher in the social sciences. In both of these instances, I cannot be certain this was done. The teachers involved in a pilot of the student or teacher survey (which was one school) were not directly invited to complete the survey. Nor did I contact any of the schools that agreed to administer the student questionnaire on my behalf. Despite these reasons for not receiving a link to the survey, membership of the New Zealand History Teachers' Association (NZHTA) and participation in the Facebook Forums gave the teachers in these schools an opportunity to find out about, and contribute their thoughts on teaching New Zealand's history of colonisation. Teachers were informed about the purpose and context of the research project and the voluntary and anonymous nature of their participation at the beginning of the survey in an ethics and information section (Appendix 1).

\section{Survey for students}

Prior to administering the survey, I sought permission from the principal of my previous school for two former colleagues to distribute a pilot version to a junior social studies and senior history class. Based on their responses I made some minor changes, making it more comprehensible to an audience of diverse literacy abilities (see Appendix 2). Then I began the process of finding teachers willing to administer it. I informally approached the head teacher of the social sciences in nearly 50 schools, including a range of school deciles, rural/city and small-town schools, boys, girls and co-educational schools, public and private schools and schools in the North and South Island. In this initial correspondence, I outlined my research and the nature of the survey and included a digital copy. Of these schools, 26 registered their interest. I then formally contacted the principal outlining the project including a consent form (Appendix $3 \& 4$ ). When I received these signed forms, I sent the participating teacher(s) either paper versions of the survey or a link to the Qualtrics questionnaire (Appendix 2). Due to a range of factors, only 20 schools actually administered 
the survey, which took students on average 15-20 minutes to complete. Some schools administered the survey to hundreds of their students and others to a single class. This led to an inconsistency of data with large, urban schools being overrepresented. Four schools (and approximately 300 students) elected to complete the survey on paper, data which I then entered by hand into the Qualtrics digital survey platform.

\section{Gaining informed consent from survey participants}

On the first page of the survey, its optional and anonymous nature was clearly explained to all research participants (see Appendix 2). Nevertheless, by asking teachers to administer the survey to students, I cannot be sure that some students did not feel pressured to complete it. To mitigate against this, I emphasised to supporting teachers that no student should feel compelled to participate. Due to the anonymous nature of the survey, all students, including those younger than 16 could decide for themselves if they wanted to participate. Some chose not to, which I could tell when the digital version of survey had been opened but no data of significance had been entered, or a paper version came back blank but with drawings on the front cover.

\section{Summary of teacher participants}

A total of $(n=298)$ teachers of history and social studies completed the survey. Teachers who completed the questionnaire drew on a range of professional experience. A slight majority $(55 \%)$ reported teaching for 11 or more years, just under a quarter reported teaching for 6-10 years $(23 \%)$ and a similar number were relatively new teachers with up to five years of classroom experience. Teachers from every New Zealand region completed the survey. Auckland, Wellington and Canterbury had the greatest representation (55\%), followed by Waikato, Bay of Plenty and Otago (24\%), and the reminder from less populated regions, primarily Northland, Nelson and Manawatū-Whanganui (13\%). Teachers from all school deciles were represented, although those in higher decile schools were more likely to complete the survey. In New Zealand, decile ratings refer to the socioeconomic status of a school's community, a figure used by the Ministry of Education to ensure equity in the distribution of central funding. High decile schools, such as those ranked 8 to 10 , represent a high socioeconomic community. Schools with a lower decile ranking, often have higher 
numbers of Māori and Pasifika students, reflecting in part the nature of inequality in New Zealand. $^{23}$

Seventeen percent of teachers reported working in low-decile schools (deciles 1-3), 37\% in mid-decile schools (deciles 4-7), and 46\% in high-decile schools (deciles 8-10). Teachers who completed the questionnaire were also mostly female (57\%) and identified primarily as Pākehā/New Zealanders or European (80\%). Teachers who identified as Māori comprised a small but significant number of respondents (13\%) and only a handful of others identified as either Pacific Peoples, Asian or Indian. Teachers were split almost exactly in half according to whether or not they were Head of Department $(\mathrm{HoD})$ or a teacher in charge of a subject (TiC), meaning that a disproportionately large number of teachers with more direct control over curriculum decision-making completed this survey. Teachers' academic expertise was mostly in the discipline of history with nearly half (48\%) majoring in this subject at university, followed by Geography for $16 \%$ of respondents (see Table 4.1). This suggests that fewer teachers of social studies with subject expertise other than history completed the survey. ${ }^{24}$

\footnotetext{
${ }^{23}$ From 2021 or 2022 the Ministry of Education will implement a new "Equity Index" that will abolish the decile system and, it is argued, make the distribution of funds more equitable, reducing the stigma associated with low decile schools.

${ }^{24}$ The data gathered from teachers and students is not a randomised sample. Nevertheless, the sample is big enough to generalise from and it reflects broad national trends in education taken from the Ministry of Education's website Education Counts. For example, $85 \%$ of secondary school teachers in New Zealand identify as European versus $80 \%$ in my sample. The national percentage for female teachers across all secondary school subjects is $68 \%$ compared to my sample of $57 \%$, (a difference that may reflect subject specificities). I chose not to use randomised samples because the overall number of teachers and students would have been less than was possible through my method of volunteer sampling.
} 
Table 4.1: Summary of teachers who completed the survey

\begin{tabular}{|c|c|c|c|}
\hline $\begin{array}{l}\text { Professional } \\
\text { teaching experience }\end{array}$ & $11+$ years, $55 \%$ & $6-10$ years, $23 \%$. & $0-5$ years, $22 \%$. \\
\hline Region & $\begin{array}{l}\text { Auckland, Wellington } \\
\text { and Canterbury, 55\%, }\end{array}$ & $\begin{array}{l}\text { Waikato, bay of Plenty, } \\
\text { Otago, } 24 \%\end{array}$ & $\begin{array}{l}\text { Northland, Nelson and } \\
\text { Manawatū-Whanganui, } \\
13 \%\end{array}$ \\
\hline School decile & $\begin{array}{l}\text { High-decile schools, } \\
46 \%\end{array}$ & $\begin{array}{l}\text { Mid-decile schools, } \\
36 \%\end{array}$ & $\begin{array}{l}\text { Low-decile schools, } \\
17 \%\end{array}$ \\
\hline Ethnicity & $\begin{array}{l}\text { Pākehā/New Zealand, } \\
\text { European, } 80 \%\end{array}$ & Māori, 13\% & $\begin{array}{l}\text { Pacific Peoples, Indian, } \\
\text { Asian, } 7 \%\end{array}$ \\
\hline Gender & Female, $57 \%$ & Male, $42 \%$ & Other, $1 \%$ \\
\hline Leadership role & $\begin{array}{l}\text { Classroom teacher, } \\
50.34 \%\end{array}$ & $\mathrm{HoD}$ or $\mathrm{TiC}, 49.66 \%$ & \\
\hline $\begin{array}{l}\text { University subject } \\
\text { majors }\end{array}$ & History, $48 \%$ & Geography $16 \%$ & $\begin{array}{l}\text { 'Other', 14\%, Classics, } \\
8 \% \text {, Māori Studies, 5\%, } \\
\text { Did not take Social } \\
\text { Science papers to } 300 \\
\text { level, } 5 \% \text {, Media } \\
\text { Studies, 3\%, } \\
\text { Economics, } 2 \% \text {. }\end{array}$ \\
\hline
\end{tabular}

\section{Summary of student participants}

The total number of student participants was $(n=1889)$. Most came from cities in the regions of Wellington, Canterbury and Auckland. Due to some large schools in Auckland volunteering to participate but then not administering the survey, the most densely populated region in New Zealand had relatively few respondents at $14 \%$. Northland, in contrast, stands out for its high representation comprising $7 \%$ of respondents. Nearly one quarter of students came outside of the main centers and in total, nearly one third of survey respondents came from schools in the less-populated South Island. Students who completed the survey also mostly attended high decile schools. Several schools from a range of deciles chose to complete a paper-based version of the survey. Entering this data by hand showed me that students in high decile schools were more likely to finish the survey and give more extensive responses than students from lower-decile schools.

The survey did not require participants to rank their ethnic affiliations and some chose up to six different ethnicities. The percentages indicating ethnicity in Table 4.4, therefore, do not 
equate to $100 \%$ because they include those who identify with more than one ethnic group. For example, a student who identified as New Zealand Māori and New Zealand Pākehā is counted in both groups, a practice consistent with Statistics New Zealand and research on the fluid and contextual nature of ethnicity and ethnic identification (Peck, 2017; "Statistics NZ: Major ethnic groups in New Zealand," 2015; Webber, 2008).

The survey included students across all year levels in New Zealand secondary schools ensuring a relatively equal representation of young people in junior social studies and senior history classes. Gender identification was calculated on the same basis as ethnicity; if someone identified as male and female they were included in both gender categories. Students who ticked every ethnicity and gender option and made facetious remarks in the space provided for 'other' were listed as blank for their ethnicity and/or gender. Overall, a greater percentage of girls completed the survey, explained by one single sex school administering the survey to a large number of its students. Tables 4.2-4.6 provide an overview of key student data. ${ }^{25}$

\footnotetext{
25 The data in Tables 4.5-4.9 relied on students indicating their school, ethnicity, year level and age. Some students chose not to answer these questions and therefore the percentages in the tables do not amount to $100 \%$. School deciles (New Zealand's system for assessing the socioeconomic status of school communities for purposes of funding) were worked out using the students' school (when they indicated this) and data about decile from the Ministry of Education's website www.educationcounts.govt.nz.
} 
Table 4.2: Survey participants by school decile

\begin{tabular}{lll}
\hline Low decile (1-3) & Mid decile (4-7) & High decile (8-10) \\
\hline $8 \%$ & $20 \%$ & $64 \%$ \\
\hline
\end{tabular}

Table 4.3: Survey participants by region

\begin{tabular}{lllll}
\hline Wellington & Canterbury & Auckland & Northland & Other \\
\hline $34 \%$ & $28 \%$ & $14 \%$ & $7 \%$ & Waikato (5\%), Manawatū- \\
& & Whanganui (3\%), \\
& & Gisborne (2\%), Otago \\
& & $(3 \%)$, Southland, (2\%), \\
& & Taranaki (2\%). \\
& & \\
& &
\end{tabular}

Table 4.4: Students' ethnicity

\begin{tabular}{|c|c|c|c|c|c|}
\hline $\begin{array}{l}\text { New Zealand } \\
\text { European/ } \\
\text { Pākehā }\end{array}$ & $\begin{array}{l}\text { New Zealand } \\
\text { Māori }\end{array}$ & Asian & European & $\begin{array}{l}\text { Pacific } \\
\text { Peoples }\end{array}$ & $\begin{array}{l}\text { Middle } \\
\text { Eastern, } \\
\text { African, } \\
\text { Indian, Latin } \\
\text { American, } \\
\text { Other. }\end{array}$ \\
\hline $65 \%$ & $15 \%$ & $12 \%$ & $9 \%$ & $6 \%$ & $13 \%$ \\
\hline
\end{tabular}

Table 4.5: Students' year level

\begin{tabular}{lllll}
\hline Year 9 & Year 10 & Year 11 & Year 12 & Year 13 \\
\hline $22 \%$ & $32 \%$ & $18 \%$ & $14 \%$ & $14 \%$ \\
\hline
\end{tabular}

Table 4.6: Students' gender

\begin{tabular}{lll}
\hline Female & Male & Other \\
\hline $51 \%$ & $42 \%$ & $5 \%$ \\
\hline
\end{tabular}




\section{Qualitative data}

My desire to gain more specific and detailed insights into the teaching and learning of New Zealand's history of colonisation required finding a range of schools that taught this issue and with the teachers that were prepared to let me observe their lessons. ${ }^{26}$ In this section I outline the process by which I found these teachers and gained permission to observe their classes.

\section{A multiple site, ethnographic study}

I selected four geographically distant schools in order to better draw comparisons and highlight important contextual differences between each site. These were differences that ultimately provided a much more nuanced picture of the complexities presented to teachers and students during their history lessons. A comparative site approach also "enables a researcher to describe what is common and unique within and across sites" (Wood, 2011, p. 72). While not strictly a case study, my approach did bear some resemblance to what Yin (2009) defines as "an empirical inquiry about a contemporary phenomenon (e.g., a "case”), set within its real-world context - especially when the boundaries between phenomenon and context are not clearly evident" (p. 18). Being present in the real-world context of several different history classrooms and participating in multiple field trips allowed me to see each site as a distinct and bounded location with its own set of influences that both enabled and constrained my research participants' engagement with the history of colonisation.

Comparing sites made for more nuanced analysis of data that helped me see beyond a onesize-fits-all approach.

\section{Selection of schools and participants}

To select my teacher participants, I used purposive sampling to identify exemplary practitioners. According to Oliver (2006), purposive sampling “[necessitates] researchers taking a decision about the individual participants who would be most likely to contribute appropriate data, both in terms of relevance and depth" (p. 2). In my case, I wanted to work with expert teachers who were currently teaching an aspect of New Zealand's history of colonisation so their experience could inform my study and eventually other teachers. By selecting exemplary teachers, my goal was to learn from "models of wisdom" (Parkhouse,

\footnotetext{
${ }^{26}$ Due to teachers' ability in New Zealand to determine the content of their history programme there is no guarantee that New Zealand's history of colonisation is taught in a whole class fashion to all students who select history as a senior and optional subject.
} 
2018, p. 283). This approach presents a more powerful and ultimately useful critique of history education in New Zealand because even the teachers most committed to grappling with difficult histories of colonisation nonetheless encountered challenges (see Chapters 6 and 7). Less confident history and social studies teachers than the ones in this study (arguably significant proportions of the profession) are likely to encounter even greater challenges when navigating the pedagogical complexities described in later chapters. I had met and come to know all the teachers in this study prior to beginning the research through attending conferences, local and national subject association meetings or through professional development initiatives. I had also worked with two teachers in a school for a short time. This familiarity had some challenges as my role was to ethically evaluate practice, but it also had many advantages as the teachers and I had each other's trust and did not require much, if any time to develop rapport.

My wish to ensure a range of geographically distinct locations and deciles also helped to determine the selection of teachers. Due to this study's focus on field trips and place-based approaches to history, I selected teachers from schools that explored different aspects of colonisation and regionally varied Māori histories of place. If I had selected schools all in the same region, I reasoned I would be less likely to encounter a diverse range of historical contexts and field trip locations. Furthermore, I wanted to work with at least one school that studied the difficult history of colonisation pertaining to their local area. I reasoned that this might be a more sensitive historical context than learning about places more remote from students' daily lives. Nevertheless, Peter, at Southern College (see Table 4.8), did not meet the criteria of running a school field trip, at least in the year I visited. However, I knew Peter was deeply interested in Māori history with a strong belief in the importance of engaging with difficult histories of place. I also knew he was a passionate advocate for ensuring that national histories of colonisation that often prioritised North Island perspectives did not dominate his South Island-oriented curriculum. Perhaps most importantly, I knew that throughout Peter's career he had taken multiple field trips, had good connections with iwi historians and would provide an interesting perspective for this study. Although ideally I would have timed this research to coincide with a field trip at Southern College, having a site that did not run a field trip that year also provided an interesting point of comparison to other schools. 
Schools were also selected to ensure a range of different deciles (Table 4.2).

\section{Gaining informed consent from teachers and students}

Gaining consent to begin this research began by informally approaching the four history teachers I considered as demonstrating exemplary practice. In an email I invited them to participate and asked if I could approach their school principal for formal consent. Before beginning my observations in classrooms, I introduced myself to each history class and explained the nature of my research. During this first meeting with students, I explained that in addition to observing as many classes as possible I was also looking for volunteers to participate in two focus groups (before and after the field trip) which, for those willing, would also include a photography activity during the field trip. I explained that students potentially willing to be involved could read over the information sheet (see Appendix 6) and return the signed consent form the following day (see Appendix 3). In New Zealand, students 16 years or older can give their own consent for research projects. My decision to work with senior history classes (Year 12 and 13) meant all research participants were at least 16 and I did not require explicit permission from their parents. Nonetheless, I encouraged them to take the research information sheet home and to discuss it with their caregivers.

Most students who wanted to be involved in the research signed the consent form immediately. Selecting students through volunteer sampling reduced the likelihood of coercion and it gave my research participants an option to participate with their existing peer groups. On the other hand, not directly inviting specific groups of students did potentially mean I heard from a less diverse range of perspectives. I overcame this problem of representation somewhat by working in four schools, and the data in Table 4.9 illustrates overall a broad range of ethnic groups who decided to participate. Immediately prior to the first focus group I went over students' rights again, explaining further about the photography task for those students participating in a field trip. Students filled in a biographical sheet, which included space for a pseudonym of their choice for this study.

\section{Summary of selected teachers, their schools and their student participants}

All four teachers who participated in this study were experienced Pākehā teachers with a history specialism. Throughout this thesis I use pseudonyms but to ensure their confidentiality I do not provide many details about their histories and identities outside of 
their professed gender and ethnicity (see Table 4.7) as schools in New Zealand are relatively recognisable.

Table 4.7: Summary characteristics of each participating college

\begin{tabular}{lllll}
\hline $\begin{array}{l}\text { Teacher } \\
\text { participant } \\
\text { (Pseudonym) }\end{array}$ & College (pseudonym) & Type of school & Decile & Region \\
\hline $\begin{array}{l}\text { Sarah } \\
\text { (Female, } \\
\text { Pākehā) }\end{array}$ & Northern College & Large, state, coeducational & Mid-decile & $\begin{array}{c}\text { Central } \\
\text { North Island }\end{array}$ \\
\hline $\begin{array}{l}\text { Peter (Male, } \\
\text { Pākehā) }\end{array}$ & Southern College & Medium sized, state, co- & Mid-decile & South Island \\
\hline $\begin{array}{l}\text { Caitlin } \\
\text { (Female, }\end{array}$ & Eastern College & Large, state, coeducational & Low decile & Lower North \\
Pākehā) & & & & Island \\
\hline $\begin{array}{l}\text { Hannah } \\
(\text { Female, }\end{array}$ & Western College & Large, state, single-sex & High decile & Lower North \\
Pākehā) & & & & Island
\end{tabular}

Due to a multitude of reasons, such as the timing of field trips and the time pressures teachers are always under, the intended process of running focus groups before and after field trips and observing as many lessons as possible did not happen uniformly. In Table 4.8 I show how the research process differed according to each site. 
Table 4.8: Similarities and differences of the research process according to site

\begin{tabular}{|c|c|c|c|c|}
\hline & $\begin{array}{l}\text { Field } \\
\text { trip }\end{array}$ & $\begin{array}{l}\text { Focus group } \\
\text { with students } \\
\text { before field trip }\end{array}$ & $\begin{array}{l}\text { Focus group } \\
\text { with students } \\
\text { after field trip }\end{array}$ & Details of classroom observations \\
\hline $\begin{array}{l}\text { Northern } \\
\text { College }\end{array}$ & $\checkmark$ & $\checkmark$ & $\checkmark$ & One lesson before the field trip \\
\hline $\begin{array}{l}\text { Western } \\
\text { College }\end{array}$ & $\checkmark$ & $\checkmark$ & $\checkmark$ & Several weeks before the field trip \\
\hline $\begin{array}{l}\text { Eastern } \\
\text { College }\end{array}$ & $\checkmark$ & $x$ & $\checkmark$ & $\begin{array}{l}\text { Over a month before the field trip and } \\
\text { several weeks after the field trip }\end{array}$ \\
\hline $\begin{array}{l}\text { Southern } \\
\text { College }\end{array}$ & $x$ & N/A & N/A & $\begin{array}{l}\text { A handful of history lessons, a } \\
\text { scholarship class and a junior social } \\
\text { studies class [Focus group held with two } \\
\text { groups of students among these class } \\
\text { observations]. }\end{array}$ \\
\hline
\end{tabular}

\section{Northern College}

Northern College is a mid-decile and small-town secondary school in the central North Island. Its roll draws on students from a wide geographical area, approximately two thirds of whom are Pākehā or European and one third Māori. According to the Education Review Office's (ERO) report, Māori students generally affiliate to major iwi in the region and only a small percentage of students are of ethnicities other than Pākehā or Māori. Northern College claims positive community relationships and a desire to work more closely with iwi and hap $\bar{u} .{ }^{27}$ The school is situated in an economically vibrant area with several longstanding institutions offering stable employment to the community. The town also draws wealth from the economic activities of its surrounding farmlands. Northern College is the only secondary school in this town.

\section{Western College}

Western College is a girls, high-decile and urban secondary school in the lower North Island. Over two-thirds of Western College's school roll is Pākehā with a relatively small population of Māori and Pacific students, together comprising approximately $10 \%$ of the student body. Nearly $20 \%$ of students at Western College identify as Asian. The school has an academic

\footnotetext{
${ }^{27}$ In order to maintain all school's confidentiality I have not provided a link to any of the ERO reports mentioned in this section.
} 
focus and a stated commitment to biculturalism through its curriculum, pastoral support and the professional development it expects of teachers. The school's location allows students considerable opportunity to engage with the local community and public institutions. Māori achievement at Western College is high, sometimes out performing school statistics overall.

\section{Eastern College}

Eastern College is a medium-sized, low-decile, multicultural and suburban high school in the lower North Island. Over half of the school's student roll is comprised of Māori and Pacific students and approximately a quarter of its students are Pākehā. The school has a reasonably large population of refugee and migrant students and over $10 \%$ of students at Eastern College identify as Asian. For a number of years, the school has been involved in programmes that develop staff capacity to respond to Māori and Pacific students' cultural and educational needs. Eastern College has also been involved in programmes that develop relational forms of behaviour management. The residential area around Eastern College is comprised of many state houses and in recent decades the suburb has struggled economically.

\section{Southern College}

Southern College is a mid-decile, urban school in the South Island. The school has a stated commitment to inclusivity and it proudly celebrates diversity within its student body. Southern College is predominately Pākehā with slightly less than 10\% of Māori students forming its student roll, approximately the same as its Asian student population. Southern College presents itself as an academically successful school valuing success in creativity and the arts in addition to traditional academic subjects. Its leadership team is committed to preparing Southern College's students for life-long learning and $21^{\text {st }}$ century learning and they have a stated commitment to supporting Māori and Pasifika students. The school has close relationships with local educational and cultural institutions and it supports students closely as they make the transition to tertiary education. Table 4.9 summarises some of these patterns across four schools. 
Table 4.9: Summary of student details from participating colleges

\begin{tabular}{|c|c|c|c|c|c|}
\hline College & $\begin{array}{l}\text { Year } \\
\text { level }\end{array}$ & Male & Female & $\begin{array}{l}\text { No. of } \\
\text { participants }\end{array}$ & Ethnicity of participants \\
\hline \multirow{6}{*}{$\begin{array}{l}\text { Northern } \\
\text { College }\end{array}$} & 13 & 2 & 13 & 15 & NZ European/Pākehā (8) \\
\hline & & & & & NZ Māori (2) \\
\hline & & & & & NZ Pākehā and NZ Māori (2) \\
\hline & & & & & Pacific Peoples and Asian (1) \\
\hline & & & & & English (1) \\
\hline & & & & & Australian (1) \\
\hline \multirow{2}{*}{$\begin{array}{l}\text { Western } \\
\text { College }\end{array}$} & 13 & N/A & 9 & 9 & NZ European/Pākehā (8) \\
\hline & & & & & Asian (1), European (1) \\
\hline \multirow{13}{*}{$\begin{array}{l}\text { Eastern } \\
\text { College }^{28}\end{array}$} & 13 & 6 & 2 & 8 & NZ European/Pākehā (3) \\
\hline & & & & & Pacific Peoples (3) \\
\hline & & & & & New Zealand Māori (1) \\
\hline & & & & & Asian (1) \\
\hline & 12 & 4 & 6 & 10 & New Zealand European/Pākehā (1) \\
\hline & & & & & $\begin{array}{l}\text { New Zealand European/Pākehā and } \\
\text { European (1) }\end{array}$ \\
\hline & & & & & New Zealand Māori (1) \\
\hline & & & & & Pacific peoples (3) \\
\hline & & & & & $\begin{array}{l}\text { New Zealand Māori and Pacific } \\
\text { peoples (1) }\end{array}$ \\
\hline & & & & & New Zealand Māori, New \\
\hline & & & & & Zealand/Pākehā, European (1) \\
\hline & & & & & Pacific peoples, European, Asian (1) \\
\hline & & & & & Pacific peoples, European (1) \\
\hline \multirow{2}{*}{$\begin{array}{l}\text { Southern } \\
\text { College }\end{array}$} & 13 & 5 & 1 & 6 & NZ European/Pākehā (5) \\
\hline & & & & & Canadian (1) \\
\hline Totals & N/A & 17 & 31 & 48 & \\
\hline
\end{tabular}

${ }^{28}$ Two history classes in this school participated in my study. 
The data gathered from these four diverse schools in Table 4.9 is not generalisable and had I selected other schools, my findings may have been quite different. However, the four sites gave me a rich data set from which to explore the complexities teachers and students contend with during lessons on the history of colonisation and, for three of the schools, on field trips to sites of colonial violence.

\section{Data Collection}

\section{Classroom and field trip observations}

The central objective of sitting in classrooms and participating in field trips was to produce "detailed, context-sensitive, and locally informed field notes" (Emerson et al., 2011), of students' and teachers' everyday experiences during history lessons, particularly their engagement with difficult histories of colonisation (p. 14). The extent to which I was able to do this and generate what Geertz (1973) calls 'thick descriptions' depended on the amount of time I had in each school (see Table 4.8). For example, in all North Island Schools I was able to go through a process of systematically recording 'jottings' or “writing on paper as quickly rendered scribbles about actions and dialogue" (Emerson, et al, 2011) followed by using these hastily written notes as the cue for a more thorough account of the day's observations (p. 29). These field notes were written in the evening after the day's observation. At Southern College, I had less time and observed only a small variety of history lessons. Instead, I spent many hours with Peter walking and driving around his town and learning about his approach to history education. At this site, my data drew more heavily on the interview and focus group transcripts than on field notes, leaving an unevenness to the qualitative data, a situation not uncommon in schools-based research that needs to fit around the needs and timings of busy teachers.

Maintaining a descriptive stance when writing up my field notes was not always easy. At times I read my accounts of the day's observations and realised I had offered multiple judgements with no real grounds for doing so. In these instances, I would go back to my jottings and rewrite the account in a more measured way. Two methods I used to help maintain a descriptive record of the interactions I observed during history lessons were the writing of asides and commentaries (Emerson et al., 2011). An aside is a brief note that elaborates, explains or raises further questions about an incident from the day's observations. 
These frequently emerged during the daily write-up of observations and I identified these in bold in my field notes. A commentary is "a more elaborate reflection" perhaps a paragraph or more long and which could include "emotional reactions to events in the field" (Emerson et al., 2011, pp. 81-82). My own emotional reactions, when clearly separated from the descriptions my participants' daily lives, became useful data, prompting questions about why I had responded in that way, and whether or not students or teachers felt the same, questions I could follow up during later field work, focus groups and interviews. Beyond asides and commentaries, I also wrote what Emerson and colleagues (2011) call "in-process memos" (p. 123). These writings "require a more extended time-out from actively composing field notes in order to do more sustained analytic writing" (p. 123). These are written as tentative 'first drafts' and serve as the preliminary to a more comprehensive 'ethnographic tale' (Van Maanen, 2011).

\section{Student photography activity}

As mentioned earlier, in order to encourage an affective and visual interaction with sites during field trips and to generate images that could be used in a focus group, I issued my participants with a camera. They were asked to take photos over the duration of their journey, using a set of prompts to inform their decisions (Figure 4.1). I did not expect students to adhere strictly to these prompts, and although I reminded them about them in the field, the laminated cards attached to the camera bag were never more than a guide. Students looked after the camera for the entirety of the trip and some students elected to use their cell phones. Some students also chose to share a camera, completing the task together. Students at Northern and Eastern College took up to 100 photographs for each group, all of which I printed and gave to students to keep at the end of the focus group. Inviting young people to use photography as a tool for making meaning during their field trip experience involved them in a form of what Pink (2007) calls "amateur autoethnography" (p. 28). Ultimately, I hoped this approach would present a "route into childrens' worlds" and encourage them to 
pay closer attention to the sites we visited and to the affective dimension of these encounters with the past (Pink, 2007, p. 28).
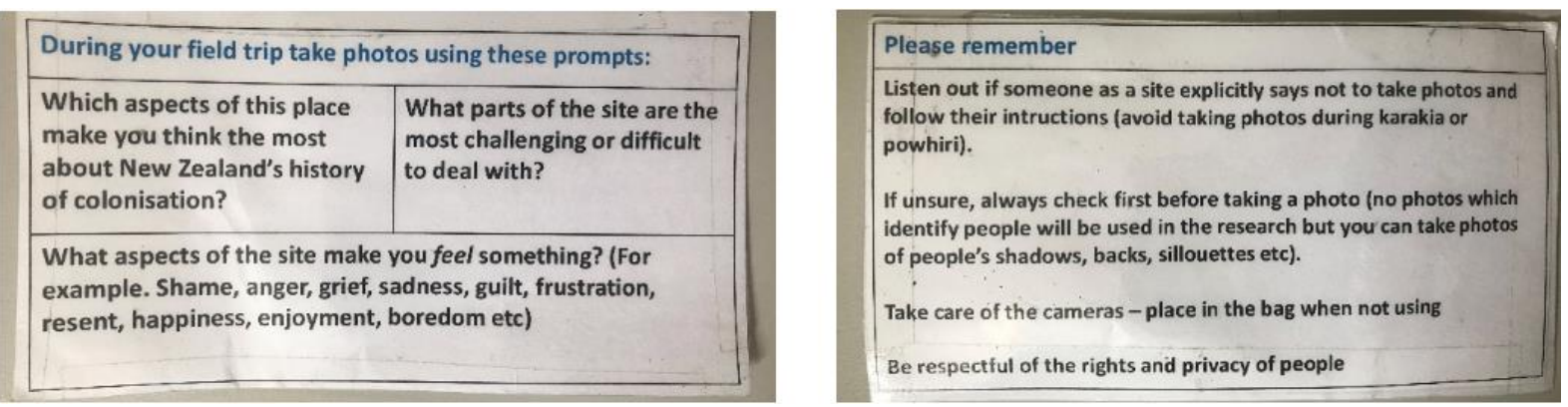

Figure 4.1: Photography prompt card used by students during field trips

\section{Semi-structured interviews with teachers}

Semi-structured interviewing is a method of research not totally controlled by the investigator and which encourages participants to talk as much as possible (Drever, 1995). Ultimately, a good interview reveals something about "the lived experience of other people and the meaning they make of that experience" (Seidman, 2013, p. 9). Based on the premise that “others' stories are important," interviews with teachers gave me better understanding of teachers' particular curriculum decisions and pedagogical practices (Seidman, 2013, p. 7). However, I only carried out one interview after the field trip. It may have been preferable to interview the teachers again the following year, because all four teachers constantly spoke about the changes they were planning to improve their practice. Taking a more longitudinal approach, and interviewing the teachers the following year after they had returned from the same field trip with a different set of students may also have revealed more about the kinds of complexities teachers experienced during lessons on colonisation. For example, as outlined in Chapter 7, Hannah from Western College had made extensive changes to her field trip based on her own and our mutual reflections.

\section{Semi-structured focus groups with students}

When doing research with young people, educational researchers need to consider two primary factors. First, they need to recognise the power dynamic present when an unknown, adult outsider attempts to prompt conversations about potentially sensitive issues. Due to the power-laden nature of all social contexts this a dynamic that will always, to some extent, shape the interaction between people and affect participants' willingness to share their views 
(Barton, 2015, p. 199). A second and related consideration for researchers is to ensure that young people are supported to share their ideas in all their rich and nuanced complexity. Kamberelis and Dimitridas (2013) suggest that focus groups, as a specific method, can "mitigate or inhibit the authority of the researcher, allowing participants to "take over" or "own" the interview space" (p. 40). For these researchers this "usually results in richer, deeper understandings of whatever is being studied" (Kamberelis \& Dimitriadis, 2013, p. 40).

While the power difference can never be completely neutralised, the democratizing effects of focus groups was especially evident when students used photographs as a discussion prompt. For Northern and Western College, I divided the total number of participants in each school in two and ran two separate focus groups, one set before the field trip and one set after. During the first focus group, I prompted discussion by asking students about their thoughts on learning New Zealand's history of colonisation, whether they enjoyed it or not, what their favourite and least favourite history topics were, and what their expectations for the field trip were. I also presented them with an image and some data from the survey administered to students in other schools, including a map illustrating Māori land loss (see Appendix 2, Question 16) and why they thought a substantial number of students judged New Zealand history to be "boring" (see Figure 5.9.2, Chapter 5). In the second focus group, I brought along copies of the photographs taken during the field trip and these formed the basis of our conversations. As Barton (2015) argues, the provision of elicitation materials, (especially those produced by students) meant they could "[share] in the definition of meaning" and "take on a more active role and exert greater agency" (p. 182) over the interpretive process.

Students at Northern College had taken over 100 photographs and I gave them time to select 1-2 before asking them to explain what the image was and why they had taken it. At Western College, students had already selected their photographs prior to the focus group. At Eastern College, I only had one focus group after the field trip and these students had also taken hundreds of photographs (all of which were printed and returned to student to take home). In this instance, I divided the time of the focus group, starting with the same questions posed at the other schools before moving to a discussion about the photographs. Unfortunately, this meant I had less time at this school to prompt discussion compared to the other schools. 


\section{Data analysis}

\section{Quantitative analysis}

Analysis of data gathered from survey responses was initially viewed within the survey tool Qualtrics and then exported to Excel. Within this software programme I set up the data in a pivot table, which allowed me to ask more fine-grained questions, such as the number of students by year level who considered learning New Zealand's history of colonisation 'boring'. From the raw figures exported from Qualtrics I generated simple bar graphs showing frequency counts that illustrated broad trends in teachers' and students' conceptions about the issue of colonisation. A sample of these graphs were checked by a quantitative expert in the Faculty of Education at Victoria University. I also sent them to Academic Consulting, an Auckland-based company that does quantitative and qualitative data analysis, with a focus on supporting postgraduate students. These experts gave advice on basic layout but considered the graphs to be strong and a useful tool for telling a story. There was some disagreement between these experts about the need to include error bars on graphs. Given the simple nature of my graphs showing basic frequency counts, I elected not include error bars.

\section{Qualitative analysis}

I analysed the interview and focus group transcripts using a method of critical thematic analysis (CTA). Critical thematic analysis is "an approach for analyzing everyday communication talks, texts, and discourses" in ways that "[seek] to understand individual and shared experiences of participants while being acutely aware of economic, social, historical, and political contexts, social and hegemonic structures, institutional power, and ideological impact" (Lawless \& Chen, 2019, p. 96). Critical thematic analysis extends Braun and Clarke's (2006) popular elucidation of thematic analysis, which they describe as a flexible method for "identifying, analysing and reporting patterns (themes) within data" (p. 79). It was important to take a take a more deliberate, critical approach to my qualitative data because history teaching practices and discourses are by nature embedded in power relations (Epstein $\&$ Peck, 2018). For these power relations and their influence on teaching and learning to be interrogated, they first need to be made visible.

Critical thematic analysis involves a two-step process of open and closed coding. In the first phase, I coded transcripts in ways that paid special attention to participants' views. This was 
followed by a process of closed coding which "[begins] to interlink the interview discourses with larger societal ideologies" (Lawless \& Chen, 2019, p. 98). In the open coding phase, I began my analysis by reading and coding each interview and focus group transcript several times, producing a set of tentative codes according to what was "recurring, repeated and forceful" (Owen, 1984, cited in Lawless \& Chen, 2019, p. 95). For each teacher's interview I developed four different lists of 10-12 codes (one from each teacher) and then looked across each set, collapsing identical or very similar codes. From this shorter list I generated an initial set of themes which began to tell a story of the complexities teachers contend with. Once I was comfortable with the themes, I then reread and coded each transcript against these themes using the qualitative data analysis software package NVivo, making adjustments where necessary.

I began the first round of open coding student transcripts by generating a long list of codes from each college, from which I developed the central themes and a range of subthemes. To begin with, these themes were tentative constructs. To test their viability, I read all transcripts again, coding and re-coding against my initial themes and using this process to iteratively create a codebook (DeCuir-Gunby, Marshall, \& McCulloch, 2011). This backwards and forwards process enabled me to refine the themes and subthemes and to develop a list of criteria for the inclusion or exclusion of data extracts. In my codebook, I could take small data extracts that illustrated different characteristics and annotate accordingly, including nonexamples. With this completed codebook I coded the transcripts a final time, connecting subthemes to appropriate data extracts. While overall a time-consuming process, it ultimately provided a systematic method that drew out important patterns in the data within each school. Generating codebooks of all four schools enabled me to then identify similarities and differences between schools.

The closed-coding phase of CTA involved "asking questions about what the emerged theme might be doing or how it is functioning" (Lawless \& Chen, 2019, p. 98). This phase makes a deliberate attempt to connect themes to particular ideologies of power. As Lawless and Chen (2019) emphasise, the purpose of the closed coding phase is not to "paint the participants as individuals who always already fail to recognize their own positionalities" (p. 104). Instead, a CTA works to uncover the workings of "larger social ideologies" so researchers and practitioners can form "a critical consciousness of the everyday communication practices that 
can be improved" (Lawless \& Chen, 2019, p. 104). More specifically, in the close-coding phase I read and reread the data for each theme using the questions in Table 4.9.1 to identify possible connections to "larger social ideologies" (p. 104).

Table 4.9.1: Sample questions to support close-coding data in a critical thematic analysis

\section{Critical questions for coding}

- How are everyday discourses enabled and constrained by social systems, dominant ideologies, and power relations?

- How do macro- and micro-level discourses, practices, and systems intersect and reproduce dominations and oppressions?

- How can individual subjects become aware of dominant ideologies and work toward challenging them and promoting social justice? (Lawless and Chen (2019, p. 97)

At the data analysis stage, I became increasingly aware of the need to reduce the data I had drawn from participants. I was particularly selective about the data I used from the student survey and I chose to focus on the field notes primarily from the field trip, rather than classrooms. The majority of the analysis of my field notes took the form of asides and commentaries (see previous section) from which I could select key vignettes that reflected questions in Table 4.9.1.

\section{Ethical considerations}

This research was approved by the Victoria University Human Ethics Committee [HEC] No. 25337. To protect individuals, I use pseudonyms throughout the thesis, and I gave students the option to select their own. At times, these had to be adjusted for the sake of confidentiality, for example, one student used his school principal's name as his non de plume. To protect schools and teachers, I describe each site in broad terms always ensuring 'plausible deniability'. At times, this also meant reducing the detail of some participants' comments. For example, one participant divulged information about her upbringing that may have helped to identify her which I removed. 
Participation in school field trips and the use of photography throughout these journeys presented some key ethical issues. First, my attendance on the four-day field trip to Taranaki had costs associated with it. I offered to drive myself and find my own accommodation but the school elected to include me in their wider arrangements for which I paid the costs. At other schools, there was no overnight stay and my presence contributed to the number of registered teachers in attendance so the burden was not as great. In addition, I used some of the funds from a grant awarded to me by the New Zealand Quaker Education Committee to provide the schools who ran field trips with a donation toward covering student hardship (\$300 per school).

A more complex issue in this study was dealing with the ethics of taking photographs at sites where extreme violence and brutality took place. To some degree, the field trips conformed to the notion of 'dark tourism' (Lennon \& Foley, 2007). By asking students to take on the mantle of 'amateur autoethnographers' and discussing the photographs taken in focus groups, I hoped to encourage deep and respectful discussion about sites of trauma, mitigating the voyeurism sometimes levelled at tourists who visit and take photographs at places of atrocity (Horne, 2017).

Another ethical challenge concerned navigating the tîkanga or cultural protocols of taking photographs at wāhi tapu (sacred sites). I consulted a range of people about this issue. For example, I spoke with Māori staff and postgraduate students at my university, I contacted a South Island iwi liaison officer who worked with teachers on the Ministry of Education's Māori History Project and a Māori history teacher at a kura kaupapa (Māori medium school) who takes students to battle sites near her school. The general advice from these people was to take a pragmatic approach and ensure the purpose of the field trip was one carried out with integrity with every effort made to include Māori perspectives. As a researcher, this was not fully in my hands, but my decision to work with exemplary teachers who I knew would do their best to meet these suggestions assured me I could use photography as a method that supported engagement and meaning making for students, albeit with some care and constraint. For example, at certain points during field trips I was able to check with a guide if it was appropriate for students to take photographs, information I relayed to students (see for example, Figure 7.2). Some photographs I elected not to use, such as one that a student had taken from the road, looking into an urupā on the Petone foreshore. I explicitly asked advice 
from Tom Roa, Associate Professor of Māori studies at the University of Waikato about the inclusion of a photograph of a mass grave of Māori killed during the invasion of the Waikato and buried at Rangiriri cemetery. Following his advice, I elected not to publish it in this thesis (see Chapter 7 for more details). On the card prompt for students I also made it clear that no photographs should be taken during karakia (prayer or incantations) or pōwhiri (welcoming ceremonies) and that when in doubt, it was best to ask, or not take the photograph (See Figure 4.1). At all times I was ready to abandon the use of photographs as a research method.

\section{Research credibility and validity}

\section{Credibility}

All of the students and teachers who participated in this study offered me generous amounts of their time and it was important that I could give back any results they could find useful. For example, I presented a broad summary of findings from the questionnaire administered to teachers at the conference of the New Zealand History Teachers' Association (NZHTA) in April, 2018. Before this conference, I also worked with Tom Roa (see above) to produce a resource for conference delegates about running field trips. For all the teachers who elected to administer the student questionnaire I produced a summary report of key findings, including graphs comparing their individual school results to those of all schools surveyed (see Appendix 7). Principals who had indicated their interest in the project also received these reports. Providing this information to teachers around New Zealand resulted in further email exchanges and professional conversations about the challenges of teaching New Zealand's history of colonisation.

For the four participating schools in which I carried out observations and interviews I produced a summary report and sent it to students who had expressed interest in receiving this information. The same report (which included a more comprehensive outline of recommendations) was sent to the teacher and the school principal. With one teacher, I was able to have a meeting before and after the following year's field trip to reflect on the experience together. For all four teachers, I continue to remain in contact and enjoy ongoing, mutually beneficial exchanges of resources and ideas. 


\section{Validity}

As outlined in Chapter 3, and reiterated at the beginning of this chapter, this thesis explicitly places itself in a postpositivist paradigm that openly acknowledges a transformative agenda. Establishing the trustworthiness of data, however, remains a critical endeavour. As Patti Lather (1986) writes, "we must formulate self-corrective techniques that will check the credibility of our data and minimize the distorting effect of personal bias upon the logic of evidence" (p. 65). In this final section, I discuss the validity of my study using Lather's (1986) criteria for 'openly ideological research': triangulation, construct validity, face validity and catalytic validity.

Triangulation refers to the inclusion of "multiple data sources, methods, and theoretical schemes" (Lather, 1986, p. 67). Because of my interest in the theme of teacher and student engagement with difficult histories of colonisation, taking a mixed methods approach provided different kinds of data that allowed for quantitative comparison between broad groups and the extent to which this was reflected at sites I worked in more closely. Choosing to work in four different schools and using a range of methods also highlighted similarities and differences between contexts, illuminating the findings from each location in ways not possible with fewer sources of data for comparison. My decision to elaborate critical theory with the notion of cognitive justice and to use two pedagogical frameworks, one that foregrounded place, and the other emotions, further strengthened my attempt to carry out observations and to look at data from different theoretical angles.

Construct validity refers to the kind of systematic reflexivity that "gives some indication of how a priori theory has been changed by the logic of the data" (Lather, 1986, p. 76). At various points during this research, I found my assumptions being challenged by the data. For example, I assumed many teachers would find resistance from local communities a major challenge when teaching New Zealand's history of colonisation. The survey results from teachers, however, did not reflect this position. One way this study could have been strengthened is the extent to which I show my assumptions being challenged by data, weaving more explicitly a critical reflexivity throughout my findings chapters.

Face validity refers to how much the researcher "recycles analysis back through at least a subsample of respondents" (Lather, 1986, p. 67). In this study I used the second focus group 
with students (when context allowed) to check back with comments made in the first round of discussions. During classroom observations and field trips, I also had multiple opportunities to check in and clarify my understanding of students' comments, or to follow up on their interpretation of experiences inside and outside the classroom. For the teachers I interviewed I provided them with transcripts of their interview and throughout the observation period (and after) I frequently checked in on points I needed to clarify. I could have improved this process by more deliberately building in to the research design explicit opportunities to share data summaries and my interpretation of it with teachers for feedback, but time and distance made this difficult. At the history teachers conference described above I attempted to do this but it was too early in the analysis stage for me to appropriately facilitate robust discussion of the emerging findings.

Catalytic validity "refers to the degree to which the process re-orients, focuses, and energizes participants" to challenge the inequalities of society (Lather, 1989, p. 67). In this regard, my study fell in between research where the participants are treated as objects and research that explicitly involves its participants as "subjects who have been empowered to understand and change their situations" (Lather, 1986, p. 75). Working closely with teachers appeared to result in mutually beneficial outcomes. For students, providing space to discuss their learning in open-ended ways, for the most part with photographs they had taken, seemed to be a genuinely positive and affirming experience. Barton (2015) supports these claims arguing that, "interview techniques themselves can hold important intellectual benefits for participants, particularly when they are students who are learning about the concepts being investigated" (p. 196). Nevertheless, neither teachers nor students were involved in the research design and they had no say in the focus of my inquiry or the development of the research questions. In this way, the project was less participatory than some other studies (see for example, Tupper, 2008). This limited the extent to which teachers or students could be considered as co-researchers, but at the same time my interest in the time-consuming process of gathering quantitative data made more participatory approaches difficult.

\section{Summary}

The central goal of this chapter has been to show how a methodological approach of transformative mixed methods illuminates my research questions and the broad issue of teacher and student engagement with difficult histories of colonisation. I have tried to 
highlight the 'messy' nature of educational research with teachers and students in busy schools with tight schedules and to acknowledge the limitations of certain decisions or weaknesses in the research design. Madison (2012) argues that "representing Others is always going to be a complicated and contentious undertaking” (pp. 3-4). Thinking carefully about the ethics of my research and the different methods of establishing validity within a critical framework helped to meet the demands and obligations of representing others to the greatest extent possible. In the following chapter, I attempt this further, exploring how teachers and students conceptualise the issue of colonisation in New Zealand. 


\title{
CHAPTER 5: TEACHER AND STUDENT CONCEPTIONS OF COLONISATION IN NEW ZEALAND
}

\author{
In Aotearoa, colonisation has not been overthrown, nor has it gone away. It not only remains \\ ever-present, it is also resilient, continually changing into new forms. \\ Graham Hingangaroa Smith, (2017, p. 91).
}

\section{Overview}

Settler societies need history and social studies curricula that actively engage young people with the emotionally difficult, historically complex features of colonisation including its "ever-present" and "resilient" nature (Smith, 2017, p. 91). This kind of curriculum can provide students with the capabilities and knowledge necessary for discussing and acting upon societal challenges, such as the ongoing effects of historical injustice and (in New Zealand) honouring the promises of the Te Tiriti o Waitangi/The Treaty of Waitangi. In this chapter, I draw on findings from my survey to explore teachers' $(n=298)$ and students' $(n=1889)$ conceptions of colonisation. This includes how they work to reinforce or challenge the ongoing, structural nature of colonisation described above by Smith (2017) and which is analsysed by other scholars of settler colonialism (Kidman, 2018; Schick, 2012; TomlinsJahnke, 2019; Tuck \& Gaztambide-Fernandez, 2013; Veracini, 2008; Wolfe, 2006). The chapter complements the following two chapters which focus more closely on the classroom and field trip experiences of four exemplary teachers and their students. Survey responses, of course, only provide a glimpse into what people think. They do not illuminate an individual's internal belief system, nor do they reveal anything of substance about the enacted curriculum. Instead, they capture a snap shot of the fluid, fleeting and context-specific nature of teachers' and students' conceptions gathered on the fly in busy classrooms and workspaces.

Nevertheless, views captured through surveys can lead to fresh insights into the broad patterns of thinking that may influence teaching and learning. These patterns, and the insights they reveal, pinpoint tensions, silences, assumptions, contradictions and opportunities that, when made visible, and used in conjunction with other data sources, illuminate pathways toward more powerful teaching of history and social studies.

This chapter has two primary sections and in the first I concentrate on the views of teachers. I show that despite some exceptions, survey respondents overwhelmingly expressed 
conceptions about colonisation that lean toward some aspects of what I called in Chapter $1 \mathrm{a}$ critical and transformative approach to history education. This suggests an ability by significant proportions of the profession to engage in sophisticated ways with New Zealand's difficult history of colonisation. In numerous cases, of course, this work is well under way. ${ }^{29}$ Nevertheless, I argue that the data indicates (at least) three key issues evident in teachers' conceptions that likely impede a deeper engagement from teachers with important curriculum and pedagogical matters. First, a significant proportion of teachers express potentially problematic views about the profession's current level of engagement with New Zealand's history of colonisation. Second, how teachers conceive the complexities of teaching history in a settler society presents some challenges that may limit teaching practices. Finally, some teachers' conceptions about, and practices of topic avoidance highlight a number of ways in which students may not learn about colonisation, or only in superficial ways. Drawing attention to these issues provides insight into the kinds of support teachers might need from subject associations, teacher educators and policy makers to extend and deepen pedagogical practices inside and outside the classroom.

In the second section of this chapter I show that like teachers, many students expressed 'critical' views about aspects of colonisation, particularly as this pertains to their acknowledgement of the close relationship between New Zealand's history of conflict and violence and many issues prevalent in contemporary New Zealand society. However, a significant proportion of students also understand this historical relationship in ways that reinforce the settler-colonial ideology of colonisation as an 'event' consigned to the distant past (Wolfe, 1998, 2006). A minority of students also characterise colonisation as benign and ultimately beneficial for society. Nevertheless, I conclude that overall, most students' are receptive to learning the history of colonisation and value it as a topic of study. Where they did not - and this number is not insignificant - understanding the nature of students' conceptions opens pathways for productive pedagogical responses that challenge stubborn, settler-colonial ideologies.

\footnotetext{
${ }^{29}$ For example, see the stories of teachers at this website: http://maorihistory.tki.org.nz/en/videos/teachingmaori-history-in-todays-world/
} 


\section{Teachers' conceptions}

\section{Critical views about the nature of colonisation and how to teach it}

One aspect of a critical and transformative history education in a settler society is the willingness of teachers to recognise and respond to the ongoing and inherently destructive nature of colonisation. The data generated from a survey $(n=298)$ shows that teachers overwhelmingly expressed such views and valued the issue of colonisation in history curriculum. For example, when asked if colonisation has contemporary consequences for people in New Zealand, 98\% of teachers either 'strongly agreed' or 'agreed' (See Figure 5.1, Question 11, Appendix 1).

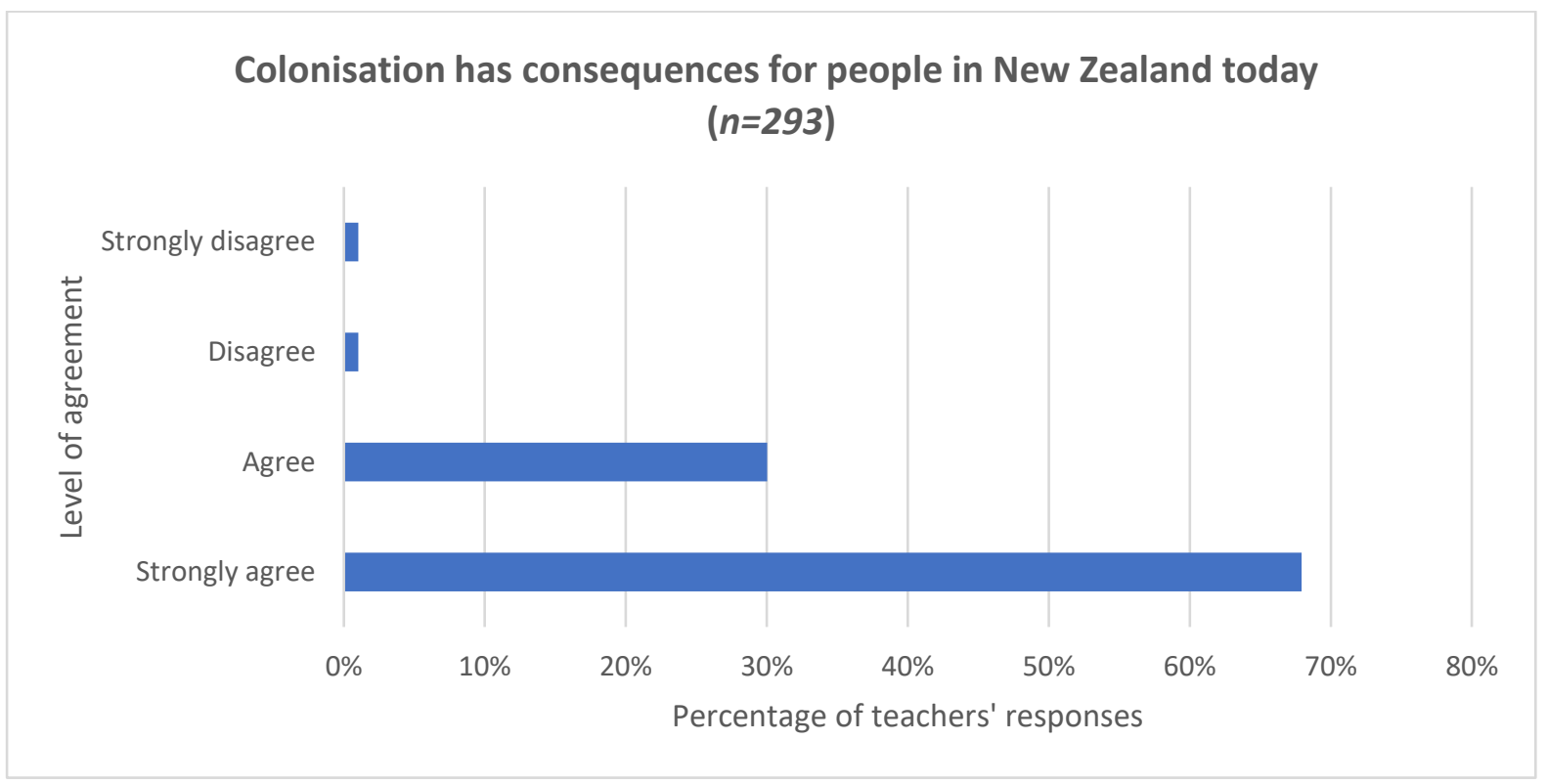

Figure 5.1: Teachers' views on whether colonisation has consequences today

Furthermore, the majority of teachers (93\%) 'strongly disagreed' or 'disagreed' with the statement 'Colonisation in New Zealand was a benign (good, kindly, humane) process' (see Figure 5.2, Question 10, Appendix 1). ${ }^{30}$

\footnotetext{
30 The questionnaire statement in Figure 5.2 is worded in a way that suggests colonisation is a purely historical phenomenon. I agree with Wolfe (1998) that colonisation is not an historical event but a structure that continues to manifest itself in the present. I was, however, concerned that it would cause confusion if the statement was phrased in the present tense. Instead, the question in Figure 5.1 more deliberately probed their conceptions about colonisation's past/present connections.
} 


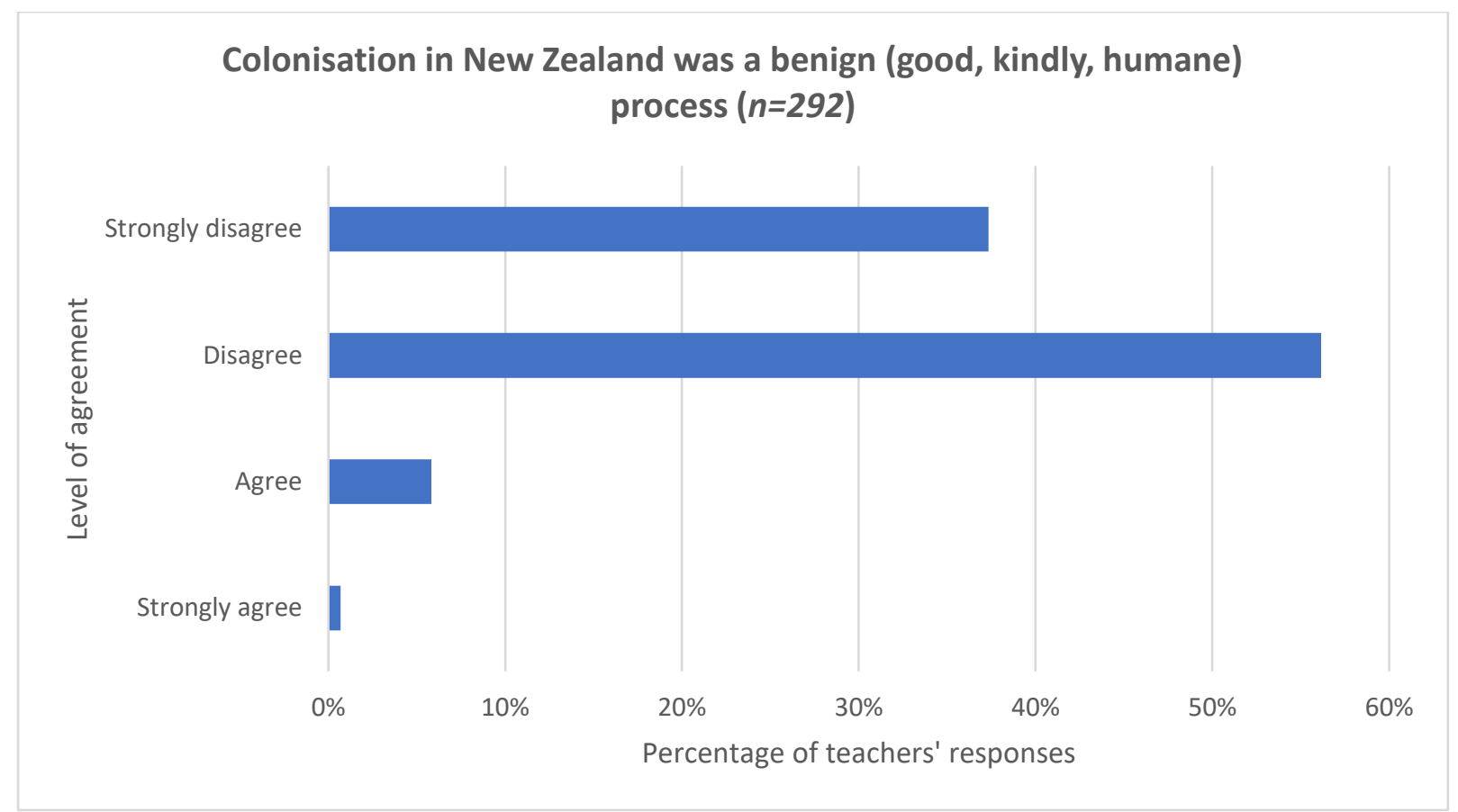

Figure 5.2: History and social studies teachers' views on the nature of colonisation

History and social studies teachers who participated in this survey were virtually unanimous that colonisation is important to teach (Figure 5.3) and they overwhelmingly endorsed the pedagogical principle of connecting the history of colonisation to contemporary issues (see Figure 5.4).

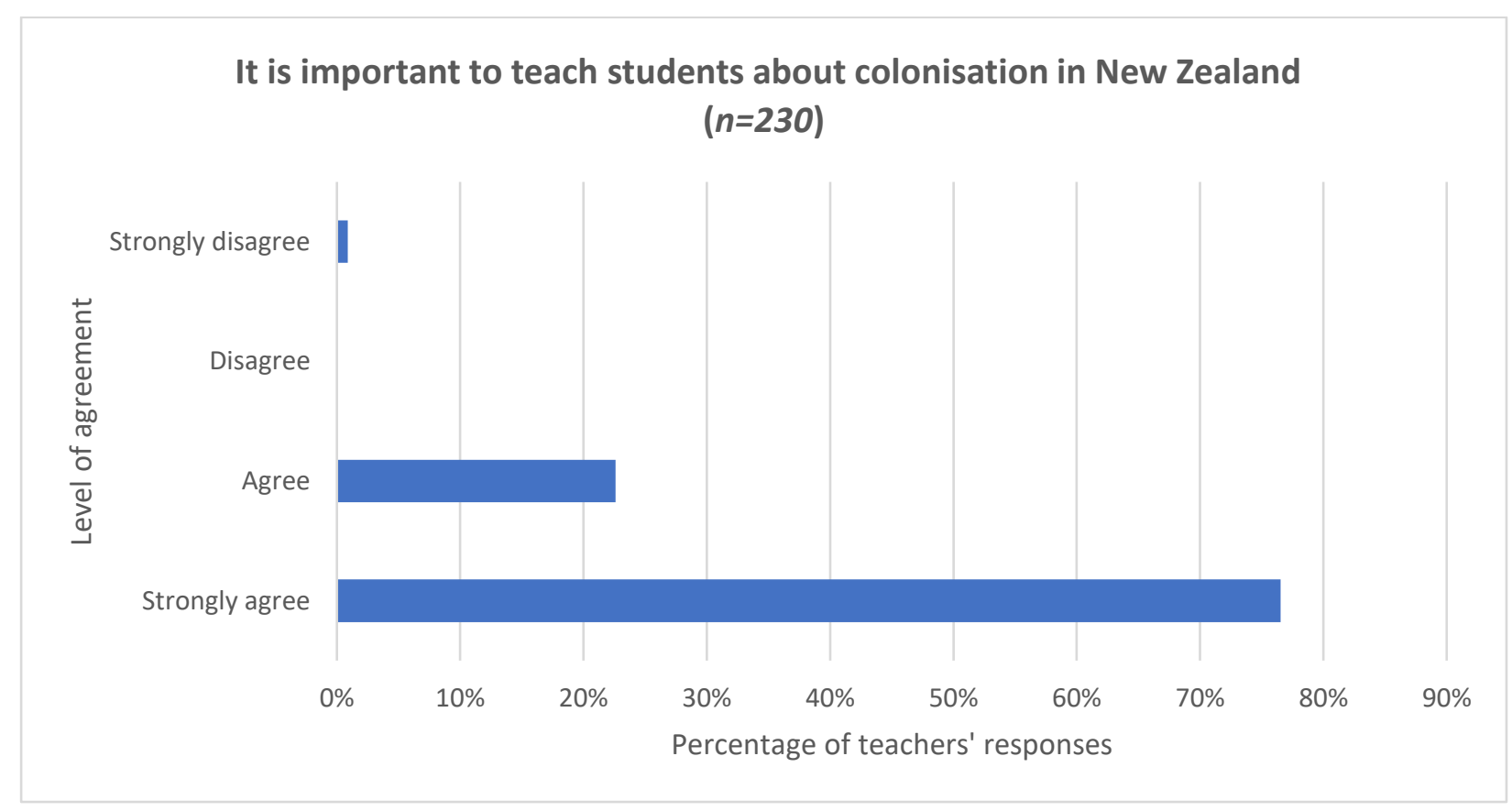

Figure 5.3: Teachers' views on the importance of teaching New Zealand's history of colonisation 


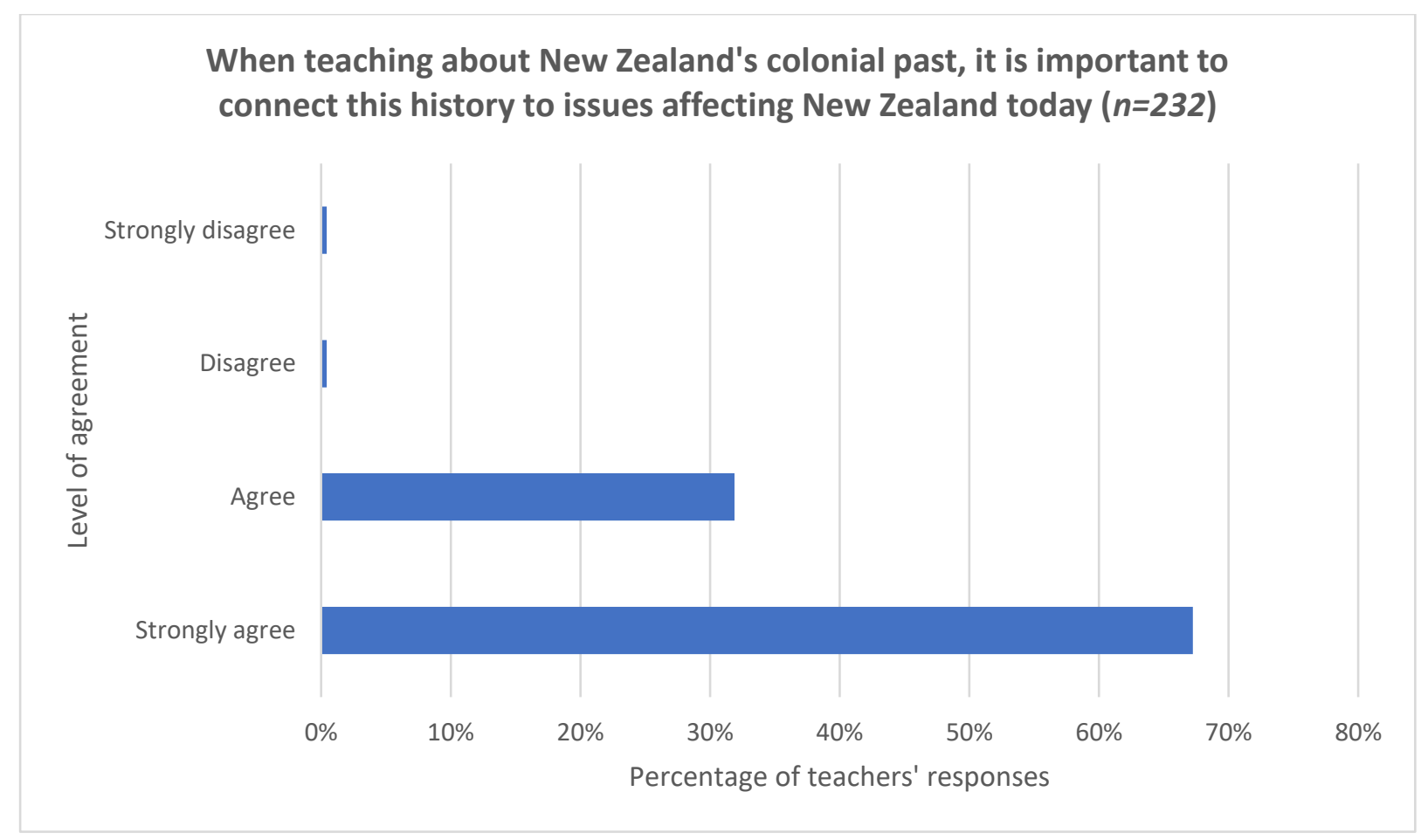

Figure 5.4: Teachers' views on the importance of connecting past and present

The majority of respondents also recognised the social value in teaching the history of intergroup violence (see Figure 5.5). The proportionally larger group of teachers who agreed or strongly agreed with the statement in Figure 5.5, frequently explained that it depended how the history was taught, arguing that when not taught well history education can be a destabilising social force. ${ }^{31}$

\footnotetext{
${ }^{31}$ Some of the comments by teachers who 'agreed' with the statement in Figure 5.5 also suggested they had misread the question, adding to the tally of those who recognise the social value of engaging with national histories of violence and conflict. In hindsight, the question should have been phrased differently for clarity.
} 


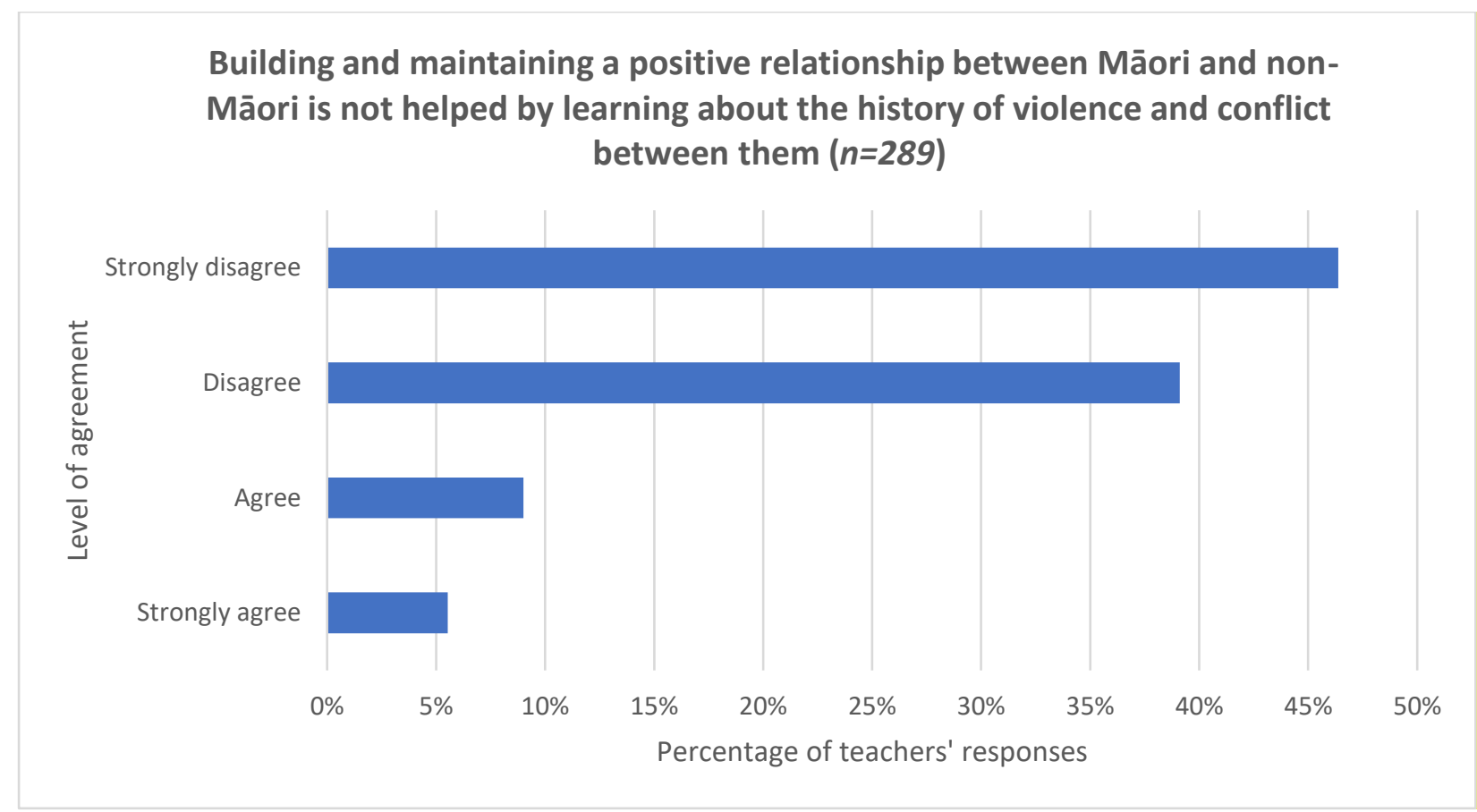

Figure 5.5: Teachers' views on the social effects of learning about settler/Indigenous conflict.

When teaching about the 'controversial' aspects of colonisation (see Figure 5.6), respondents mostly reported using the kinds of progressive pedagogies suitable for teaching sensitive (historical) issues frequently endorsed by scholars (See, for example, Baildon, Afandi, Bott, \& Rajah, 2018; Barton \& Levstik, 2004; Barton \& McCully, 2007; Hess, 2009; Seixas \& Morton, 2013; VanSledright, 2010). Some teachers, however, reported using classroom approaches for which there is less scholarly support from the literature on teaching difficult history. For example, a number of teachers explained that they focussed on colonisation in places beyond New Zealand $(n=67)$ although it is unclear if teachers considered this as a strategy for teaching about colonisation in addition to, or instead of including more local historical contexts. Epstein (2009), for example, endorses learning about less sensitive contexts if they are used as a lever into concentrated exploration of controversial topics. A small group of teachers asked students not to be too emotive $(n=16)$ and others said they emphasised teacher-centered instruction $(n=17)$, or emphasised the benefits of colonisation to New Zealand $(n=13)$. 


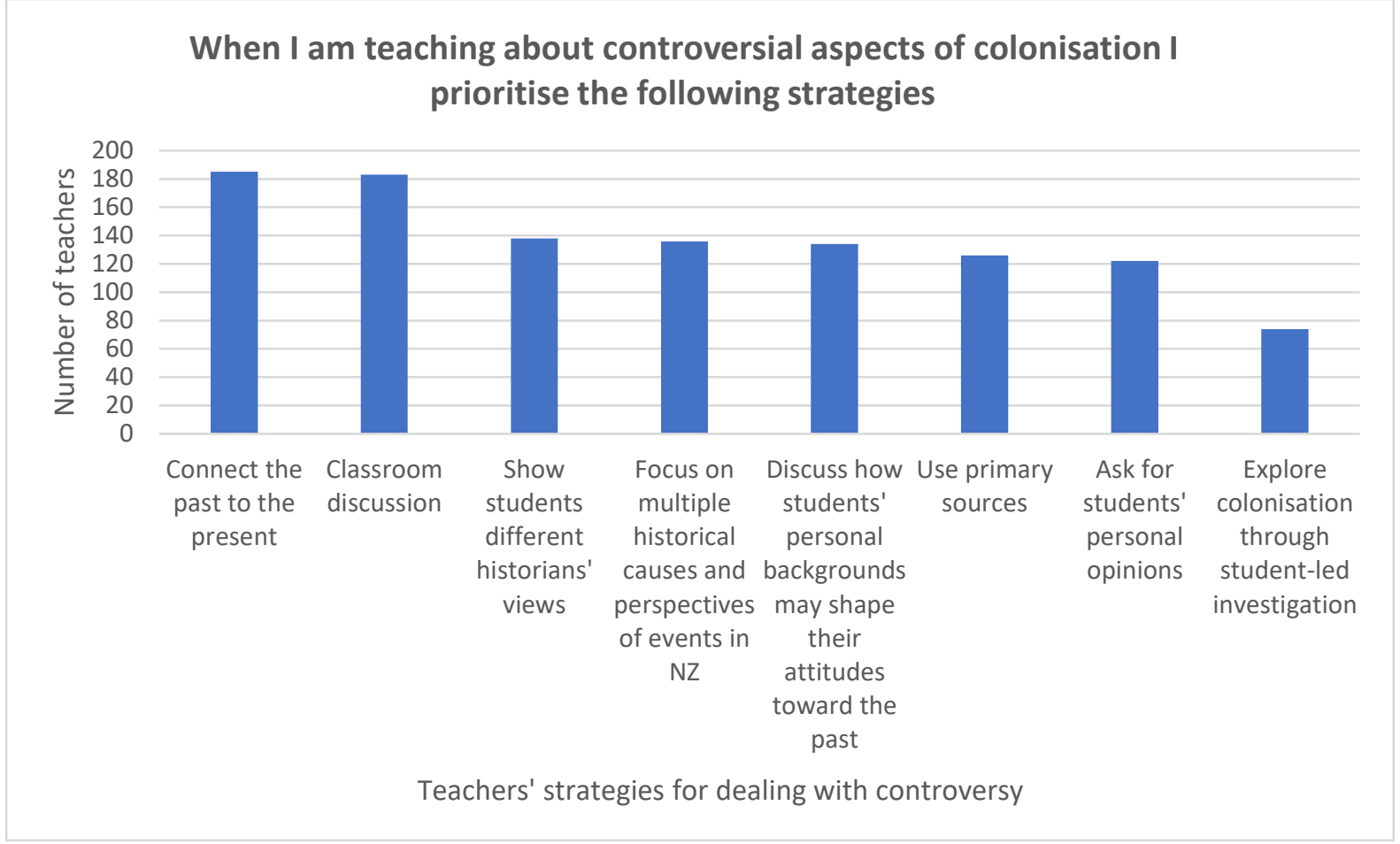

Figure 5.6: Approaches teachers report using when teaching controversial aspects of colonisation

As commented on earlier, teachers' conceptions about the subject of colonisation do not tell us much about the enacted pedagogies in classrooms or other places of instruction. Saying that one prioritises classroom discussion, for example, is different to actually carrying out high quality forms of discussion (Barton, 2019, Hess, 2009). Quantitative survey responses indicate, however, an important trend in what teachers value. The high number of teachers who endorse the practice of connecting past to present and who say they use discussion-based methodologies (Figure 5.6) show that much of the profession may already engage in some depth with difficult histories of colonisation, or at the very least, they would be willing to do so. Analysis of questionnaire comments help to provide a more comprehensive perspective. From qualitative responses to the statements 'Colonisation was a benign (good, kindly, humane) process' and 'Colonisation has consequences for people in New Zealand today' I coded several themes that further suggest that most teachers are open to histories of colonisation that recognise its ongoing and destructive nature. To illustrate, the most common theme in qualitative responses $(n=45)$ showed that teachers were aware of the ongoing negative effects of colonisation particularly in terms of individual or institutionalized forms of racism. For example, one teacher wrote that:

The intergenerational consequences of being alienated from the basis of our spiritual, cultural and economic well-being, has had an enduring and significant impact on 
Maori and this is evident today in the negative, over representation of Maori in various social indices.

Another teacher described the institutional nature of racism today and racist attitudes toward Māori as anchored in historical processes of colonisation:

You can't separate the past from the present. Over representation of Maori in negative statistics has its origins in a population displaced and marginalised by Pakeha government which is perpetuated by racist attitudes towards Maori today.

Another theme commonly expressed in qualitative responses was the view that colonisation is inherently destructive $(n=33)$. In response to the questionnaire statement that colonisation was 'benign' (Figure 5.2), one teacher wrote “I laughed! Sure, this is how it was sold by Pākehā in the 1840s but I sure hope the answers from history teachers in New Zealand are unanimous here". Others highlighted the greed for land at the heart of colonisation and the repeated violations of the Treaty of Waitangi. One teacher wrote "the terms rape and pillage come to mind" and another explained that there is "clear evidence of atrocities on the European side". Some teachers emphasised the assumptions of white supremacy that lie at the heart of settler colonialism, for example:

Colonisation was built on notions of racial superiority. On that count alone, it cannot be considered good. The realities of colonisation in New Zealand led to the relegation of Māori to second class citizens within their own lands. It led to numerous wars and long-lasting racial tensions.

The data above illustrate that the unsympathetic views expressed by some vocal New Zealanders to this nation's history of colonisation are not widespread among teachers of history and social studies (see, for example, Kidman \& O’Malley, 2018; Sheehan, 2017). Nevertheless, a minority of teachers did appear resentful about how New Zealand deals with its history of injustice. For example, as evidence of the ongoing consequences of colonisation, one teacher wrote "the Waitangi Tribunal is still examining past grievances, and that we remain shackled to a 170 year old Treaty is also evidence". Another commented, "we are still clinging to the past in many ways. At some stage a line needs to be drawn and we get on with things". As illustrated in Figure 5.2, 7\% of teachers agreed that overall, colonisation was a benign historical process. To illustrate this minority view, one respondent wrote, "obviously the impact was not good for everyone, but the question is regarding the process which, I believe, was generally fair and conducted with good, humane intentions". It is 
difficult to assess the extent of these minority views and teachers who believe strongly in the benign nature of colonisation are less likely to complete a survey like the one that was distributed.

In summary, qualitative and quantitative data reinforce the claim that significant proportions of the teaching community in New Zealand are more likely than not to express a critical stance on the nature of colonisation and endorse sound practices for teaching difficult and controversial aspects of the past. This baseline position is important to recognise, but neither is it particularly surprising. Most practising teachers have lived and trained in New Zealand, a nation that has undergone considerable historical revision which has given significantly more attention to Māori historical perspectives and the consequences of colonisation than previous decades (Ballantyne, 2012). Nevertheless, I now describe three key issues evident in teachers' conceptions which still might stand in the way of a more critical and transformative engagement with New Zealand's history of injustice and the "ever-present" nature of settler colonialism (Smith, 2017, p. 91).

\section{Perceptual barriers to deeper pedagogical engagement with colonisation}

\section{Conceptions about how the profession prioritises colonisation}

Unlike the consensus views among teachers about key aspects of colonisation and how to teach it described above, there was little agreement about how well the profession as a whole prioritises the issue of colonisation. On one hand, nearly one in five teachers, or $17 \%$ were concerned that 'few' schools adequately prioritise the teaching of colonisation. On the other hand, nearly one third of teachers reported that 'many' or 'almost all' schools adequately prioritise New Zealand's history of colonisation in their curriculum (see Figure 5.7). 


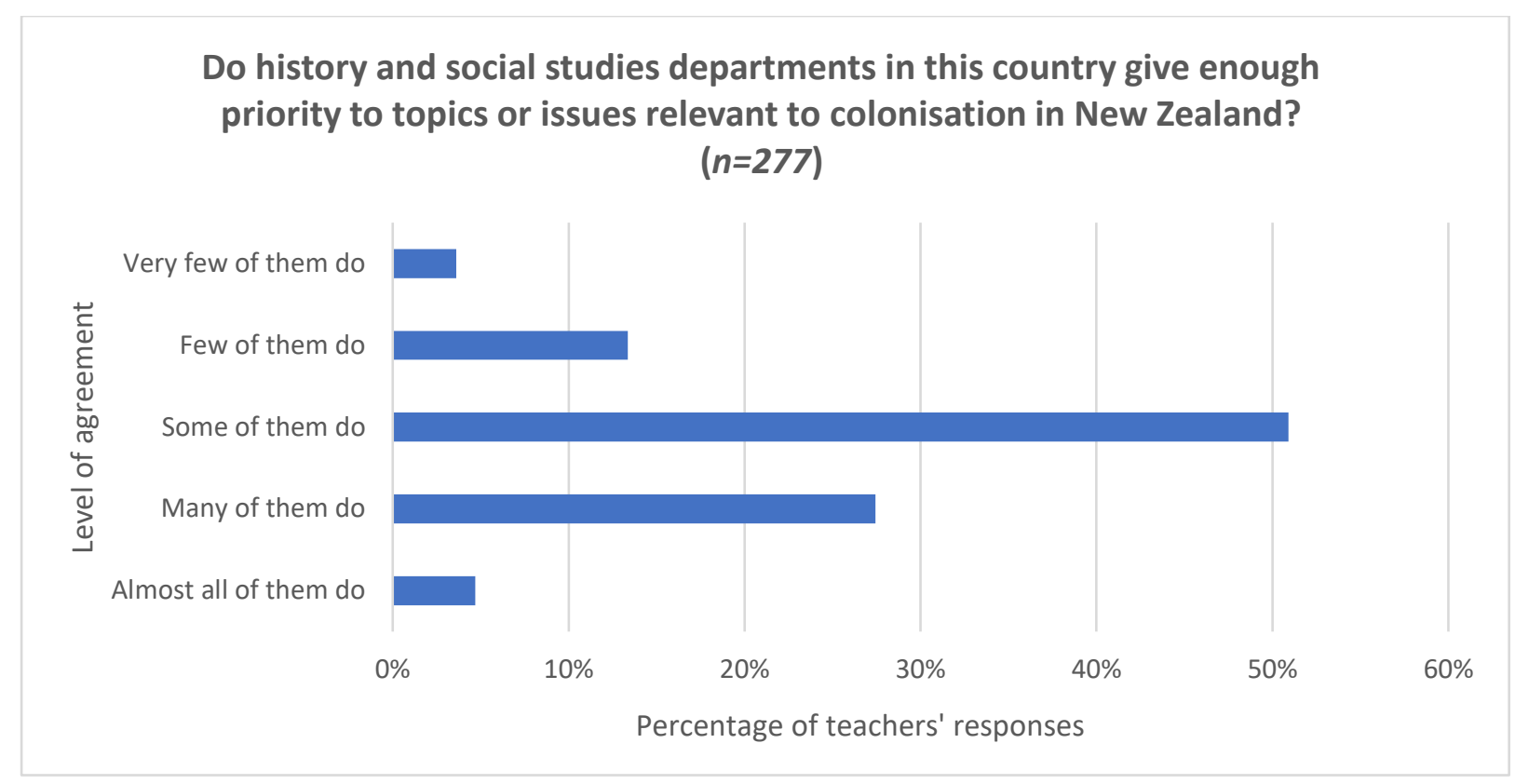

Figure 5.7: Teachers' views on how well their profession prioritises colonisation

This data prompts questions about the significance of a relatively large proportion of teachers unconcerned with their profession's current level engagement with New Zealand's history of colonisation. Clearly, the question was a subjective one and some respondents were reluctant to cast a judgement on other school departments, citing a lack of evidence to do so.

Nevertheless, the views of survey respondents who stated that "few" or "very few" teachers give enough priority to topics or issues relevant to colonisation lends some support to the claim that many schools struggle to deal with this history in a robust fashion. In their large and multi-national study of teachers' sensitivity to historical issues, Goldberg and colleagues (2019) argue that "if a teacher feels their group is inadequately representing a sensitive issue this can lead to a duty to do or feel 'the right thing' when the community the individual identifies with fails to live up to the same standard" (p. 13). The $17 \%$ of teachers in this study who thought that 'few' or 'very few' departments sufficiently address colonisation may represent this category of teacher described by Goldberg et al (2019). For example, one teacher made the comment "I have worked in five schools across the province and found that colonisation and colonialism are not taught with rigour across any of them". The insight of teachers like this provides circumstantial, yet important evidence of a potentially broader problem in history education. 
The challenge of establishing the extent to which school departments prioritise colonisation is compounded further by the difficulties of assessing precisely what schools teach under a national curriculum framework with no mandated content. There is, however, consistent, albeit intermittent research-based evidence from a range of New Zealand sources showing a broad trend of avoidance or, at best, an unconscious tendency to disengage from contested histories of colonisation (see Chapter 2 and Harcourt, 2020 for a summary of this research). This research evidence, combined with the concerned views of nearly one in five teachers suggests that many teachers have an overly optimistic view of how deeply their profession prioritisies issues and topics regarding colonisation. Nevertheless, care needs to be taken when using data like this because teachers' views should not be seen as "a fixed disposition" (Goldberg et. al, 2019, p. 28). Instead, data about teachers' conceptions captured in a survey can help to "target an audience with specific needs and as a way to support what seem[s] to be a quite consensual commitment among teachers to tackle challenging topics" (p. 28). It is unlikely, for example, that teachers have easy access to some of the research that clearly shows aspects of New Zealand history being routinely sidelined. However, what appears to be an overly confident view of current curriculum decision-making by many teachers in the profession does create an obstacle to deeper engagement with the history of colonisation and suggests the need for more analysis over the kinds of history being taught within local school communities by the teaching profession.

\section{Conceptions about the challenges and complexities of teaching history in a settler society}

Teachers in New Zealand tend not to consider this country's history of colonisation a challenging subject to teach, a view that may on some counts lead to downplaying or overlooking the complexities of teaching history in a settler society. Half of the ten potential challenges given for teaching the history of colonisation were deemed as "not significant" by respondents (see Figure 5.8). This includes $84 \%$ of respondents who did not view a lack of support from senior colleagues as problematic and $78 \%$ of respondents who did not consider local community pressures posing any barriers to curriculum inclusion of New Zealand's history of colonisation. Of the challenges that were considered highly significant, a lack of student interest registered the most high with $19 \%$ of teachers considering this issue as 
'highly significant' (see Figure 5.8). ${ }^{32}$ No other challenge was rated as high, though a lack of resources (15\%) and a lack of access to iwi and hapū perspectives (12\%) also featured as significant challenges. These findings are supported by Goldberg's et al (2019) multi-national study that showed 'fear of superiors' and peers' reactions and sanctions were the teachers' smallest concerns" (p. 26). This study also shows that "sensitivity to pupils' feelings is most frequently the highest concern leading to hesitation to teach [difficult history]" (p. 21).

\section{Challenges when teaching the history of colonisation}

$$
(n=223)
$$

Students will be more successful in NCEA if they focus on non-NZ topics

The history of colonisation where I teach is very raw for local communities

Other topics have a higher priority

Senior colleagues are not supportive of it being taught

I do not have access to iwi and hapū who could help me

My school's community is not supportive of it being taught

It's a controversial topic
Students do not find the topic interesting

It's a controversial topic
Students do not find the topic interesting

My historical content knowledge needs development

The topic is under resourced
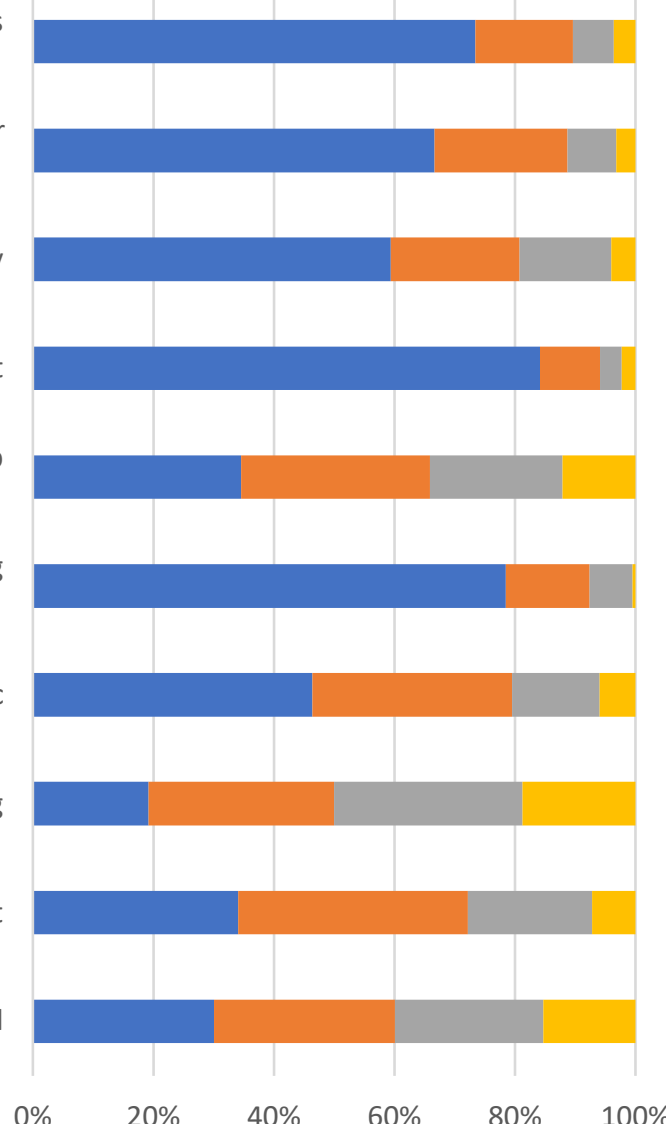

$100 \%$

— Not significant $\quad$ Slightly significant

@ Somewhat significant Highly significant

Figure 5.8: Teachers' views on the significance of particular challenges when teaching New Zealand's history of colonisation

${ }^{32}$ The likert scale in this survey question (Figure 5.8) was not worded in a way that elicited optimal responses from participants because the difference between "slightly" and "somewhat" significant is ambiguous. For this reason I have focussed here on the results from the "highly significant" end of the scale. 
Comments about student interest explicitly or implicitly noted Pākehā students and their reluctance to engage with the history of colonisation. For many teachers, these students' emotional reactions appear to present the greatest challenges to teaching the history of colonisation. For example, one teacher commented that

My students tend to come from very privileged backgrounds. They (and their parents) don't like to feel uncomfortable so they don't like to know negative impacts. They also tend to come in very opinionated about Maori issues being only Maori issues not NZ issues. I do tend to change most of these mindsets but it is an uphill battle at the beginning of the topic. There is also a general rallying against any NZ based topic they don't want to learn it again even though they haven't learnt it before. Often they think it will be boring.

Another teacher explained with a different response to the same issue that:

Students at my school have continually railed against New Zealand focussed history learning. They clearly see the outside world as exotic and interesting, and probably without the attached guilt or prejudice of New Zealand topics. Of course, I find this disappointing but I am obligated to respond to student needs.

A lack of student interest is clearly a legitimate concern and a common challenge faced by many teachers (see also Figure 5.9.2). Teachers' comments, however, overwhelming conceived of their students' emotional responses as a barrier, instead of a resource for working through the difficult aspects of the past.

Teachers also frequently located the source of their Pākehā students' racist attitudes within individuals, beliefs that were cultivated by family values (and for which little could therefore be done). As one teacher put it "when students' parents are bigots and that's what they've grown up with it's hard to teach them another way at looking at things". A number of scholars, however, discuss the pedagogical risks of treating racism as primarily located within individuals (DiAngelo, 2018; Sensoy \& DiAngelo, 2012; Wills, 2019). This tendency ignores the institutionalised and structural nature of white supremacy and makes it harder to develop pedagogical responses that move beyond a simple denouncement and 'calling out' of views unacceptable in civil society. Furthermore, teachers' focus on Pākehā students' emotional struggles - while an important and very real challenge - risks the centring of white students' emotions and the overriding concern to limit their feelings of discomfort, emotions which these young people likely need support from teachers to stay with, and make sense of 
(Applebaum, 2017; Leonardo \& Porter, 2010). It is also significant that no teacher commented on the emotional challenges of learning the history of colonisation faced by Māori students. A number of scholars, however, discuss the emotional struggle and discomfort that students of colour feel during lessons about their 'in-group', especially when these lessons highlight only their subjugation or victimhood (King, 2014; Traille, 2007; Webber \& O'Connor, 2019). Together, these conceptions of colonisation and the challenges of teaching this issue highlight potential barriers to critical engagement with the emotional dynamics that arise during history lessons, dynamics that may operate to sustain the operation of settler colonialism in the present.

Another challenge accorded little significance by teachers concerned the "rawness" or sensitive and painful nature of colonisation for local communities (Figure 5.8). Sixty seven percent of respondents did not think local sensitivities posed challenges to their teaching and $22 \%$ considered this only a 'slightly significant' challenge. Although it was not specified that "local communities" referred to Māori, the decades of Waitangi Tribunal reports and settlements that address the historical injustices of colonisation and the intergenerational trauma associated with the loss of land, language and culture nonetheless make this a surprising assessment. The Turanga a Kiwa (2004) Waitangi report, for example, highlights the ongoing frustrations felt by Māori communities:

While only one side remembers the suffering of the past, dialogue will always be difficult. One side commences the dialogue with anger and the other side has no idea why. Reconciliation cannot be achieved by this means. Thus, it seems no more than common sense that if stories such as those from Turanga were more widely known in the community, particularly local communities more directly affected, the need to heal the wounds of the past before moving forward would be better understood by all (p. 740).

Furthermore, Māori scholars frequently illustrate the painful histories of the places they write about (Buchanan, 2009; Keenan, 2008; Kidman et al., 2018; Williams, 2014). If teachers are struggling to recognise the curriculum challenges of working on Indigenous land it lends support to Manning's (2009) contention that many are not well connected to their local Māori communities and their histories and urgently require help to develop such relationships. To some degree, many teachers, who position it as the third most significant challenge they face when teaching histories of colonisation (see Figure 5.8), also recognise this lack of access to 
iwi and hapū.

\section{Teachers' conceptions and the issue of topic avoidance}

Some teachers were uncomfortable teaching histories of colonisation and appear to find it relatively easy to avoid. For example, a core group of teachers $(n=24)$ commented explicitly on their own, or some of their colleagues' ability to resist or avoid teaching about colonisation. One teacher explained, "there are entrenched negative views about avoiding New Zealand history in our senior school". Another commented simply that there is little New Zealand content in their school because "our school head of department is from the United Kingdom so avoids New Zealand content". One teacher explained the need for a more directive curriculum in their school:

We just don't do it at our school. We don't have the resources and it is not seen as a high priority. We are still teaching Middle Ages, China, Japan, Nazi Germany etc. If we are to teach New Zealand history there needs to be a clear directive from the government that this is to happen.

Another teacher explained their views on the impact of a non-prescriptive curriculum on the inclusion of certain content areas: "the absence of a prescriptive curriculum and decontextualized exam questions means that challenging issues are ignored, to the detriment of understanding this country's history". Others were either neutral or positive about the flexible nature of New Zealand's curriculum, but their views clearly illustrated how course content could mean New Zealand's history of colonisation did not feature in their curriculum. For example, one teacher explained that, "individual teachers can teach topics relevant to colonisation if they so choose" (my italics) and another wrote that "a strength of the NZ curriculum is its flexibility - so teachers are able to focus on this issue if they wish to" (my italics). The importance some teachers place on student choice also illustrates how some teachers (and their students) might avoid engaging with difficult histories of colonisation. One respondent explained that at their school "students vote on topics of their interest, so the student voice may (or may not) choose a colonisation-related topic in any given year". Another outlined, "I believe teaching colonisation is very important, at our school we, however, follow student interest and therefore sometimes more contemporary issues are chosen...therefore although colonisation and other important issues within NZ can be woven in, they are not always the sole purpose of the unit". One teachers' comment emphasised the low priority placed on the subject of colonisation in their school: 
It is difficult to slot it in. The students in my school have literacy problems and difficulty with critical thinking. The subject is too important to be taught superficially in the junior school and by the time NCEA kicks in students would rather learn what they consider to be "more sexy" topics. I have tried teaching Year 13 but students didn't enjoy it and their results reflected this.

This view also highlights how the subject of colonisation in some schools might at best find its way into the curriculum in the final years of an optional subject. Teacher avoidance of difficult history is by nature a 'slippery' topic to research and this data raises many more questions about the extent of avoidance, why difficult histories are addressed in some contexts and not others, and what kinds of interventions are most likely to support teachers to teach the "hard bits" (Keown, 1998) of the social sciences. Internationally, many studies have been conducted on teachers avoiding difficult and controversial histories and it is unsurprising to also find this a problem in New Zealand (Misco, 2018). Existing research from Manning (2009) and Kunowski (2005) provide two studies that document some teachers avoiding Māori history and the Treaty of Waitangi but relatively little is known empirically about the extent of the problem in New Zealand.

To conclude this section, the views expressed by many history and social studies teachers illustrate a solid baseline position from which teachers might respond to the denial and 'forgetting' of difficult history common to settler societies. There are, however, a range of perceptions that operate as potential barriers to such teaching. These barriers collectively help to reinforce 'colonial regimes of ignorance', or the constellations of structures, practices and actions that create and actively maintain an ignorance of certain difficult histories (Schaefli, Godlewska, \& Rose, 2018; Tomlins-Jahnke, 2019). Some of these barriers come into even sharper relief when students' conceptions of colonisation are unpacked.

\section{Students' conceptions}

\section{Views on the nature of colonisation, especially past/present relations}

Like teachers, most students in my survey recognised the close relationship between the colonial past and the "settler-colonial present" (Veracini, 2015). This is important because viewing colonization as a purely historical topic, a process or series of events completed sometime toward the end of the nineteenth century, makes it hard to recognise and respond to 
its "ever-present" and "resilient" nature (Smith, 2017, p. 91). To illustrate the relative commonality of this critical view, Figure 5.9 shows that $69 \%$ of students agreed or strongly agreed that "past conflict and violence between Māori and non-Māori still has an effect on life in New Zealand today" (see Question 9, Appendix 2). Nearly a third of students surveyed, however, did not recognise this fundamental historical relationship, underscoring some of the pedagogical complexities of teaching New Zealand's history of colonisation. I analysed the data from Figure 5.9 according to ethnicity, region and gender but it was by year level that highlighted a clear trend in students' conceptions of colonisation (see Figure 5.9.1). For example, there was a steady increase in the percentage of students between Year 9 to Year 13 who 'strongly agreed' with the existence of an historical relationship between the colonial past and the present. Nevertheless, it is a challenge for teachers that nearly a quarter of Year 13 history students report disagreeing or strongly disagreeing that important historical events in New Zealand's history of colonisation continue to have effects that reverberate in the present (Figure 5.9.1, Year 13).

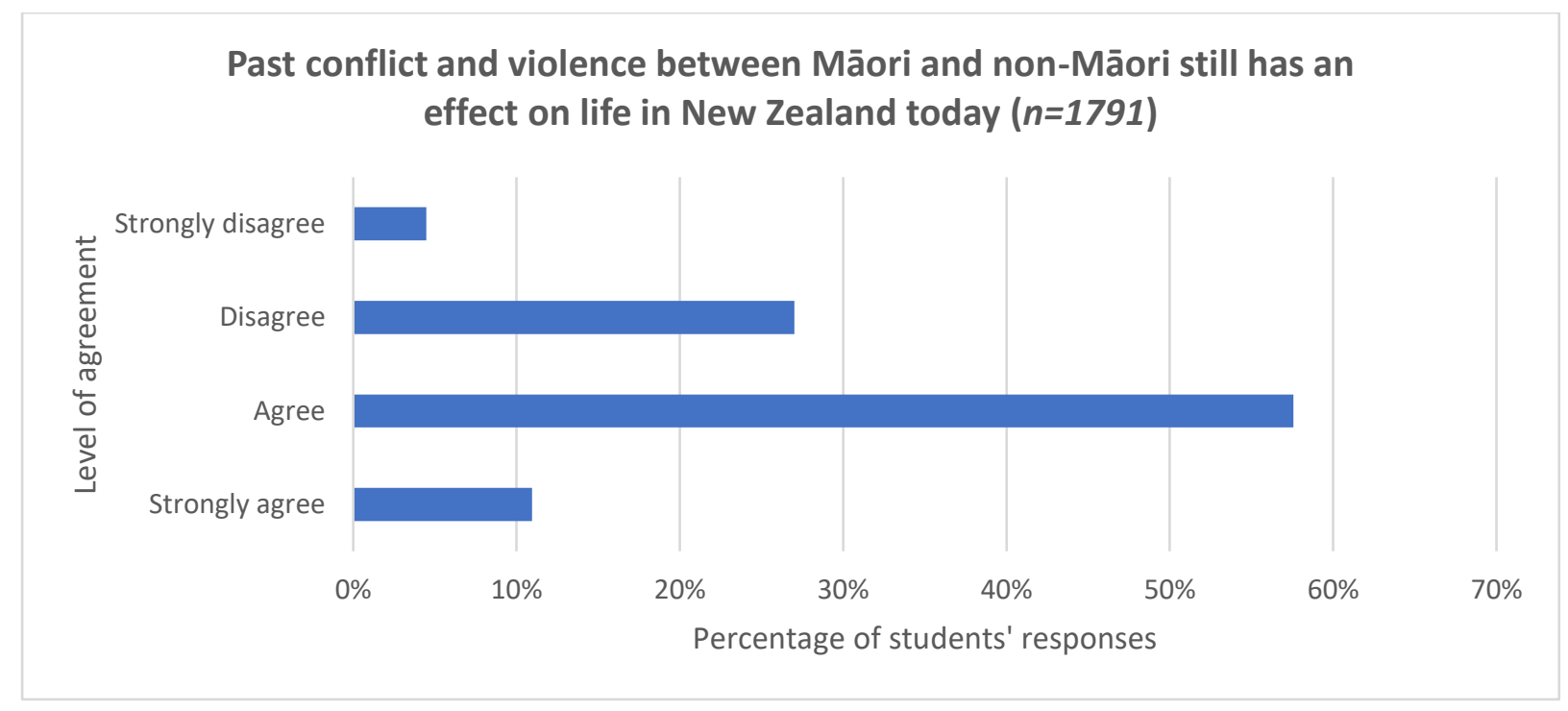

Figure 5.9: Students' responses to a question about the relationship between past conflict and the present 


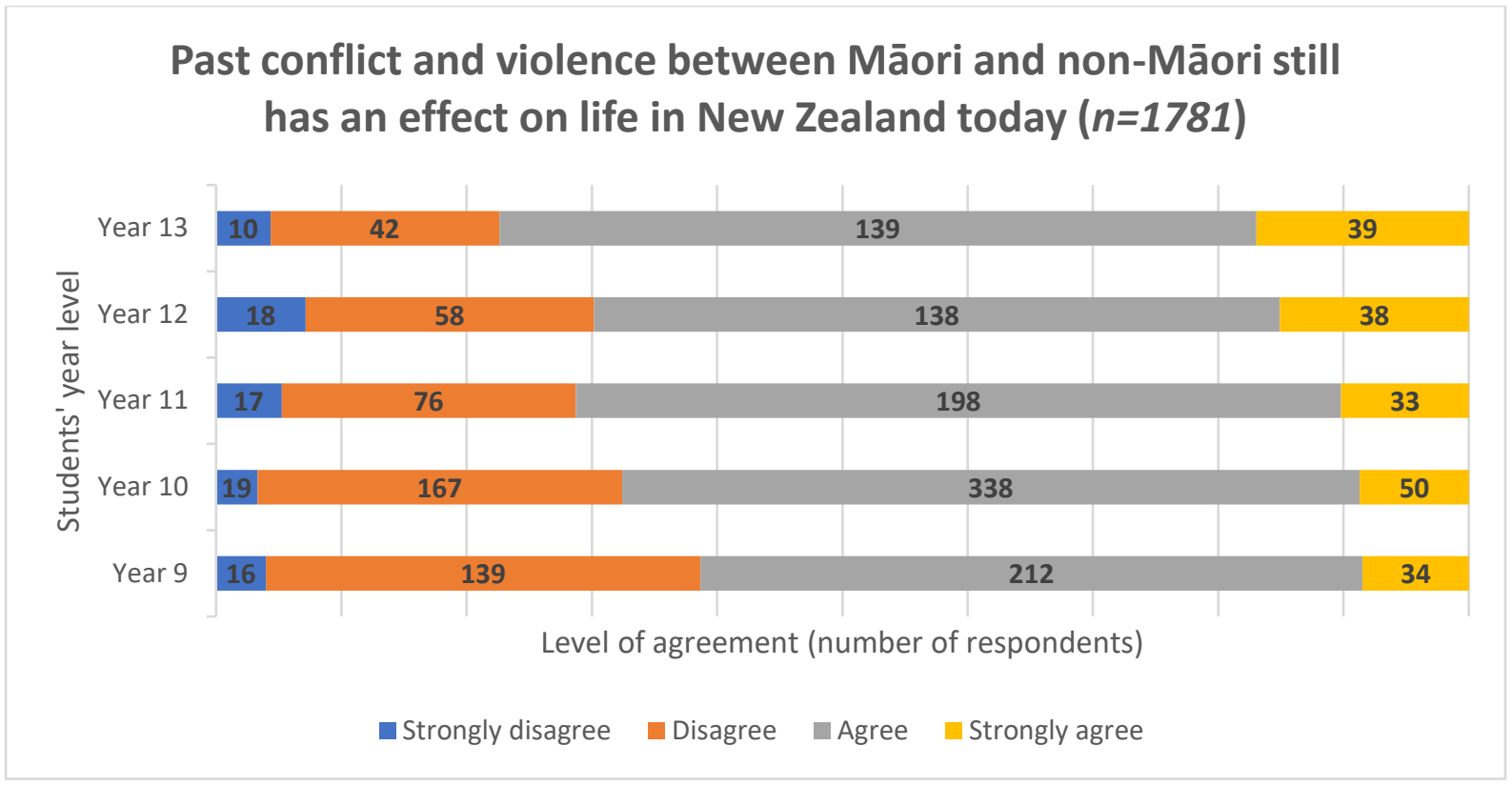

Figure 5.9.1: Students' views about the relationship between past conflict and violence and the present according to year level. ${ }^{33}$

Similar to teachers, students' comments provided a rich source of evidence that further helped to reveal how they conceptualised key aspects of colonisation. From the qualitative responses elicited from several survey questions (see Questions 9a,10a,11a, Appendix 2) the most dominant theme I coded regarded students' views on the existence of the relationship between the (colonial) past and present $(n=615)$ followed by those who did not recognise this relationship ( $n=249)$. A smaller, but nonetheless significant theme concerned students who explicitly regarded colonisation as a benign and beneficial historical process $(n=62)$.

The students who agreed that historical events continue to effect contemporary New Zealand society usually pointed to ongoing instances of racism and inequality as evidence $(n=258)$. For example, on numerous occasions students explained that historical legacies were evident in the fact that "people are still being racist". Many students described how Māori were the victims of personal insults, stereotypes, discrimination and slurs from Pākehā who "treat Māori like shit". One student explained that "in New Zealand society there is white supremacy, and white people that think that they are above Māori and do not acknowledge Māori culture”. Occasionally, Māori students gave specific examples from their own lives. To illustrate, one young person stated, “as a Māori I feel and hear it everywhere I go". Many

\footnotetext{
${ }^{33}$ The difference of 10 respondents between Figures 5.9 and 5.9.1 can be explained by some students who chose not to indicate their year level.
} 
students also described the structural forms of racism endured by Māori, which they connected to the historical context of colonisation. For example, one student wrote, "there is still a huge difference in wages and living conditions which could have been caused by the conflicts with Māori". Another explained, "it would be remiss to ignore the links between Māori's current socio-economic condition and the past conflicts and violence they were involved in". Others connected the history of colonisation to social issues such as alcoholism among youth, educational disengagement, domestic violence, Māori incarceration rates, homelessness, poverty and language loss. One student summarised this situation by stating, "the socio-economic problems that many Māori experience today can be traced back to colonialism and the theft of their land/livelihood".

For many students, the present connects to the violent past through the emotional burdens of the past carried by Māori today $(n=126)$. For example, students frequently claimed that Māori continue to be angry explaining that "people are still angry over what happened to their ancestors" and "Māori people can feel some sort of resentment as their land was taken from them unlawfully". Some students shifted the burden of reconciliation to Māori explaining that their inability to forgive Pākehā was how the past affects the present. For example, one student wrote, "a lot of Māori are yet to forgive the Pākehā for their ancestors' actions". Others emphasised the pain that Māori feel today due to certain historical events: "some Māori are still hurting from what the Pākehā did to them. It affected their ancestors and they are a part of them so it affects them too". Similarly, another student wrote that "some Māori people still feel the injustice that their ancestors felt when everything they owned/had was stolen by the British”. One student vividly illustrated this sense of pain and injustice: "I just want a moment to look at the Treaty. We were supposed to be partners, yet Māori were screwed over. Nowadays we are only given $1 \%$ of what we owned. RAUPATU! [confiscation]".34

Students recognized ongoing inter-ethnic tensions as legacies from the past and frequently referred to what some referred to as the "still present" and "underlying" tensions between Māori and Pākehā New Zealanders (n=117). One student explained, "there is still a split and a difference of treatment between the races" and another stated that "there is still conflict

\footnotetext{
${ }^{34}$ Raupatu is most commonly translated as confiscation and refers to large tracts of land taken from some iwi primarily during the period of conflict known as the New Zealand Wars (see Chapter 7).
} 
between Māori and non-Māori even if it is less easy to see on the surface". Students often attributed these tensions to ongoing struggles over land rights and protests over the meaning and significance of the Treaty of Waitangi. To illustrate, one student commented, "there are still some conflicts between the Māori and non-Māori about the land" and another, "there is still some sort of racial conflict between them. Land rights, river rights still are a big issue in New Zealand and that's because of the past wars we had with each other". Others pointed to protests they saw on the news on Waitangi Day. Many students saw tensions between Māori and non-Māori manifest in lingering resentment and grievances over historical events.

Reflecting this notion, one student wrote, "grudges are held and people despise Maoris because of past conflicts between each other" and another that "both sides still hold grudges over one another, there are still disagreements about ownership of land and such. Stories are still told of the atrocities caused by both Māori and non-Māori.” Not all students, however, saw land issues as a cause for inter-ethnic tension. A significant group of respondents $(n=89)$ named in more neutral (and mostly less descriptive) ways the nation's attempt at reconciliation and the settlement of historical grievances.

A minority of students expressed the view that that New Zealand's inability to "move on" from the past was evidence that history continues to effect the present $(n=25)$. One student explained that the past effects only those "who can't put it behind them". It was exclusively Māori who were subjects of this critique and Māori were accused variously of "hanging on to the past", "continuing to cry about the past" or "having a harder time moving on from what happened to their ancestors". One student explained, "I am not affected by [the past]. It is not because I am Pākehā but it is because the Pākehā have settled their sides of things. It is the Māori who keep going on about it and whining”.

As illustrated in the data from Figures 5.9 and 5.9.1, a significant proportion of students did not recognize that past conflict and violence between Māori and non-Māori still has an effect on life in New Zealand today $(n=249)$. These views reinforce the hegemony of settler society through their denial of New Zealand's origins in the "invasion and expropriation of Māori land and culture" (Kidman, 2018, p. 104). The biggest group of students in this category justified this position due to their understanding that New Zealand society is harmonious with no real intercultural tensions or inequality $(n=155)$. These students made statements such as “today no one really cares if you are Pākehā or Māori” and that "the past has nothing to do 
with relationships today". One person claimed, "New Zealand has done a great job of making Māori and Pākehā equals". Some claimed that because they had not observed racial discrimination taking place, it therefore did not occur, leading them to conclude further that the colonial past had no impact on the present. For these students, New Zealand was a country where "Māori and non-Māori have the same opportunities. I don't think Māori people are under too much pressure". Students also regularly asserted some variation of "we all live in peace' with one Pākehā student claiming: "There are only a handful of Māori left in New Zealand who want independence and believe they have been wrongly treated. The rest of the Māori in New Zealand happily work alongside us."

In addition to the belief that New Zealand's 'harmonious' and 'equal-opportunities' society is reason to discount any past/present relationship, one group of students $(n=66)$ tried to contain colonisation in the past, arguing that its distance from the present discounted any connection to contemporary life. For example, one student explained that, "we recognise it as a significant event in the past, and the key word here is past. It is too long ago to have full relevance in today's society." Another group of students $(n=28)$ either could not recognise or did not want to recognise a relationship between the colonial past and New Zealand because they thought New Zealand had "forgotten" or "moved on". To illustrate, one student explained that they disagreed that past conflict affected contemporary New Zealand society, "because I think we have decided to put the past behind us and move on to the future". One European student claimed that "I disagree [that the history of violence and conflict are connected to the present] because we Europeans try to live and forget what we did in the past. We/I prefer to live the present day not the past". Another student thought that, "in today's society no one appears to be fazed by the war. This is over to this all being in the past".

In addition to a significant number of students struggling to recognise the relationship between past and present, a small group of students $(n=62)$ characterised colonisation in New Zealand as benign, beneficial, and/or inevitable, therefore justifying any negative consequences for Māori. One student explained:

Britain did this to everyone. In fact, the colonisation of New Zealand was one of the least hostile committed. New Zealand is where it is today because of this. So I believe this to be necessary. Also, why are people so angered by colonisation in the present time. It has happened forever. 
Another wrote simply: "Invasion. It's how the world works" and another explained that "New Zealand would have been colonised anyway so war was inevitable”. Expressing a similarly inevitable understanding of history, yet another student explained that:

The British found another small country and decided they wanted to make themselves the majority. It's the history of the world. White man come to country, white man ends up on top.

These students also believed that colonisation may have had some harsh side effects for Māori but ultimately it created the modern and economically prosperous state of New Zealand. For example, one student claimed that the alienation of Māori land meant:

Land was now shared between settlers as settlers came to create industries in New Zealand and an economy as they would trade our resources, bring religion and technology, making New Zealand a more civilised country.

Some students acknowledged the negative impact on Māori of colonisation but nevertheless promoted colonisation as ultimately beneficial. For example, "it's sad that the Māori lost things, but we wouldn't have what we have now if that didn't happen" and "the anger of the Māori can be understood, however, the seizure of land - although handled incorrectly by the colonizers - was necessary in expanding an empire and building a new nation”. Others did not make any attempt to consider the negative consequences of colonisation for Māori:

The 'finders-keepers' mind-set that has plagued the Māori for the past 200 years has only clouded their vision. The fact remains that conquest and colonisation were a large part of our history and have forged the society we live in today.

\section{Students' receptivity to learning New Zealand's history of colonisation}

In contrast to some of the views expressed by students above, overall most survey respondents report being receptive to learning difficult histories of colonisation. Students were asked to indicate the statement that "best describes your personal feelings about learning New Zealand's history of colonisation" and were given nine descriptive terms to choose from (see Question 14, Appendix 2). Figure 5.9.2 compares the top six most frequently chosen descriptors for Māori and non-Māori students. ${ }^{35}$ It shows that for all

\footnotetext{
35 The other three descriptors included 'exciting' $(n=16)$, 'uncomfortable' $(n=27)$ and 'disturbing' $(n=26)$. The totals given in both figures on the following page include these numbers but exclude those who indicated 'other' $(n=160)$. This latter group tended to voice comments such as 'boring and interesting' and did not reveal any other significant adjectives. The total between these figures is slightly different due to some students not providing complete biographic information.
} 
students, New Zealand's history of colonisation was most often considered 'interesting'. Māori students, however, are more likely to interpret learning the history of colonisation as 'important' or 'meaningful' and were less likely to consider it 'boring' or 'meaningless' than their non-Māori classmates. These attitudes are not significantly different according to year level and Figure 5.9.3 is striking for the uniformity in students' conceptions over the course of five different year levels. Unlike Figure 5.9.1, which showed some progressive changes according to year level in students recognising the effects of the past on the present, it appears that students' views on the personal value of learning New Zealand's history of colonisation are more static, varying little over five years of secondary schooling.

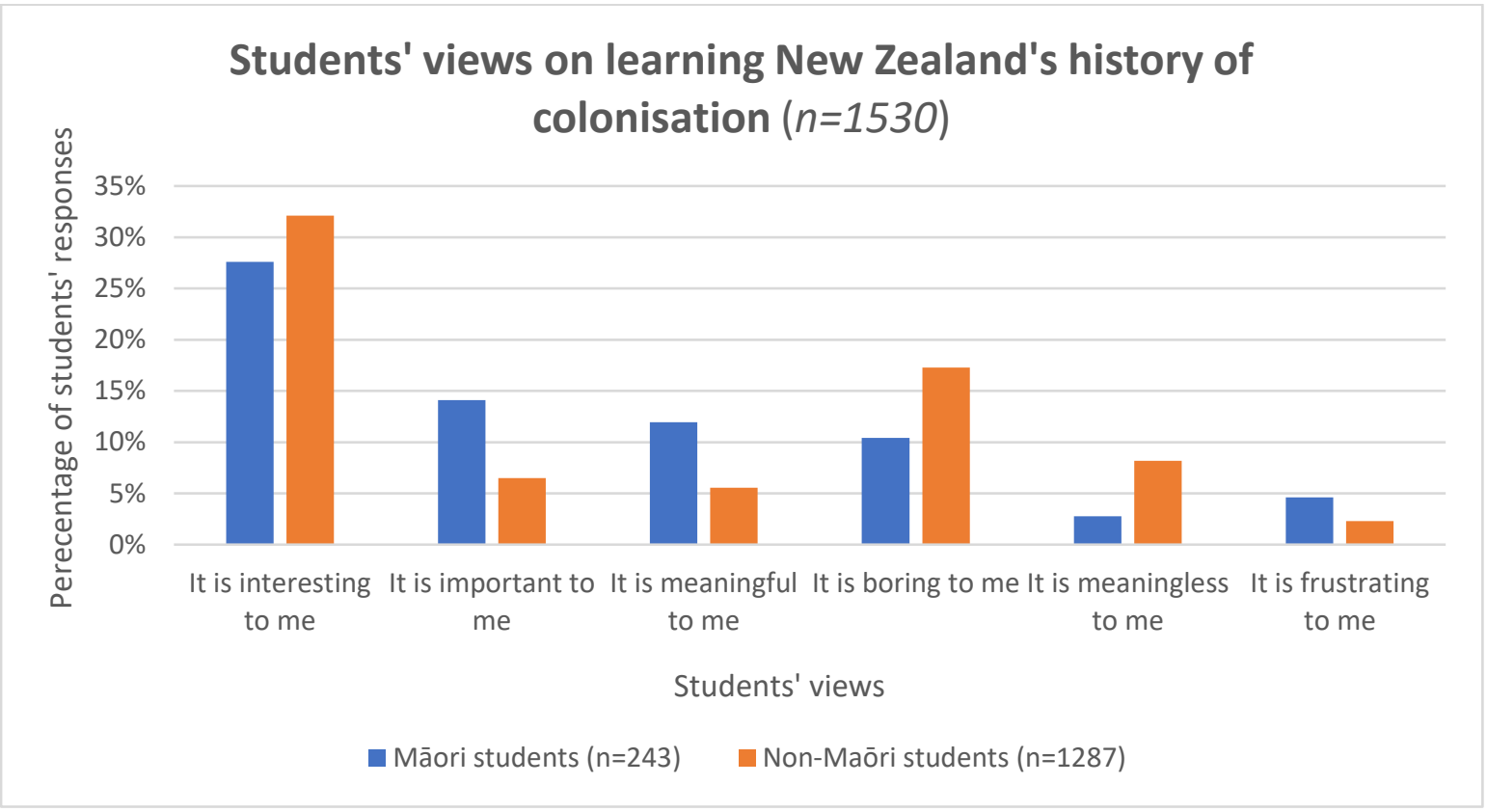

Figure 5.9.2: Māori and non-Māori students' views on learning New Zealand's history of colonisation. 


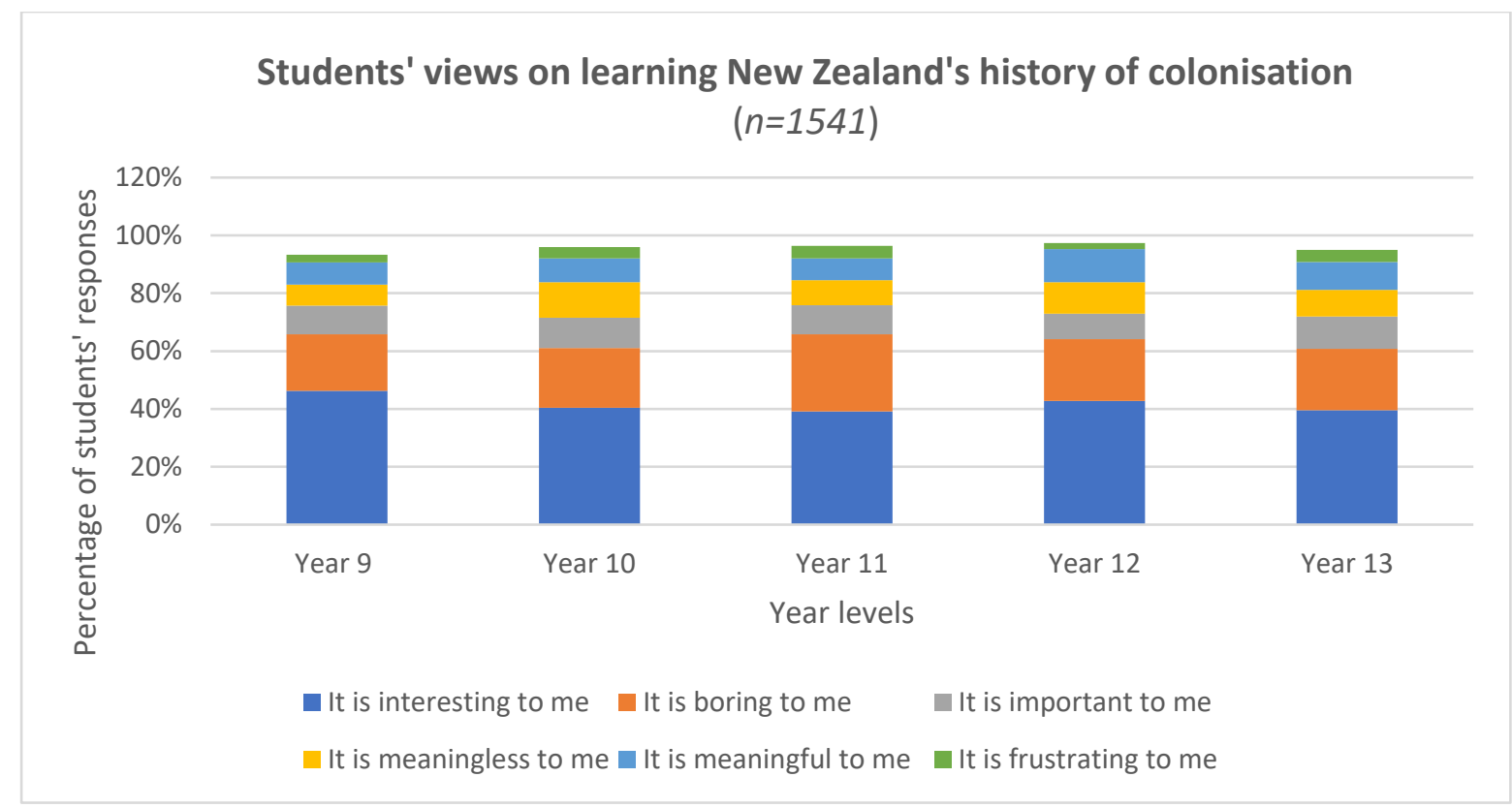

Figure 5.9.3: Views about learning New Zealand's history of colonisation according to year level.

For the remainder of this section, I draw on students' survey comments to outline in greater detail the nature of students' receptivity (or lack of it) to learning New Zealand's history of colonisation. The data is drawn from select survey questions and arranged according to two broad categories of response: First, students' openness and/or rejection concerning this history and second, the opportunities and risks students perceived arising from this learning. The former category of responses draw from an analysis of comments elicited by the survey question describing students' personal opinions about learning New Zealand's history of colonisation (see Figures 5.9.2 \& 5.9.3). The latter category of responses draws from my analysis of comments elicited from a survey question about the effects of learning about colonisation on inter-group relations (see Question 10, Appendix 2) and the responses generated from a piece of stimulus text describing the impacts of the Waikato invasion on Māori (see Questions 7a and 8a, Appendix 2). Within these broad categories I present findings which collectively paint a picture of students' receptivity to learning New Zealand's history of colonisation.

\section{Openness and rejection to learning New Zealand's history of colonisation}

\section{Openness}

Most students $(n=496)$ expressed views that suggest an openness to learning New Zealand's history of colonisation. Their reasons for this openness varied but most commonly they could 
establish a personal connection to their ancestors or had feelings of attachment to the place and nation of New Zealand ( $n=241)$. Those who connected to their ancestors were overwhelmingly Māori and made comments such as "I am Māori and it is important to know what happened to my people". One student commented on the usefulness of historical knowledge to take action in the present: "As a Māori it helps me take action and understand more about the present". Others simply wrote comments like "I want to learn more about my tipuna [ancestors]". Occasionally, Māori students highlighted the significance of learning more about their ancestors' agency in the face of colonial domination. One Māori student was particularly clear that this is what he wanted to gain from his history lessons:

[The history of colonisation] is important for me to know due to how almost every single Māori person in the country struggled and defended themselves in that time due to the pressure and pain the European settlers did to them so I find this important to me.

Many students were open to learning New Zealand's history of colonisation because they considered it important to understand, connect with and know about the country they called home. Students explained that "I live in this country and I think its really important to know about its past" and "when you live somewhere you should learn how you are living there". One person explained that

I want to learn as much as possible about the history of our land because it's something that we should cherish. The good and the bad and learning about it can do that. It's a lot more special than learning about something from Europe or China etc. Some young people not originally from New Zealand also commented that learning the history of colonisation was an important aspect of living in their adopted country. For example, one student explained "I am from the UK and it is interesting to learn about the history of another country" and another "I'm new here so I want to know some New Zealand history". In addition to the obligations of knowing about one's own country, many students saw learning New Zealand's history as an important feature of what it meant to be a New Zealander. One frequent response was "we should all know about New Zealand history", or it "is the history of our country". Others saw significance in learning about "the history of my nation and the coming together of two peoples".

Many students were open to learning New Zealand history because they thought it was important to know how their country had led to the present and where it might be leading 
society in the future $(n=114)$. Some students considered this important in order for them to understand the progress New Zealand had made. For example, "people can see how badly [Māori] were treated in the past and can see how far we have come to today" and "I think it is important to learn about this so everyone can know how far New Zealand has come”. Others were more interested in the historical processes that have led to New Zealand being what it is today. For example, "it is interesting how a nation that is now prospering and peaceful had such a rough history filled with bloodshed" and another commented that, "it's interesting to learn how New Zealand became New Zealand, after colonist occupation". A common response was simply "I like learning about how our country was made to be how it is today". A handful of students were open to learning New Zealand's history of colonisation because it "gives us insight into attitudes and issues nowadays" and "because the problems are essentially ongoing".

A smaller group of students $(n=87)$ also explained their openness to learning New Zealand's history of colonisation in terms of gaining new knowledge and many young people saw this knowledge as intrinsically beneficial; they liked history, they liked learning, and therefore colonisation provided no barrier to the enjoyment of their history or social studies lessons. Others were more specific and explained that they had not learnt this material before and wanted to be more knowledgeable. One student wrote, "because I have never learnt about it before and if I do I may be able to understand more about New Zealand". Only a very small group of students $(n=14)$ reported being open to learning New Zealand's history because they believed it gave them a chance to act in the present.

\section{Rejection}

Approximately a quarter of survey respondents also stated they did not want to learn New Zealand's history of colonisation $(n=303)$. Inversely to the previous section, the reasons most commonly cited in this group were a failure to establish a personal connection to the topic $(n=135)$. Many students characterized this lack of connection in terms of indifference. One young person explained simply "it bores me" and another that "New Zealand history is duller than ditchwater". Others did not connect personally because they could not identify with the historical groups involved and this was especially the case for Asian students. One student commented, "I was born in Japan, and we have immigrated over. I don't feel any connection toward the Māori people, and likewise, don't feel concerned about the history of New 
Zealand". Another wrote, "as an Asian who has migrated from a far away country I feel that this history of colonisation is not important to me". One student claimed that New Zealand's history of colonisation was not something he connected with because "I'm Indian and we weren't as involved in European colonisation". Some students of European descent also struggled to see themselves in New Zealand history, which affected their beliefs about the value of learning this history. For example, an Australian student explained, "because being an Australian I had nothing to do with this" and another, "I have next to no heritage that relates to this event. Most of my background comes from Scotland, the Netherlands and a tad England".

Students also rejected learning New Zealand's history of colonisation due to a belief they had already done so $(n=69)$. Some students reflected thoughtfully on their schooling experiences and even gave advice on how to avoid turning students off history through overexposure to the same material. Mostly, students were less forgiving. In this vein, they made comments such as "because we learn about it throughout our whole entire school years and it gets boring, I'd rather sit in the cold and rain" or "it has been beaten to death throughout schooling". Another student explained that "I have been taught the same thing like 100000000000 times!"

Some students reject learning New Zealand's history of colonisation because they do not consider it historically significant $(n=57)$. Students in this category often claimed that New Zealand was unimportant compared to more interesting international contexts and they commented that "other countries have a lot more deep and interesting history" and "New Zealand history is bland to me compared to other countries' history". Others determined historical significance by its 'scale of impact' making claims like "I was hoping to learn about topics that affected the entire world and that had a large impact on society and in history" or "yes tragedy did happen but bigger things have happened that effected the whole world not just one tiny minority". Some students thought New Zealand history was too short to warrant learning about: "New Zealand has not existed for long enough to establish its own rich history" or that the past was too distant: "Because it was so long ago and doesn't affect how I live now and its really just a boring topic". 


\section{Opportunities and risks when learning New Zealand's history of colonisation}

\section{Opportunities}

Of the students who commented on the opportunities or risks, most saw opportunities in learning New Zealand's history of violence and conflict $(n=374)$. Frequently students saw these opportunities emerging from increased inter-cultural understanding between Māori and non-Māori $(n=208)$. For many this could not happen if New Zealanders remained historically ignorant, or as one student put it, "to not learn [about colonisation] would be like erasing it, and unjustly ignoring the injustices that are occurring against Māori”. A number of students thought that learning history helped New Zealanders to appreciate the extent of the historical injustices that Māori had endured and why Māori continue to struggle against Pākehā domination. One student, for example, explained "talking about the issue allows for the Māori peoples' hardship to be recognised" and another:

We need to know the history of this country and the injustice that was done and how badly Māori were treated. If people understand what happened maybe they would realise why Māori continue to fight. It would benefit the whole of the New Zealand population.

Others commented that historical knowledge can help people understand that past actions were not the fault of those in the present. In this vein, one young person explained "it makes us realise that we're not the ones responsible, our ancestors are" and another that "it is encouraging people to acknowledge the past but not blame any modern group and rather look to a positive future". A handful of responses explicitly acknowledged contemporary inequalities in New Zealand society. These students attributed this inequality to historical conflicts and described how history gave society the tools and perspectives needed to act. For example, one student stated "it is important to learn about the history of your country in order to understand the problems that are still occurring today". A much more common response from students highlighted the lessons that history allowed us to draw in the present. However, students tended to explain their position in clichéd terms using variations of the phrase 'those who ignore the past are doomed to repeat it'.

For a number of primarily non-Māori students, learning New Zealand's history of colonisation provided them with an opportunity to empathise with Māori $(n=123)$. One student, clearly not Māori, explained "it is sad for us as we realise how poorly they were treated as we robbed them of all their resources and land, until they practically had none". 
Another commented that "I understand why Māori are angry and can sympathize with them". Most comments expressed their empathy as a passive kind of sadness or pity that Māori had been negatively affected by colonisation. For example, "it's sad they lost their land" or “terrible for Maoris to lose land”. On rare occasions, students' empathy for Māori would include a desire to make a difference to society today. For example, "when we hear about what we did to the Māori we want to help them so we get closer together" and "it makes people realise how unfairly the Māori were treated and may cause people to actually be on the side of the Māori because of what the British did".

A small number of students $(n=26)$ thought Pākehā would be the particular beneficiaries of learning New Zealand's internal history of war and conflict. These students often responded in personal terms, collectively identifying as descendants of European colonists:

I think that this makes people realise that what happened wasn't acceptable and we should try to change for the better and be accepting of the Māori and their culture as they were here before us and are a big part of New Zealand. Not only that but they should have the same rights as we do.

Others thought that historical knowledge would encourage Pākehā to act in the present in response to historical injustices: "for descendants from Britain, it makes them want to do something in order to hopefully right their ancestors wrong".

\section{Risks}

In contrast to the perspectives above, a number of young people saw risks in learning New Zealand's history of injustice $(n=173)$. Students generally thought that learning these difficult histories threatened their classroom learning environment and inter-ethnic relations beyond the classroom $(n=124)$. For the classroom, students often talked about the risk of enflaming racial tensions: "Racial tensions that are rife in our current political atmosphere mean that the teaching of this hugely controversial issue is likely to inflame tensions and exacerbate current divides". Another student thought

There are sometimes conflicts because some people are very opinionated about certain topics and find it a sensitive subject. This does cause some conflict as peoples' views are not always the same and if you defend your view that is not held by lots of the class, it turns quite awkward. 
Despite these comments, nearly $50 \%$ of students believe that colonisation 'almost never' causes disagreement in class (Figure 5.9.4). In contrast, $31 \%$ of teachers claim that colonisation is 'almost never' controversial (Figure 5.9.5). Overall, teachers tended to perceive colonisation as more controversial than students.

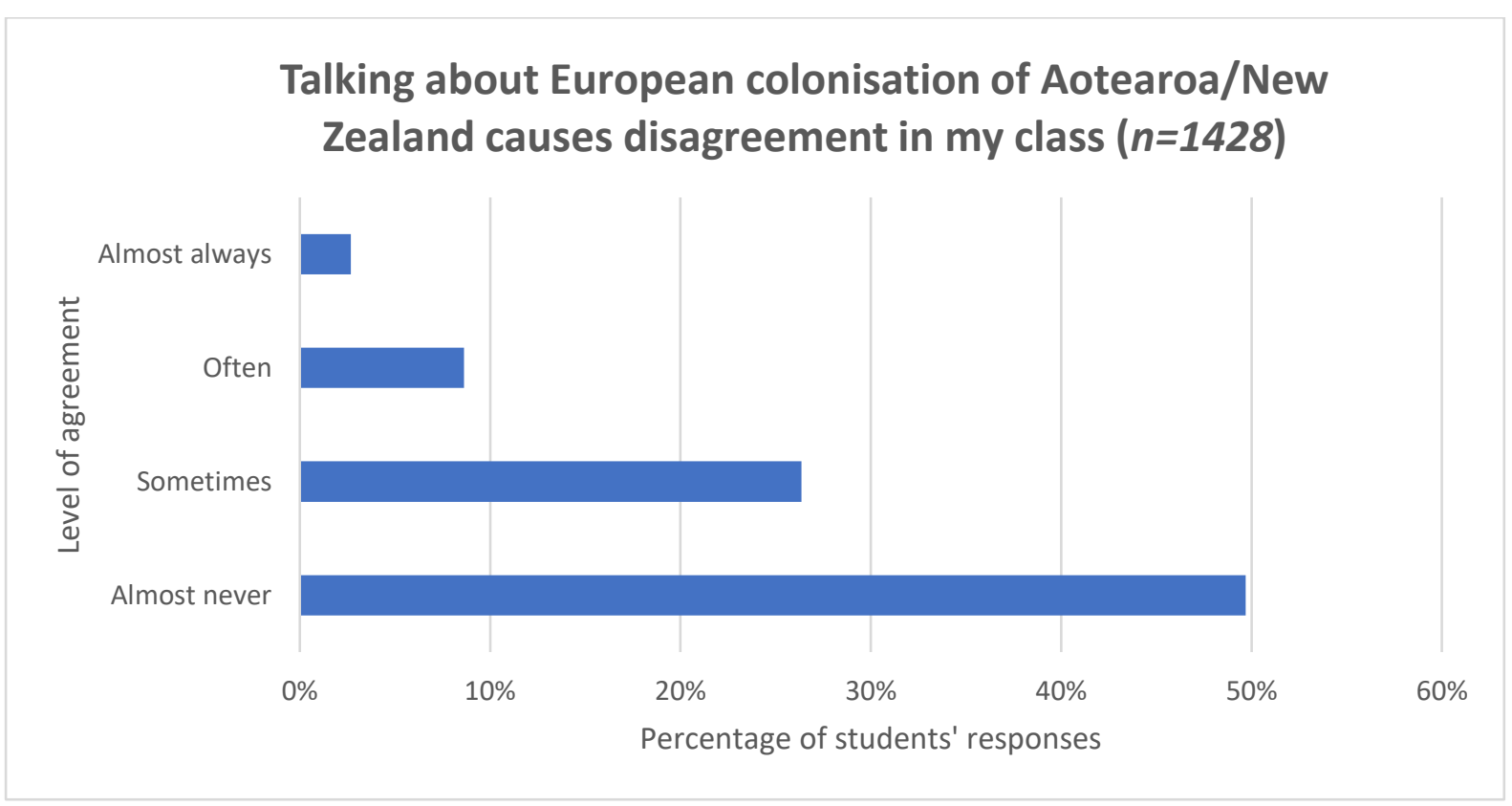

Figure 5.9.4: Students' views on the controversial nature of colonisation. ${ }^{36}$

${ }^{36}$ The total percentage does not add to $100 \%$ because some students left the question blank. Furthermore, due to an error, the likert sclae used for two schools who completed a paper copy of this survey was different to the digital version. For this question, these schools were excluded from this graph. 


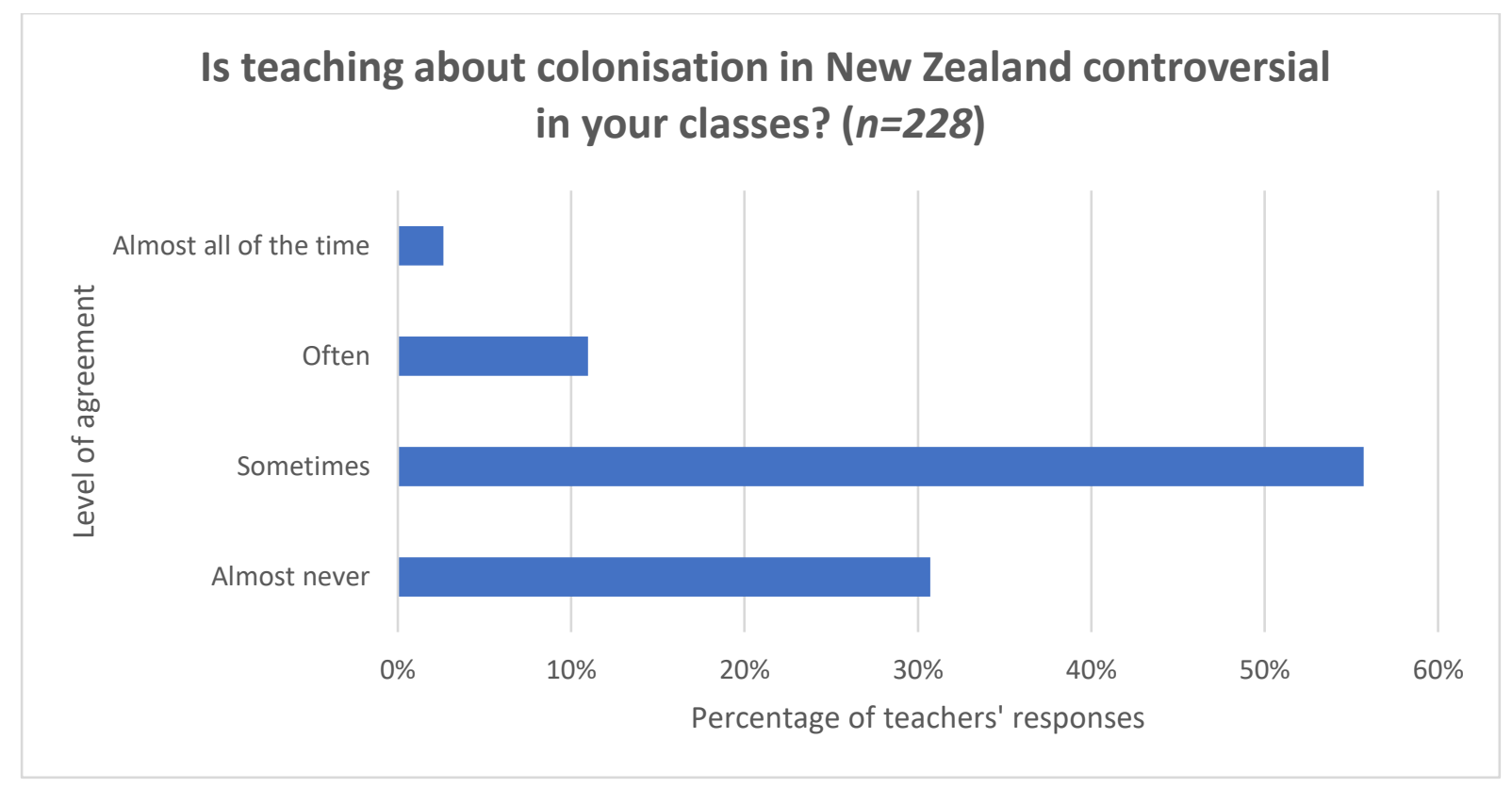

Figure 5.9.5: Teachers' views on the controversial nature of colonisation

Students mostly commented on the risks of learning the history of past conflict in general ways that did not specifically mention the classroom. Sometimes they explicitly named the value of historical ignorance:

If nobody knew what had happened in the past then there would be little or no problem because the Māori would not know they had been mistreated and the nonMāori people would not know that they had mistreated the Māori.

Students often described the consequences of learning histories of colonial violence for its ability to "polarize people", "fuel tensions", "make it harder to get along" and "bring back the feelings of resentment and anger". One student thought it was risky learning this content "because non-Māori have done a lot of nasty things to Māori people". Several students used the metaphor of a 'wound' explaining that learning histories of violence reopens "historical wounds". One student simply argued "I think we should just forget about this stuff".

In addition to students believing that New Zealand's history of colonisation threatened classroom situations and society in general, a small proportion of students considered it especially dangerous for Pākehā $(n=34)$. For these students, learning difficult histories of war and conflict could lead Pākehā to experience guilt about the actions of their ancestors, a situation they saw as unfair. More frequently, students saw danger in Māori students becoming angry or resentful and directing this anger toward Pākehā today. One student 
explained that learning history "makes Māori hate white people" and another that "Māori will view white people as invaders and evil when all we did was improve the damn country". Another student insightfully explained that history education in New Zealand was unfairly political making non-Māori feel empathy toward Māori:

A lot of learning I've done in class about the colonialism of New Zealand has been me learning about the opinion of why the colonialists were objectively the bad side and why they're horrible and I should feel guilt and support modern day efforts for reparation, and not leaving enough space for people to learn everything that happened and leaving them to form their own opinion. If people learned more of what happened and less of how they should feel about it there would be less distrust over the issue. A much smaller group of students saw danger in learning the history of historical injustice explicitly for Māori students. These students saw a greater risk of Māori being judged by their peers, or that Māori would experiences emotions of betrayal, sadness and anger. One student thought historical understanding might make it harder for Māori to trust their nonMāori peers. No students commented on the potentially traumatic effects on Māori of learning about colonisation although one student wrote, "for many people the history between the Māori and the colonisers is still very fresh in their family's history".

\section{Summary}

In the first section of this chapter I argued that teachers overwhelmingly expressed views that resonate with my definition of critical and transformative history education, as outlined in Chapter 1. However, three issues evident from teachers' responses make it harder for history education to operate as a means for challenging the ongoing nature of settler colonialism. Namely, overly optimistic conceptions about the profession's prioritisation of certain historical contexts, a tendency to downplay or overlook some of the challenges associated with teaching difficult history in a settler society and finally the issue of topic avoidance by some in the profession. My reason for highlighting these obstacles is due to a firm belief that educational research has little use if it does not lead to better teaching. Laying out some of the tensions, silences, assumptions, contradictions and opportunities within teachers' conceptions can progress important conversations and debates about curriculum. 
In the second half of this chapter, I explored how students conceptualised the subject of colonisation. Although many students demonstrate critical views on colonisation, a large percentage also struggle to recognise the structural, ongoing nature of colonisation and some see colonisation as beneficial and justified. Overall though, most students are receptive to learning about the issue of colonisation and express a range of complex positions on the matter. When young people reject wanting to learn about this historical process and see risks in doing so, their views illuminate pathways toward more powerful teaching of history and social studies. For example, students who reject New Zealand's history of colonisation because they feel it does not connect personally to them, need lessons that deliberately cultivate this connection. Similarly, students disengaged from events such as the New Zealand Wars because they do not see their own nation's history as historically significant, need lessons that highlight how these events are part of a global story of Indigenous resistance to imperial domination.

The complexity of all participants' survey responses vividly illustrates the challenges of teaching and learning history and social studies in a settler society. But survey responses, as explained already, are fleeting accounts that provide only a small window into the lives of participants. In the following chapter I draw from my ethnographic fieldwork to explore in greater depth the challenges and opportunities presented to four exemplary teachers and their students in schools at different sites across New Zealand. 


\section{CHAPTER 6: TEACHERS AND THEIR STUDENTS NAVIGATE THE COMPLEXITIES OF NEW ZEALAND'S HISTORY OF COLONISATION}

We need to develop an ability to be in relation with other ontologies rather than to be in charge Avril Bell (2017, p. 20).

\section{Overview}

In settler societies teachers are increasingly being asked to incorporate Indigenous knowledge, perspectives and histories into their curriculum (Dion, 2007; Harrison \& Greenfield, 2011; Tupper, 2011). This presents a range of pedagogical challenges for teachers in countries such as New Zealand, who for the most part, do not have expertise in Indigenous languages and may have had little formal training in Indigenous history. Historian Judith Binney (2001) describes some of the challenges presented to historians working in similarly cross-cultural contexts. In her writing she refers to a "bihistorical past" (2009) explaining that:

If a society that evolved from a divided past attempts to become bicultural in its later reconstruction - as Aotearoa New Zealand seeks to do - its historians must also become consciously 'bihistorical'. This involves recognising not simply that there are 'alternative accounts of the same events, but alternative cultural codes which give conflicting accounts of what authority is'. This perception requires historians to mediate between radically different perceptions - and experiences - in history ( $\mathrm{p}$. viii). ${ }^{37}$

The notion of 'becoming bihistorical' is an approach useful for considering how teachers might imagine history education's contribution to the broader goals of cognitive justice (see Chapter 3). 'Bihistorical teaching', which might be defined as the pedagogical recognition of diverse knowledge systems, is not a concept widely discussed among history and social studies educators. Consequently, its implications for pedagogy have not been extensively developed.

\footnotetext{
${ }^{37}$ Binney's reference to 'alternative accounts of the same event' is taken from J.G.A Pocock's book The Discovery of Islands: Essays in British History, Cambridge, 2005, pp.231,243.
} 
To extend this thinking, in this chapter I use Santos' (2014) notion of cognitive justice as the broad framework for examining the particular complexities presented to four teachers and their students $(n=48)$ during lessons on colonisation. Cognitive justice, as outlined in Chapter 3 , seeks to challenge the dominance of western ways of knowing that help to maintain contemporary systems of power (Andreotti, 2011; Mignolo, 2007; Santos, 2014; Smith, 1999a; Zembylas, 2017a). As I also outlined in Chapter 4, the methods employed for this part of the study included classroom observations, interviews with teachers and students and attendance at field trips. In the first section of this chapter, I describe three distinct pedagogical complexities that affected teachers' ability to "engage with the coexistence of multiple bodies of knowledge and ontologies" (Bell, 2017, p. 19). In navigating these challenges, teachers opened pathways to theorising in more concrete terms what teaching history for cognitive justice might look like. Unsurprisingly, the manner in which these pathways were opened varied as each teacher worked within the constraints of their particular contexts.

In the second section of the chapter, I describe students' enthusiasm to learn difficult histories of colonisation, and I explain a range of complex features that hindered their genuine desire to do so. These features included students (initially) wanting to resist history lessons about colonisation, Pākehā students grappling with feelings of "white guilt" (Gachago, Bozalek, \& Ng'ambi, 2018) and all students speaking of their limited historical understanding prior to their senior history classes. Collectively, these obstacles made it more challenging for students to engage deeply with the past, especially in ways that acknowledged diverse epistemological positions. Before beginning the main section of these findings, I first outline the socio-political situation of history curriculum in New Zealand. By doing this, the complexities encountered by teachers and their students are placed within a broader context, aiding their explanation.

\section{The socio-political context of history curriculum in New Zealand today}

As outlined in Chapter 1, history teachers in New Zealand operate within an outcomes-based, 'high autonomy' curriculum framework, which gives them considerable license over what content to include in their programmes. The shift to a national curriculum framework, one which prioritises generic competencies and skills over the specification of content knowledge was part of a global pattern of neoliberal policy that significantly influenced the development 
of curriculum in New Zealand in the early 2000s (Priestley \& Sinnema, 2014). This policy resulted in a single curriculum document front-ended by broad statements of intent for education and a range of 'key competencies' that are developed through the vehicle of traditional subjects, clustered under seven 'learning areas'. In contrast to a more prescriptive syllabus, the New Zealand Curriculum (Ministry of Education, 2007) gave teachers little direction about what to teach, particularly in history and social studies.

These global changes in education toward curriculum frameworks and generic competencies remain highly contested. For some they led to an overemphasis on 'social knowledge' and the demotion of 'powerful knowledge' (Rata, 2012; Wheelahan, 2010; Young \& Lambert, 2014). The latter, it is argued, can reliably predict and explain the world existing beyond a child's immediate experiences (Young \& Lambert, 2014). Social knowledge, in contrast, is "the knowledge that comes from an individual's experience within a socio-cultural group" (Rata, 2012, p. 104). For some scholars, a curriculum framework that does not specify disciplinary knowledge with enough clarity and precision cannot ensure the entitlement to powerful knowledge that all students deserve, thus "[fixing] groups in the working class to a never ending present" (Rata, 2012, p. 103). Others declare that the curriculum framework democratises education, enabling schools the autonomy required to do justice to their students within a new conception of knowledge as a verb, rather than a 'thing' imposed on students by a centralised syllabus (Gilbert, 2005).

Operating in this contested environment of neoliberal policy and high curriculum autonomy, history teachers are in a difficult position. On the one hand, experienced and capable teachers with support from their schools and community can use this flexibility to design programmes highly suited to their students' needs. On the other hand, all teachers, irrespective of experience, shoulder a significant responsibility as "independent curriculum makers" (Ormond, 2017) to select and sequence content (without support from central government) while juggling the pressures of assessment (p. 599).

Added to teachers' difficulties are the challenges of navigating national curriculum politics at local levels. Teachers are left largely on their own to deal with that most contested of curriculum issues: what to include and what not to include in their teaching programmes (Taylor \& Guyver, 2011). One teacher in this study, for example, commented specifically on 
local media interest in her school's history curriculum in light of a national conversation concerned that topics such as the New Zealand Wars are not adequately addressed by schools. Beyond this broad context of history curriculum outlined above, teachers who opt to prioritise New Zealand's history of colonisation face a number of pedagogical issues. In the following sections, I explain three specific complexities that emerged from data gathered while working closely with four exemplary teachers dedicated to teaching New Zealand's difficult histories of colonisation.

\section{The complexities of teaching New Zealand's history of colonisation}

\section{Discomfort and active resistance}

Teachers who actively respond to their students' feelings of discomfort open doors to engagement with difficult history, including the ability of young people to grapple with Indigenous and non-Indigenous systems of knowledge and ways of knowing. In the lower North Island school of Western College, Hannah spoke at length about some of the subtle forms of resistance she encounters mainly from Pākehā students when teaching New Zealand's history of colonisation. She described a number of strategies, such as not talking about the upcoming topic in the weeks prior to studying colonisation and deliberately emphasising her own personal interest and excitement about the topic:

That's where I think you have to leverage your relationships and just, like I try not to [say] "oh next term we're going to do..." you know? I just go, we are doing Empire and I just, yeah, I'm so excited because we are in New Zealand and I try and minimise the talking about it before it happened and then I just use my relationships to just try and...."this is what we do".

Sarah, at Northern College, discussed the challenge of some teachers at her school who resisted engaging with colonisation. When I asked if junior students learned about the Treaty of Waitangi she explained

Not anymore no. They've taken that aspect out. Our first topic in Year 10 used to be about migration and colonial New Zealand, the consensus among staff [was] that it wasn't enjoyed by teachers and I think the reason it wasn't enjoyed by teachers is because the staff didn't have the passion to teach it so they were 'doing' the Treaty of Waitangi, you know they were going through the motions and actually I think they were doing a bit of disservice. 
Peter did not report any student resistance to learning New Zealand's history of colonisation, although he could understand why students might resent learning about an issue like the Treaty of Waitangi if it was taught as a narrow form of civics education not contextualised within broader narratives of time and space. For Peter, "incorporating it [the Treaty of Waitangi] into an historical exploration of Indigenous and settler interactions makes it quite different". Caitlin explained that at her school "there are students that loath the Treaty of Waitangi just simply because the teachers say this is something I have to teach, I have to get on and do it". For Caitlin, place-based experiences were key to supporting students to learn difficult histories of place, but were not valued by her colleagues in the same way: "you could actually put so much meaning and passion behind it and create trips around our area that would actually get kids out seeing this stuff".

All teachers reported times when they or their students had felt some kind of discomfort or emotional turmoil when learning New Zealand's history of colonisation. Hannah was the only teacher who primarily highlighted her own personal struggles and concerns. For example, she was anxious about her students' fascination with the history of colonial violence in Australia and thought that this came at the expense of recognising New Zealand's own violent past: "it feels like it [studying Australian history] consolidates the myth that New Zealand is better". Hannah also talked about the challenges of dealing with students who think that racism is not an issue in her school explaining that "sometimes they think that there is no racism at this school and I'm sure if we talked to our Māori and Pasifika students they would experience at the very least, microaggressions all the time". Sarah, on the other hand, thought students' feelings of discomfort were healthy and it was important for them to learn that historical injustices had taken place in their own communities. Her own drive to prioritise the invasion of the Waikato was motivated by personal memories of discomfort from her time in university:

I did history [in high school], all three years and I had no idea that there had been a conflict on my back door step until I got to university and was sitting in a Level 1 New Zealand history paper thinking that I knew my history quite well and then feeling like an absolute idiot because I didn't know anything from basically... - I knew the Treaty of Waitangi had been signed - but I didn't really know anything from there to probably about the 1920s. That whole period of history and I swore to myself 
then that I was never going to have students feel as uncomfortable in that situation as I did.

The discomfort that Sarah felt in her university days ensured that she made the invasion of the Waikato a central part of her history curriculum: "I don't give them a choice. This is what I'm teaching. You can come and learn it or you don't and.....the numbers haven't changed that much, in fact they've grown". ${ }^{38}$ Sarah's example highlights Kanu's (2005) observation that teachers who prioritise the inclusion of Indigenous perspectives and knowledge have often had some kind of "transformation experience" (p. 54) which gives them the motivation to undertake approaches that go beyond a safe 'additive' approach to teaching new material.

\section{Forming relationships with iwi and hapu and navigating cultural spaces}

All four teachers commented on the benefits of involving iwi and hapū when delivering their history lessons, an approach often endorsed by educationalists as the most authentic way of incorporating Indigenous knowledge and ontologies into school curriculum (see Chapter 2). At Western College, Hannah was particularly successful at engaging directly with Māori communities. This was evident during her four-day field trip through Taranaki on the west coast of the North Island, where the students visited a number of different locations and heard perspectives from iwi experts. For example, Hannah's class spent most of a day at the village of Parihaka, where members of this community taught students about its history of nonviolent resistance to settler aggression. In Chapter 7, I examine these field trip experiences extensively, but it is worth mentioning here that Hannah's ability to establish relations with iwi experts was central to ensuring that tribal histories, told on local terms, were a part of her senior history programme.

Although Hannah felt at times overwhelmed by the complexity of navigating a cultural space that was not her own, her efforts behind the scenes (and over a number of years) with both immediate Māori colleagues and key people from Parihaka enabled her to act as an agent of intercultural translation (Santos, 2014, see Chapter 2). These efforts created spaces for dialogue across cultural and historical differences and for many students, included them for the first time in an alternative epistemological realm. For example, students took part in two pōwhiri (a formal welcome) at different marae (ancestral houses), they experienced place-

\footnotetext{
${ }^{38}$ Sarah's comment about "the numbers" refers to the optional nature of senior history and the challenges teachers face in recruiting students into their subject.
} 
based histories of and on tribal lands, and participated in the protocols of karakia (ritual prayers) and the ritualistic use of water after visiting these sites (see Chapter 7).

At the other Lower North Island school of Eastern College, Caitlin placed an equally high priority on collaborating with mana whenua (local Māori communities with tribal authority over particular territories). Nevertheless, her experiences contrasted significantly with Hannah and illustrate some of the challenges individual teachers might experience when working in isolation on Indigenous lands with complicated histories of colonisation. When describing to me the biggest challenge she faced when teaching the history of colonisation in her region, Caitlin stated that, "for me it's been the iwi engagement". She made several enquiries to local tribal authorities both alone and through senior staff members and she had some productive conversations with key mana whenua representatives. Although these conversations did not progress to any kind of formal collaboration, she was at pains to point out that local iwi were not uninterested in collaboration. Highlighting also Caitlin's sympathy for the multiple pressures tribal authorities frequently face, she explained instead that, "I would hate to create the perspective that they [local iwi] don't want to be in that space, I think they do, they just don't have the energies to direct anybody there at the moment”.

Despite being unsuccessful at collaborating formally with iwi experts, Caitlin worked hard to include different tribal perspectives into her curriculum. She relied extensively on resources produced by a local iwi historian and constantly referred to competing perspectives and motivations of dominant iwi in the Hutt Valley, Porirua and Wellington regions in the 1840s. Caitlin's approach reflected Keenan's (2018) notion of “leaving” the classroom in symbolic terms "through engagement with Indigenous-produced educational materials, such as historical texts, literature, art, music, and other forms of media" (p. 69). She regularly used images, maps and descriptions to illustrate where historical events and processes had unfolded and was meticulously careful in her approach toward field trips. For example, at field trip locations she began sentences with "my understanding is" and sometimes posed students questions such as "what might a Te Ātiawa expert say about this?" or "if you could ask a tribal expert a question about this place, what would it be?" [Field notes, 19/06/2018]. ${ }^{39}$ Throughout my time with Caitlin she often told me stories indicating a deep respect for an Indigenous ontological existence. This included telling stories of places some of her family avoided due to their proximity to wāhi tapu (sacred places). She referred to childhood

${ }^{39}$ Te Ātiawa refers to a significant tribal grouping within the Wellington Harbour area. 
memories of local kaumātua (elders) talking about dangerous water holes inhabited by taniwha (see vignette below for a description of this term) and she also used her historical knowledge of an inter-tribal battle site on a family farm to problematize the location of a farm building [Field notes, June, 2018]. This openness to an Indigenous world view surfaced in the classroom too, validating in small but significant ways the existence of Indigenous "ontological styles" (Salmond, 2012). This is captured in the following excerpt from a field note:

Caitlin asked students "what would your description of a taniwha be?" And one student calls out "a sea monster". Caitlin glances at me and I think it is because we were both on a field trip recently where a hapū representative made the explicit point of this kind of characterisation illustrating a modern form of colonisation. Caitlin writes on the board two other words students call out, "monster" and "scary" and then asks "what does a taniwha do?" She writes "protecting" and "spiritual" on the board which I think comes from students. But the sea monster student calls out again "eats people!?" Caitlin cries "No! The first thing we need to take out of our brain is that it is a monster!" A Māori student then says “my koro [grandfather] always talks to me about these stories". The student tells a story about his koro being saved from drowning and his grandfather putting it down to the protection of a taniwha. He finishes that its "probably an old man's story" to which Caitlin responds "I wouldn't say that last sentence!" [Field notes, 18/05/2018].

In another example of Caitlin's ability to recognise the existence of Māori ontologies, during the field trip to an urupā (see Chapter 7 for the extended vingette) Caitlin would not let her students enter the site. She did not feel comfortable navigating the cultural and spiritual significance of this location and explained this to students. Instead, she pointed to the gravestones from a distance and facilitated a conversation about the significance of some of those buried there, before offering water for students to cleanse themselves before moving on to the next site. Despite not managing to collaborate with local tribal authorities, these illustrations of Caitlin's practice show how her teaching was nonetheless able to validate diverse 'ecologies of knowledge' (Santos, 2014) and mediate students' misperceptions of important cultural concepts such as taniwha as 'monsters'.

Sarah, from Northern College, also deeply valued Māori involvement in her teaching about colonisation. She had guest speakers who affiliated with Waikato Māori talk with her 
students and on the second day of the field trip, her collaboration with the museum in $\mathrm{Te}$ Awamutu meant that students were guided by an expert who affiliated with Ngāti Maniapoto and Pākehā ancestry. Sarah also attempted to use Māori cultural expertise provided by the Rangiriri Culture and Heritage Centre but was not successful at making this work in a way that fitted the dates of the field trip, which school management requires timetabling often months in advance. When I asked about the possibility of her school and others throughout New Zealand establishing closer links with local iwi and hapū for their perspectives and knowledge on Māori perspectives on colonisation, she was open about the challenges:

It would be scary for some people too....you know, especially if it's not a world you are comfortable in it would be quite hard to work out, how do you start? Where do you start?...I don't know if going through councils might be one way to kind of build bridges or make connections and some areas are more complex than others because...there [are] multiple layers...

Peter, from Southern College, also highly valued collaboration with local iwi to ensure Māori perspectives and knowledge were central to his department's curriculum. He had formed close relationships with a number of local iwi experts over a period of years and would regularly liaise with them when he had questions and needed advice. Peter also had knowledge of local iwi and hapū politics and history and was working with senior management in his school to navigate these complexities and establish more formal links that "ensures their [mana whenua] stories are at the centre of our programmes" (Email correspondence, October 16, 2019).

One constraint to teachers prioritising in greater depth Māori histories of colonisation (and noted by all four teachers) was their own cultural positioning as Pākehā New Zealanders. Recognising one's cultural positioning may well form a fundamental starting point for any teacher's ability to contribute to the goals of cognitive justice in a bicultural, settler society like New Zealand. Teachers who cannot acknowledge the limitations of their own worldview, for example, may not look for ways to compensate for that bias, and how it might inhibit fundamentally different ways of knowing and being in the world. To illustrate one teacher's reflexive recognition of her cultural positioning, when asked about the biggest challenge she faced when teaching the invasion of the Waikato, Sarah, from Northern College, replied

Making sure that you address both sides of the story. I'm a white female who has grown up in [Waikato town] and [North Island city] so I've lived a very white, 
privileged upbringing, you know what I mean? And for me the biggest challenge is making sure that I do get that balanced view and my bias of my history doesn't dictate how I teach the history of the Waikato Wars.

Teachers in this study were all aware of the need to include local Māori communities into their curriculum design to ensure tribal perspectives featured as part of their history programmes. Depending on context, their ability to do so varied, highlighting the ways in which teacher training, cultural competency, local histories of colonisation, and school structures all worked to open and close doors leading to mutually beneficial relationships between iwi and hapū and the history teachers working on their land.

\section{The difficulty of articulating and implementing critical approaches to past/present relationships}

Implementing teaching practices that deeply and critically engage with the relationship between past and present is essential in settler societies where contemporary inequalities are routinely divorced from their roots in historical injustices and trauma (Dion, 2008; Kidman et al., 2018; Pihama et al., 2014; Tupper, 2011). In recent years, the dominant curriculum discourse in New Zealand has concentrated less on pedagogical challenges such as drawing past and present connections and more on the politics of topic inclusion (see the outline of recent history and curriculum issues in Chapter 1). Nevertheless, teachers' understanding of the relationship between past and present affects the kinds of contribution their practice can make to the goals of cognitive justice. Santos (2014) aligns the goals of cognitive justice with history's relationship to the present when he argues, "history is an intense, constitutive part of the present" (p. 209). As outlined in Chapter 5, teachers surveyed overwhelmingly agreed that when teaching the history of colonisation, the past should connect to contemporary issues. Among the teachers I observed, there was less of a consensus in this approach, suggesting that implementing critical approaches to past and present relationships is considerably more difficult within actual teaching situations.

Caitlin and Hannah, for example, found it harder to answer questions about how they linked past and present when teaching New Zealand's history of colonisation. Caitlin described her difficulties in the following way: 
Because how do you bring it through to the present day apart from the memorials?...and the time and space between the event and when it happened now, there's not actually a lot of connection that you can bring during that middle time frame.

Hannah also explained that,

We might do something on legacy and that might be featured but probably that would just be one part of the examination so they might include legacy as a key idea or something like that but we wouldn't do too much.

These responses do not reflect the position that "history is an intense, constitutive part of the present" (Santos, p. 209). Nevertheless, despite struggling at times to make past and present connections in the classroom, both teachers used their field trips experiences to reduce the 'historical distance' between the past and students' sense of history's significance today (Klein, 2016).

Peter, the teacher at Southern College in the South Island, illustrated a deep understanding of the nature of past and present connections and the significance of teaching these associations in connection to local places. For example, he explained,

Iwi historians...talk about the land and the past as something that in a sense they're in. That in a way you live in the past, not that the past is over here that you look at, you examine and pick it up and you arrange it as you wish, it is actually just something that is there and it's part of you.

Peter's response illustrates his understanding of the significance of place and land within Indigenous contexts. According to Harrison (2013), this is an approach that begins from the epistemological assumption that knowledge is embedded in the land (p. 214). From this premise, where, and not just how or what history is learned matters deeply. Peter elaborated this understanding by referring to the significance of a number of local sites, explaining the former location of kāinga (villages) that were dotted around his town and the significance of his school's site to Ngāi Tahu (a major South Island iwi). Peter was also in the process of designing place-based curriculum that drew past/present connections through significant places "so students understand... why we have places with [names like] Wellers Rock, that's why the marae is at Otākou, and that at Whareakeake there was a particular thing that happened and this is a consequence of the contact period." This understanding of the past illustrates the kind of thinking needed for history education to "connect the past with the present in physical locations" (Kidman \& O’Malley, 2018, p. 3) 
Sarah, from Northern College, raised several contemporary issues regarding colonisation which opened opportunities for discussing the concept of historical legacies. For example, she described talking with students about the appropriateness of colonial symbols at her school, a sensitive issue that many teachers might struggle to explore. She also described the frequency of news articles in recent years about the New Zealand Wars, which made it easier to establish contemporary relevance. Sarah also explained that she used the Waikato-Tainui Settlement (1995) and its impact on the local Māori economy to bridge the past/present divide. Unfortunately, I was not able to spend extensive time in Sarah's classroom and witness actual practices of connecting past and present. Like Sarah, Peter gave several examples of contemporary issues he brought into his history teaching: "we talk about the role of the Treaty now, the Tribunal, we talk about...current Māori issues". Peter also described looking at issues facing Indigenous peoples elsewhere in the world, such as the United States and comparing those to major social problems in New Zealand. Illustrating his understanding of the relationship between historical and contemporary relations of power Peter explained that, "I get concerned by notions of the "colonial past" because I don't see it as finished and I don't see it as something that we can parcel up and see it as something that happened then". Peter's understanding of the interrelationship between place, the past and the present, and his sense that colonisation is ongoing, illustrates a particularly powerful set of conceptions about history education conducive to the goals of cognitive justice. In the next section, I explore in greater depth the complexities faced by students when learning New Zealand's history of colonisation.

\section{The complexities of learning New Zealand's history of colonisation}

Students at all four schools encountered profound challenges when learning New Zealand's history of colonisation. They also frequently recognised the importance of navigating through these challenges. For example, at Southern College, in the South Island, students were particularly eloquent at describing the opportunities inherent in their history classes, explaining that lessons about colonisation were highly relevant to their lives as young people living in New Zealand. They especially wanted to understand more about the development of their country in regards to settler/Indigenous relations. Commenting on the curriculum in his previous secondary school, Sam Wojicki thought that "we never really looked at the roots of the country or how it came about". Because of this lack of learning, Sam Wojicki reported 
that his favourite school history topic was learning about New Zealand's history of colonisation:

What I am doing now with learning about the colonisation of New Zealand is probably the favourite thing I've done just because I don't know that much. Whereas I've written so many essays on World War 1 and World War 2 and at this point I'm pretty much "interested-out" of it, like I have done it so much it has just become oversaturated in my mind....

To illustrate his enthusiasm for learning New Zealand history, one student at Southern College contrasted human stories of survival and resistance in New Zealand with the abstract statistics of casualties from the World Wars: "it's just these battles with these massive numbers of people dying. It's just like so much more boring than if it is like one person climbing down cliffs with vines and stealing ships and stuff, it's so sick" (Dogboi Supreme, in a reference to the Māori leader Te Kooti). For Elizabeth, learning about Māori women's leadership was a revelation: "I focussed on Te Puea last year and like strong female leadership in New Zealand! Like it's incredible and you just don't know who she is! It's just an outrage!" Although Elizabeth did not enjoy learning about wars and struggled with a topic on World War Two, learning about the New Zealand Wars was different. She valued learning about these conflicts and the consequences of them for Māori, particularly the policies of assimilation imposed on Māori by successive settler governments. Learning this history led her to want to learn Te Reo Māori (the Māori language). For Elizabeth, "I just never would have got that if I hadn't been exposed to [this history]".

Students at Eastern College in the Lower North Island expressed, for the most part, similar views. For example, when first told about the new topic, Big Daddy Donkey was "excited to learn about our heritage" and Nigel commented on looking forward to "the real in-depth things about what colonisation was" which he did not feel had been a feature of his social studies learning. Not all students agreed. Te Whiti ${ }^{40}$, for example, expected the topic to be "boring" explaining that "I just don't see how it relates personally to the Samoan people". For this Samoan student, history's value lay in its ability to validate or expand his identity as Samoan. Aliyshlious also claimed to have "lost interest" since the previous year. She later explained that “I guess we don't, like, as Polynesians, [we] don’t really - no offence!

\footnotetext{
${ }^{40}$ This Samoan student chose the pseudonym 'Te Whiti' after an important Māori leader and prophet that he had recently studied.
} 
(looking at Māori and Pākehā students), [we] don't really care about it cos we didn't, it's not our history." Aliyshlious and Te Whiti's direct attribution of this lack of interest to their Pacific identity was, however, challenged by Bob Doodle-Boy, also a Pacific student who explained, "not all Polynesians have the same perspective!".

Papa Russ, a Māori student at Eastern College, did not struggle in the same way to see the topic's meaning and relevance and he made explicit reference to his Māori and British ancestry:

It was good seeing both perspectives because I'm from both sides, I'm British and I'm Māori and all I ever knew was the Māori stories and I know that they are pretty different to how the British make out so it was good to be able to understand what actually happened.

Learning New Zealand's history of colonisation also helped Papa Russ understand and appreciate the consequences of colonisation for some of his Māori family. He highlighted the topic's personal relevance, which made it easier for him to connect and stay motivated to learn:

A lot of my family are from Hastings and Tauranga and places like that. They're real Māori activists. When their land was taken they got really pissed off about that and to this day they still try and fight for their land and they are always facing up with the government trying to fix that so it's good to understand cos I actually don't understand why they don't just let it happen cos you know it's in the past but now I see the bigger story and why they're trying to fix the future and get what used to be theirs back.

Other students at Eastern College also talked about history in terms of their cultural identity. For example, Aroha, a Māori student explained how her prior knowledge, drawn from Māori contexts enabled her to connect with New Zealand's history of colonisation at a deeper level than other aspects of the history curriculum:

Michael: So, when you heard that you were going to spend quite a long time on New Zealand, a New Zealand context, what were your initial reactions to that?

Aroha: I like learning about us more than everyone else. I don't know, it's more interesting and I can relate more.

Michael: And why can you relate more? 
Aroha: Cos I know some of the stuff they are talking about. So, when they are talking about America and all that I'm like confused and don't really know.

Michael: How do you know it? Have you done it in class before?

Aroha: Yep and like some of the places, like Māori places I've been to and learnt about.

Michael: From your family, or?

Aroha: [nods] or like in songs cos I do like Kapa Haka [Māori performing arts] so some of the stuff we talk about in songs we do.

Aroha's mention of the role of waiata (Māori songs) as a source of historical evidence and the means by which her histories are performed is significant. For Aroha, she did not perceive her history lessons (when they focussed on colonisation) conflicting with the history she learnt through waiata and visiting places with her whānau (family). Instead, she seems to suggest they worked together in mutually beneficial ways, no doubt aided by her teachers' strong desire to validate the knowledge students bring with them. Aroha's comments illustrate one example where a student explicitly recognised the performative aspect of 'doing' history from an Indigenous standpoint and acknowledged that different systems of knowledge can operate together.

These mostly positive views illustrate why many students' were open to learning New Zealand's history of colonisation. The findings here also replicate those from Chapter 5, in which I showed a majority of students valued learning New Zealand's history of colonisation (Figure, 5.9.2). Several barriers, however, stood in the way of this receptivity leading to deeper engagement with difficult histories of colonisation, including recognition of diverse 'epistemological realms' that students like Aroha at Eastern College touch on. In the following sections I draw on key examples from different schools that best illustrate the themes of overcoming resistance, dealing with white guilt and grappling with limited historical knowledge and understanding. As explained in Chapter 5, understanding the nature of obstacles to teaching and learning opens important pathways for pedagogical reform, which should include a history education that contributes to the goals of cognitive justice. 


\section{Overcoming resistance}

Many students interviewed at the lower North Island school of Western College initially resisted wanting to learn about their topic on the nineteenth century conflict in Taranaki. They frequently attributed this resistance to negative experiences in junior social studies (Years 9-10). Sophie Hill, for example, explained that "we did the Treaty of Waitangi topic in Year 10 social studies and apart from that we haven't learned [it] and that wasn't very deep". Carolin Hamblin claimed that "you get to high school and you do it in Year 9 or 10 and its still sort of skirting and you never feel like you are doing something new". These experiences helped to set up students' expectations that their learning of similar issues in senior history would be 'boring':

Myah: I do also think that this learning about New Zealand history this year has been way more interesting than Year 10 social studies.

Lana: For sure.

Cerise: Definitely.

Myah: Like in Year 10 social studies I was so bored.

Cerise: I think we all dreaded it in Year 10.

Sophie Hill also illustrates the link between previous, negative learning experiences and an initial resistance to the topic explaining that "I think the reason I wasn't feeling that excited about the topic was just off the Year 10 social studies really cos [that was] all I had ever learnt and it was very boring". Nutmeg Sox reiterated these views explaining that "I was worried it was going to be really boring because every time I've been taught New Zealand history it has always been really boring".

Students at Western College also described their resistance to learning about colonisation due to a belief that it was a sanitized, and therefore not very interesting historical issue. Myah explained, "when [the teacher] said we are doing New Zealand history, I have to be honest, I was like... [pulls face]". She went on to explain that her reaction was due to a general belief that compared to other historical contexts New Zealand history was considered "mellow" and "not as sort of harsh as some history". Myah's beliefs were no doubt shaped by the fact that prior to her Year 13 history course she had not heard of the war in Taranaki. Others in the group had heard of the conflict but openly conceded that they knew nothing further about the 
event other than it had happened, an ignorance some of them put down to their previous experiences in social studies:

Myah: I feel like it is very general, like it doesn't go in depth so there wasn't really an opportunity for us to get emotional, they didn't talk about like...

Cerise:...perspectives

Myah:...people getting killed.

Lana: And I mean we were year 10 so they tried to keep it quite...

Myah:...peachy,

Lana: ...light almost,

Wolfgang: ...they did kind of sugar coat it a little bit for us.

Students at Northern College also tended to attribute their experiences in social studies to an initial resistance to learning the history of colonisation, particularly the invasion of the Waikato. For example, Bigham explained that social studies "was kind of boring, you learn about it [colonisation] every year". John Parks commented on the narrow nature of his learning about the Treaty of Waitangi: “we didn't even learn about the differences, we just learned that it happened on...what was it? 1840? 1839? 1840. And that's about it. And the whole cutting of the flag". Vanjie contrasted the depth of knowledge she felt she was acquiring in Year 13 history with her Year 10 social studies class: "from what I had learned in Year 10 it wasn't like very, it didn't relate back...there wasn't a lot of significance or depth. We didn't see different perspectives so I wasn't like very interested in it".

Some students at Northern College claimed that their reluctance to engage with New Zealand's history of colonisation was due to an awkwardness about its 'nastiness'. John Parks, a Pākehā student, explained, "to be honest, I kind of don't like some of the things that happened back then. Like, when Miss talks about it and stuff I just think it's nasty what happened". When I asked him to elaborate, John Parks said "yeah, it's nasty what happened back then, I guess especially now that I didn't even know about it, and you get brought up with no war...it's just something that doesn't occur, you don't learn about that kind of stuff here". One other student agreed that the conflict's 'nastiness' was a reason for not wanting to engage with the region's history of invasion, although most did not see it in these terms. Overall, students were less explicit in their acknowledgement of resistance to the topic than the students at Western College. However, after several weeks of learning, not all students 
were engaged with the topic and it took direct experience of the places being studied during a school field trip to shift their attitudes (see Chapter 7).

\section{Dealing with white guilt}

Many Pākehā students at Northern, Western and Southern Colleges wrestled with their feelings of discomfort, particularly 'white guilt'. According to Gachago et al., (2018), white guilt "is backward looking, making us defensive and paralysed, without an opportunity to connect" (p. 234). Shame, on the other hand involves "actively taking responsibility for systemic injustices" in ways that lead to action (Gachago et al., 2018, p. 234). Lana, from Western College, explained, "I think guilt has to come across every Pākehā's mind. Like we, well not specifically me, but our ancestors did this to these like "natives" so you can't help but feel slight guilt". When I showed one group of students at this school an image of a map detailing Māori land loss from 1840-1939, and asked what it made them think about or feel, Lana said, "I think guilt definitely". Wolfgang supported this sentiment adding "very sorry, like we haven't even respected... I don't mean to be like 'us and them', but I know that Māori people have that view that, like, land isn't to be owned". Myah on the other hand disagreed that the image or lessons on colonisation made her feel guilty. She explained, "in general a lot of things that have happened in history have been pretty nasty and like it's kind of important to take into account that we shouldn't do that now but not necessarily feel guilty because we didn't do it". Myah's position seemed to shift the views of others, and Cerise admitted it was perhaps more sadness she felt, rather than guilt. Myah emphasised again that "it's not like I personally feel guilty for the actions of others however I do feel sad that it happened".

Students oscillated between the emotions of guilt and sadness, seemingly not always sure of how to make sense of their emotional expression. Myah's general confidence in articulating the appropriateness of feeling guilt or sadness at the historical actions of colonists seemed to give Wolfgang a window to explain a different position again. Wolfgang claimed that perhaps her guilty feelings were due more to her own ignorance of the past and less a result of the historical actions of colonists: "I feel like us as Pākehā didn't know anything about it and we are pretty uneducated....I feel like then I feel like 'Uh I feel a bit guilty about it'". She elaborated that gaining knowledge of the colonial past was a particular responsibility of Pākehā New Zealanders. Wolfgang felt this knowledge should lead to action in the present, a challenge she did not feel she was personally living up to: "white people should be going out 
and doing stuff, but I haven't been doing that, I think if there is a sense of guilt it would be that".

At Northern College the issue of guilt was raised among students when I asked if visiting sites associated with the invasion of the Waikato would be uncomfortable for their class, considering that many of them were descended from and identified with groups historically in conflict with each other. In the interaction below, students discuss the relevance of guilt to their learning:

Vanjie: I think a little bit, but....I don't know.

Lola: It makes it a bit more personal.

Student 1: It's been more confronting because it has been your...

Student 2: Your people.

Gspicemoo: This is what happened - your people did this.

Student 1: Yeah, even though it isn't your fault you still feel a little bit like....

Student 2: Guilty!

Student 1: Yeah, guilty.

Gspicemoo: Yeah, especially because we are still paying for it today.

Vanjie: Yeah, definitely. It's still not resolved at all.

Gspicemoo: We're probably still angsty at each other. ${ }^{41}$

Northern College was the only school where students explicitly commented on the sensitive or "angsty" nature of colonisation in the communities they lived. Gspicemoo, a Māori student, described how the invasion and colonisation still had a profound impact on her family: “you hear it still affects people today...My grandparents are still angry about it...it's just like a storm if it gets brought up". Kytothian, a Pākehā student agreed that it was a sensitive community subject and gave an example from her mother's work place:

Yeah it does generate A LOT of anger I mean if it's brought up, even briefly, people just get furious over it, which is understandable, because everything was taken away from them and they couldn't really do anything about it.

Students at this school also explained that it would be controversial and challenging for the local Pākehā community to have conversations about the historical roots of their wealth and

\footnotetext{
${ }^{41}$ Outside noise during this focus group made it difficult to identify with precision which student was speaking.
} 
its connection to the confiscation of Māori land or its transfer by other means to Crown control and Pākehā settler ownership.

Overall, feelings of guilt about the history of colonisation was the emotion that students at Northern College discussed most explicitly and had some difficulty coming to terms with, especially Pākehā students. Māori and other non-Pākehā students, on the other hand, did not conform to this emotional expression, either remaining largely silent during discussions or, as illustrated by Gspicemoo, positioning themselves apart from their Pākehā classmates. For example, in the interaction below, students were all Pākehā with the exception of Gspicemoo (see italics):

Michael: So, you said you can't help but feel a little bit... what's the emotion you could put to that?

Tee: I don't want to say "bad" but that is basically what it is....like, guilty a little bit but without being able to do anything about it because it happened before...

Lola:...you were born

Student: It was most definitely not our fault but like....

Student: but it feels like it is

Gspicemoo: You're descendants of the people who did it

When I showed some students at Northern College the same image of Māori land loss that had prompted discussions and feelings of guilt at Western College, Julius responded that "you kind of feel bad for them" and highlighted that the map included the Waikato. John Parks replied "Yeah we axed their land! We stole their land, kind of thing! Well, we didn't steal, well, we kind of stole". I probed the group for further comment, making the point that guilt was an emotion that students had discussed at length in focus groups in other schools. John Parks emphasised further that "yeah, I feel a little bit guilty" and Julius that "yeah, those are like my ancestors, the Pākehā people; we've done this to others". Aware that students at Western College had been conflicted about their feelings of guilt, I asked this group specifically if there was anyone who did not feel this way about the past. Julius, at this point acknowledged, “at times I feel like oh, it's in the past, I can't really do much about it so it's not much point feeling guilty about it". 
Students at Southern College in the South Island did not identify as closely as other schools with the concept of guilt when learning about historical injustices against Māori, although they understood why others might feel that way. Some students described guilt as a challenge they and others in their class had in previous years had to deal with. Others were particularly clear in their rejection of guilt as an appropriate response to historical injustice:

Michael: Is feeling guilty about the treatment of Māori for example, is that a feeling that you can relate to, or not?

Hungus Rodriguez: I can see how people would feel guilty but I personally wouldn't feel that because I don’t oppress or you know, enslave or kill Māori people or did any of my family.

Michael: So why do you think [others] feel guilty because obviously they didn't do that either?

Hungus Rodriguez: Is it because they have such a connection to feeling like, well, we are white people so we must feel bad because we did this in the past. I feel like that is sort of like a, just sort of not a very good way to go about it because you should be looking ahead to be positive to all people instead of dwelling in the past and feeling guilty about it.

Deborah: I mean there is a certain amount of history that we have to learn from it and you have to be able to look at it to move forward but there is also a point when you just start lingering on it too much and being guilty is not necessarily the most productive way of acknowledging what your ancestors did.

Students at this school were also less likely to become tangled within the same sad/guilty emotional binary as students at the other schools. Sam Wojcicki, for example, said "it [feelings experienced when studying the history of colonisation] was less like a guilt thing and more just like a shock because I hadn't considered that before". Elizabeth's group did, however, describe feelings of guilt during lessons on colonisation in previous years:

Elizabeth: A lot of people left history last year during that whole period hating white people and being white, but like...

Michael: Oh really?!

Elizabeth: Oh yeah, definitely!

Michael: So, was it like white guilt? 
Elizabeth: Definitely! There were a lot of discussions having to remind each other that it's not us that made those decisions and to say that we haven't benefited from those decisions would be completely wrong but you do have to have a certain level of like "it wasn't you, yourself".

The emotion that some students at Southern College struggled with (though they did not discuss it in depth) was anger at the historical injustice they had encountered during history lessons. When I showed students the map of Māori land alienation Elizabeth responded enthusiastically saying that "see this is the kind of thing that ignites anger...I just really get into it". In contrast to Gachago's et. al (2018) claim that shame leads to action, for Elizabeth it was anger that most motivated her desire to take action.

\section{Grappling with limited historical knowledge and understanding}

Prior to their senior history classes, students at all schools claimed to have very limited historical knowledge and understanding concerning New Zealand's history of colonisation, including how historical events and processes shaped the present. At Western College, students recognised at a general level that colonisation was an issue of ongoing contemporary significance rooted in historical injustices committed against Māori but they still found it difficult to explain this to any depth. ${ }^{42}$ When I asked students if their teachers made a point of connecting New Zealand's history of colonisation to contemporary issues Lana explained that “I think it's history based". Wolfgang followed Lana's comment with:

I think in Year 10 I remember towards the end of the topic we talked about it a little bit but I think, it's not all history but it is mainly, definitely at the moment all we are doing is history but I feel like because it's Year 13 definitely we will hopefully do the legacy because I think there is significance now because Māori and like the equity and equality.

Nutmeg Sox also explained that "we might later in the topic after we've done all the history stuff we might move on to more modern stuff'. When I asked explicitly if they thought that the conflict and war in Taranaki from the 1860s-80s (the topic of their field trip) still affected society today, both groups struggled to answer. Caroline Hamblin responded to my question with "I think it's a bit unknown to us, like...that's its legacy, that it's almost a, like, a mystery, that we just find out about suddenly". Bella Forbes emphasised this comment,

\footnotetext{
${ }^{42}$ At the time of the focus groups students at Western College had only recently begun a senior history unit on "empire" which included a context exploring the conflict in Taranaki.
} 
adding that "it's been erased from our history. Like it's 'oh that's embarrassing we're not going to talk about that".

At the time I spoke with students at Eastern College they had spent a substantial amount of curriculum time learning New Zealand's history of colonisation. They were many weeks into a unit on the process of colonisation as it had unfolded locally, and the New Zealand Wars more generally. This possibly explains why their limited historical knowledge and understanding did not seem quite as evident as other schools. It may also explain (in addition to the greater number of Māori and Pacific students in the focus group) why they did not characterise New Zealand history with the same sanitised words as students at other sites. Nevertheless, like other schools, some students had never heard of the New Zealand Wars and most were unfamiliar with the broad contours of colonisation in New Zealand prior to their history classes.

Prior to their Year 13 history class, students at Northern College either knew very little about the invasion of the Waikato and its broader context or were entirely unaware it had taken place. For Kytothian, the Year 13 unit on the invasion of the Waikato was the first time she had heard of the conflict. Vanjie, when asked how familiar she was with the war prior to the current unit, exclaimed "didn't even know there was one!". Julius also said that he "didn't know about it" and John Parks exclaimed that "yeah, I was like, "But wait, there was a war in the Waikato?'”. Illustrating clearly the notion of forgetting (Kidman, 2018) common to settler societies, it was only Pākehā students at Northern College who claimed to have never heard of the invasion. For Gspicemoo, a Māori student, her grandparents had told her about the conflicts and she had visited with her whānau several of the sites that the class would stop at during the field trip. Wai also explained that she knew of the conflict from her whānau and marae. Other Māori students less vocal during interviews did not claim the same surprise as Pākehā students that a war had taken place where they lived.

Students at Northern College also struggled to explain how the invasion of the Waikato shapes the present and they thought better understanding of these connections would help establish the topic's personal and social significance:

Michael: So, do you think it is important that teachers do make frequent past/present connections? 
John Parks: I think it would get you more engaged that you could see it in today's society

Michael: [Bigham] do you want to elaborate on that? You'd personally prefer that, or like that?

Bigham: Yeah, I would. Cause then you get a deeper understanding of the event. You don't have to be like "oh this is dumb, I don't have to listen to this, it's not going to be useful, I don't see a connection", so, yeah, I think, I would"

Unlike at Western College, students at this school were able to point more quickly to examples of how the history of colonisation connects to the present, especially in regards to local sensitivities. As indicated in the interaction above, however, it was an historical relationship students felt needed strengthening.

Students at Southern College were generally aware that major military conflicts between Māori iwi and the British had taken place during the nineteenth century. They reported that studying it in senior history was their first opportunity to develop their knowledge of these conflicts and did not report knowing anything of substance about them until senior history classes. Sam Wojicki, who had recently moved from another school to Southern College claimed that, “I didn't know that wars happened in New Zealand that weren't World War One and World War two until Term Two this year". Dogboi Supreme described his attitudes to colonisation prior to his senior history classes: "I thought that it was all very squeaky clean, and it's actually not, that's one of the things that I have learnt about and it's interesting to see that it is kind of brushed over". For this student, his senior history education was successful in disrupting sanitised notions of colonisation arguably prevalent throughout New Zealand society (Belich, 2001; Bell, 2006; O’Malley, 2016). Despite their professed lack of historical understanding and knowledge, the students at this school generally praised their history programme and were remarkably informed about New Zealand's history of colonisation. They made frequent reference to significant local iwi, they had all seen the map I showed them of Māori land alienation from 1840-1939 and during interviews made regular references to specific aspects of New Zealand's history of colonisation. However, had they not taken senior history, it seems unlikely that their junior social studies classes would been successful in shifting their understanding away from a "squeaky clean" version of colonisation that Dogboi supreme referred to. 
Similar to students in the North Island schools, students at Southern College were frustrated at their prior learning in junior social studies classes, which they felt had not sufficiently improved their historical understanding of colonisation in New Zealand. This was particularly salient at Southern College because of the sharp contrast with their overwhelmingly positive experiences in senior history. Students struggled with social studies because they did not think it had been taught in depth or in ways that connected to their lives. Elizabeth claimed that:

There is just such a dead kind of atmosphere around it but I found in junior school whenever New Zealand history was talked about I'd have questions and they'd be like "we don't cover that now like we learn about that later" and I found that really frustrating because you are too young you know. We just need to shelter you for a little bit longer!

For Deborah, the minimalist treatment of New Zealand's history of colonisation in social studies and some of the unsuccessful pedagogies employed were due to teachers' lack of content knowledge: "A lot of the time teachers actually don't know much which is why they give you worksheets". For Elizabeth social studies was "very watered down like they didn't really discuss any of the heavier stuff". Dogboi Supreme added that "we did a bit on the Treaty of Waitangi but it was all just figures". Elizabeth also recalled an instance that for her characterised her social studies education:

I just vividly remember memorising what breed of rat they brought with them to New Zealand and stuff like this and I'm like my time could have been spent learning about something so much more relevant to me in terms of my country, my culture, my person.

Collectively, the three complexities that students describe above make it harder for most to engage with the concept of cognitive justice to the same degree that teachers were frequently able. Nevertheless, recognition of different epistemological frameworks for interpreting the past remains an important issue and within the reach of students. For example, Māori students often referred to an alternative way of knowing and being in regards to their history education, whether through their performance of history through waiata (songs) or, as I discuss in the next chapter, the kinds of experiences they had during field trips. 


\section{Summary}

In this chapter I laid out some of the pedagogical complexities presented to teachers and students during lessons on colonisation. Beginning with a description of the broad sociopolitical context in which all history teachers in New Zealand operate, I then used the concept of cognitive justice to appraise teachers' practices, particularly as they related to the pedagogical complexities of discomfort and active resistance to the history of colonisation, developing relationships with iwi and hapū and the difficulty of implementing critical approaches to past and present historical relationships. By using the term cognitive justice in this way, I started to expand ideas about what bihistorical teaching might entail (see Chapter 8 for a more extended discussion). In the second section, I turned to the complexities presented to students during lessons on colonisation. I showed that despite a deep receptivity to this learning, a range of barriers made engagement more difficult. These included overcoming resistance, dealing with white guilt, and grappling with limited historical knowledge and understanding, barriers that put the added challenge of exploring diverse epistemologial and ontological realities largely out of reach. In the next chapter, I focus more specifically on the role field trips to sites of colonal violence play on students' engagement with the past, further extending my contention that teaching and learning histories of colonisation is a deeply complex and challenging act. 


\section{CHAPTER 7: YOUNG PEOPLE AND THEIR ENCOUNTERS WITH COLONIAL VIOLENCE DURING SCHOOL FIELD TRIPS}

A landscape whose story is told is harder to dismiss

Frank Gohlke (2009, p. 194).

\section{Overview}

Traces of the New Zealand Wars lie within the landscape serving as persistent reminders of these brutal conflicts between the colonising power and opposing Māori iwi and hapū. This chapter explores the role of school field trips in shaping students' encounters with three of these 'conflict-scapes' (Drozdzewski, De Nardi, \& Waterton, 2016). It extends the previous chapter's focus by detailing how students in three schools engaged, in situ, with the invasion of the Waikato (1863/64), the war in Taranaki (1860/61), the sacking of Parihaka (1881) and the War in Wellington (1846). Learning the contested stories of colonisation at places of colonial violence is important because it can be a more visceral, embodied and emotional experience than classroom-based learning, potentially deepening students' historical understanding and even leading to "action toward justice" (Boler, 1999, p. 157). At best, these place-based encounters with the past occur with the tribal custodians of wāhi tapu and the knowledge they hold (and are willing to share), creating experiences that cannot be replicated within even the most dynamic of classroom-based teaching. As Manning (2017) argues, the classroom is

No substitute for place/land based learning exercises which require students and teachers to actively engage with Indigenous worldviews which emerge like a breath of fresh air from the landscape beyond the windows of musty classrooms. (p. 157)

Despite the pedagogical potential of field trips for students' learning, they are not widely used in New Zealand. Of the 231 teachers who answered a survey question about field trips (see Appendix 1, question 19), 77\% responded that they 'almost never' or only 'sometimes' took students outside the classroom, frequently citing expense and school management as obstacles. These were also obstacles faced by the teachers in this study and yet none of them could imagine teaching the history of colonisation without such outdoor experiences. Caitlin, Hannah and Sarah were willing to go to considerable lengths to ensure fieldtrips formed a central part of their teaching programmes, further consolidating their status as curriculum 
'risk-takers' (Kitson \& McCully, 2005). ${ }^{43}$ During the field trips with these exemplary teachers and their students, my theoretical interest in the intersection of place and emotion led me to consider particularly the "the body's capacity to act, to engage, to resist, and to connect" (Zembylas, 2014b) at the places of profound violence and suffering we visited (p. 397).

As discussed in Chapter 2, public engagement with historical sites of suffering and violence has been extensively theorised within geography, heritage, tourism and museum studies. In this chapter, I expand upon this field by examining young people's engagement with placebased, difficult histories of colonisation as a part of their schooling experiences, an area that receives comparatively less scholarly attention. An analysis of the data through affect theory (see, for example, Zembylas, 2014b) highlighted the significant role that emotions played in enhancing and constraining students' learning and the findings described here have implications for place-conscious pedagogies of difficult history in international contexts, especially in settler societies. The chapter argues that history field trips held potential as place-based 'counter narratives' (Goldberg, Porat, \& Schwarz, 2006) with consequences that both led to, and inhibited critical and transformative history education. As explained previously, history educators Goldberg and colleagues (2006) define a counter narrative as one that focuses on "groups underrepresented or excluded from the official institutions or the official narrative" (p. 323). As a transformative experience, the teachers' willingness to highlight the destructive consequences of colonisation for Māori was enhanced by placebased encounters. These helped to develop students' historical understanding and challenged their ignorance of colonial aggression. Furthermore, field trips opened opportunities for students to participate in Māori cultural contexts and they occasioned moments for emotional and affective engagements with place-based history.

In addition to the transformative potential of field trips as counter narratives, I also argue that for two schools, these excursions had the unintended consequence of inhibiting students' learning through the establishment of an emotional regime that encouraged feelings of empathy for Māori as victims of colonisation. The emotional 'rules' generated from this affective climate tended to make it more difficult to connect the past to the present, it

\footnotetext{
${ }^{43}$ Peter also had considerable experience with history field trips. Unfortunately, and as outlined in Chapter 4, I was not able to participate in one during the timing of this study.
} 
oversimplified complex historical narratives and it inhibited difficult and important conversations about power, history and colonisation. This work builds on those scholars who problematise empathy during lessons on difficult histories (Cook, 2015; Stastny, 2018; Zembylas, 2013d). During one school's field trip, where an emotional regime of empathy was less noticeable, students were also constrained in their learning by a struggle to find meaning at some key sites of colonial violence. Before advancing these arguments, and to contextualise broadly the field trips of Northern, Western and Eastern Colleges, I begin with a short overview of the New Zealand Wars and the itineraries of each field trip.

\section{The New Zealand Wars in context}

The signings of Te Tiriti o Waitangi (The Treaty of Waitangi) in 1840 and Governor Hobson's cession of the South Island through a declaration of terra nullius, formally annexed New Zealand into the British Empire. These actions tightly bound the South Pacific nation to the outside world, embedding it firmly in numerous 'webs of empire' (Ballentyne, 2012). The New Zealand Wars are one conflagaration of conflicts that illustrate these webs and sit within "the long sequence of crises that shook the British Empire in the middle of the nineteenth century" (Ballantyne, 2012, p. 161). These crises include:

The Matabele rebellion in Ceylon in 1848, the Xhosa cattle-killing of 1857-7, the Santhal insurrection of 1855-6, the Indian rebellion of 1857-8, the Morant Bay rebellion of 1865 and the New Zealand wars between 1860-1872. (Ballentyne, 2012, p. 161)

In addition to their global signifiance, the New Zealand Wars also need to be understood within the broader context of New Zealand history. In the two decades prior to the outbreak of war in Taranaki in 1860, colonial administrators, settlers and Māori struggled over conflicting interpretations of key ideas within Te Tiriti, namely the notions of kawanatanga and rangatiratanga (Anderson et al., 2014). From the Crown's perspective, the cession of sovereignty, translated as kawanatanga in the Māori text, put New Zealand and all its citizens, Māori and British, under the British rule of law. From a Māori perspective, kawanatanga did not mean cession of sovereignty because this would have meant the chiefs giving up their cheiftenship over their lands. After the signings of Te Tiriti in 1840, which took place at various locations around New Zealand, the Crown's alleged sovereignty remained nominal. Māori were numerically dominant and chiefs continued to exercise their rangatiratanga (chiefly authority) and Māori tikanga, or cutomary law. This situation changed 
as European colonists flooded onto the beaches and into ports, establishing towns and colonial institutions such as a settler government in 1854. In the late 1850s Māori and Pākehā populations were, for the first time, roughly equivalent. For Māori leaders, the affirmation of their rangatiratanga in the Māori text of the Treaty of Waitangi protected their chiefly authority and assured the retention of their lands. For settlers and the Crown, however, "transferring land out of Māori ownership and into settler hands would be key to achieving practical control of the country" (Anderson et al., 2014, p. 194). Māori had certainly not agreed in the Treaty to mass European migration and their own "political marginalisation" (Anderson et al, 2014, p. 198).

It was in the broader context of threats to the chief's rangatiratanga that a disagreement over land led to the deaths of four Māori and 22 settlers at Wairau, at the top of the South Island. According to the historian Danny Keenan (2018) this event put New Zealand on a "war footing" for the next 17 years (p. 18). Two years after the 'Wairau incident', settler pressure on land and the detrimental effects of colonial control over some Northland chiefs led to a major conflict between some iwi and the Crown (1845/46), followed almost immediately by conflict in Wellington (1846) and Whanganui (1847/48). These events begin what are today most commonly known as the New Zealand Wars, of which the main theatres of conflict are generally considered to have taken place in the 1860s before finally ending in 1872 .

As historian Vincent O’Malley (2019a) notes, the wars "profoundly shaped the course and direction of [New Zealand's] history" (p. 9). Illustrating the global significance of these conflicts, historian James Belich (1986) highlights the extent of the colonial power summoned to New Zealand to subjugate Kinngitanga fighters (those fighting for the Waikatobased Māori king) during the invasion of the Waikato. He writes that in the mid 1860s "the Imperial forces in New Zealand amounted to 12,000 men - more than were available for the defence of England at the time" (p. 125). By the conclusion of the wars, it is estimated that 2000 Māori fighting against Crown forces died in contrast to 560 British troops killed and 250 Māori who had strategically aligned themselves with the Crown (O'Malley, 2019, p. 235). In some places, the proportion of casualties endured by Māori communities far exceeded the casualties of the World Wars (O’Malley, 2019, p. 238). Millions of acres of land were confiscated, formerly vibrant Māori economies were devastated and communities 
suffered the effects of being dislocated from their land, the source of their economic, spiritual and cultural sustenance (Keenan, 2009).

The New Zealand Wars achieved a key goal of settler colonialism: they helped to consolidate settler power through the acquistion of Indigenous land. Over three million acres of land was confiscated as punishment for tribes in 'rebellion' against the Queen and in 1865 legislation passed allowing for the establishment of the Native Land Court, an institution that for decades provided the legal mechanism for alienating Māori from their land through the individualisation of customary title. After the wars, the sovereignty (kawanatanga) ceded in 1840 through the Treaty of Waitangi was for the most part substantive. With little to no land, Māori tribal authority (rangatiratanga) of those most affected by the wars was difficult to exercise, making it hard to resist further land sales and the assimilationist agenda of a settler society.

Whilst devastating, the New Zealand Wars were also characterised by determined Māori resistance (Belich, 1986; Keenan, 2009; Walker, 2004). In the post-war period, this resistance to settler colonialism and the ongoing campaign for recognition of the promises of Te Tiriti o Waitangi (the Māori version of the Treaty) took non-military forms. Māori had to find new ways to battle settler incursion into their lands and ways of life. Historians Anderson, Binney and Harris (2014) argue that between 1860 and 1890, Māori responses to these incursions took three major forms. First, Māori “developed new forms of tribal and supra-tribal organisation" designed to better meet a new era of challenges (p. 253). Second, some Māori leaders worked within the parliamentary system to advocate for their people. Finally, in places such as Parihaka, one Māori response to the new realities of settler colonialism was for prophetic leaders to "[offer] their people a spiritually grounded pathway from upheaval and uncertainty" (p. 253).

In the 1970s and 1980s - more than a century after the New Zealand Wars ended - Māori demands finally forced parts of Pākehā society to accept that grievances arising from breaches to Te Tiriti o Waitangi needed addressing (Orange, 2004). This period saw a number of high-profile Māori land occupations and protests, the establishment of the Waitangi Tribunal that was eventually authorised to investigate Treaty of Waitangi breaches dating back to 1840 , and an increasing focus by the state to promote biculturalism and 
reconciliation between the Crown and iwi (Harris, 2004). These were some of the factors that contributed to an historical revisionism that paid greater attention to Māori historical experiences and underpin much of contemporary historical scholarship in New Zealand.

\section{Contextualising the field trips}

It is within the broad context of history-making and biculturalism from the previous few decades that history teachers were schooled, trained and teach in today. Some scholars consider this period of social change "one of the most important social and political developments in New Zealand in the last half century" (Sibley \& Liu, 2004, p. 88). As argued in Chapter 5, therefore, it is not altogether surprising that teachers such as those in this study wanted to prioritise Māori perspectives and challenge sanitised interpretations of the past. Such an approach also characterised both the desire to undertake the field trips to sites and the kind of teaching that took place at these locations. To contextualise each field trip, in Table 7.1, I summarise the key details of the field trips observed as part of this study, including each teachers' primary pedagogical purposes. 
Table 7.1: Key information for three Year 13 history school field trips.

\begin{tabular}{|c|c|c|c|}
\hline & $\begin{array}{l}\text { Northern College } \\
\text { (Sarah) }\end{array}$ & $\begin{array}{l}\text { Western College } \\
\text { (Hannah) }\end{array}$ & $\begin{array}{l}\text { Eastern College } \\
\text { (Caitlin) }\end{array}$ \\
\hline $\begin{array}{l}\text { Field trip topic } \\
\text { and location }\end{array}$ & $\begin{array}{l}\text { Conflict in the Waikato } \\
1863 / 64 \text { (Central North } \\
\text { Island) }\end{array}$ & $\begin{array}{l}\text { Conflict in Taranaki } \\
\text { 1860/61, 1881, (West Coast, } \\
\text { North Island) }\end{array}$ & $\begin{array}{l}\text { Conflict and colonisation } \\
\text { in the Hutt Valley, } \\
\text { Porirua, 1840s, } \\
\text { (Wellington Region, } \\
\text { southern North Island) }\end{array}$ \\
\hline $\begin{array}{l}\text { Duration of field } \\
\text { trip (in days) }\end{array}$ & 2 & 4 & $\begin{array}{l}1 \text { (with two short half } \\
\text { day excursions to local } \\
\text { sites) }\end{array}$ \\
\hline $\begin{array}{l}\text { Total number of } \\
\text { students } \\
\text { participating }\end{array}$ & 18 & 75 & 10 \\
\hline $\begin{array}{l}\text { Field trip } \\
\text { itinerary }\end{array}$ & $\begin{array}{l}\text { Day 1: Mercer } \rightarrow \text { Queen's } \\
\text { Redoubt } \rightarrow \\
\text { Whangamarino } \rightarrow \\
\text { Meremere } \rightarrow \text { Rangiriri. } \\
\text { Day 2: Te Awamutu } \\
\text { Museum } \rightarrow \text { Rangiaowhia } \\
\rightarrow \text { Ōrākau } \rightarrow \text { Rewi } \\
\text { Maniapoto Memorial } \\
\text { (Kihikihi) } \rightarrow \text { St John's } \\
\text { Church (Te Awamutu). }\end{array}$ & $\begin{array}{l}\text { Day 1: Parihaka } \\
\text { Day 2: St Marys Church } \\
\text { (New Plymouth) } \rightarrow \text { self- } \\
\text { guided tour of Puke Ariki } \\
\text { museum } \rightarrow \text { Te Koru Pa. } \\
\text { Day 3: Te Kohia (Waitara) } \\
\rightarrow \text { Puketakauere } \rightarrow \text { Pratt's } \\
\text { Sap } \rightarrow \text { Ōwae Marae } \\
\text { (Waitara). } \\
\text { Day 4: Journey home }\end{array}$ & $\begin{array}{l}\text { Petone Foreshore } \rightarrow \mathrm{Te} \\
\text { Puni Urupā } \rightarrow \text { site of } \\
\text { Maraenuku village } \\
\text { (Lower Hutt) } \rightarrow \\
\text { Boulcott's Farm Golf } \\
\text { Course } \rightarrow \text { Boulcott's } \\
\text { Farm Memorial (High } \\
\text { Street, Lower Hutt) } \rightarrow \text { St } \\
\text { Alban's Church and } \\
\text { cemetery, Pāuatahanui. }\end{array}$ \\
\hline
\end{tabular}

Primary aims of

To highlight the consequences of colonisation, particularly for Māori

the field trip for

teachers

\begin{tabular}{|c|c|c|}
\hline \multicolumn{2}{|c|}{$\begin{array}{l}\text { To introduce students to new and potentially challenging } \\
\text { historical events using place-based pedagogies. }\end{array}$} & $\begin{array}{l}\text { To consolidate what } \\
\text { students had learned } \\
\text { about colonisation in } \\
\text { class with place-based } \\
\text { pedagogies. }\end{array}$ \\
\hline $\begin{array}{l}\text { To support students to } \\
\text { recognise how power is } \\
\text { embedded in the material } \\
\text { landscape and within the } \\
\text { interpretations of historical } \\
\text { markers. }\end{array}$ & $\begin{array}{l}\text { To ensure students } \\
\text { encountered historical } \\
\text { perspectives from iwi }\end{array}$ & $\begin{array}{l}\text { To highlight different } \\
\text { perspectives of } \\
\text { colonisation from } \\
\text { various iwi and } \\
\text { European settlers }\end{array}$ \\
\hline
\end{tabular}

Source: Discussion and email contact with teachers and field notes

Of particular significance in this table is the outline of the teachers' pedagogical purposes.

These shaped the kinds of pedagogies employed and the experiences that teachers worked to 
generate at sites for their students. In the next section, I outline in more detail the itinerary of each field trip.

\section{Northern College: Conflict in the Waikato 1863/64}

Northern College's field trip took place over two consecutive school days with no overnight stay. On the first day, the group travelled by bus over the Mangatāwhiri Stream, the boundary crossed by General Cameron's army in July 1863 which triggered armed resistance from Kingitanga fighters. The first stop was to the town Mercer where students completed a critical thinking task at a World War One Memorial which had been created from the turret of a gunboat used during the Waikato invasion. From there the group visited Queen's Redoubt, a key launching pad of the invasion for the colonial armies, followed by the military position of Whangamarino, and the better known Māori defence lines of Meremere and Rangiriri where key battles took place. The second day started at a museum in a town called Te Awamutu. The museum was used as a place to establish the historical context for the day's field work. Here students received an overview of the invasion and handled a number of artefacts associated with the conflict such as unexploded grenades and a soldiers' bible. The group was then taken by a guide to the village of Rangiaowhia (a haven for women, children and the elderly which was attacked by soldiers), Ōrākau, (a infamous site where, according to Anderson et al. (2014) up to 150 Māori were killed) and to the important chief Rewi Maniapoto's memorial in Kihikihi and St John's church in Te Awamutu.

\section{Western College: Conflict in Taranaki 1860/61, 1881}

The first stop for students at Western College was to Parihaka, a now small village not far from the town of New Plymouth on the West Coast of the North Island. Established as a refuge after the conflicts of the 1860s, Parihaka used non-violent resistance to settlers surveying their land (Buchanan, 2009). This led to the imprisonment of many men as far away as Dunedin in the South Island, an experience that not all survived. In 1881 over 1500 volunteers and members of the Armed Constabulary arrested the peace prophets Te Whiti o Rongomai and Tohu Kākahi, sacked the village and sexually assaulted women. It was not until 1897 that the last of the political prisoners could return home (Keenan, 2015). In 2017 the Crown delivered a formal apology at the village in a ceremony of reconciliation which included a settlement package. The sacking and arrest of Parihaka's leaders took place more 
than two decades after the 'First Taranaki War' of 1860/61 (and strictly speaking are not always considered by historians to be part of the 'New Zealand Wars'). The field trip began at this location in order to fit with the Parihaka community's often busy schedule of visitors. The second day comprised a visit and tour around the grounds of St Mary's Church in New Plymouth and its settler cemetery, followed by a visit to an old Māori pā, or fortress, called Te Koru dating to well before European contact. The third day focussed students' attention to some key battle sites associated with the First Taranaki War, namely Te Kohia (where the first shots of the conflict were fired), Puketakauere (where the British suffered a humilitating defeat) and Pratt's Sap, where the conflict eventually ended in an uneasy truce. That final evening, students were welcomed on to a marae in Waitara, not far from New Plymouth where they stayed the night before travelling home the following day.

\section{Eastern College: Conflict and colonisation in the Hutt Valley, Porirua, 1840s}

Eastern College's one-day field trip around the Hutt Valley and Porirua navigated two themes. The first was the broad context of European settlement and the pressures it put on various iwi and hapū around the Hutt Valley. The second was the 'War in Wellington', a period when Governor Grey had declared martial law and used troops to attack chiefs and destroy villages he thought threatened European settlement. The field trip included stops at the Petone Foreshore, (where New Zealand's first settler ships started to arrive en masse in 1840), the estimated location of Maraenuku (a Ngāti Tama village sacked by colonial troops), Boulcott's Farm (where a small battle took place resulting in the deaths of eight European soldiers) and St Alban's Anglican Church (a pā site of the chief Te Rangihaeata before he was forced to flee with his people from the Wellington area). Within this broad context of settler colonialism, Eastern College also stopped at a small urupā, or private Māori cemetery, where key leaders of the era such as Te Puni and Te Kāeaea are buried. Two other short trips, not discussed in this chapter included a visit to the Dowse Art Gallery to view

Nukutewhatweha, a large carved storehouse that connected local iwi in the Hutt Valley to the Kingitanga Movenment and another trip to the National War Memorial and to view the Treaty of Waitangi held at the National Library.

\section{The pedagogically transformative features of school field trips}

School field trips to sites of colonial aggression encouraged encounters with history that undermined, challenged and weakened - in small but significant ways - the ongoing 
operations of settler colonialism. The field trips achieved this through several key and overlapping mechanisms. First, they developed students' thinking in ways that challenged their ignorance of colonisation and "[created] an opportunity to include multiple perspectives and/or challenge traditional metanarratives" (Salinas, Blevins, \& Sullivan, 2012, p. 18). Second, field trips opened opportunities for participating in Māori cultural contexts and finally they occasioned emotional and affective engagements with the past. These mechanisms were not deployed evenly across schools and at times students encountered specific challenges that limited their effectiveness, highlighting further the complexities of teaching difficult histories of colonisation. Nevertheless, Hannah, Sarah and Caitlin's field trips illustrate some important successes that highlight what is possible when history education reaches beyond the confines of a classroom.

\section{Challenging ignorance and developing critical historical thinking}

For students at Northern College, their field trip resulted in important changes to their prior knowledge and understanding of the invasion of the Waikato. Even the students who before the field trip had been ambivalent about their learning had changed their view when I spoke to them in a post-field trip focus group interview. Some of these students interpreted the field trip as an important opportunity to consolidate their classroom learning, gaining a deeper insight into the invasion's historical and geographical significance. John Parks, for example, said it was "easier to visualise, kind of like reading a book". Julius, who prior to the trip was doubtful about how much it would engage his historical imagination explained that:

At times I'd just be like "oh yeah" this is alright I suppose it's just a field, I don't really care. But then at other times they're like "over here" this is where the river where the steam boats would have come down through the North here, the battles happened here. I'd be like "oh yeah this is interesting, this happened, what happened at this battle site? Can you tell me?"

Commenting more specifically on her changed understanding of the nature of history, Beanz found one museum educator's description of history as a conversation that people today continually participate in particularly useful. When I connected this comment from the museum educator to the act of renaming the "battle" at Ōrākau to the "massacre" (which someone had scrawled under the official sign, see Figure 7.6), Beanz responded that "[we] can't change what has happened in the past but we can change how it is interpreted now". Another student, Tee, also saw the trip as enabling her to better picture the past rather than it 
just being "that name".

In and around the Hutt Valley and Porirua, students at Eastern College actively used their field trip to think critically about history. For example, they consistently noticed power relations embedded within the memorial and heritage landscape. Students visited a number of different sites and the use of cameras encouraged them to notice the physical features of urban "landscapes of memory" (Alderman \& Inwood, 2013). In addition, the teacher sometimes pointed specifically to power imbalances within the process of colonisation and the settler perspective assumed by some memorials. Of particular interest to students were the differences between an urupā in an industrial area of Petone and other locations they visited. One student, for example, described several photos her group chose to discuss, making these comparisons:

So this one here is Te Puni's actual stone in the urupā and it's been remade but as [the teacher] said a part of it has been taken off so it's not remade the same way so it's disrespect for him and what he deserves and how he should be treated. And you've also got another one in the gravesite where the head had actually been taken off one of the statues and when you compare it to the other (European settlers) grave site that we went to at the church, there was actually no heads been taken off and they had actual fences around each gravesite. (Sarah)

Roger and Jimmy also photographed a monument erected by the New Zealand government in honour of the chief Te Puni with Roger commenting that "it hasn't been maintained, like some of it is cracked". Jimmy added that “Te Puni helped the settlers and the settlers aren't paying him the respect that he is due". Jelan also chose to discuss two photos she took that clearly showed the well-kept, St Alban's church in a semi-rural area beside the Pāuatahanui inlet and the broken headstones at the urupā on the Petone foreshore. In reference to the church photo, she commented that "this is where Te Rangihaeata and his troops escaped to but when you come here and you see the gravestones I guess you'd see mostly Pākehā names I'd say, European names and how surrounding it is just trees and nature, its faraway from civilisation". ${ }^{44}$ Roger commented on the lack of any formal recognition of the sacking of the Ngāti Tama pā at Maraenuku by colonial soldiers saying, "we didn’t even get out of the car,

\footnotetext{
${ }^{44}$ I chose not to publish photographs taken by students of the urupā (Māori cemetery) in Petone, using them instead as stimulus for discussion only. Although now in a central and publically accessible location, urupā are nevertheless private places and I would likely require permission to include images here.
} 
there was just nothing we could emphasise or learn from". Although students mostly noticed power imbalances between 'Māori' and 'settlers' as relatively homogenous groups, one student commented on her interest in finding a gravestone to Sarah Ann Jones, one of the earliest settlers to Wellington in 1840:

We had never really heard of her and generally with history being that old you generally only hear a perspective from a male's point of view and never really from a female. So like throughout the history that we have been learning females have been mentioned but not to a point where they are actually of significance.

For students at Western College, the critical historical thinking they had practised in the classroom prepared them to deconstruct white supremacy in local landscapes (Burgard \& Boucher, 2015). For example, during a visit to St Mary's Cathedral students were encouraged to engage with the suffering of European settlers during the 1860 conflict in Taranaki. The local guides provided by the church delivered a Eurocentric and sanitised tour that emphasised good relations between settlers and Māori and highlighted an ultimately prosperous settlement after the conflict. Although this experience challenged students, who appeared restless and bored [Fieldnotes, 30/5/18], both groups of students I interviewed were able to critique their tour for its "one-sided" approach. Bella Forbes felt that "even at Parihaka" they had received a version of events that acknowledged multiple perspectives but "at the church it was from this very European-centric sort of, 'this is the way things were'...". At St Mary's students were also struck by the perspectives revealed by language on the tombstones and several chose to photograph salient examples (see Figure 7.1). 


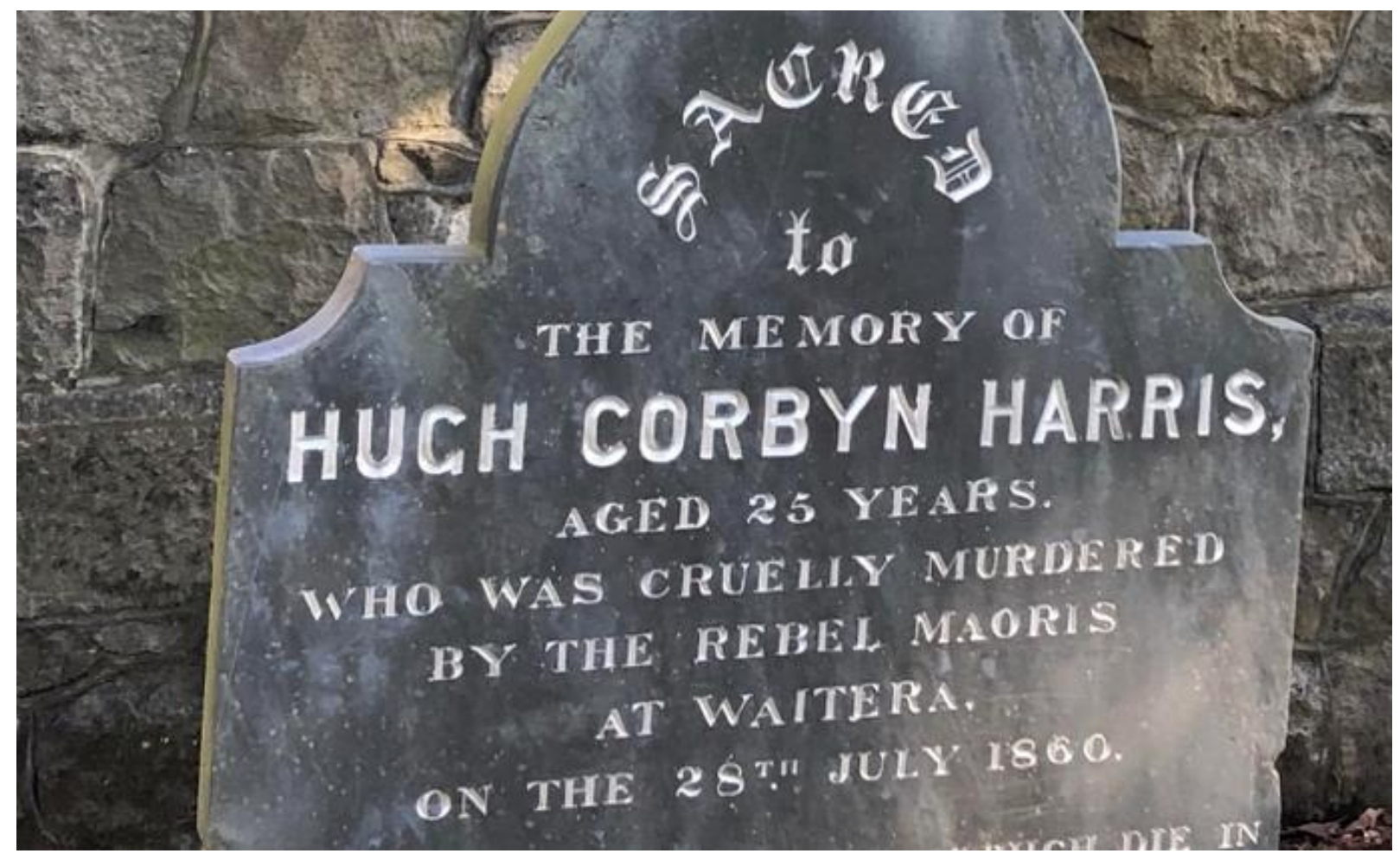

Figure 7.1: Gravestone at St Mary’s Church settler cemetery. Photo by Bella Forbes

For Bella Forbes, the language on the gravestones was representative of the historical relationship between Māori and Pākehā. Caroline Hamblin, who also photographed a gravestone commented that "the bit I found the worst was like "hostile" then I thought, oh ok, that's really decided, the attitude there. And then the "Māori trouble"; I found that really, like almost like it's only the trouble of the Māori, it's nothing to do with us, it's all their trouble".

\section{Providing opportunities for participation in Māori cultural contexts}

As discussed in the previous chapter, Hannah's field trip with her students from Western College enabled the deepest kinds of participation with Māori cultural contexts. This began at the beginning of the field trip when students were formally called into one of Parihaka's meeting houses with a karanga (ceremonial call) and given an Indigenous perspective on the events at this village, including a walking tour around the site, as this excerpt from a fieldnotes entry describes:

Our guide took us on a hīkoi (journey or walk) around Parihaka. It was bitterly cold with a ferocious southerly. I had six layers on and was only just warm enough whereas some of the students looked very uncomfortable. The mountain was hidden behind rain clouds that would periodicially dump water on us. Nevertheless, the 
students were all very attentive to the guide and the stories he told as we walked through the village. During the walk our guide took us up Purepō, a small hillock upon which the Armed Constabularly had mounted a cannon, aimed at the villagers below on the day of the sacking. Before we climbed the hill, the rain and wind started again. The guide chuckled and said "we are going to bear this", making a reference to the ancestors and what they had to put up with. Even in the wind and the rain when you can't really talk or linger it is a powerful experience being on this hill and seeing the village below. Thinking back on the whole visit to Parihaka, we weren't TOLD much - yet we learned a lot about the significance of Parihaka and the nature of history for those with ties to the village. One of our hosts was clear that to really learn the Parihaka story you have to make the journey there. This seems like the Parihaka way - create experiences, rather than give workshops or lessons based on direct instruction. They welcomed us warmly, created experiences and provided lots of opportunities to ask questions, which highlighted the importance of coming prepared. Parihaka, as our guide explained is a place for "political literacy 101" [Fieldnotes, June, 2018].

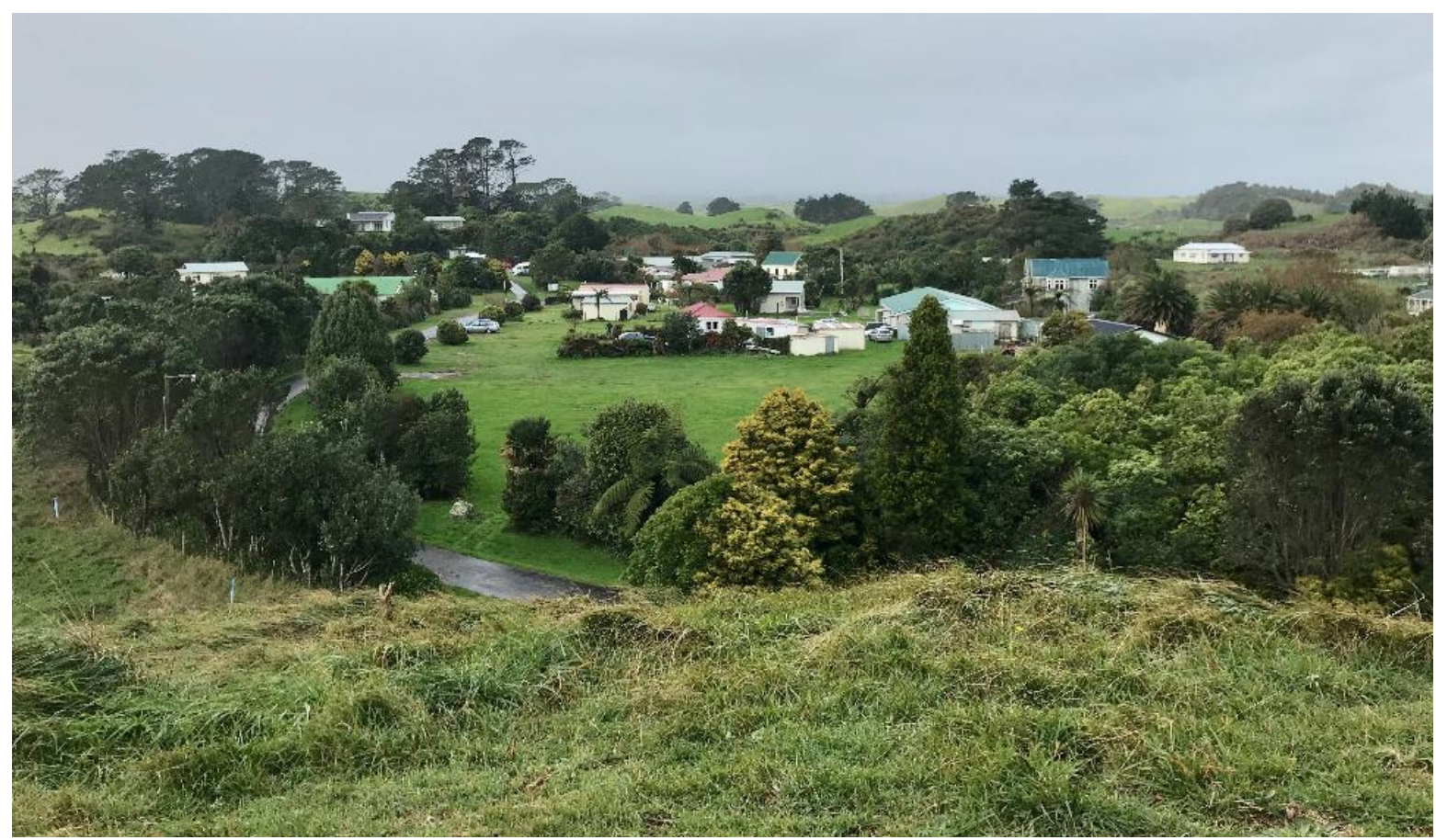

Figure 7.2: Parihaka from the top of Purepō. Photo (taken with permission) by Caroline Hamblin

After the field trip, students I interviewed recollected their time at Parihaka as being the most memorable and transformative of the entire visit to Taranaki. Being wet and cold on the top of Purepō, feeling the warmth, both physical and metaphorical of the meeting house Te Niho 
$o$ Te Atiawa, experiencing the manaakitanga (hospitality) of the village, seeing their economic struggles and feeling the emotion of people today when they speak of the pahuatanga, the sacking of the village and the arrest of their prophets, were all experiences that very much placed the body "at the centre of our experience of place/place learning (Somerville, 2010, p. 335). Carolin Hamblin exclaimed that "I feel like when you are at Parihaka you can't at all say to yourself that the past doesn't matter". For Sabrina Romanova, navigating the cultural space of Parihaka made her productively uncomfortable:

When we were at the graveyard, for me, it wasn't anything to be proud of or anything but I found it, I enjoyed it because it was easy to learn about, it was just like, you learn about white people and their disease and their churches and that's just like kind of easy and when we were at Parihaka, even though it was so interesting, I found it confronting. I enjoyed it and it was interesting and I'm glad I did it but maybe I didn't enjoy it as much, because I was uncomfortable the entire time.

When I asked further about this sense of discomfort at Parihaka, Sabrina Romanov emphasised that her feelings of discomfort were ones she wanted to bear and learn from, rather than an experience she resented or tried to resist, a position reflecting Boler's (1999) notion of witnessing in contrast to spectating (see Chapter 2). Although students such as Sabrina Romanova found navigating aspects of Te Ao Māori (the Māori world) difficult and at times awkward, students at Western College were unanimous that these cultural experiences and opportunities to participate in Māori contexts were key benefits of the field trip. The productive feelings of discomfort described by Sabrina Romanov and the desire to learn from their participation in Māori cultural contexts were all entirely dependent on their physical presence at locations of colonial violence. Their reflections demonstrate how placebased experiences are interconnected with affect and emotion which had, in this case, a positive effect on their learning.

\section{Occasioning opportunities for emotional and affective engagements with place-}

\section{based history}

Students at all schools experienced moments during their field trip of profound emotional and affective engagement with placed-based histories of colonisation. Affective engagement with the past, however, is not necessarily desirable and much research in history education highlights the destructive ways in which emotional responses to the past can legitimate violence toward those living in the present (Bekerman \& Zembylas, 2012; Zembylas, 2011, 
2014c). For students at Northern College, their affective engagement with history often had a positive impact on their learning. For one student an emotional response was necessary "if you want to start liking [the topic] and get more and more involved" (John Parks). Visiting sites was also considered a "haunting" experience for some students with Gspicemoo (a Māori student introduced previously) asking her group "Am I the only other one who felt haunted the whole time?". Another (Pākehā) student agreed, to which Gspicemoo added "I had to constantly cleanse myself because I was like "this is uncomfortable"". 45

At Northern College, students' emotional and affective engagement with places of colonial aggression tended to concentrate around a small number of distinct geographic locations on the field trip: the cemetery at Rangiriri, the church at Rangiaowhia and the memorial at Ōrākau. Sarah highlighted the structural inequality embedded within the cemetery landscape at Rangiriri in ways that no classroom-based encounter with the past could achieve. For students, the visit to the mass grave for Kīngitanga fighters at Rangiriri produced the greatest affective response compared to any other site during the first day of their field trip (see Table 7.1). For example, when I asked if anger was an emotion they felt at any stage during the field trip Kytothian was clear that this was something she felt at Rangiriri: "Definitely. It definitely came up, especially going around the gravesites...this is where they are buried with no memorial. It is just really sad. It makes me really angry". Gspicemoo agreed and connected to this site on more personal terms: "I was the same on that, like these were like my family, like where is your memorial? You did just the same. You fought for your rights and there's nothing to show for it". Lola photographed the concrete slabs representing British soldiers killed at the battle at Rangiriri (see Figure 7.3). For her Rangiriri was a place that allowed her to understand the sadness and human impact of this conflict: "But then it looks really nice but then behind it there's like nothing to show the Maoris (sic). It's really sad." Lola's reference to the location behind her photo of a nameless mass grave for Kingitanga fighters was chosen by John Parks for being "probably the most challenging to deal with". John Parks explained his reason for selecting this photo of a mass grave for discussion: ${ }^{46}$

\footnotetext{
${ }^{45}$ In keeping with Māori tradition the teacher provided water at each site for students (especially Māori students such as Gspicemoo) to cleanse themselves after visiting cemeteries, battle sites and other locations where people had been buried or killed. See also Chapter 8 for a discussion of this comment.

${ }^{46}$ After seeking advice from a respected academic and kaumātua from the Waikato, I elected not to reproduce John Park's photo of a mass grave of Māori fighters killed during the invasion of the Waikato. To do so would require the permission of Ngāti Naho, the tribal custodians of the area. I also acknowledge that the school's presence at the site without Ngāti Naho's guidance was problematic, highlighting the need for training and
} 
When they said they don't know how many bodies there are, they just chuck them in and covered it up. Every European name had a grave and even if they didn't have like their name on it they at least had the like boxes saying that was where they lay.

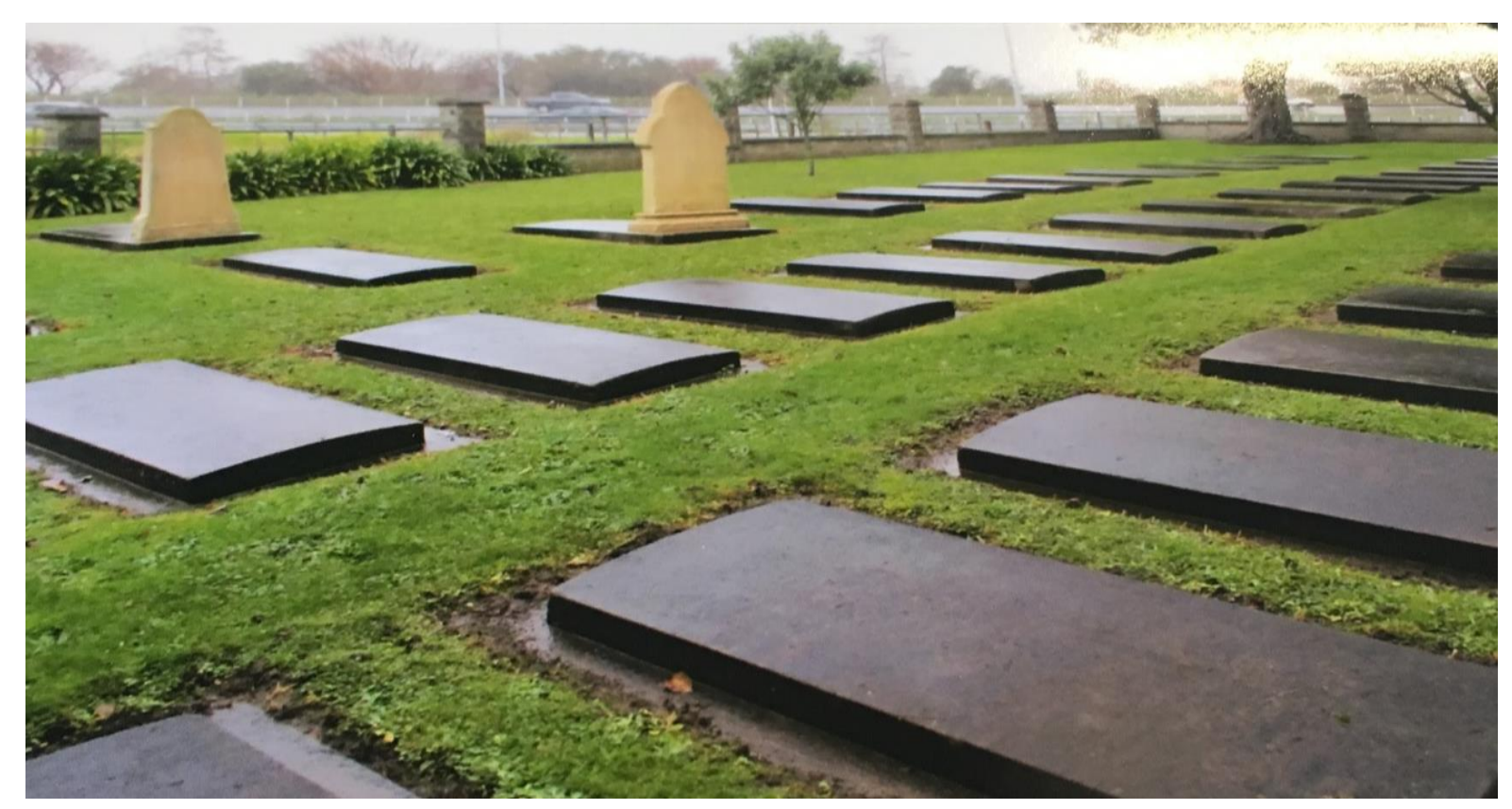

Figure 7.3: Individual gravestones of European soldiers killed during the invasion of the Waikato at Rangiriri cemetery. Photo by Lola

Visiting Rangiaowhia, a small village that was raided by colonial troops in February 1864 was also a profoundly emotional experience for many students at Northern College, evoking feelings in students of guilt, anger and sadness. Beanz said she felt "really upset in the church and also at Ōrākau". Kytothian, explained that

Sitting in the church, listening to [the museum educator] talk about all the things that had happened, I just felt really guilty because I AM a Pākehā. And just hearing all of it, I thought 'this is what the people in our past did' and they took all this land, which hasn't been resolved.

Most students did not report feeling guilt at places like Rangiaowhia. Tee commented insightfully that despite expecting to feel some guilt this did not happen because she found herself instead identifying strongly with Māori and empathising with their plight. She explained that “because I didn't relate to the Europeans so I didn't really feel guilty”. Sadness

support for teachers to ensure iwi and hapū perspectives are a central feature of lessons at sites of colonial violence. 
more strongly characterised Tee's experience at Rangiaowhia, a visit which she found "upsetting" because of the contradiction in what a church should symbolise and what actually happened at this site:

Churches are supposed to signify something that is so peaceful and lovely but something so horrible happened there. So I don't want to say irony, but of that, cos it was put up for such a nice reason for a place for people to gather and to be like at peace and to find something to praise and then something so horrific happened.

For Vanjie, the British raid on Rangiaowhia made her angry at the injustice of the event. Recounting the British attack on the settlement when Waikato Māori understood it would be a safe haven for their women, children and elderly, Vanjie stated that "it was so disgusting!....it's just a dog thing to do!". Vanjie's anger was also underpinned by sadness, bordering on grief: "and shooting at that little four-year-old, like running around...I was like trying not to get emotional!". Kytothian had to actively hold back tears when the museum educator read to the group a short account describing what a colonist had seen during the raid: "I was just sitting there [inside the Anglican church at Rangiaowhia] and I'm thinking if I keep hearing about this I'm going to cry my little life out and in front of the entire class and I'm not going to do that!". Others in the group agreed they were also fighting back tears. The visit to Rangiaowhia was significant to Gspicemoo who took a photograph inside the church (see Photo 7.5) as a site representing a particularly challenging or difficult place to deal with.

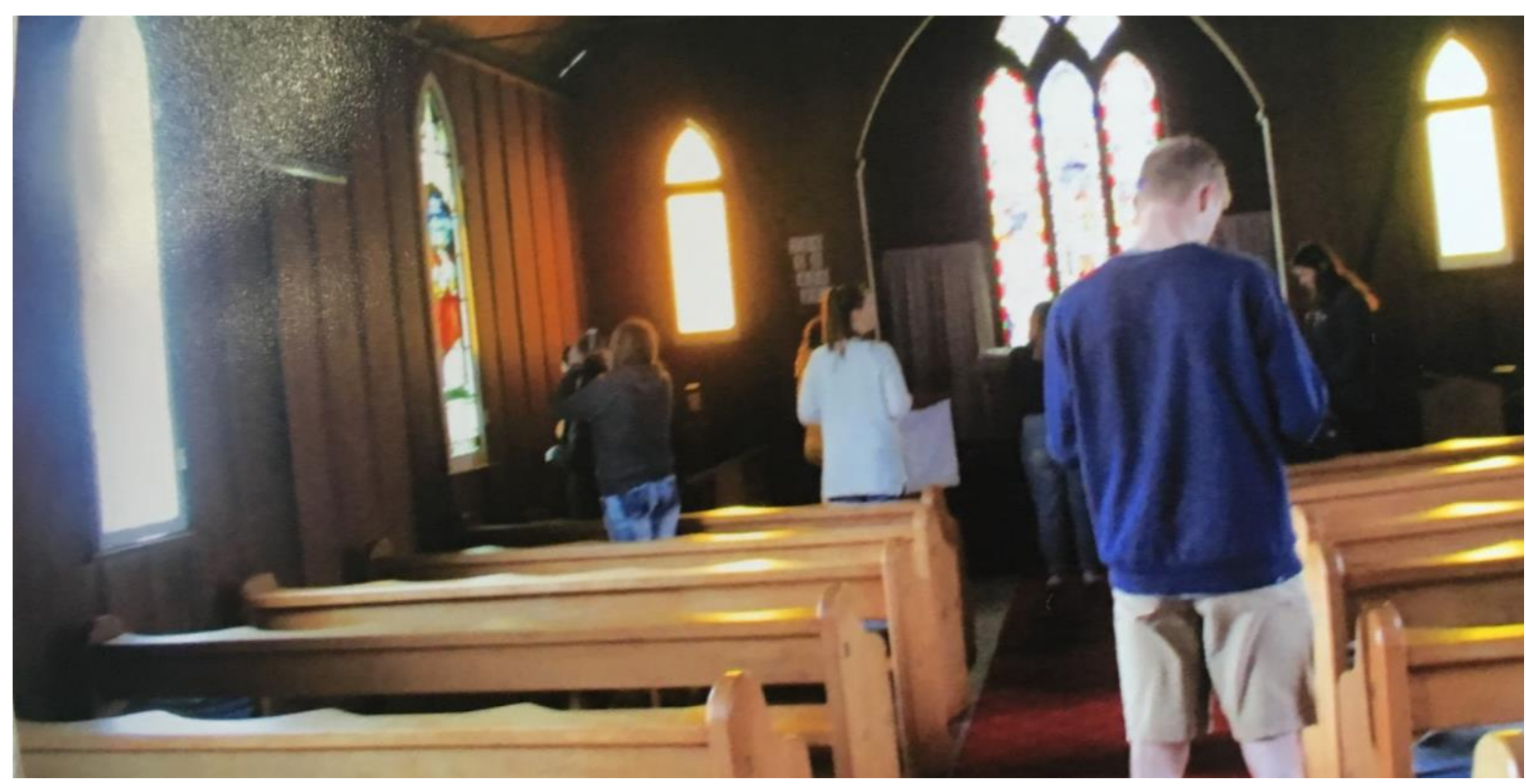

Figure 7.5: Rangiaowhia Anglican church. Photo by Gspicemoo. 
She explained that, "the stories that we got told there just STUCK with me. And just the feeling that somebody could have been right where I am in the middle, crying for their life or something. I dunno, that just kind of made me go 'ahhhhhh!'”. For some students (and for this researcher) the church at Rangiaowhia made them felt at ease whereas for others it had the opposite effect:

Cameron: Did anyone else feel relaxed in that church, kind of?

Wai: No! I felt very tensed up

Michael: Did you feel relaxed?

Cameron: Yeah

Michael: Yeah I did too what was it that...?

Cameron: I don't know

John Parks: It was peaceful, quiet

Michael: And you felt tensed up?

Wai: Yeah, I just don't feel anything in a church, I feel like I'm in like, I don't know, I'm not a church person. For Māori culture it's different for us, for our church. So we don't have like "church" we have a marae and we are just in the marae.

Wai's direct reference to her cultural identity as an explanation for her reactions to the Anglican church at Rangiaowhia highlights how sites can act as places of both belonging and exclusion for different field trip participants. Teachers and educators could use these affective responses as the basis of important conversations about how their students relate to places and interpret historical events and their contested meanings.

Possibly New Zealand's most infamous theatre of war, Ōrākau also affected students emotionally, although compared to the other two sites it did not feature quite so significantly in our discussions. This was perhaps due to the visit to this site occurring at the end of the field trip and the class spent slightly less time at this location compared to Rangiriri and Rangiaowhia. Nevertheless, at Ōrākau the museum educator explained in some detail what happened at the site. Students listened attentively and asked questions of clarification. They were particularly intrigued that someone had defaced the sign with an alternative historical interpretation; crossing out the word "battle" and replacing it with "massacre" a good example of what critical geographers call "symbolic accretion" or the "the appending of commemorative elements onto already existing memorials" (Dwyer, 2004) (see Figure 7.6). 


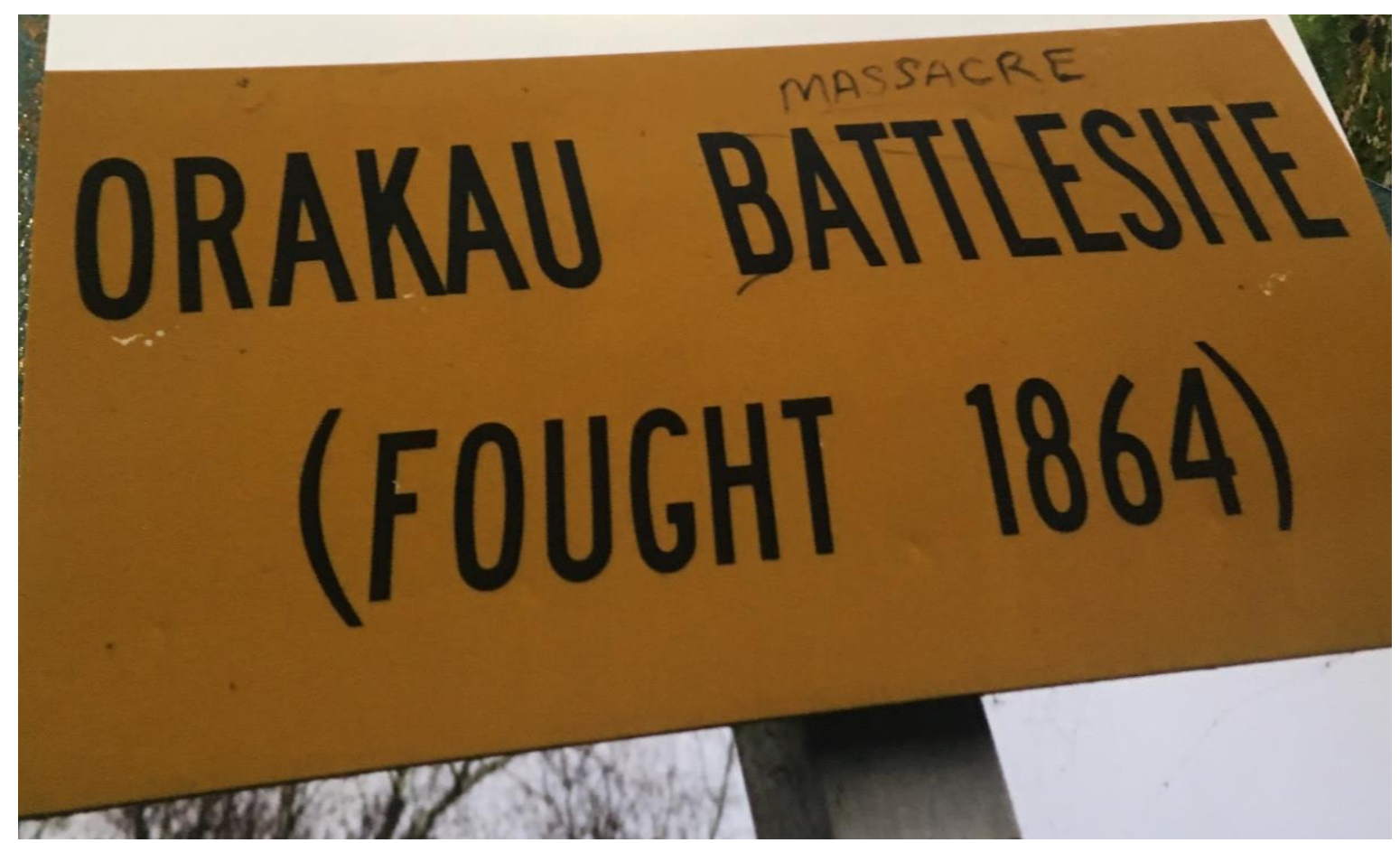

Figure 7.6: Official sign reinterpreted at Ōrākau. Photo by Gspicemoo.

Gspicemoo took this photograph "because I feel like this site was more personalised to me. It's something that I've also seen through my childhood. And I feel like 'massacre' suits it more. I completely agree with that". Vanjie reacted angrily to the fact that a road went directly through Ōrākau which she thought "defiled" the site. Finally, Gpsicemoo commented on the house not far from the memorial site and wondered how anyone could live there: "why did you build a house there? How are you not [dead]? From hauntings...”. This comment revealed again differences in the way some Māori students connected to places and discussed colonisation differently than their non-Māori peers. At Ōrākau, the sensory and affective responses generated serendipitous 'teachable moments' and revealed the pedagogical potential of place-based history. The combination of the graffitied sign, Vanjie's observation of the road, Gspicemoo's comment on 'hauntings', the museum educator's description of the aggression and suffering that took place and the simple materiality of the site all 'opened' Ōrākau as more than a mere backdrop for hearing a dominant narrative.

\section{The pedagogically constraining features of school field trips}

In addition to the significant affective responses described in the previous section, field trips also tended to invoke an emotional regime - a set of power-laden emotional rules - that 
encouraged feelings of empathy for Māori as victims of colonisation. Regimes of empathy have been observed in other international studies of difficult history (Cook, 2015; Modlin et al., 2011; Stastny, 2018; Zembylas, 2013b). In my research, it was established and sustained through a range of practices employed by teachers, museum educators and students themselves. On the one hand, students need to know about historical instances of injustice which are often sanitised or denied in settler societies (Attwood, 2017; Tupper, 2011). On the other hand, when this learning is shaped through a dominant regime of empathy it has a range of consequences that may ultimately perpetuate settler colonial narratives of history. These consequences, as stated previously, created challenges connecting the past to the present, oversimplified complex historical narratives and made it a struggle to use sites as places for difficult yet important conversations about history, power and colonisation. Although evident to some degree at all schools, it was most recognisable at Northern and Eastern Colleges, which I describe separately below.

\section{Emotional regimes of empathy at Northern College}

My study showed that history lessons at places of trauma can evoke emotional regimes of empathy that constrain students' capacity to engage productively with the past. At Northern College, empathy was evoked through an emphasis on Māori as the victims of a deeply unjust colonial invasion. For example, at the the military position of Whangamarino, Sarah cleverly curated an analysis of the site that drew attention to how unequal power relations were reflected within the site's historical markers. These did not, in Sarah's view, adequately represent Māori suffering or historical perspectives. At this site, Sarah also described the Great South Road as “chopping” through Māori land, a student responsed to the presence of the road as "very disrespectful" and another student commented on the huge powerlines that sweep across the landscape as "shitty". Collectively, examples like these indicate the presence of an emotional regime that permitted students to empathise with Māori and the negative consequences of the invasion. The 'rules' of this regime were highlighted even more explicitly at Meremere when a student subtely attempted to challenge them, as this excerpt from my field notes illustrates:

Pointing to a hill in the distance, a student says "is that where we just climbed up?" Sarah says "take photos of the strategic positions" followed by "what is the most important strategic route?" to which the students respond "the river". Sarah says "the whole point of the Great South Road being built was to invade the Waikato". It was at 
this point that a student made the point that "you can see why, it benefits everyone". This created a slight pause and was immediately followed by another student saying "New Zealand is very disrespectful to its monuments" [Fieldnotes, June, 2018]. This student's comment that the military road (now a state highway) ultimately benefitted everyone was shut down almost immediately by another student's remark that conformed more closely to the goals of the dominant, more approved emotional regime. Though a brief and seemingly insignificant exchange, it was the only time I observed a student on any field trip attempt to challenge a teachers' emphasis on the negative consequences of war and colonisation for Māori.

Sarah's place-based, critical-historical approach was effective in drawing students' attention to the destructive nature of the Waikato invasion, a war that up until then some students had never heard of. This field trip was a powerful example of a teacher working to disrupt what one prominent historian calls 'an intergenerational cycle of ignorance' concerning the New Zealand Wars (O'Malley, 2019b). At the same time, the emotional regime of empathy evoked during the field trip had some negative consequences, raising a number of pedagogical issues relevant to all teachers of history.

One negative consequence of an emotional regime of empathy is that conversations about the past's relationship to the present are less likely to occur, precluding important conversations about the legacies of colonisation in the present. For example, the brief challenge to Sarah's lesson on the Great South Road contradicted the pedagogical goal of building empathy for Māori victims of colonisation. Therefore, it did not eventuate in a potentially productive discussion about the manner in which settler colonialism, whether through colonial warfare or other means of dispossession, created the appartaus of a modern, democratic nation state (such as roads and powerlines). This is difficult territory for any teacher to tread and I am not suggesting that Sarah should have engaged students in the sterile debate of whether or not colonisation was a good or bad thing. However, the presence of this emotional regime made it more difficult to elaborate Sarah's powerful teaching about the injustice of the invasion and to extend it to issues directly affecting the present. For example, with more explicit awareness of how certain emotional regimes are evoked and cultivated, teachers could use a comment about the benefits of the Great South Road to explore challenging questions such as: Who benefits the most today from an economy reliant on infrastructure such as the Great South 
Road? Who owns the farmlands that the road passes through and the wealth generated from these lands? Is the poverty of some Māori comunities linked to the wealth concentrated in Pākehā neighbourhoods? Or, how do we ethically animate 'conflictscapes' in ways that acknowledge all pain and suffering while simultantously recognising the deep asymmetry of colonial violence perpetuated on Māori communities?

The emotional regime of empathy invoked during Northern College's field trip at times encouraged an oversimplification of complex historical narratives and perspectives. For example, a brief yet illuminating episode at the battle site of Rangiriri and captured in my field notes, illustrates how a tendency to prioritise Māori as victims of colonisation obscured or negated diverse historical perspectives that could otherwise challenge simple accounts of war:

At one of the signs [Figure 7.7] looking over the highway there was a statement about British soldiers and how they died at the very site. I waited for some students to come over to see how they would interact with the sign. One student read it aloud and at the bit where it said "where many soldiers lost their lives" she made the impression of a gun with her hand, pointed it to the ground and said "shame bitch, bang, bang, bang" and they giggled together before moving away. [Field notes, June, 2018]

The interaction of these students with this sign (ironically placed to trigger an affective engagement with soldiers) demonstrates a difficulty to view colonial aggressors as humans with their own stories to tell. Instead, soldiers were a source of ridicule for the students in the present. 


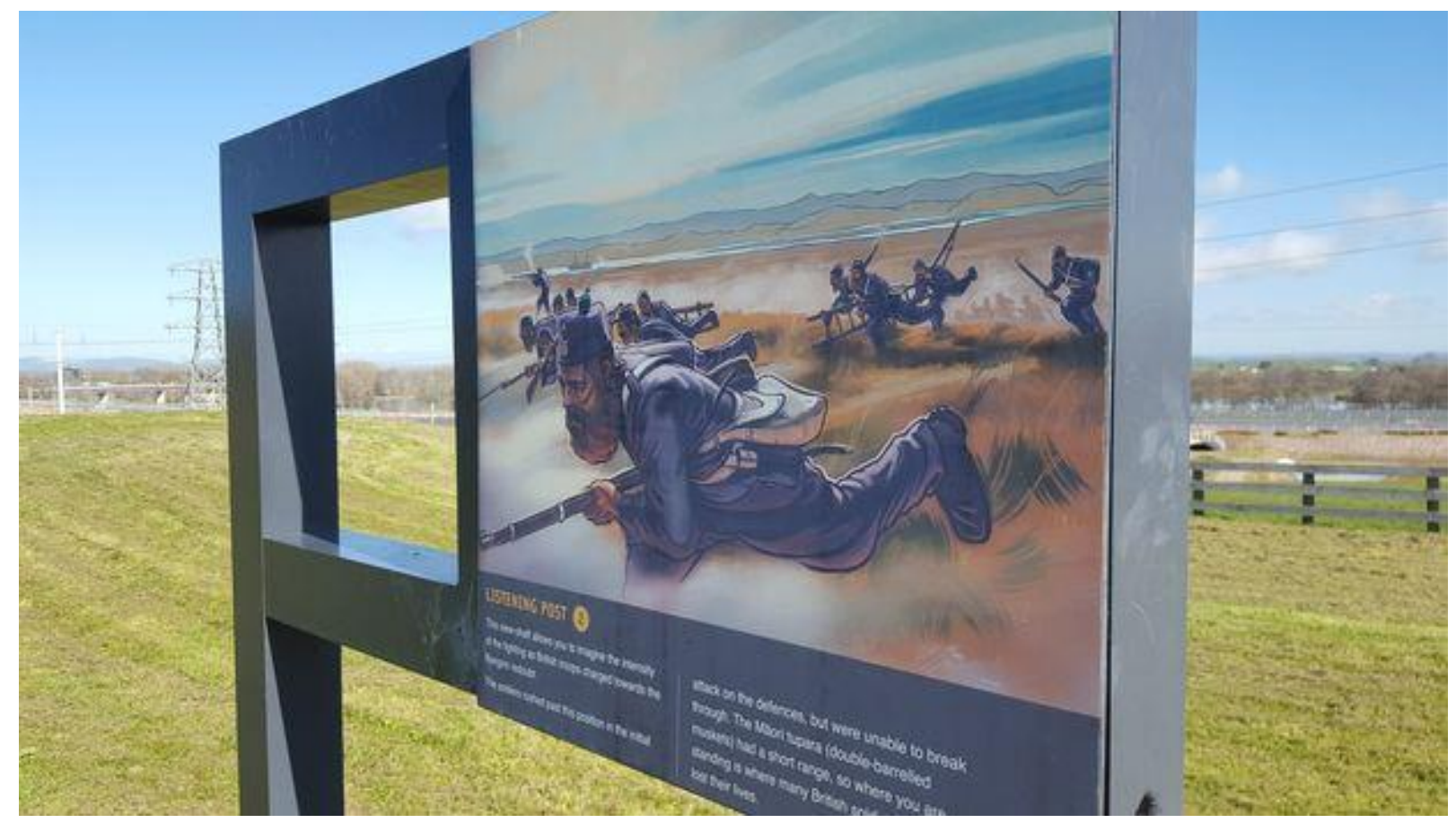

Figure 7.7: Ministry for Culture and Heritage historical display sign at Rangiriri. Photo by Shannon Haunui-Thompson and courtesy of RNZ.

When an emotional regime of empathy for Māori dominates, other histories struggle to surface including stories of the past that emphasise Māori as historical agents. For example, narratives that centre acts of Indigenous resistance to colonisation tend to be downplayed, as do the the experiences of Māori fighting alongside the British Army during conflictsEuropean soldiers fighting in wars far from home, the harsh realities of working in the British Army or the contradictions many Irish soldiers may have felt when fighting a war of disposession for the British are also less likely to emerge as part of a history lesson when an emotional regime of empathy dominates. With these latter examples there is a balance to be struck here by teachers that would make for a good point of discussion with young people. Colonial soldiers, like everyone else in this conflict were vulnerable to being killed, but in a war stacked heavily in their favour. But to not acknowledge their humanity at all, as demonstrated in the example above, has consequences for the kinds of relationships young people might form with one another. When the lives of any group from history that students may identify with are not considered worth grieving over, it makes it harder to develop what one New Zealand scholar calls "decolonial solidarities" (Mahuika, 2018). Sarah in this instance was powerless to do anything because she was nowhere near the students concerned, illustrating that emotional regimes have effects that extend well beyond a teacher's immediate sphere of 
influence. This observation also stands in stark contrast to a moment in Sarah's field trip on the following day when students handled a soldier's personal bible that still had flowers pressed between its pages. Although not described in depth here, the interaction with this artefact had a much more positive effect on students' understanding of soldiers as real human beings with hopes, dreams and fears. This illustrates that emotional regimes of empathy could, with Sarah's powerful teaching, be successfully challenged.

\section{Emotional regimes of empathy at Eastern College}

Students at Eastern College were frequently encouraged to empathise with the injustices of colonisation for Māori, limiting to some extentthe complexity of their engagement with places and their pasts. At this school, however, the emotional regime of empathy worked in more subtle ways and additional ethnographic analysis of Caitlin's field trips would be necessary to describe fully the operation of particular emotional rules at this site. The excerpt below highlights how Caitlin cultivated this empathy at one site, in addition to underscoring her culturally sensitive approach to wāhi tapu (sacred sites) described in the previous chapter:

We pulled up alongside the urupā near the Petone foreshore. Before we got out of the van one of the girls exclaimed "oh wow I didn't even realise there was a graveyard here" and "I actually want to get out of the van". Caitlin explained she did not want students going into the urupā, just to look at it from the footpath. The students took some photos and did not seem disturbed by the fact they could not enter. After five minutes or so Caitlin gathered them in and explained that there are rangatira (chiefs, leaders) buried in here and they are significant to this day through the decisions they made in the past. She asked the group, 'What decisions did they make for their people?' and reiterated that there were two major iwi (tribal) groupings in the valley, Te Ātiawa and Ngāti Toa, and that there was disagreement between them over the issues that settlers had created through their presence. Caitlin drew students' attention to the Spain Commission and how the land was effectively bought twice in ways that were not fair to Māori. She then mentioned the chiefs asking "how significant is Te Puni and Te Wharepouri to our story?" followed by "when the settlers first arrived what did they (the chiefs) do?" "Gave them food?" a student responded. "Yes" Caitlin replied, they "were feeding settlers for some significant time". The conversation then turned to the actual site and how the urupā is surrounded by industrial buildings. Caitlin talked about how the site had in the past been vandalised 
underlining the irony here that, "Māori had actually welcomed settlers". She emphasised that an urupā is a sacred space and explained about the use of water upon leaving an urupā, and how "you leave one part of our world for the next" and this transition was enabled by water. Students washed their hands with water provided by the teacher. In the van I asked if she had ever allowed students in and she said no. For her it was too tapu (sacred) and she wasn't confident in navigating the complexities required to visit the urupā in culturally safe ways [Field notes June, 2018].

It is worth reiterating here that Caitlin (and Sarah's) desire to highlight the negative consequences of colonisation did help to break down ignorance of colonial injustices often silenced by contemporary settler society. Nevertheless, for Caitlin's field trip, creating 'iwi' and 'settlers' into relatively homogenous entities and evoking empathy for the former as illustrated in the vingette above arguably limited the development of more nuanced historical categories, thereby constraining a richer engagement with complex and highly contested histories of colonisation of the Hutt Valley and Porirua regions. For example, describing only two dominant tribal groupings may have been a pedagogically strategic decision, but it is unlikely to have conveyed the level of historical contestation over land in the Huttt Valley to students. Settlers in Wellington also were a deeply divided group (McLean, 2000) and later on in the field trip, at the St Alban's cemetery, a female student was captivated by a head stone that described an early settler woman's experiences of colonisation in the Hutt Valley. As evidenced in an earlier section of the previous chapter, this student lamented the fact that womens' histories of colonisation are rarely taught in school. The visit to places like the urupā and settler cemetery, while powerful in many ways, could have more deliberately explored the different historical experiences of those buried and the context of settler colonialism they all operated within. Caitlin's teaching could have been extended through the following kinds of questions: What women were buried in the urupā and cemetery? What agency did they have in history? What were their stories? Did any students trace their ancestry to particular individuals buried at the different buriel grounds? What were the different ways in which these people were affected by, and implicated in settler colonialism? (see Figure 8.1). Questions such as these could lead to deeper understanding of the historical experiences of people from different tribal, cultural and socio-economic backgrounds, potentially forging solidarities and relationships of trust among students with different social identities and perspectives. 
Like other schools, the content of Eastern College's field trip tended to focus on the historical nature and consequences of colonisation, encouraging students to empathise with Māori as victims of this process rather than active agents, constantly looking for way to maintain and secure their land. As a pedagogical goal, this approach did not tend to promote explicit discussions about the implications of historical injustice, the responsibilities it might produce for people today and the manner in which Māori continue in this struggle. For example, students spent some time gathered around a memorial commemorating the lives of Pākehā soldiers killed during the battle at Boulcott's Farm May, 1846 (Figure 7.8).

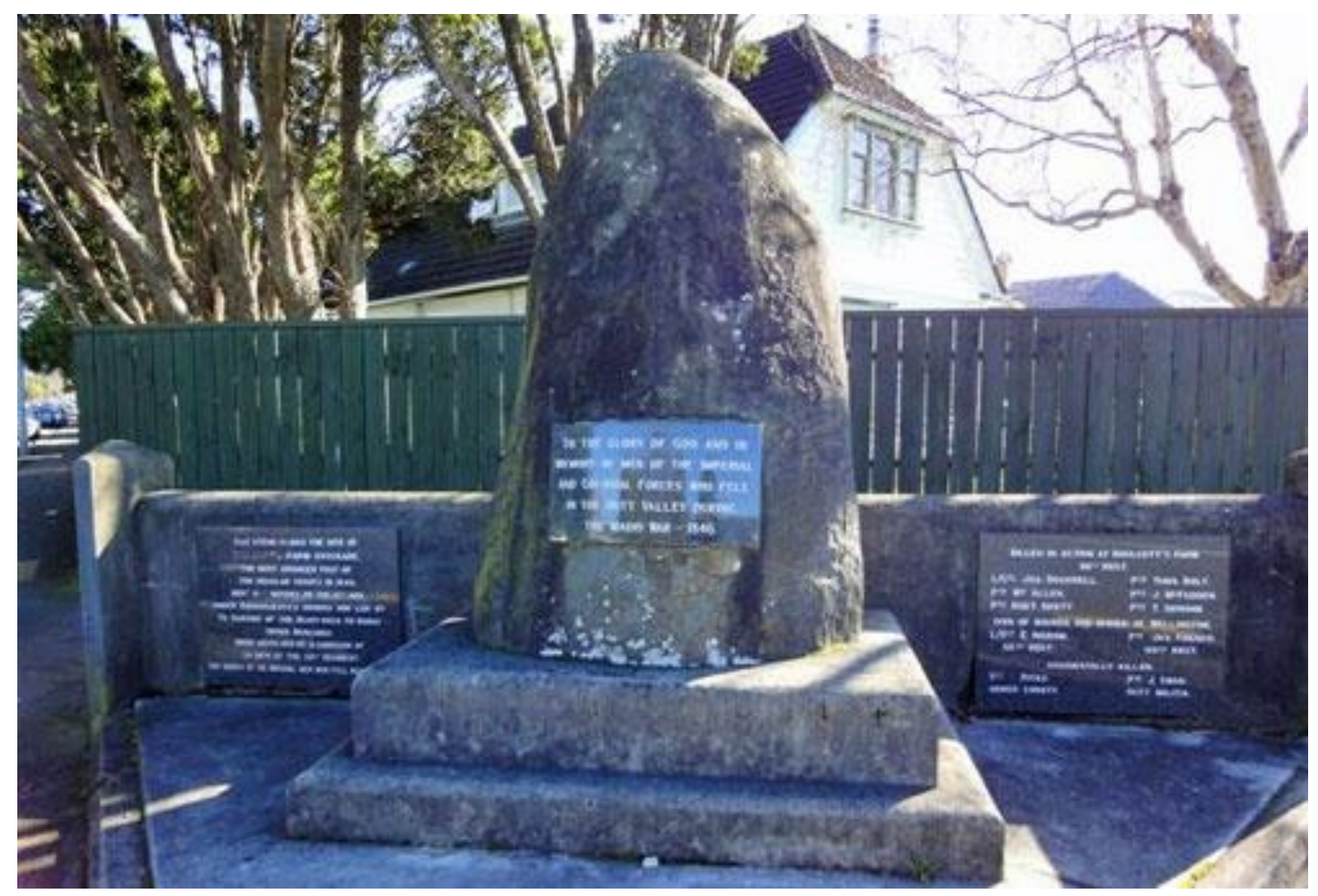

Figure 7.8: Memorial to the soldiers killed at Boulcotts Farm, May 1846. Photo by Gary Lewis/NZHistory

As the fieldnote below shows, students easily recognised the perspective-laden nature of this memorial and the manner in which it represented a settler-colonial world view:

As students were looking at the inscription and taking photos a student said "why are there only British names?" Caitlin moved the group around the back of the memorial so students weren't so close to the road and started off by saying that this was a 
"highly contested monument". She said "think about perspective". One student then said that that it was a settler perspective and it suggested that their actions were more significant than Māori. Caitlin asked "what were they fighting for?" with responses like Queen, power and sovereignty following. She then asked "what does it not show?" [Fieldnotes, June 19, 2018].

These questions clearly indicate Caitlin's commitment to critical approaches to history education (see Chapter 3). However, shortly before we moved on to the next location, she made a brief reference to the present asking "why is [the memorial] so contested and what could be done?" followed by "is it possible to change (representations of the past)?". These useful and provocative questions, emerging spontaneously at the end of the site visit did not lead to any responses from students, the main purpose of which was to discuss historical power relations. Significant opportunities exist here for teachers like Caitlin to extend existing practices and more deliberately engage with contemporary questions of power and the legacies of historical injustice.

\section{Feelings of disconnection at key sites at Western College}

Aspects of Western College's field trip to key battle sites of the conflict in 1860/61 in Taranaki illustrate some of the enormous challenges all teachers face when designing field trip experiences, especially ones that function as a counter narrative to dominant versions of New Zealand history. For example, many students I interviewed at Western College struggled to understand the significance of key locations and how they fitted into an overall historical narrative. This led to feelings of disorientation and disconnection during important stages of the field trip through Taranaki. Wolfgang, for example, explained that "I'm unaware if there was like a whole journey, of like one war that went along all the places we went to or if there were multiple wars or iwis (sic)....like, I don’t know”. Other students commented that:

Bella Forbes: I think in general students had a hard time piecing together everything that had been happening cos we'd go to one place and learn about what had happened and you'd go to another place.

Caroline Hamblin: You don’t know who's where...

Bella Forbes: You couldn't like order it all and you didn't have the visuals so that pā sites were literally just like....

Nutmeg Sox: Fields... 
Bella Forbes: ....lumps, like that sounds bad but you know....

Caroline Hamblin: But it was, you don't know what it means.

Some students felt that their feelings of disconnection had consequences for the way they acted at certain locations:

Because I feel that affected the way we all sort of behaved at each place because the attitude towards them: 'I don't know why we are here, I'm bored, I just want to go back to the hotel' and so that sort of affected the way we took it and that was why it was so different to Parihaka because everyone was so respectful because we understood what was going on, but in other places there was no context so there was no... so it was like 'can we leave now?' (Myah).

Another student explained that “generally everywhere we went...we didn't really understand the significance of each place". At Te Kohia, the site where, according to Belich (2004) "New Zealand's great civil wars of the 1860s began", Caroline Hamblin explained that "we were all standing there like "can we go? We don't know what is going on". Students also reported that the interactive methods used by the museum staff at Puketakauere and Pratt's sap, while fun and engaging, did not develop their understanding of the brutality and violence of a war waged against an Indigenous people defending their lands against settler invasion:

Michael: Wolfgang, you were shaking your head? You didn't get that sense that these, that intense suffering had taken place at these sites?

Wolfgang: I think I just remember, the guy who gave us the gun. I was just like 'oh this is just a gun'. I didn't get the sense of brutality - at all.

Despite these feelings of disconnection, they did not fundamentally detract from the overall field trip experience. Students were also sometimes able to use these negative experiences to reflect deeply on the importance of the places they visited. For example, Myah saw in her own disengagement at Te Kohia a bigger problem at stake: "Like the fact that we going to these places, we didn't understand why we were there and to us they just looked like fields but they had so much historical significance to our country and I think that is the problem in itself'. 47

\footnotetext{
${ }^{47}$ After receiving some of this feedback from this field trip, Hannah and her colleagues made significant changes to the following year's journey to Taranaki. Hannah explained to me that based on the changes, she and her colleagues were much more satisfied with the way that students responded during and after their field trip experience. (Personal communication, 22/08/19)
} 


\section{Summary}

For participants of all schools, field trips regularly functioned as a powerful counter narrative that challenged the sanitised notions of history that downplay or ignore the violence that sits at the heart of settler colonialism (Walker, 2004; Wolfe, 2006). For example, Caitlin and Sarah's careful curation of particular sites and the power relations embedded within the material environment illustrated the strength of teachers using their local regions as a 'landscape of memory' (see Chapter 3) for developing students' critical historical consciousness. The exposure of Hannah's students to Māori cultural contexts enabled face-toface encounters and learning from, and not simply 'about' Māori histories (see Chapter 2). These examples, including students' profound affective engagement unlocked by visiting particular locations all reinforce the power of field trips to operate as a counter narrative with the potential to challenge dominant and settler-centric histories that minimalise the significance and consequences of colonisation.

In addition to these important successes, field trips also invoked a regime of empathy that was effective at recognising those with less power. However, this regime had a contradictory and at times less positive outcome because it also made colonisation safe and put difficult questions about the settler-colonial present and its relationship to the past out of reach. This presents a profound challenge to teachers of history because as the examples above show, an emotional regime of empathy frequently intersected with the successful aspects of teachers' field trips. The field trip run by Sarah at Northern College, for example, offered the clearest example of an emotional regime of empathy at work but it was also the field trip that led to the most observable shifts in students' knowledge, producing deep emotional and affective encounters with the past that challenged students' ignorance of the invasion of the Waikato and developed their historical understanding of these events. This paradox illustrates the complexity of teaching difficult history. It further reinforces the importance of shifting recent conversations in New Zealand from mandating certain historical contexts toward discussions that recognise the profound pedagogical challenges that emerge when young people engage with New Zealand's difficult histories of colonisation. In the next chapter, I contribute to this conversation by highlighting key themes from the previous three chapters and discussing the implications of these findings. 


\title{
CHAPTER 8: DISCUSSION OF FINDINGS
}

\author{
Every emotional response is pedagogically fruitful, since it reveals an implicit struggle with \\ the ethical aspects of encountering difference
}

Sharon Todd (2003, p. 146)

\section{Overview}

In this thesis I investigated how teachers and students engaged with New Zealand's difficult history of colonisation. More specifically, I set out to explore teachers' and students' conceptions of the contested subject of colonisation in New Zealand, the pedagogical complexities experienced by exemplary teachers and their students during their senior history lessons and finally the role of field trips in shaping students' encounters with difficult histories of place. I was particularly interested in exploring the emotions evoked when young people are confronted with the historical injustices of colonisation, whether inside or outside the classroom. In this chapter, I discuss two significant 'patterns of engagement' evident in the findings outlined in Chapters 5-7 and which respond to the lines of inquiry above. By patterns of engagement I mean common actions and practices, guided by particular conceptions of history that are shared among the community of history and social studies teachers and their students in New Zealand.

The first pattern of engagement I discuss relates to the teaching of Māori history, knowledge and perspectives. As would be expected, teachers demonstrated approaches that varied in the degree to which they might be considered critical and transformative. ${ }^{48}$ At the more critical

\footnotetext{
${ }^{48}$ As outlined in Chapter 1, this includes: Teachers support students to build the knowledge needed to recognise colonial narratives and the historical basis of contemporary New Zealand settler society, particularly the relationship between the past and the present; Teachers engage with, and support students' engagement with Indigenous epistemological traditions and Indigenous peoples' stories of place, told on their terms (Rey \& Harrison, 2018); Teachers explore their own, and encourage their students to explore their emotional responses to historical injustice in ways that ask probing questions about the roots of their "values and cherished beliefs" (Boler, 1999, p. 176) [This includes their attachment to these responses and the role of these emotions in maintaining or challenging (settler-colonial) relations of power (Zembylas \& McGlynn, 2012)]; Teachers develop in themselves and their students "a critical understanding of the conflictual past through the cultivation
} 
and transformative end of the spectrum, some key themes emerged which together highlighted what 'bihistorical' teaching might look like in practice. The second pattern of engagement concerns the nature of students' emotional discomfort when confronted with the historical injustices of colonisation. In this section, I discuss the ways in which expressions of anxiety, resentment, anger, guilt and indifference were significant for students in classrooms and during field trips and valuable entry points for teaching. These dominant patterns of engagement with history lead to a number of implications for policy makers and the wider teaching community, which I address in the latter part of this chapter.

\section{Teachers' pedagogical efforts to engage with Māori communities and history}

\section{Critical and transformative approaches}

Some of the teachers in this study illustrate how 'bihistorical' teaching (Binney, 2009) demands an engagement with Māori history and its epistemological and ontological standpoints, which may not always reflect disciplinary norms and criteria. In addition, teachers' pedagogical engagement with colonisation demonstrates that bihistorical teaching introduces students to counter narratives, or accounts of the past that speak back to and challenge colonial histories and legacies that ignore, downplay or sanitise New Zealand's history of colonisation. Although Binney's (2009) original notion of "becoming consciously bihistorical" (p. viii) was intended for historians, it is a concept well suited to theorising what a critical and transformative history education might look like for New Zealand.

All four teachers I spoke with and observed shared a willingness to include Māori tribal histories into their curriculum, histories they knew were often located in material places well removed from the classroom. This willingness was indicated by their desire to plan and carry out field trips in collaboration with other community members, including tribal custodians of the histories being visited. Hannah, as described in Chapters 6 and 7 was particularly successful at working with people at Parihaka and other parts of Taranaki such as the Māori staff at a local museum and the community at Ōwae marae. This field trip demonstrated a clear example of a teacher who took seriously the idea that secondary school students can

of historical thinking, empathy, an overcoming of ethnocentric narratives and the promotion of multiperspectivity" (Psaltis, et al, 2017, p. vi). 
learn from, not merely about Indigenous people (Harrison \& Greenfield, 2011). Hannah's practice also highlighted the significance of teachers spending considerable time (in Hannah's case a period of years) cultivating relationships of trust with the right people.

The teachers I worked with were for the most part comfortable navigating different historical approaches and were not limited by binary distinctions between "Indigenous" and "nonIndigenous" worldviews that sometimes characterise scholarly debates (see Chapter 2). In fact, some teachers appeared particularly adept at slipping seamlessly between different epistemological orientations toward the past without feeling contradicted. Caitlin, for example, taught students to use evidence to develop a causal argument about the New Zealand Wars, and not long after facilitated a conversation about the nature, purpose and cultural significance of taniwha (see Chapter 6). On the field trip Caitlin also moved fluidly between establishing the historical significance of a place, including its broader historical context, and explaining the difference between tapu and noa ${ }^{49}$ and why she was not prepared to navigate the spiritual world of an urupā. Peter had also learned from local iwi historians that

In a way you live in the past, not that the past is over here that you look at, you examine and pick it up and you arrange it as you wish, it is actually just something that is there and its part of you. (Chapter 6)

This understanding, and the relationships with tribal experts he had developed in coming to this knowledge, had a significant impact on the way Peter designed curriculum across year levels. He was continually looking for ways to centre Indigenous knowledge and perspectives, develop students' historical thinking and, where possible, facilitate visits to nearby places of significance including to local marae. Teachers like Peter and Caitlin clearly demonstrated an 'ontology of teaching' that reflected the notion of intercultural translation (see Chapter 3). They demonstrated a way of being in the world that intuitively valued "hybrid forms of cultural understanding" (Santos, 2014) as they sought to stake out a middle ground that acknowledged the value of engaging with Māori histories and the power of disciplined historical thinking (p. 212).

\footnotetext{
${ }^{49}$ See glossary of terms.
} 
Some of the teachers in this study showed that finding ways to connect the past, present and place forms a key component of bihistorical teaching. This includes an explicit recognition of colonisation as a structure, as illustrated by Peter's statement that "I get concerned by notions of the "colonial past" because I don't see it as finished and I don't see it as something that we can parcel up and see it as something that happened then" (Chapter 6). The effect of this belief on Peter's practice was evident in the passion and ease with which his students' talked about the significance of history and its connection to contemporary issues. A different kind of example from Sarah's field trip illustrates how even when not intended, her commitment to taking lessons outside the classroom created a space for the expression of a different epistemological understanding of the relationship between past, present and place. To illustrate, some students at Northern College recognised what Bevernage (2010) describes as "memories of offence" (p. 121). These memories of atrocity "refuse to let the past go" and “insist that the past habitually 'haunts' the present" (p. 116). As outlined in Chapter 7, one (Māori) student (Gspicemoo), reflecting on her field trip experiences throughout the Waikato, asked "am I the only other one who felt haunted the whole time?" and "I had to constantly cleanse myself because I was like 'this is uncomfortable"”. At Ōrākau, this same student commented on the "hauntings" that people living in a nearby house must experience and could not understand why anyone would live there. For Bevernage (2010), 'memories of offence' such as those described by Gspicemoo "[refuse] to let go of the atrocious past and [keep] it 'alive' in all its frightening proximity" (p.126). This refusal to let go, to insist that difficult histories are just as much difficult 'presents', experienced in certain places, speaks back to "the absent and irreversible dimensions of the past [promoting] the attitude of letting 'bygones be bygones"” (p. 154). Whether or not this kind of response from a student was intended, Sarah's dedication to taking history instruction outside the classroom made this response possible, opening opportunities for a deeper engagement with a place of deep trauma and suffering.

In addition to opening spaces for Māori approaches to history, the teachers in this study expressed views and used the conceptual tools of the discipline to challenge a colonial version of New Zealand's national history. They did this by recognising the ongoing and destructive nature of settler colonialism and introducing counter narratives into their curriculum (Goldberg et al., 2006). In Chapter 5, for example, I showed that teachers overwhelmingly recognised that colonisation affects contemporary life in New Zealand and 
that it was far from a 'benign' process. Many of these teachers also valued classroom strategies such as discussion, connecting the colonial past to the present and teaching students key ideas of historical thinking such as multiperspectivity (McCully, 2012). Although a number of significant obstacles likely prevent these conceptions of colonisation bearing full fruit in classrooms, the bicultural turn within historiography in recent decades has clearly had an influence on the way many history teachers think about the past and their ability to respond to Eurocentric interpretations of New Zealand history.

My research participants in the four colleges illustrate in deeper ways the commitment of some teachers to a critical and transformative history education that prioritised counter narratives. Such teaching, however, could not simply be taken from a text book and delivered in the same manner as other topics commonly taught in New Zealand such as the Russian Revolution or Nazi Germany. For my four participants, units of learning about the history of colonisation appeared to be in a different category of significance. They were morally invested in ensuring that their students developed an evidence-based historical understanding of New Zealand's history of colonisation, a history they frequently considered unrecognised by society. Sarah's realisation early in her university days that she knew very little about her own country's history and her commitment to ensure none of her students were ever in that same position is one example of this deep personal commitment to teaching counter narratives (Chapter 6).

In classrooms and on field trips, teachers' counter narratives frequently emphasised the destructive effects of colonisation and the brutal consequences of conflict for Māori. As I show in Chapter 7, this approach had some negative implications. Nevertheless, these teachers successfully engaged students, combating their prior ignorance or even apathy, and developed in them a desire to learn more. Students sometimes compared their prior understanding of New Zealand history as "squeaky clean" (Southern College), or "mellow" (Western College) in contrast to their more realistic understanding gained during history lessons. Counter narratives also had the effect of challenging some students' total ignorance of the New Zealand Wars (Chapter 6). As one student explained, his response to being told about the Waikato invasion was "but wait, there was a war in the Waikato?!” (Chapter 6). 


\section{Less critical and transformative approaches}

A number of teachers surveyed indicated that they need more support and resources to ensure that iwi and hapū perspectives were a part of their curriculum (Figure 5.8). Furthermore, teachers appear to find it difficult to take their teaching outside the classroom (see Chapter 7), which may also account for why they struggled to access these Māori perspectives. Interestingly, over a quarter of teachers did not think insufficient access to iwi and hapū was a challenge for their teaching (Figure 5.8). While this may be because they already have good relations with local iwi and hapū, this is unlikely and suggests a deeper issue of knowledge, epistemology and 'curricular gate keeping' (Thornton, 2005). Caitlin and Sarah's struggle to collaborate with iwi and hapū illustrates in more detail the challenges teachers are likely to face and the unlikihood that over a quarter of teachers already work closely with their Māori communities. Furthermore, the Māori History Project, (the only formal Ministry of Education programme explicitly designed to support secondary school teachers to work with mana whenua) was terminated after only two years in 2017. Until Māori perspectives, knowledge and epistemology are integrated more deeply into school programmes, which includes lessons beyond the school site, it is unlikely that history education can play any major role in challenging settler narratives of history, narratives that consolidate and reinforce settler society.

In this study, critical and transformative history education was further constrained by the struggle to draw past and present connections and to foreground the legacies and ongoing manifestations of colonisation. In Northern Ireland, the educationalist Alan McCully (2018) argues that history teaching "involves students in continuing dialogue between the events of the past and the present" (p. 163). Although teachers in the survey overwhelming claimed they connected the colonial past to issues affecting New Zealand today, on the ground, the situation was more complex. Furthermore, these survey responses need to be considered alongside the indication by many teachers that the "rawness" of local histories of colonisation did not provide a significant challenge to teaching history (Chapter 5). Even if teachers are not aware of the mamae (pain) caused by colonisation, many of their Māori students surely are, a point underscored by some Māori students at Northern College (Chapters 6 and 7).

None of the four teachers in my school-based sites denied the significance of teaching about legacies of colonisation or the importance of drawing stronger past and present connections. 
Two teachers, however, did find it more challenging to answer questions about how they linked past and present when teaching New Zealand's history of colonisation. As demonstrated in Chapter 6, when responding to a question about the teaching of historical legacies Caitlin asked "how do you bring it through to the present day apart from the memorials?" Hannah also explained that the pressures of assessment meant that "we wouldn't do too much (teaching about legacies of colonisation)". These responses do not reflect the position that "history is an intense, constitutive part of the present" (Santos, 2014, p. 209). Although both teachers were exemplary at discussing issues of power in the past, these conceptions, and the context in which they were formed, made it more difficult to develop pedagogies that encouraged critical dialogue about contemporary issues and their basis in the 'structural' nature of colonisation.

\section{Students' emotional discomfort when learning the history of colonisation}

In this section I discuss the nature of students' emotional discomfort when confronted with the historical injustices of colonisation in New Zealand. ${ }^{50}$ More specifically, I explore the extent to which expressions of anxiety, resentment, anger, guilt and indifference were significant for some students and potentially capable of transforming learning and repudiating settler-colonial ideologies. As outlined in Chapter 2, some theorists endorse a pedagogy of discomfort as an important approach for educators concerned with social justice (Boler, 1999; Zembylas, 2015). To reiterate from an earlier chapter, this is a pedagogical tactic that does not cultivate particular emotional responses but instead deliberately focuses on feelings of discomfort as a way to work through the challenges of difficult knowledge. Its goal is to "uncover and question the deeply embedded emotional dimensions that frame and shape daily habits, routines, and unconscious complicity with hegemony" (Zembylas, 2015, p. 166). In providing specific examples of students' discomfort I am not suggesting these are representative of broad patterns of emotional engagement with the past from which generalisations about how to teach can be made. Instead, each example presents an illustration of the emotional possibilities open to young people and how these shape their engagement with difficult histories of colonisation. Collectively, these examples show the importance of teachers being alert to the complex nature of their students' emotional

\footnotetext{
${ }^{50}$ Teachers also experienced emotions of discomfort, though in this study it was the students (in surveys and in schools) who more openly discussed and described their affective responses to learning New Zealand's history of colonisation.
} 
expressions when they are confronted with historical injustice. Paying attention to the vicissitudes of students' emotions, including how these responses can generate flows of affective energy that may establish harmful dominant emotional regimes, ultimately helps teachers to "practice alternative visions of affective spaces and communities in schools practices that are grounded in solidarity, human vulnerbility and social justice" (Bekerman \& Zembylas, 2012, p. 194).

\section{Anxiety}

Feelings of anxiety were evident among some of the students I spoke with in schools. Although anxiety was not usually interpreted as a significant emotional challenge, when it was present it had important consequences for the way students engaged with difficult histories of colonisation and their classroom peers. For one student at Western College, the anxiety she felt during the visit to Parihaka added educational value for the very reason that it made her feel "uncomfortable the entire time" (Sabrina Romanova, Chapter 6), heightening her awareness of her own cultural locatedness as a Pākehā New Zealander. The 'Pākehāspace' of a settler cemetery, in contrast, did not provoke her in the same way, despite the lessons here focusing on suffering and the death of settlers who perished in battle or through disease while living in the besieged town of New Plymouth. It was rare for a student to so explicitly recognise the value of feeling discomfort during a history lesson and her anxiety was clearly experienced as transformative to their learning. In contrast, at Northern College, John Parks' described the "nastiness" (Chapter 6) of the invasion of the Waikato. For this student, these feelings of anxiety were to be avoided and, as he explained, served as a possible reason to disengage from the history of colonisation in his region.

Anxiety also shaped the willingness of Pākehā students to discuss the past in the presence of their Māori peers. At Western College, for example, students all acknowledged that they felt anxious about class discussions because of "how tricky it can be to discuss things without coming across as racist" (Bella Forbes). Sophie Hill from Western College also claimed that unlike the field trip, where there would be many Māori students in attendance and therefore a greater risk of saying "something really uneducated" she felt freer to speak during classroombased history lessons "because we don't really have a lot of Māori students in class". For these Pākehā students, learning about colonisation with diverse others could have been a sensitive issue due to a need to protect their anti-racist credentials. If this was the case, this 
fear of being labelled racist - what DiAngelo (2018) calls 'white fragility' - can prevent deeper explorations of history, promote Pākehā complicity in settler society and, most importantly, inhibit difficult conversations about moving together beyond colonial relations (Bell, 2006, p. 259). These same Pākehā students, however, were also desperately searching for their own identity and place within New Zealand society. They were frequently doing so, as the comment by Sabrina Romonov shows, with bravery and humility. One challenge for teachers is recognising the line between students' anxious desire to recognise responsibility for historic wrongs and feelings of resentment.

\section{Resentment}

Students who expressed resentment at New Zealand's history of colonisation present teachers with a particularly challenging form of emotional discomfort. In the main, this was not a large proportion of students and by far the clearest indication of resentment came from anonymous survey respondents. The comment from one survey respondent that "all we did was improve the damn country" captures most clearly the depth of resentment felt by some students (Chapter 5). Those who resented learning New Zealand's history of colonisation also tended to explain away colonial injustice or expressed other settler-colonial ideologies such as colonisation as a "civilizing mission" (Bell, 2006, p. 256). For example, one student claimed that land acquired from Māori led to the introduction of industries, technology, religion and trade opportunities which collectively "[made] New Zealand a more civilised country" (Chapter 5). Another student, illustrating the social-Darwinian ideology of colonisation as the 'survival of the fittest' claimed that "it's the history of the world. White man come to country, white man ends up on top".

Negative emotions of resentment present teachers with a dual challenge. History lessons might trigger resentment and the airing of racist settler-colonial ideologies like those above. Or, by avoiding the history of colonisation and the risk of these sentiments being publically expressed, students' views are left intact. For Bekerman and Zembylas (2012) “it is insufficient to change students' mistaken views simply by criticising them as wrong or as illegitimate" (p. 192). Instead, teachers need to find ways to "[follow] the process and rationales by which [students' views] were formed in the first place (Burbles, 2004, cited in Bekerman and Zembylas, 2012, p. 193). For feelings of resentment to be interrogated as a resource for transforming students' engagement with the history of colonisation, emotions, 
especially negative ones like resentment, must be the starting point for critical analysis by teachers and their students.

\section{Anger}

Expressions of moral anger (in contrast to its defensive version), appeared to hold pedagogical promise for some students (Boler, 1999). Like resentment and anxiety, however, moral anger was also an emotional response expressed relatively infrequently by students. At Southern College, evidence of historical injustice made Elizabeth angry which resulted in her desire to take action as a young person passionate about contemporary social justice issues. This included Elizabeth wanting to learn more history and potentially start learning te reo Māori (the Māori language). Elizabeth also appeared angry at the quality of her social studies lessons and wanted to make up for the learning she felt she had missed out on through selection of an optional senior history class. At Western College, some students were also angry at the economic disparity they saw existing during their field trip between Māori and Pākehā communities. They were particularly irrate that the government's 2017 financial settlement for the sacking of Parihaka in 1881 was less than the fundraising efforts to earthquake strengthen a settler church in New Plymouth. It was partly as a result of this anger that motivated Carolin Hamblin to give a presentation at her church about the injustice at Parihaka's sacking.

Students at Northern College also expressed anger but these students were more explicitly upset at the unfairness of past actions. For example, when talking about the raid of Rangiaowhia, a village that acted as a haven for women, children and elderly during the invasion of the Waikato, Vanjie claimed that "it was so disgusting!...it's just a dog thing to do!" (Chapter 7). This anger at historical injustice, felt also at the site of the mass grave for Kīngitanga fighters at Rangiriri, motivated students at this school to want to learn more about events they had not all recognised as hugely significant or were even aware had taken place. The anger felt by one group of students at this school led to their desire to follow up primary source evidence that the museum educator referred to during their field trip.

Outrage at what students thought was unfair transformed students by generating an oftentimes intense desire to learn more about difficult histories of colonisation and sometimes to take action in the present. While students' moral anger presents teachers with some 
important opportunities, it also highlights an important challenge. Zembylas (2018) explains that:

I am concerned that even when there are 'good intentions', there is always a risk of forcibly or coercively causing students to act, think and feel on the basis of a certain ideology that promotes particular political emotions, regardless of how 'noble' those emotions might be. (p. 2)

In Chapter 5, one insightful comment by a student in the survey highlighted the same concern when it was argued that "if people learned more of what happened and less of how they should feel about it there would be less distrust over the issue". Similarly, Barton and Levstik (2004) argue that controlling students' emotional responses such as moral outrage at injustice is not a desirable form of pedagogy. Instead, for these educators "the point is to give [students] the chance to engage in reasoned judgement through public deliberation, not to determine the outcome of that deliberation" (p. 102). If feelings of outrage and anger at the injustices of the past and their contemporary legacies can be a resource - as they appeared to be for the students described above - teachers also need to be careful not to enact unnecessary forms of 'ethical violence' when teaching (Zembylas, 2015). This is no easy task and is perhaps most likely to take the form of a teacher unconsciously shaping lessons to generate their preferred emotional response. Nevertheless, for Zembylas (2015) some forms of ethical violence are inevitably "entangled" within a pedagogy of discomfort (p. 172).

\section{Guilt}

In Chapter 6, I explained in some detail the struggles young people had with navigating their discomforting feelings of guilt. As I showed, it was only Pākehā students at Northern, Western and Southern Colleges who struggled with these feelings. At Northern College (the only school that discussed guilt and which had Māori and non-Māori students in the focus group) Māori students clearly positioned themselves apart from their Pākehā peers; guilt was not a burden they felt they had to carry because they did not identify with the Pākehā soldiers who had invaded the Waikato. Some Pākehā students, however, felt the same as these Māori students but only because of their place-based experiences outside the classroom. For example, in Chapter 7 I show that Tee, a Pākehā student, expected to feel guilty during her school field trip but did not “because I didn't relate to the Europeans so I didn't really feel guilty". Instead, she explained that by visiting the location she empathised and therefore identified more strongly with Māori as the victims of historical injustice. This example 
illustrates the complicated ways in which emotions such as guilt, history, identity and place all intertwine. It also points to a deeper issue of this student's personal discomfort with the history of colonisation. History, in this case, is made more comfortable to deal with through a disidentification with the European soldiers, a group that before the fieldtrip she had seen as members of her own 'in-group' (Goldberg, 2017). What may have been useful for this student is to actively explore the changing nature of her identification with particular historical actors and what it could mean for her, as a Pākehā student, making sense of and taking responsibility for the legacies of colonisation in her own community.

As an emotional response to historical injustice, guilt has been theorised extensively in the educational literature (Caouette \& Taylor, 2015; Gachago et al., 2018; Schick, 2012; Todd, 2003). Guilt can be a problematic emotion if it prevents students from actively engaging with difficult histories of colonisation and accepting responsibility for their complicity in ongoing instances of structural violence and the lingering effects of historical injustices. Furthermore, if some students interpret 'sadness' as the emotional opposite of guilt, such passive feelings of empathy "produce no action toward justice" and thus leave intact the ignorance upon which setttler societies depend for their legitimacy (Boler, 1999, p. 157). Nevertheless, philosopher Sharon Todd (2003) is critical of educational critics who condemn what she terms 'liberal guilt'. These critics usually argue that guilt "detracts from marshalling the energy needed to recognize the larger, systematic factors that promote violence and maleficence toward others" (2003, p. 95). Todd (2003) asks instead:

Can we recover an understanding of guilt that seeks not to deny or repudiate its affective power but instead considers the significance of such affect for moral action? Might we, as teachers, resist the urge to denounce our own and others' guilt in order to think carefully about how guilt is implicated in making reparation and in assuming responsibility for deeds that we may not have committed ourselves? (p. 97)

Like Todd (2003), I am not convinced that guilt is necessarily an obstacle, "standing in the way of making adequate and effective social change" (p. 96). Instead, transformative history education may become more likely when teachers are better supported to explore the ambiguities and complexities of young peoples' emotional feelings of discomfort, including feelings such as guilt. 


\section{Indifference}

A significant proportion of students in surveys described feelings of indifference, framed as 'boredom' when learning New Zealand's history of colonisation. The "affective-discursive practice" (Huygens, 2018, p. 269) of labelling New Zealand's history of colonisation as 'boring' needs interrogation, especially because it can lead some teachers to justify not teaching certain historical issues (Biddle \& Redmond, 2018). As I show in Chapter 5, in Year 10, "boring" was the second highest descriptor students gave for their views on learning this history at $15 \%$ of students (Figure 5.9.2). In New Zealand, this is the year in which students decide whether or not they will carry on with history as an optional subject and teachers start competing for placements in their classes. Thus, it seems likely that students who characterise the history of colonisation as boring may not continue with history if they think it requires learning this subject, forgoing opportunities to develop a deeper knowledge of this history.

Despite quantitative data highlighting a relatively high frequency of students who described history as boring (and making their engagement with it less satisfying), this data says little about why they might describe it in these terms, or why Māori students tend to derive more meaning from the study of colonisation than their non-Māori counterparts (Figure 5.9.1). The qualitative data presented in Chapter 5 is more useful for illuminating answers to these questions. It shows that non-Māori students struggled to understand how the history of colonisation connects to their lives. In contrast, Māori students frequently explained this history as valuable for its contribution to their personal, family and tribal identities. NonMāori students were also indifferent about learning the history of colonisation because they had trouble recognising how New Zealand history is part of world history and therefore part of a broader human story. Many of these same students struggled to make any sense of history because they could not recognise coherent patterns in the past, feeling instead that they continuously learned the same material at multiple year levels.

The students I spoke with in the four colleges provide even clearer insight into the emotional struggles of boredom and indifference. These feelings, (which sometimes led to an initial resistance to learn about the subject in senior history classes), were largely shaped by their experiences in junior social studies (see Chapter 6). Many students in all schools consistently contrasted the satisfaction they gained from learning about colonisation in their senior history classes with the dull and frustrating experiences of learning about the Treaty of Waitangi and 
colonisation in Years 9 and 10. These findings illuminate a number of challenges for many teachers in this subject, especially if New Zealand history is compulsory from 2022. Social studies teachers, for example, do not necessarily possess the disciplinary expertise in history and, as teachers of a compulsory subject, likely face a more complex array of students' views about colonisation than those teachers of students who willingly enter a senior subject aware of what their course might require them to study.

It is likely in Years 9 and 10, therefore, that New Zealand secondary schools face their greatest challenge and their highest stakes for overcoming feelings of boredom and indifference toward the history of colonisation. Teachers at this year level need the historical content knowledge to feel confident teaching the history of colonisation (Kunowski, 2005). They also need access to theoretical approaches such as pedagogies of discomfort that "[begin] by inviting educators and students to engage in critical inquiry regarding values and cherished beliefs" (Boler, 1999, p. 176). Perhaps then teachers can avoid what Elizabeth (Chapter 6) described as the "dead kind of atmosphere" during social studies lesson on the history of colonisation. For South African scholar Chana Teeger (2019), this kind of boredom was also evident among South African students learning about their difficult history of Apartheid. Teegan's findings show that without an explanatory framework supporting students to make sense of Apartheid they become disengaged, a finding similar to Anna Clark's (2008) research with young Australians. I have considerable sympathy for Clark (2008) and Teegan's (2019) explanations for why students were indifferent to learning their own nation's difficult history. Indifference and boredom, however, may also be a settlercolonial strategy of avoiding an uncomfortable encounter with the histories of injustice and the contemporary privileges accrued to certain groups and not others from these injustices.

\section{Implications of findings: why these patterns of engagement are important}

History education can make valuable contributions to settler society by promoting cognitive justice and helping young people to "deconstruct single truths and negative images of the Other and to critically confront and navigate divergent narratives of conflict" (Bentrovato et al., 2016, p. 21). I also concur with Zembylas (2016) when he argues that one purpose for history curriculum is "addressing the legacies of conflict and trauma by helping to overcome prejudice, resentment and hatred (p.333). These ideas, and the findings discussed in this thesis raise a number of implications for policy makers, teachers and educators. 


\section{Implications for policy makers}

New Zealand needs a history and social studies curriculum that explicitly recognises Indigenous and non-Indigenous "knowledge streams" (Cram et al., 2018). As established in Chapters 2 and 3, the challenge of reconciling systems of knowledge that sometimes operate from quite different, even contradictory epistemological and ontological assumptions has been a topic of extensive scholarly research and debate in multiple academic arenas, including history education. In New Zealand, educationalist Angus MacFarlane (2015) and colleagues have promoted the metaphor of a 'braided river' or He Awa Whiria as an approach to knowledge and the reduction of social harm. The metaphor of a braided river was recently used by the Social Policy Evaluation and Research Unit (SUPERU, formerly the Families Commission) to theorise and plan interventions for social sector policy in ways that were more responsive to the needs of Māori and the obligations of the Treaty of Waitangi:

The aim was to shift thinking away from a 'one stream' paradigm, where a mainstream dominant knowledge is considered, along with mātauranga Māori knowledge, to a 'two streams' approach where both knowledge systems have equal status. This approach does not exclude other cultures or worldviews as it also provides a platform for them to be considered and included. (SUPERU Bridging Cultural Perspectives, 2018, p. 8).

In their elaboration of this metaphor, the authors of the Bridging Cultural Perspectives Report (2018) explain that:

In the braided river metaphor, both streams start at the same place and run beside each other in equal strength. They come together on the riverbed and then they move away from one another. Each stream spends more time apart than together. In the model, when they do converge, the space created is one of learning, not assimilating. (p. 8)

This metaphor may or may not be suited to curriculm theorising in history education, but it is a productive place to begin exploring a framework that takes seriously the aims of cognitive justice and includes the contributions historical thinking can make to a critical and transformative history education. It centres a way of thinking about knowledge in terms of what it can do, not only what it represents. As outlined already in Chapter 3, this reflects Santos' (2014) argument that "the credibility of cognitive construction is measured by the type of intervention in the world it provides, assists or hinders" (p. 207). 
Within a curriculum framework that explicitly recognises the value of young people engaging with Indigenous approaches to history, policy makers may find historical consciousness a productive 'knowledge stream' in addition to historical thinking. Curriculum theorist Joseph Smith (2019) describes historical thinking as deriving from a modernist interest in disciplinary thinking that progressively develops students' understanding of the historical method (p. 5). It is this approach that largely shapes the history curriculum in countries such as New Zealand, Australia, Canada and the United States (Seixas, 2017a, p. 59). Historical consciousness, in contrast "emphasises the question of how individuals in the present relate to the past" (Smith, 2019, p. 5). This latter approach has its philosophical roots in Germany where it also shapes the design of history curriculum. Curriculum informed by historical consciousness "considers the ways in which the past intrudes into the present, and how individuals comprehend and assimilate these intrusions" (Smith, 2019, p. 5). A history curriculum underpinned by ideas derived from historical consciousness "[places] the individual, rather than disciplinary norms, at the 'centre' of history" (Smith, 2019, p. 5). As a broad orientation to curriculum design, this approach includes historical thinking. It might, however, lead to forms of curriculum that encourages teachers to more deliberately use their history lessons to explore the relationship between the past, present and future, opening opportunities for challenging but important conversations about the legacies and ongoing nature of settler colonialism.

In addition to broad and official curriculum design, the findings in this thesis suggest an urgent need for a carefully considered programme of ongoing professional development about New Zealand history and associated pedagogies for teachers of history and social studies. In his study on the challenges of developing pre-service teachers' historical knowledge of African American history, LaGarret King (2014) argues that

Too many social studies teachers enter the profession without the necessary knowledge to explicitly challenge the official curriculum and present a nuanced understanding about African Americans as well as other historically marginalized groups. (2014, p. 448)

Similar challenges to this exist in New Zealand, although they extend to teachers (the majority of whom are Pākehā) becoming more comfortable in Te Ao Māori (Jones, 2017) and more responsive to the complex power dynamics that operate in all learning situations (Jones, 1999). For most teachers, this kind of professional development will require some deep self- 
reflection on the nature of history, their own privilege and the benefits they gain from living in a settler society. The Ministry of Education's Māori History Project and expertise developed from programmes that develop culturally responsive and relational pedagogies may provide some sources of wisdom. 


\section{Implications for teachers and educators}

My study has some important implications for how New Zealand's history of colonisation is taught. These include the importance of treating all emotions as a resource, transforming spaces into places and discussing legacies and drawing past/present connections. To unpack these implications in greater detail, Figure 8.1 summarises some of the key questions, assumptions and core ideas that might inform a history education drawn from the pedagogical positions outlined in Chapter 3, namely critical pedagogies of place and critical pedagogies of emotion. I intend this as a generative discussion for teaching in light of my study's findings rather than any strict blueprint for success in the classroom.

Table 8.1: Conceptual frameworks for teaching difficult, place-based histories of colonisation in New Zealand

\begin{tabular}{|c|c|c|}
\hline $\begin{array}{c}\text { Zembylas's (2017d) key } \\
\text { questions for the 'un-making of } \\
\text { ignorance' (p. 510). }\end{array}$ & $\begin{array}{c}\text { The primary elements of } \\
\text { Somerville's (2010) place } \\
\text { inquiry. }\end{array}$ & $\begin{array}{c}\text { Some core assumptions of } \\
\text { Manning's (2011) approach to } \\
\text { teaching Māori history } \\
\text { (paraphrased) }\end{array}$ \\
\hline $\begin{array}{l}\text { "Whose difficult histories are } \\
\text { being recognised?" }\end{array}$ & $\begin{array}{l}\text { "Our relationship to place is } \\
\text { constituted in stories (and other } \\
\text { representations) (p. 335)" }\end{array}$ & $\begin{array}{l}\text { Teaching on Indigenous land } \\
\text { obliges teachers to work } \\
\text { closely with Indigenous people }\end{array}$ \\
\hline $\begin{array}{l}\text { "Are there any difficult } \\
\text { histories that are ignored?" } \\
\text { "How are vulnerabilities } \\
\text { symetrical or asymetrical for } \\
\text { different individuals or groups } \\
\text { featured in difficult histories?" }\end{array}$ & $\begin{array}{l}\text { "Place learning and is } \\
\text { necessarily embodied and local } \\
\text { (p. 336)" } \\
\text { "Place is a contact zone of } \\
\text { cultural contact (p. 338)". }\end{array}$ & $\begin{array}{l}\text { Teachers need to abdicate their } \\
\text { role as the primary storehouse } \\
\text { and conduit of historical } \\
\text { narratives about Indigenous } \\
\text { people }\end{array}$ \\
\hline $\begin{array}{l}\text { "In what ways could } \\
\text { individuals or groups be } \\
\text { complicit to others' suffering } \\
\text { and trauma without knowing } \\
\text { it?" }\end{array}$ & & $\begin{array}{l}\text { Tribal histories are taught } \\
\text { outside the classroom and } \\
\text { students engage more closely } \\
\text { with local ecologies, histories } \\
\text { of place and forms of evidence } \\
\text { beyond the written word }\end{array}$ \\
\hline $\begin{array}{l}\text { "What can be done to } \\
\text { understand oneself as both } \\
\text { vulnerable and complicit?" }\end{array}$ & & $\begin{array}{l}\text { Teachers need to develop their } \\
\text { knowledge of Te Reo and } \\
\text { Tikanga Māori (Māori } \\
\text { language and cultural } \\
\text { protocols). }\end{array}$ \\
\hline
\end{tabular}


These three approaches draw from my theoretical interest in place and emotion in the context of teaching and learning difficult histories of colonisation. Collectively the questions and statements could be used by educators to inform lesson and programme design in ways which I outline in more detail below.

\section{Treating all emotions as a resource}

In this study I have shown that teaching difficult histories of colonisation evokes a complex mix of emotional responses, demanding equally complex pedagogical responses. These responses need to consistently work toward recognising and dislodging rigid and essentialised notions of 'Us' and 'Them' (Jansen, 2009; Zembylas, 2013c). To illustrate in more detail the potential of students' negative emotions as a resource rather than a barrier for teaching and learning, Zembylas (2013a) presents a vingette of a teacher working in a multicultural classroom in Cyprus that faced significant issues of discrimination and xenophobia toward migrant students. Working toward the "unmaking of ignorance" with her students (see Figure 8.1) the teacher used a range of creative methods that supported students to investigate "the hardships of vulnerable people in their community" (Zembylas, 2013a, p. 19). She also encouraged projects where students needed to interview 'out-group' community members and look for similarities between diverse experiences of migration. The teacher also pushed some students to recognise their privilege and was fearless in engaging the root assumptions of students' negative emotions, making it clear to her class that "other people and groups have been victimized in the world we live; recognising their pain and suffering does not devalue our own pain and suffering [as the dominant group]" (Zembylas, 2013a, p. 20). The teacher in Zembylas' (2013a) study witnessed some positive changes in her students toward migrants in Cyprus. Experiences of teaching in charged contexts like this provide New Zealand educators with an illustration of what is possible in the classroom when negative emotions (such as indifference and resentment) are critically engaged with in a schooling context.

\section{Transforming spaces into places}

Some students from Western College made the observation during their field trip that for some places "they were just fields" despite knowing the "fields" were places of major historical and cultural significance (Chapter 6). This highlights the challenges of transforming what are for students sometimes underwhelming spaces into places of stories and meaning. 
Somerville's (2010) notion of a place inquiry (see Figure 8.1) and Manning's (2011) core assumptions for successful teaching of Māori history present teachers with a framework that responds powerfully to the pedagogical potential of taking history instruction outdoors. When this is done alongside iwi and hapu it leads to deep learning and transformative experiences, as illustrated particularly through Hannah's field trip (see Chapter 6 and 7).

Somerville's (2010) second element of a place pedagogy - "place learning is necessarily embodied and local" (p. 336) - further supports teacher to transform spaces into places. This element outlines how place and emotions are material and intimate: "The weather, and the quality of the air and clouds, the sound of the frogs, the smell of the tadpole holes, and the day by day growing into frogs. It is place learning that derives from a deep, embodied intimacy" (p. 338). For Somerville, this element is "the most radical, transformative, and challenging" (2010, p. 336). As described briefly in Chapter 3, it is also the hardest to explain and demands, instead, a story from the field. Shortly before attending one of my field trips in the Waikato, I practised approaching the battle and massacre site of Ōrākau with "an attentiveness to place from the whole body" (Somerville, 2010, p. 338). My intention was to test out if simply being in a place, letting it enfold me, rather than trying to intellectually learn 'about' it would make a difference to the way I experienced and learned from it. The short experience of slowing down and deliberately being still at this site of profound violence and suffering - even without the benefit of a tribal custodian - started to approach what Somerville (2010) describes as

An ontology of self-becoming-other in the space between self and a natural world, composed of humans and non-human others, animate and inanimate; animals and plants, weather, rock, trees. (p. 338)

At Ōrākau (see Figure 8.2), I let the cold of the memorial stone's granite, the distant warmth of the winter sun on my face, the smell of the walnut tree, the singing of a tui and the rumbling of passing vehicles flood through my body in ways that resonate to this day. 


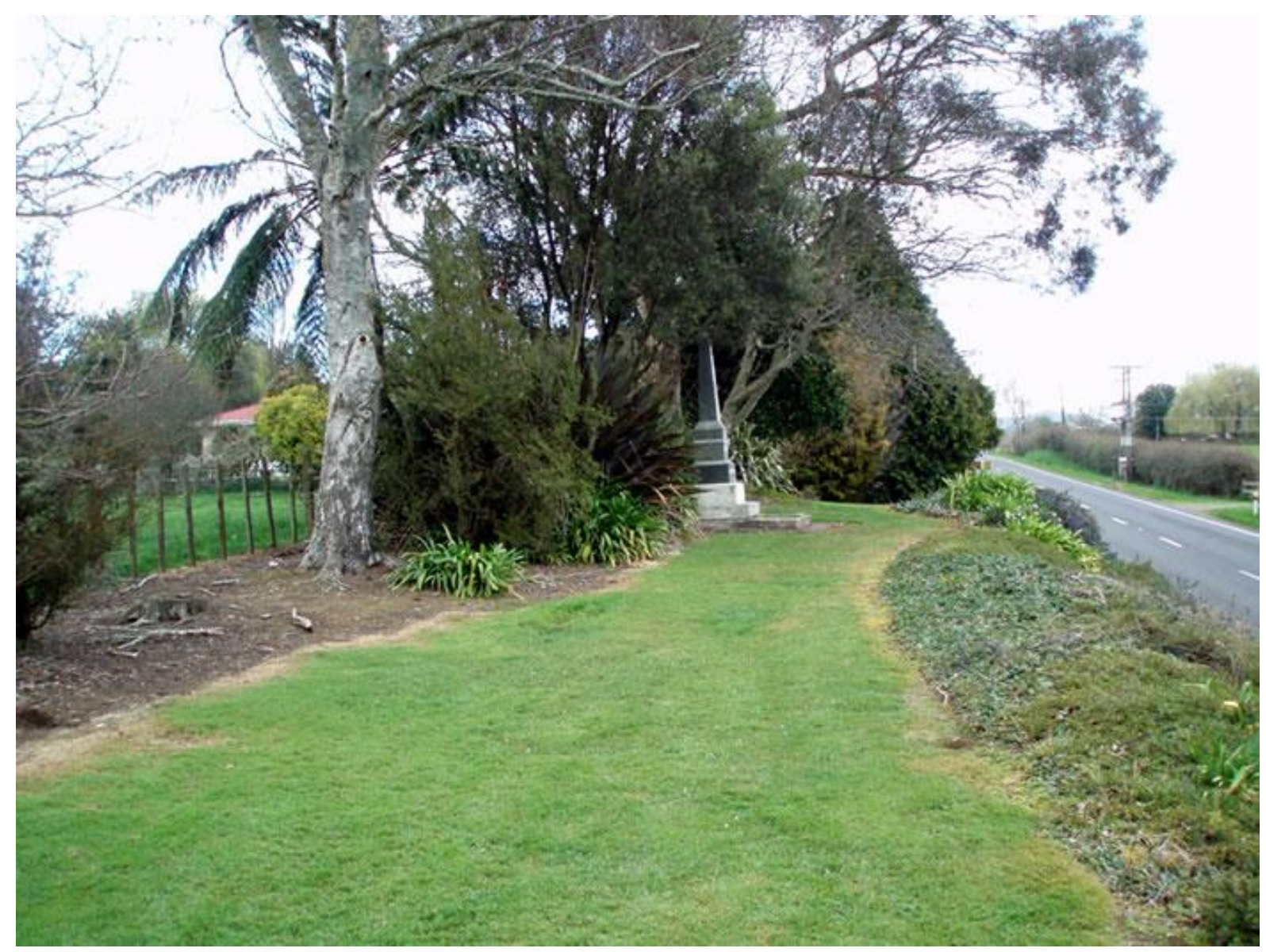

Figure 8.2: Ōrākau battle and massacre site. Photo by Margaret Marks/NZHistory

Opening myself to the possibility of a more intimate, bodily experience of place made me appreciate the incongruity of cars and trucks driving at high speed through Ōrākau. By slowing down I could literally feel their vibrations shake the earth as they passed by. Previously I had been intellectually aware that a road cut directly through this wāhi tapu but feeling the road's presence in such a sensory fashion helped me to understand in new and deeper ways what I had previously known abstractly. Later the experience led me to wonder, 'What if the asymmetry of this conflict and the brutality of what happened at this site was more widely known?' What was the logic that made the events at this place possible and how does this same logic exist, albeit in different forms, today? I left Ōrākau that day transformed, knowing its material reality and myself deeper than I had in all previous visits. I share this encounter at Ōrākau here as an experience of place that supports Somerville's (2010) contention that "we learn about place through embodied connections in particular local places" (p. 337). Although not identical to learning from the land and its Indigenous people as described by the notion of 'sensational pedagogies' (Harrison et al., 2017), the interpretive stance I took at Ōrākau nonetheless illustrates the usefulness of affective modes of learning. 
Some scholars refer to this as 'slow pedagogy' which "is about spending time in places for more than a fleeting moment so that we can listen and receive meaning from that "place" (Tooth \& Renshaw, 2009, p. 98).

Another way to transform space into place is for teachers to theorise field trips as complex 'spatial narratives of history' always embedded within broader systems of settler colonial story-telling (Behrendt, 2016). Geographers Kenneth Foote and Maoz Azaryahu (2007) explored what they called the 'spatial narratives of history' generated from the strategic placement of plaques, historical trails and memorials. Their interest was in how and to what effect various groups narrated the landscape with 'storylines' made of different kinds of historical marker arranged permanently on the landscape. Teachers could extend these scholars' notion of a spatial story-line, or a static set of points, by critically planning and reflectively enacting a 'spatial narrative of history' with their students every time they organise a field trip. As Modlin and colleagues (2011) remind us, "any tour through any historical site is a selective, political process which makes certain people, places, and perspectives appear legitimate while rendering others invisible" (p. 4). Field trips to sites of colonial violence are, therefore, inherently political acts and need to be recognised at such and actively discussed and reflected upon with students.

\section{Discussing legacies and drawing past/present connections}

Van Straaten and colleagues (2016) argue that history becomes more socially relevant and therefore meaningful for students when the past, present and future are connected. They suggest teachers use longitudinal lines, enduring questions, historical analogies, and decisionmaking and scenario thinking as a means to this end. For these scholars, longitudinal lines enable students to "position themselves as historical beings in the context of narratives that extend beyond the story of their own lives" (Van Straaten et al., 2016, p. 491). Enduring questions develop curriculum around perennial issues such as "are there limits to the degree of freedom we can create? Why do we obey laws? Why do people live in societies or groups?” (p. 493). Historical analogies explore "parallels between historical and contemporary phenomena" (p. 494) and finally, decision making and scenario thinking approaches help students use historical knowledge to serve the purpose of thinking about plausible future scenarios" (p. 495). Guldi and Armitage's (2014) advocacy for teaching the "processes that take a long time to unfold", which they argue better supports students to 
"[engage] false myths about the future" are also important ideas for making connections between past and present and have implications for how teachers design courses (p.12)

These ideas about connecting past and present illustrate some avenues by which critical historical thinking can help teachers and young people discuss legacies and draw connections between past and present. What these ideas do not address is the significance of place and its role as a mediator between past and present, especially within Indigenous contexts. Peter's explanation, learned from Māori colleagues and friends that "in a way you live in the past, not that the past is over here that you look at" is an idea that could help push teachers in New Zealand to extend the four strategies described above. As the four teachers in this study illustrate, field trips, especially when they actively involve tribal custodians of wāhi tapu, are a key pedagogy to employ when discussing legacies and drawing past and present connections within the context of places. Webber and O'Conner's (2019) notion of whakapapa as a pedagogical tool (see Chapter 2) also presents teachers with a uniquely Māori way to conceptualise past and present historical relationships in ways that are anchored to particular Indigenous territories.

\section{Summary}

In this chapter I discussed two 'patterns of engagement' that illustrate how teachers and students interact with the history of colonisation. In the first, I argued that teachers' conceptions and practices in regards to exploring Māori history, knowledge and perspectives could be transformative. These approaches help to illustrate in more detail what 'bihistorical teaching' might look like in schooling contexts. I argued that bihistorical teaching includes a willingness to incorporate place-based, Māori tribal histories into curriculum, an ability to slip seamlessly between different orientations toward the past and finding ways to connect past, present and place. Bihistorical teaching also involves recognition of the ongoing and destructive nature of settler colonialism and introducing 'counter narratives' that speak back to sanitised and marginalised versions of the past. Less transformative approaches included an inability or unwillingness to connect with local Māori communities and their local histories of colonisation and a tendency to leave the past in the past, and not explore historical continuities and contemporary legacies of colonisation. In the second section of this chapter, I discussed students' emotional discomfort when learning difficult histories of colonisation. These emotions shaped the way students engaged with the past, often in quite 
profound ways. Emotions, I showed, cannot be ignored because they have such a strong influence on the way students make sense of the interplay between history, identity, power and place. These patterns of engagement lead to a number of implications for policy makers and the wider teaching community which I addressed the latter part of this chapter. It is through addressing these implications that New Zealand educators can shift toward more critical and transformative forms of history education. 


\section{CHAPTER 9: CONCLUSION}

\section{Overview}

At the beginning of this thesis, I suggested that schools have not been very successful at developing students' long-term knowledge and perspectives on colonisation. I also outlined a heightened public interest in New Zealand history, particularly the nineteenth century New Zealand Wars between the British and many Māori iwi. In order to develop critical and transformative approaches to history education (see Chapter 1), I stressed the need for research into how young people and their teachers engage with New Zealand's difficult history of colonisation and in doing so I addressed three sub-questions:

1. How do teachers and students conceptualise the subject of colonisation in New Zealand?

2. What complexities do teachers and students contend with during lessons on New Zealand's history of colonisation?

3. What role do field trips to sites of colonial aggression play in shaping students' encounters with the past?

I explored these questions through a lens of critical theory, elaborated with the notions of cognitive justice and settler colonialism. Data collection involved administering surveys to teachers and students and carrying out ethnographic research in four schools. I was particularly interested in extending the existing literature on difficult history by researching the role of place and emotion during lessons on colonisation in a settler society. In the last chapter, I return to my research questions, suggest a number of limitations of the study and put forward avenues for future research.

\section{Review of findings}

To address my first research question regarding conceptions of colonisation I reported on a large-scale survey of teachers and students (Chapter 5). I showed that contrary to what might be implied from previous research in New Zealand, history and social studies teachers expressed overwhelmingly critical and pedagogically progressive views on the nature of colonisation and their approach to teaching this issue. I also argued that despite these views, three dominant responses presented barriers to deeper engagement with difficult history, barriers that limited history teachers' collective ability to disrupt the workings of settler colonialism in schooling contexts. The first set of conceptions regarded teachers' views on 
the depth of their profession's prioritisation of colonisation. I showed that many teachers reported feeling confident that schools adequately prioritise topics related to colonisation, a view which contradicts educational research, NZHTA surveys and nearly $20 \%$ of survey respondents who expressed concern about the status quo. Second, I showed that common conceptions about the complexity of teaching the history of colonisation are potentially problematic, particularly in regards to teachers' views on the sensitivity of, and challenges to teaching local Māori histories. Finally, some teachers expressed views on their colleagues' reluctance to engage with colonisation. These indicated a potentially larger problem of avoidance, compounded by those who use student choice as a means to select content, illustrating further how topics and issues about colonisation might be side-lined or minimised.

Students' conceptions of colonisation were multidimensional and varied. Many students, for example, struggled to recognise the nature of the relationship between the colonial past and what Wolfe (2015) calls the 'settler colonial present'. Nevertheless, in total, most of the students surveyed were receptive to learning the history of colonisation and could name a range of different opportunities to arise from this learning. A smaller, but proportionally significant group of students rejected learning the history of colonisation and outlined the risks they perceived to result from such lessons. The combination of these views underscores Zembylas' (2012) point that classrooms are “deeply divided places where contested narratives are steeped in the politics of emotion to create complex emotional and intellectual challenges for teachers" (p. 42).

In Chapter 6, I moved to the classroom to investigate some of the complexities teachers and their students contend with during their history lessons on colonisation (Research Question 2). I used the concept of cognitive justice to interpret these findings, and suggested a range of issues that either enabled or constrained the ability of teachers and students to engage with diverse 'ecologies of knowledge' (Santos, 2014). I described some of the struggles teachers faced as they had to deal with resistance from students and sometimes even fellow staff members, the challenges and opportunities of collaborating directly with iwi and hapu and the difficulties of drawing past and present relationships in ways that connected to (local) places. 
For the most part, students navigated different kinds of complexities than their teachers. Reflecting the broad findings from Chapter 5, most students were receptive to learning New Zealand's history of colonisation. Nevertheless, they also frequently described at some point in their schooling a reluctance to engage with colonisation, often attributing this to negative experiences in junior social studies classes. Pākehā students - who comprised the majority of participants - also struggled with feelings of white guilt, and most students grappled with a lack of prior knowledge and understanding of New Zealand's history of colonisation. Some students explained that their senior history lessons had been successful at challenging sanitised versions of colonisation and colonial warfare as "mellow" and "squeaky clean". Many others had never heard of events like the New Zealand Wars until their senior history classes.

In Chapter 7, I addressed my third Research Question by exploring in greater depth the nature of young peoples' engagement with New Zealand history when they visited landscapes of colonial violence. This chapter demonstrated some of the complexities of teaching and learning history outside the classroom and argued that teachers successfully used field trips as counter narratives which challenged students' prior ignorance of the New Zealand Wars and developed their historical understanding of these events' violence and brutality. Field trips were also successful at providing opportunities for students to participate in Māori cultural contexts and hear histories of colonisation from Māori perspectives. Finally, field trips presented students with valuable opportunities for affective encounters with the past, deepening their engagement with history, particular places and promoting a desire to learn.

In this chapter I also explained some of the challenges students faced when exploring difficult histories of place. For two schools, students' learning was constrained by an emotional regime of empathy. This emotional regime of empathy emphasised Māori as victims of colonisation, making it harder to connect the past to the legacies and ongoing manifestations of colonisation today or to discuss these challenging issues in productive ways. Emotional regimes of empathy also tended to simplify or flatten the historical experiences of diverse Others. At another school, the students' main challenge was feeling disconnected from sites, not fully understanding their significance or how they connected to a broader, contextualised narrative. 
Looking across these findings, in Chapter $8 \mathrm{I}$ analysed two primary 'patterns of engagement' by teachers and students with the history of colonisation in New Zealand. In the first, I discussed teachers' pedagogical efforts to connect with Māori communities and history. Some of these efforts were highly critical and transformative, leading to productive engagement with Māori history and its epistemological traditions. These efforts also included the development of critically informed counter narratives that challenged ignorance, refuting settler narratives of history. Other pedagogical approaches were more limited, included teaching history without the benefit of relationships with iwi and hapū, a failure to adequately prioritise New Zealand's history of colonisation and difficulties with connecting past and present.

The second pattern of engagement described in Chapter 8 concerned students' emotional discomfort, particularly when learning about colonial histories of injustice. I described a range of different emotions drawn from survey data and focus group reflections, including anxiety, resentment, anger, guilt and indifference. I was interested in the extent to which feelings of discomfort could be considered a resource for repudiating settler colonial ideologies. I showed that learning the history of colonisation is emotionally burdensome for all learners, a situation that presents a range of pedagogical challenges and opportunities for teachers. In the final section of this chapter, I explained the implications of these 'patterns of engagement'.

\section{Limitations of this study and avenues for future research}

The study had a number of limitations that became apparent during the research process. First, my experiences in the field led me to want to ask some different survey questions, ones that could have provided me with richer forms of data. For example, based on my fieldwork I would have asked teachers in the survey more targeted questions about their views on the challenges and opportunities of working with iwi and hapū and their conceptions of Māori history, as this emerged as an important component of what I termed a critical and transformative history education. Asking more explicitly about how teachers drew past and present connections for students would also have been revealing, as would a more targeted focus on the extent to which colonisation is perceived as a "sensitive historical issue" by teachers and students (Goldberg et al., 2019). The surveys generated some descriptive frequency data and short written responses of these issues. While useful, the analysis and 
conclusions drawn from this level of quantification is relatively low and the ethnographic study was needed to expose deeper layers of meaning.

There were a number of limitations with the qualitative findings which also present opportunities for future research. Chapters 6 and 7 documented ethnographic research about students who, for the most part, were committed to learning difficult histories of colonisation, or who could be convinced of its value by their teachers. A similar or longer ethnographic study carried out in more challenging contexts, perhaps in the compulsory subject of junior social studies with teachers who are not necessarily subject experts will shine greater light on the pedagogical challenges and emotional regimes that histories of colonisation evoke. More longitudinal ethnographies, and ones that pull together a wider range of people involved in field trips also present a valuable opportunity for future research. For example, at Northern College, interviews with our bus driver, the two museum educators, junior teachers of social studies in the social sciences department, the school principal and some students' family and whānau would broaden our understanding of the complexities and opportunities involved with teaching and learning difficult histories of colonisation.

In Chapter 4, I explained that as my knowledge of settler colonialism grew during this study, so too did my understanding of colonisation's 'structural' nature. One limitation of this study, therefore, was deeper questioning of teachers' and students' understanding of the relationship between past and present. In both the school visits and the survey I could have explored this important issue further. For example, most teachers surveyed expressed views about the deep significance and pedagogical value of connecting the past to contemporary issues regarding colonisation, yet in three schools, classroom teachers or their students often struggled to make or recognise these connections. An important avenue for future research is to focus in greater depth on teachers' and students' understanding of this particular historical relationship, the kind of pedagogical practices effective at developing such understandings and the impact of field trips if they are used to deliberately make, extend and facilitate dialogue about the nature of the relationship between past, present and place.

None of the schools I worked in took an explicitly ecological stance toward colonisation and yet the exploitative dynamic of settler colonialism arguably sits behind many of the world's pressing environmental problems. Kyle Whyte (2018), for example, argues that "settler 
colonialism is a form of domination that violently disrupts human relationships with the environment" (p. 125). An urgent area for further research, therefore, is a study of teachers who engage critically with colonisation's past and present through local studies of ecologically damaged places (Gruenewald, 2003). A research design that actively supports teachers to work with local iwi and hapu to prioritise this approach to history education would be of even greater use. An ecological approach may also respond to Marker's (2019) concern that including difficult histories of colonisation in the curriculum will teach only "the darkness of racism and cultural genocide", lessons that will come at the expense of "the light of Indigenous wisdom that was devastated by the catastrophes of colonization" (p. 196). Future research like I describe here may open opportunities for students to take action, developing "critical hope" (Zembylas, 2013) in an age when apocalyptic scenarios of climate change threaten the ability of young people to imagine alternative futures.

Finally, in this study I did not begin with an expectation I would find evidence of teachers attempting to "engage with the coexistence of multiple bodies of knowledge and ontologies" (Bell, 2017, p. 19). Although the teachers I worked with generated valuable data that helped me to develop Binney's (2009) notion of 'becoming bihistorical', all recognised their own struggles to do so. More research, therefore, is needed that explores how teachers engage with local iwi and hapū. This should include how they represent and respond to the contested nature of tribal histories and the challenges of recognising Indigenous epistemological and ontological realities. Of course, what it means to successfully 'engage with local iwi and hapū' is open to interpretation. Tuck and Yang (2012) warn that "there is a long and bumbled history of non-Indigenous peoples making moves to alleviate the impacts of colonization" (p. 3). Smith (1999) also makes clear that for Indigenous communities 'research' is often interpreted as a dangerous term representing exploitation and expropriation of Indigenous knowledge for the benefit of the coloniser. Despite these warnings, if teachers are to become more consciously bihistorical and "open to Māori knowledges" (Jones, 2017, p. 188) they will need access to models and stories of colleagues who have carefully and successfully walked that path before them. 


\section{Contributions of the study to history education}

My study makes a number of contributions to history education research and theoretical framings for such research in general. One major contribution this thesis makes is highlighting the pedagogical approaches needed by teachers to address New Zealand's history of colonisation. As my study showed, students exhibited an enormous range of affective responses to the issue of colonisation, requiring teachers to be confident at recognising and responding to these emotional 'climates' and the broader power systems in which they are embedded. Moreover, my analysis of field trips highlighted the significant pedagogical skills that were needed to curate rich outdoor engagements with the past. These experiences presented teachers with multiple opportunities to develop a place-based counter narrative that challenged settler colonial interpretations of the past. In the absence of such skills, it is likely that students in classrooms and on field trips could miss valuable opportunities and 'teachable moments' - or worse - retain or gain negative attitudes and damaging understandings about New Zealand history.

In addition to pedagogical skills, my study also drew attention to the exceptionally high levels of commitment in time and energy that was required to teach New Zealand's history of colonisation effectively. The four exemplary teachers in this study demonstrated this commitment through deep knowledge of their students and their family contexts, their sustained engagement with historical scholarship, the extra effort they went to understand Māori perspectives on colonisation and Te Reo Māori, and the effort they put into developing enduring relationships with key Māori experts in knowledge, history and tīkanga, especially so they could enrich their students' fieldtrip experiences. Despite their expertise and capacity for critical reflection, the four teachers in this study still faced challenges and wanted more support. Until those charged with supporting teachers to do their job (especially the Ministry of Education but also teacher trainers and academics) recognise the pedagogical complexities of teaching difficult histories of colonisation, interventions designed to promote teachers' capacity to act are not likely to have any long-term and lasting effect.

Highlighting the challenges as I have done here is not intended make an already difficult situation appear hopeless, especially for those teachers new to the profession and less confident at teaching New Zealand's history of colonisation. Another important contribution of this thesis, therefore, is its portrayal of exemplary models of practice from the classroom. 
Despite the daily challenges faced by Sarah, Peter, Caitlin and Hannah, they offer some much-needed representations of excellent teachers doing their best with limited time and resources and yet succeeding in exceptional ways. The deeply reflective comments of their students in Chapters 6 and 7 are a testament to this. These teachers show the complexity I highlight above is not something to be feared. It is a natural part of the teaching life that can never be fully managed or 'controlled'. Caitlin, Peter, Sarah and Hannah appeared to have accepted this and acknowledged that they could not get everything right. Instead of running from the challenges, they rolled up their sleeves and committed themselves to their practice. While their identities remain confidential in this study, by bringing a slice of their teaching into the public forum of a $\mathrm{PhD}$ dissertation, my hope is that their stories and experiences can help others working to improve history education.

A further contribution of this study has been to highlight the significance of settler colonialism, or what is sometimes referred to as 'settler colonial theory' to history education research. All teaching, learning and research in countries like New Zealand takes place on Indigenous land, land which for the most part has systematically been transferred to Pākehā control. This land nonetheless retains a history, inseparable from the present, to which iwi and hapū still feel a deep sense of belonging and obligation to protect. In my study, I acknowledged this connection by drawing on key concepts such as place, decolonisation and reinhabitation. Doing so opened up ways to engage pedagogically with the land and its history of colonisation. While the application of these concepts to history education is not new, rarely have studies brought these ideas to bear on research alongside teachers and students, specifically in the context of history and social studies. Perhaps more novel, this study took these ideas and brought them into further conversation with literature that focused on the emotional dynamics of teaching and learning difficult history. In this way, a key contribution of this study to the field of history education has been to draw together critical pedagogies of place with critical pedagogies of emotion as frameworks for making sense of encounters with the history of colonisation.

Finally, this study makes a number of empirical contributions. To my knowledge, no survey has been carried out in New Zealand of teachers and students that asks specifically about the teaching and learning of difficult histories of colonisation. The findings outlined in Chapter 5, 
therefore, provide a unique window into the conceptions of teachers and students. As I outlined in Chapter 2, existing qualitative research in New Zealand on difficult history has been sporadic and small-scale and has not necessarily focussed on colonisation. What does exist also tends to focus on the lack of attention given to topics associated with colonisation, especially in the context of New Zealand's high-autonomy curriculum. In this study I present empirical data on how teachers and students engage with the history of colonisation.

Particularly through the use of ethnographic approaches, which included sitting in classrooms and attending field trips, I was able to present detailed empirical data of the daily challenges and opportunities presented to teachers and students in their everyday contexts of teaching and learning history.

\section{Concluding statement}

In this thesis I have showed that teachers' and students' engagement with colonisation is complex and varied. This recognition should be the starting point for all teachers wanting to wrestle further with the history, legacies and ongoing manifestations of colonisation in settler societies. This is especially so for New Zealand as the nation moves toward the compulsory teaching of New Zealand history by 2022. Sitting at the heart of this challenge is the need to critically engage with the emotional terrains of teaching spaces and to extend history education beyond the classroom and into the field. Developing students' historical understanding according to disciplinary criteria should play a key role in this endeavour, and students should also benefit from learning Māori histories in tribal contexts. If these factors intersect, New Zealand can claim its place as a nation providing a truly transformative history education. 


\section{REFERENCES}

Ahmed, S. (2004). The cultural politics of emotion. Edinburgh: Edinburgh University Press.

Ahonen, S. (2012). Coming to terms with a dark past: How post-conflict societies deal with history. Frankfurt: Peter Lang.

Aikenhead, G. (2001). Integrating Western and Aboriginal Sciences: Cross-Cultural Science Teaching. Research in Science Education, 31(3), 337-355. doi:10.1023/A:1013151709605

Alderman, D. H., \& Inwood, J. F. J. (2013). Landscapes of Memory and Socially Just Futures. In N. C. Johnson, R. H. Schein, \& J. Winders (Eds.), The Wiley-Blackwell Companion to Cultural Geography: John Wiley \& Sons, Ltd.

Anderson, A., Binney, J., \& Harris, A. (2014). Tangata whenua: a history: Wellington, New Zealand : Bridget Williams Books.

Anderson, C. B. (2012). Misplaced Multiculturalism: Representations of American Indians in U.S. History Academic Content Standards. Curriculum Inquiry, 42(4), 497-509. doi:10.1111/j.1467-873X.2012.00604.x

Andreotti, V. d. O. (2011). (Towards) decoloniality and diversality in global citizenship education. Globalisation, Societies and Education, 9(3-4), 381-397. doi:10.1080/14767724.2011.605323

Apple, M., Au, W., \& Gandin, L. A. (2009). Mapping Critical Education. In M. W. Apple, W. Au, \& L. A. Gandin (Eds.), The Routledge International Handbook of Critical Education. London: Routledge.

Applebaum, B. (2017). Comforting Discomfort as Complicity: White Fragility and the Pursuit of Invulnerability. Hypatia, 32(4), 862-875. doi:10.1111/hypa.12352

Attwood, B. (2017). Denial in a Settler Society: the Australian Case. History Workshop Journal, 84(1), 24-43. doi:10.1093/hwj/dbx029

Baildon, M., Afandi, S., Bott, S., \& Rajah, C. (2018). Guiding students in Singapore to investigate historical controversy using a disciplinary approach. History Education Research Journal, 15(2), 308-327. doi:10.18546/HERJ.15.2.11

Ballantyne, T. (2012). Webs of empire: locating New Zealand's colonial past. Wellington, N.Z.: Bridget Williams Books.

Bang, M., Curley, L., Kessel, A., Marin, A., Suzukovich, E. S., \& Strack, G. (2014). Muskrat theories, tobacco in the streets, and living Chicago as Indigenous land. Environmental Education Research, 20(1), 37-55. doi:10.1080/13504622.2013.865113

Bargas, I. (2005). God defend New Zealand or Save the kings and queens? An examination of the status of New Zealand history at Year 13. (Master of Museum Studies), Victoria University of Wellington, Wellington.

Bargh, M. (Ed.) (2007). Resistance : an indigenous response to neoliberalism. Wellington, N.Z: Huia.

Barnhardt, R., \& Kawagley, A. O. . (2005). Indigenous knowledge systems and Alaska Native ways of knowing. Anthropology \& Education Quarterly, 36(1), 8-23

Barton, K. (2009). The Denial of Desire: how to make history education meaningless. In L. S. and \& W. Wilschut (Eds.), National History Standards: the problem of the canon and the future of teaching history. Charlotte: Information Age.

Barton, K. (2019). Teaching Difficult Histories: The Need for a Dynamic Research Tradition. In M. Gross \& L. Terra (Eds.), History and Social Studies Education in a Context of Intolerance : Imagined Communities and Collective Memory. New York: Routledge.

Barton, K., \& Levstik, L. (2004). Teaching History for the Common Good. Mahwah: Erlbaum.

Barton, K., \& McCully, A. (2005). History, identity, and the school curriculum in Northern Ireland: an empirical study of secondary students' ideas and perspectives. Journal of Curriculum Studies, 37(1), 85-116. doi:10.1080/0022027032000266070

Barton, K., \& McCully, A. (2007). Teaching controversial issues... where controversial issues really matter. Teaching History, 127, 13-19. 
Barton, K. C. (2015). Elicitation Techniques: Getting People to Talk About Ideas They Don't Usually Talk About. Theory \& Research in Social Education, 43(2), 179-205. doi:10.1080/00933104.2015.1034392

Basso, K. H. (1996). Wisdom sits in places: landscape and language among the Western Apache Albuquerque: University of New Mexico Press.

Beck, W., \& Somerville, M. (2005). Conversations between disciplines: historical archaeology and oral history at Yarrawarra. World Archaeology, 37(3), 468-483. doi:10.1080/00438240500204403

Behrendt, L. (2016). Finding Eliza: Power and Colonial Storytelling. St Lucia, Australia: University of Queensland Press.

Bekerman, Z., \& Zembylas, M. (Eds.). (2012). Teaching Contested Narratives: Identity, Memory and Reconciliation in Peace Education and Beyond. Cambridge: Cambridge University Press.

Belich, J. (1986). The New Zealand wars and the Victorian interpretation of racial conflict. Auckland, N.Z.: Penguin.

Belich, J. (1996). Making peoples : a history of the New Zealanders : from Polynesian settlement to the end of the nineteenth century. Auckland, N.Z.: Allen Lane/Penguin.

Belich, J. (2001). Paradise reforged: a history of the New Zealanders from the 1880s to the year 2000. Auckland: Allan Lane Penguin.

Belich, J., Stephens, T., \& McRae, C. (2004). The New Zealand Wars - Pakanga nunui o Aotearoa. Auckland, N.Z.: Television New Zealand.

Bell, A. (2006). Bifurcation or Entanglement? Settler Identity and Biculturalism in Aotearoa New Zealand. Continuum, 20(2), 253-268. doi:10.1080/10304310600641786

Bell, A. (2009). A Conversation through History: Towards Postcolonial Coexistence. Journal of Intercultural Studies, 30(2), 173-191. doi:10.1080/07256860902766974

Bell, A. (2017). Co-existing Indigenous and Settler Worlds: Ontological Styles and Possibilities. Journal of New Zealand Studies, 24, 15-24.

Bentrovato, D., Korostelina, K. V., \& Schulze, M. (Eds.). (2016). History can bite: History education in divided and post-war societies. Göttingen: Vandenhoeck \& Ruprecht Gmbh \& Co.

Berkes, F., Colding, J., \& Folke, C. (2000). Rediscovery of Traditional ecological knowledge as adaptive management. Ecological Applications, 10(5), 1251-1262. doi:10.1890/10510761(2000)010[1251:ROTEKA]2.0.CO;2

Bermudez, A. (2012). The Discursive Negotiation of Narratives and Identities in Learning History. In M. Carretero, M. Asensio, \& M. Rodriguez-Moneo (Eds.), History Education and the Construction of National Identities. Charlotte: Information Age Publishing.

Bevernage, B. (2010). Writing the Past Out of the Present: History and the Politics of Time in Transitional Justice. History Workshop Journal, 69(1), 111-131. doi:10.1093/hwj/dbq008

Biddle, D.-L., \& Redmond, A. (2018). History teacher: Students say NZ Wars 'too boring'. Retrieved from https://www.stuff.co.nz/national/education/107046200/history-teachers-lament--students-say-nz-wars-too-boring

Binney, J. (2001). Maori oral narratives, Pakeha written texts: Two forms of telling history. In J. Binney (Ed.), The Shaping of History: Essays from the New Zealand Journal of History, 19671999. Wellington: Bridget Williams Books.

Binney, J. (2009). Encircled lands : Te Urewera, 1820-1921. Wellington, N.Z: Bridget Williams Books.

Boler, M. (1999). Feeling Power: Emotions and Education. New York: Routledge.

Braun, V., \& Clarke, V. (2006). Using thematic analysis in psychology. Qualitative Research in Psychology, 3(2), 77-101. doi:10.1191/1478088706qp063oa

Brett, P. (2016). "Frost Still Clings to the Shadows": Port Arthur, Convict History, Pedagogy and Place. International Journal of the Inclusive Museum, 9(4).

Bridging Cultural Perspectives. (2018). Retrieved from Wellington: https://thehub.sia.govt.nz/assets/Uploads/Bridging-Cultural-Perspectives-FINAL-0.pdf 
Britzman, D. P. (1998). Lost Subjects, Contested Objects. Albany, UNITED STATES: State University of New York Press.

Buchanan, R. (2009). The Parihaka album: lest we forget. Wellington, N.Z: Huia.

Buchanan, R. (2018). Ko Taranaki Te Maunga. Wellington: Bridget Williams Books Limited.

Bunce, R. J. (2018). Slippery Jim or patriotic statesman? : James Macandrew of Otago. Dunedin: Otago University Press.

Burgard, K., \& Boucher, M. (2015). The Special Responsibility of Public Spaces to Dismantle White Supremacist Historical Narratives In A. M. Labrador \& N. A. Silberman (Eds.), The Oxford Handbook of Public Heritage Theory and Practice. Oxford: Oxford University Press.

Burgard, K., \& Boucher, M. (2016). Same Story; Different History: Students' Racialized Understanding of Historic Sites. The Urban Review, 48(5), 696-717. doi:10.1007/s11256-016-0374-9

Burow, P. B., Brock, S., \& Dove, M. R. (2018). Unsettling the Land: Indigeneity, Ontology, and Hybridity in Settler Colonialism. Environment and Society, 9(1), 57. doi:10.3167/ares.2018.090105

Byrnes, G. (2001). Boundary markers: land surveying and the colonisation of New Zealand Wellington, N.Z.: Bridget Williams Books.

Calderon, D. (2014a). Speaking back to Manifest Destinies: a land education-based approach to critical curriculum inquiry. Environmental Education Research, 20(1), 24-36. doi:10.1080/13504622.2013.865114

Calderon, D. (2014b). Uncovering Settler Grammars in Curriculum. Educational Studies, 50(4), 313338. doi:10.1080/00131946.2014.926904

Caouette, J., \& Taylor, D. M. (2015). "Don't Blame Me for What My Ancestors Did". In D. E. Lund \& P. R. Carr (Eds.), Revisiting The Great White North? Reframing Whiteness, Privilege, and Identity in Education (Second Edition) (pp. 89-104). Rotterdam: SensePublishers.

Carlson, K. T. (2010). The Power of Place, the Problem of Time: Aboriginal Identity and Historical Consciousness in the Cauldron of Colonialism. Toronto: University of Toronto Press.

Carter, L. (2006). Postcolonial Interventions Within Science Education: Using postcolonial ideas to reconsider cultural diversity scholarship. Educational Philosophy and Theory, 38(5), 677-691. doi:10.1111/j.1469-5812.2006.00219.x

Charmaz, K. (2012). Mixing or adding methods? An exploration and critique. In N. K. Denzin \& M. D. Giardina (Eds.), Qualitative inquiry and the politics of advocacy. Walnut Creek: Left Coast Press.

Clark, A. (2008). History's children: History Wars in the classroom. Sydney: UNSW Press.

Clark, A. (2018). Teaching and Learning Difficult Histories: Australia. In T. Epstein \& C. Peck (Eds.), Teaching and Learning Difficult Histories in International Contexts: A Critical Sociocultural Approach. New York: Routledge.

Clough, P. T. (Ed.) (2007). The Affective Turn: Theorizing the Social. Durham: NC: Duke University Press

Cole, E. A. (Ed.) (2007). Teaching the violent past: history education and reconciliation. Lanham: Rowman \& Littlefield Publishers.

Cook, M. R. (2015). Counter-narratives of slavery in the Deep South: the politics of empathy along and beyond River Road. Journal of Heritage Tourism, 11(3), 1-19. doi:10.1080/1743873X.2015.1100624

Country, B., Wright, S., Suchet-Pearson, S., Lloyd, K., Burarrwanga, L., Ganambarr, R., . . Sweeney, J. (2016). Co-becoming Bawaka: Towards a relational understanding of place/space. Progress in Human Geography, 40(4), 455-475. doi:10.1177/0309132515589437

Cram, F., Vette, M., Wilson, M., Vaithianathan, R., Maloney, T., \& Baird, S. (2018). He awa whiriabraided rivers: Understanding the outcomes from Family Start for Māori. Evaluation Matters-He Take Tō Te Aromatawai, 4, 1. doi:10.18296/em.0033

Cresswell, T. (2004). Place: a short introduction. Malden: Blackwell Pub. 
Creswell, J. W. (2014). Research design: qualitative, quantitative, and mixed methods approaches (4th ed.). Thousand Oaks: SAGE Publications.

Cutrara, S. (2018). The Settler Grammar of Canadian History Curriculum: Why Historical Thinking Is Unable to Respond to the TRC's Calls to Action. Canadian Journal of Education, 41(1), 250275.

Davis, B., Sumara, D., \& Luce-Kapler, R. (2008). Engaging minds : changing teaching in complex times. New York: Routledge.

Davis, O., Yeager, E., \& Foster, S. (2001). Historical empathy and perspective taking in the social studies. Lanham, Md: Rowman \& Littlefield.

DeCuir-Gunby, J. T., Marshall, P. L., \& McCulloch, A. W. (2011). Developing and Using a Codebook for the Analysis of Interview Data: An Example from a Professional Development Research Project. Field Methods, 23(2), 136-155. doi:10.1177/1525822x10388468

den Heyer, K. (2009). Sticky points: teacher educators re-examine their practice in light of a new Alberta social studies program and its inclusion of Aboriginal perspectives. Teaching Education, 20(4), 343-355. doi:10.1080/10476210903254083

Denzin, N. K., \& Lincoln, Y. S. (2003). The discipline and practice of qualitative research. In N. K. Denzin \& Y. S. Lincoln (Eds.), Strategies of qualitative inquiry (2nd ed., pp. 1-45). Thousand Oaks: Sage.

Derbyshire, A. (2004). Anyone's but our own: the teaching of New Zealand history in New Zealand Secondary schools 1925-2000. (Unpublished Masters thesis), The University of Auckland, Auckland.

DiAngelo, R. (2018). White fragility: why it's so hard for White people to talk about racism. Boston: Beacon Press.

Dion, S. (2008). Braiding Histories: Learning from Aboriginal People's Experiences and Perspectives. Toronto: UBC Press.

Dion, S. D. (2007). Disrupting Molded Images: Identities, responsibilities and relationships-teachers and indigenous subject material. Teaching Education, 18(4), 329-342. doi:10.1080/10476210701687625

Drever, E. (1995). Using semi-structured interviews in small-scale research: a teacher's guide. Glasgow: Scottish Council for Research in education.

Drozdzewski, D., De Nardi, S., \& Waterton, E. (2016). Geographies of memory, place and identity: Intersections in remembering war and conflict. Geography Compass, 10(11), 447-456. doi:10.1111/gec3.12296

Dwyer, O. J. (2004). Symbolic accretion and commemoration. Social \& Cultural Geography, 5(3), 419435. doi:10.1080/1464936042000252804

Education, M. o. (2007). The New Zealand Curriculum. Wellington: Learning Media.

Eisner, E. W. (1985). The educational imagination: on the design and evaluation of school programs (2nd ed.). New York: Macmillan.

Emerson, R. M., Fretz, R. I., \& Shaw, L. L. (2011). Writing ethnographic fieldnotes (2nd ed. ed.). Chicago: The University of Chicago Press.

Endacott, J., \& Brooks, S. (2018). Historical Empathy: Perspectives and Responding to the Past. In L. M. H. Scott Alan Metzger (Ed.), The Wiley International Handbook of Histroy Teaching and Learning. New York: Wiley Blackwell.

Epstein, T. (2009). Interpreting national history : race, identity, and pedagogy in classrooms and communities. New York: Routledge.

Epstein, T., \& Harcourt, M. (2019). Soft or Hard Biculturalism and Beyond: How New Zealand Adolescents Construct Contemporary Significance of the Nation's Founding Document. In M. Gross \& L. Terra (Eds.), History and Social Studies Education in a Context of Intolerance: Imagined Communities and Collective Memory. New York: Routledge.

Epstein, T., \& Peck, C. (Eds.). (2018). Teaching and Learning Difficult Histories in International Contexts: a Critical Sociocultural Approach. New York: Routledge. 
Escobar, A. (2004). Beyond the Third World: imperial globality, global coloniality and antiglobalisation social movements. Third World Quarterly, 25(1), 207-230. doi:10.1080/0143659042000185417

Feldman, J. (2002). Marking the Boundaries of the Enclave: Defining the Israeli Collective through the Poland 'Experience'. Israel Studies, 7(2), 84-114. doi:10.2979/ISR.2002.7.2.84

Foote, K. (1997). Shadowed ground: America's landscapes of violence and tragedy. Austin: University of Texas Press.

Foote, K., \& Azaryahu, M. (2007). Towards a geography of memory: geographical dimensions of public memory and commemoration. Journal of Political and Military Sociology, 35(1), 125144.

Fountain, G. (2012). Caught in-between: The Impact of Different Forms of Mandated National Assessment for Qualifications on Teacher Decision-Making in Year 12 History in New Zealand, 1986-2005. (Master of Education), Victoria University of Wellington, Wellington.

Freeman, J. (2014). Remembering the First World War: Using a Battlefield Tour of the Western Front to Help Pupils Take a More Critical Approach to What They Encounter. Teaching History(155), 45-52.

Freire, P. (1993). Pedagogy of the oppressed. New York: Continuum.

Gachago, D., Bozalek, V., \& Ng'ambi, D. (2018). White guilt and shame: Students' emotional reactions to digital stories of race in a South African classroom. In L. Smith, M. Wetherell, \& G. Campbell (Eds.), Emotion, Affective Practices, and the Past in the Present. London: Routledge.

Gahman, L. (2016). White Settler Society as Monster: Rural Southeast Kansas, Ancestral Osage (WahZha-Zhi) Territories, and the Violence of Forgetting. Antipode, 48(2), 314-335. doi:10.1111/anti.12177

Gaztambide-Fernández, R. (2012). Decolonization and the pedagogy of solidarity. Decolonization, Indigeneity, Education \& Society, 1(1), 41-67.

Geertz, C. (1973). The interpretation of cultures; selected essays. New York: Basic Books.

Gibbons, P. (2003). The Far Side of the Search for Identity: Reconsidering New Zealand History. The New Zealand Journal of History, 37(1), 38-49.

Gibson, L., \& Case, R. (2019). Reshaping Canadian History Education in Support of Reconciliation. Canadian Journal of Education, 42(1), 251.

Gilbert, J. (2005). Catching the knowledge wave? : the knowledge society and the future of education. Wellington, N.Z: NZCER Press.

Gohlke, F. (2009). Thoughts on landscape: collected writings and interviews. Tucson, AZ: Hol Art Books.

Goldberg, T. (2017). Between Trauma and Perpetration: Psychoanalytical and Social Psychological Perspectives on Difficult Histories in the Israeli Context. Theory \& Research in Social Education, 45(3), 349-377. doi:10.1080/00933104.2016.1270866

Goldberg, T. (2018). "On Whose Side are You?": Difficult Histories in the Israeli Context. In T. Epstein \& C. L. Peck (Eds.), Teaching and Learning Difficult Histories in International Contexts: A Critical Sociocultural Approach. New York: Routledge.

Goldberg, T., Porat, D., \& Schwarz, B. B. (2006). Here started the rift we see today: Student and textbook narratives between official and counter memory. Narrative Inquiry, 16(2), 319-347.

Goldberg, T., \& Schwarz, B. (2016). Harnessing emotions to deliberative argumentation in classroom discussions on historical issues in multi-cultural contexts. Frontline Learning Research, 4(4), 7-19.

Goldberg, T., Wagner, W., \& Petrović, N. (2019). From sensitive historical issues to history teachers' sensibility: a look across and within countries. Pedagogy, Culture \& Society, 27(1), 7-38. doi:10.1080/14681366.2019.1566165 
Grande, S. (2007). Red Lake Woebegone: Pedagogy, Decolonization, and the Critical Project In P. McLaren, \& Kincheloe, J. L. (Ed.), Critical Pedagogy: Where are we now? New York: Peter Lang.

Grande, S. (2013). Red-ing the Word, Red-ing the World. In R. Lake \& T. Kress (Eds.), Paulo Freire's intellectual roots; toward historicity in Praxis. Ringgold Inc: Portland.

Greenwood, D. (2009). Place, Survivance and White Remembrance: A Decolonizing Challenge to Rural Education in Mobile Modernity. Journal of Research in Rural Education, 24(10), 1-7.

Greenwood, D. (2010). Education in a culture of violence: a critical pedagogy of place in wartime. Cultural Studies of Science Education, 5(2), 351-359. doi:10.1007/s11422-009-9231-4

Gross, M. H. (2014). Struggling to deal with the difficult past: Polish students confront the Holocaust. Journal of Curriculum Studies, 46(4), 441-463. doi:10.1080/00220272.2014.923513

Gross, M. H., \& Terra, L. (Eds.). (2019). Teaching and learning the difficult past: comparative perspectives. New York: Routledge.

Gruenewald, D. A. (2003). The Best of Both Worlds: A Critical Pedagogy of Place. Educational Researcher, 32(4), 3-12. doi:10.3102/0013189X032004003

Guldi, J., \& Armitage, D. (2014). The History Manifesto. Cambridge: Cambridge University Press.

Harcourt, M. (2020). 'But wait, there was a war in the Waikato?!' Settler colonialism, white ignorance and the New Zealand history curriculum. In N. Fink, M. Furrer, \& P. Gautschi (Eds.), The Teaching of the History of One's Own Country - International Experiences in a Comparative Perspective. Frankfurt: Wochenschau Verlag.

Harrison, N. (2012). Putting History in its Place - Grounding the Australian History Curriculum: History in local community. Paper presented at the Joint AARE APERA International Conference, Sydney.

Harrison, N. (2013). Country teaches: the significance of the local in the Australian history curriculum. Australian Journal of Education., 57(3), 214-224.

Harrison, N., Bodkin, F., Bodkin-Andrews, G., \& Mackinlay, E. (2017). Sensational pedagogies: Learning to be affected by country. Curriculum Inquiry, 47(5), 504-519. doi:10.1080/03626784.2017.1399257

Harrison, N., \& Greenfield, M. (2011). Relationship to place: positioning Aboriginal knowledge and perspectives in classroom pedagogies. Critical Studies in Education, 52(1), 65-76. doi:10.1080/17508487.2011.536513

Harrison, N., Page, S., \& Tobin, L. (2015). Art has a Place: Country as a teacher in the city. Educational Philosophy and Theory, 48(13), 1321-1335. doi:10.1080/00131857.2015.1111128

Hart, V., Whatman, S., McLaughlin, J., \& Sharma-Brymer, V. (2012). Pre-service teachers' pedagogical relationships and experiences of embedding Indigenous Australian knowledge in teaching practicum. Compare: A Journal of Comparative and International Education, 42(5), 703-723. doi:10.1080/03057925.2012.706480

Helmsing, M. (2014). Virtuous Subjects: A Critical Analysis of the Affective Substance of Social Studies Education. Theory \& Research in Social Education, 42(1), 127-140. doi:10.1080/00933104.2013.842530

Hess, D. E. (2009). Controversy in the classroom the democratic power of discussion / Diana E. Hess. In C. Ebooks (Ed.). New York: New York : Routledge.

Horne, M. (2017). Selfies at Auschwitz: conference examines ethics of 'dark tourism'.(News)(Conference news) (pp. 17): NI Syndication Limited.

Hoskins, G. (2010). A secret reservoir of values: the narrative economy of Angel Island Immigration Station. cultural geographies, 17(2), 259-275. doi:10.1177/1474474010363850

Hoskins, T. K. (2017). A Provocation for Kaupapa Māori. In T. K. Hoskins \& A. Jones (Eds.), Critical Conversations in Kaupapa Māori. Wellington: Huia Publishers.

Hoskins, T. K., \& Jones, A. (2017). Non-human Others and Kaupapa Māori Research. In T. K. Hoskins \& A. Jones (Eds.), Critical Conversations in Kaupapa Māori. Wellington: Huia Publishers. 
Howard-Wagner, D., Bargh, M., \& Altamirano-Jiménez, I. (Eds.). (2018). The neoliberal state, recognition and indigenous rights: new paternalism to new imaginings. Acton, ACT, Australia: Australian National University.

Howse, T. (2019). Kā Huru Manu. Retrieved from http://www.kahurumanu.co.nz/cultural-mappingstory/cultural-mapping-project-begins

Hunter, P., \& Farthing, B. (2004). Talking history: teachers' perceptions of "their" curriculum in the context of history in the New Zealand Curriculum 1980-2003. Hamilton: Wilf Malcolm Institute for Educational Research.

Huygens, I. (2018). 'Head and heart' responses to Treaty education in Aotearoa New Zealand: feeling the timeline of colonisation. In L. Smith, M. Wetherell, \& G. Campbell (Eds.), Emotion, Affective Practices, and the Past in the Present (Vol. 1). Milton: Routledge.

Jansen, J. D. (2009). Knowledge in the Blood : Confronting Race and the Apartheid Past. Redwood City: Stanford University Press.

Johnson, J. (2012). Place-based learning and knowing: critical pedagogies grounded in Indigeneity. Spatially Integrated Social Sciences and Humanities, 77(6), 829-836. doi:10.1007/s10708010-9379-1

Johnson, J. T., \& Larsen, S. C. (2017). Being together in place : indigenous coexistence in a more than human world Minneapolis University of Minnesota Press.

Johnson, J. T., \& Murton, B. (2007). Re/placing Native Science: Indigenous Voices in Contemporary Constructions of Nature. Geographical Research, 45(2), 121-129. doi:10.1111/j.17455871.2007.00442.x

Johnson, R. B., \& Onwuegbuzie, A. J. (2004). Mixed Methods Research: A Research Paradigm Whose Time Has Come. Educational Researcher, 33(7), 14-26. doi:10.3102/0013189X033007014

Jones, A. (1999). THE LIMITS OF CROSS-CULTURAL DIALOGUE: PEDAGOGY, DESIRE, AND ABSOLUTION IN THE CLASSROOM. Educational Theory, 49(3), 299-316. doi:10.1111/j.17415446.1999.00299.x

Jones, A. (2017). Dangerous Liaisons: Pākehā, Kaupapa Māori, and Edcational Research. In T. K. Hoskins \& A. Jones (Eds.), Critical Conversations in Kaupapa Māori. New Zealand: Huia Publishers.

Journell, W. (2009). An Incomplete History: Representation of American Indians in State Social Studies Standards. Journal of American Indian Education, 48(2), 18.

Jupp, V. (2006). The Sage dictionary of social research methods. In V. Jupp (Ed.), Dictionary of social research methods. London SAGE Publications.

Kamberelis, G., \& Dimitriadis, G. (2013). Focus groups from structured interviews to collective conversations. Abingdon: Routledge.

Kanu, Y. (2005). Teachers' Perceptions of the Integration of Aboriginal Culture Into the High School Curriculum. Alberta Journal of Educational Research, 51(1), 50.

Kearney, A., \& Bradley, J. J. (2009). 'Too strong to ever not be there': place names and emotional geographies. Social \& Cultural Geography, 10(1), 77-94. doi:10.1080/14649360802553210

Keenan, D. (2008). Terror in our midst? : searching for terror in Aotearoa New Zealand. Wellington, N.Z: Huia.

Keenan, D. (2009). Wars without end. Auckland, N.Z.: Auckland, N.Z. : Penguin.

Keenan, D. (2015). Te Whiti o Rongomai and the resistance of Parihaka. Wellington: Huia Publishers.

Keenan, D. (2018). The cause of this war is the land: origins of war in 19th-century New Zealand. In J. Crawford \& I. McGibbon (Eds.), Tutu te puehu: New perspectives on the New Zealand Wars. Wellington: Steele Roberts Aotearoa

Keenan, D. (Ed.) (2012). Huia histories of Māori: ngā Tāhuhu Kōrero. Wellington, N.Z: Huia.

Keenan, H. (2018). Visiting Chutchui: The making of a colonial counterstory on an elementary school field trip. Theory \& Research in Social Education, 1-24. doi:10.1080/00933104.2018.1542361

Keown, P. (1998). Values and social action: Doing the hard bits. In P. Benson \& R. Openshaw (Eds.), New horizons for New Zealand social studies. Palmerston North: ERDC Press. 
Keynes, M. (2018). History Education for Transitional Justice? Challenges, Limitations and Possibilities for Settler Colonial Australia. International Journal of Transitional Justice. doi:10.1093/ijtj/ijy026

Kidman, J. (2018). Pedagogies of Forgetting: Colonial Encounters and Nationhood at New Zealand's National Museum. In T. Epstein \& C. L. Peck (Eds.), Teaching and Learning Difficult Histories in International Contexts: A Critical Sociocultural Approach. New York: Routledge.

Kidman, J., \& O'Malley, V. (2018). Questioning the canon: Colonial history, counter-memory and youth activism. Memory Studies, 175069801774998. doi:10.1177/1750698017749980

Kidman, J., Ormond, A., \& MacDonald, L. (2018). Everyday Hope: Indigenous Aims of Education in Settler-Colonial Societies. In J. E. Petrovic \& R. M. Mitchell (Eds.), Indigenous Philosophies of Education around the World. New York: Routledge.

Kincheloe, J., \& McLaren, P. (2005). Rethinking critical theory and qualitative research. In N. K. Denzin \& Y. S. Lincoln (Eds.), The SAGE handbook of qualitative research (3rd ed.). Thousand Oaks: Sage Publications.

King, L. J. (2014). Learning other people's history: pre-service teachers' developing African American historical knowledge. Teaching Education, 25(4), 427-456. doi:10.1080/10476210.2014.926881

Kitson, A., \& McCully, A. (2005). 'You hear about it for real in school.' Avoiding, containing and risktaking in the history classroom. Teaching History(120), 32-37.

Kunowski, M. (2005). Teaching About the Treaty of Waitangi: Examining the Nature of Teacher Knowledge and Classroom Practice. (Unpublished Professional Doctorate), Griffith University, Brisbane.

Landsberg, A. (2004). Prosthetic memory: the transformation of American remembrance in the age of mass culture. New York: Columbia University Press.

Lather, P. (1986). Issues of validity in openly ideological research: Between a rock and a soft place. Interchange, 17(4), 63-84. doi:10.1007/BF01807017

Lawless, B., \& Chen, Y.-W. (2019). Developing a Method of Critical Thematic Analysis for Qualitative Communication Inquiry. Howard Journal of Communications, 30(1), 92-106. doi:10.1080/10646175.2018.1439423

Lehrer, E., Milton, C., \& Patterson, M. (2011). Curating difficult knowledge violent pasts in public places. Houndmills: Palgrave Macmillan.

Lennon, J. (2017). Dark tourism - visitation, understanding and education; a reconciliation of theory and practice? Worldwide Hospitality and Tourism Themes, 245-248. doi:10.1108/WHATT-012017-0002

Lennon, J., \& Foley, M. (2007). Dark tourism: The attraction of death and disaster. London: Thomson.

Leonardo, Z., \& Porter, R. K. (2010). Pedagogy of fear: toward a Fanonian theory of 'safety' in race dialogue. Race Ethnicity and Education, 13(2), 139-157. doi:10.1080/13613324.2010.482898

Levstik, L. (2001). Crossing the empty spaces: perspective taking in New Zealand adolescents' understanding of national history. In O. L. Davis, E. A. Yeager, \& S. J. Foster (Eds.), Historical empathy and perspective taking in the social studies. Oxford: Rowman \& Littlefield.

Lindquist, J. (2004). Class Affects, Classroom Affectations: Working through the Paradoxes of Strategic Empathy. College English, 67(2), 187-209. doi:10.2307/4140717

Long, J. (2019). New Zealand history to be taught in schools by 2022, says PM Jacinda Ardern. Retrieved from https://www.stuff.co.nz/national/education/115712569/new-zealandhistory-to-be-taught-in-schools-by-2022-says-pm-jacinda-ardern

Macfarlane, A., Macfarlane, S., \& Gillon, G. (2015). Sharing the food baskets of knowledge: creating the space for a blending of streams. In A. Macfarlane, S. Macfarlane, \& M. Webber (Eds.), Sociocultrual Realities: exploring new horizons. Christchurch: Canterbury University Press.

Madison, D. S. (2012). Critical ethnography : method, ethics, and performance (2nd ed. ed.). Thousand Oaks: SAGE. 
Mahuika, N. (2018). "Kotahi Te Kohao o Te Ngira": Decolonial Solidarities and the Healing of Historical Trauma in Aotearoa New Zealand. Paper presented at the New Zeaaland History Teachers' Association Conference "Te Awhiorangi ki te Aomarama - We Are Making a New World", Hamilton.

Maldonado-Torres, N. (2004). The topology of being and the geopolitics of knowledge: Modernity, empire, coloniality1. City, 8(1), 29-56. doi:10.1080/1360481042000199787

Manning, R. (2009). Place, power and Pedagogy: A critical analysis of the status of Te Ātiawa histories of place in Port Nicholson Block secondary schools and the possible application of place-based education models. Victoria University of Wellington, Wellington.

Manning, R. (2009). The status of Te Ātiawa histories of place in Port Nicholson Block (Wellington, Hutt Valley) secondary schools: Some research findings. Curriculum Matters, 5, 5-24.

Manning, R. (2011). A Critical Pedagogy of Place?: Te Ātiawa (Māori) and Pākehā (Non-Māori) History Teachers' Perspectives on the Teaching of Local, Māori and New Zealand Histories. The Australian Journal of Indigenous Education, 40, 102-111. doi:10.1375/ajie.40.102

Manning, R. (2017). The New Zealand (School Curriculum) 'History Wars': The New Zealand Land Wars Petition and the Status of Māori Histories in New Zealand Schools (1877-2016). The Australian Journal of Indigenous Education, 1-11. doi:10.1017/jie.2017.13

Manning, R. (2017). Place-Consciousness and Bronfenbrenner's Ecological Systems Model: A Discussion of Recurring Issues that Undermine the Teaching of Indigenous Histories in New Zealand and Australian Schools. The Australian Journal of Indigenous Education, 46(02), 148159. doi:10.1017/jie.2016.31

Manning, R., \& Harrison, N. (2018). Narratives of Place and Land: Teaching Indigenous Histories in Australian and New Zealand Teacher Education. Australian Journal of Teacher Education, 43(9)(4), 59-74. doi:http://dx.doi.org/10.14221/ajte.2018v43n9.4.

Manning, R. (2011). A Critical Pedagogy of Place?: Te Ātiawa (Māori) and Pākehā (Non-Māori) History Teachers' Perspectives on the Teaching of Local, Māori and New Zealand Histories. The Australian Journal of Indigenous Education, 40, 102-111. doi:10.1375/ajie.40.102

Manning, R. (2017). Place-Consciousness and Bronfenbrenner's Ecological Systems Model: A Discussion of Recurring Issues that Undermine the Teaching of Indigenous Histories in New Zealand and Australian Schools. The Australian Journal of Indigenous Education, 46(02), 148159. doi:10.1017/jie.2016.31

Marker, M. (2011). Teaching History from an Indigenous Perspective: Four Winding Paths up the Moutain. In P. Clark (Ed.), New Possibilities For The Past. Vancouver: UBC Press.

Marker, M. (2019). The "Realness" of Place in the Spiral of Time: Reflections on Indigenous Historical Consciousness from the Coast Salish Territory. In A. Clark \& C. L. Peck (Eds.), Contemplating historical consciousness: Notes from the Field. Oxford: Berghahn Books.

McCully, A. (2012). History teaching, conflict and the legacy of the past. Education, Citizenship and Social Justice, 7(2), 145-159. doi:10.1177/1746197912440854

McCully, A. (2018). Teaching History and Educating for Citizenship: Allies or "Uneasy Bedfellows" in a Post-Conflict Context? In T. Epstein \& C. L. Peck (Eds.), Teaching and Learning Difficult Histories in International Contexts: A Critical Sociocultural Approach. New York: Routledge.

McGregor, H. E. (2017). One classroom, Two teachers? Historical thinking and indigenous education in Canada. Critical Education, 8(14), 1-18.

McKernan, A. (2017). Discomfort at the Australian War Memorial: learning the trauma of war. History Australia, 14(1), 99-114. doi:10.1080/14490854.2017.1287005

McKnight, A. (2015). Preservice teachers' learning with Yuin Country: becoming respectful teachers in Aboriginal education. Asia-Pacific Journal of Teacher Education, 44(2), 110-124. doi:10.1080/1359866x.2015.1066491

McLean, G. (2000). Wellington: the first years of European settlement, 1840-1850. Auckland: Penguin Books. 
Mertens, D. M. (2012). Transformative Mixed Methods. American Behavioral Scientist, 56(6), 802813. doi:10.1177/0002764211433797

Mignolo, W. D. (2007). INTRODUCTION. Cultural Studies, 21(2-3), 155-167. doi:10.1080/09502380601162498

Mikaere, A. (2011). Colonising myths: Māori realities he rukuruku whakaaro. Wellington: Huia Publishers

Miles, J. (2019). Seeing and feeling difficult history: A case study of how Canadian students make sense of photographs of Indian Residential Schools. Theory \& Research in Social Education, 1-25. doi:10.1080/00933104.2019.1626783

Ministry of Education, (2007), The New Zealand Curriculum, Learning Media: Wellington.

Misco, T. (2018). Contextual Gatekeeping: Teacher Decision-Making in Multiple and Overlapping Milieus. In L. T. Magdalena H. Gross (Ed.), Teaching and Learning the Difficult Past: Comparative perspectives. New York: Routledge.

Modlin, E. A., Alderman, D. H., \& Gentry, G. W. (2011). Tour Guides as Creators of Empathy: The Role of Affective Inequality in Marginalizing the Enslaved at Plantation House Museums. Tourist Studies, 11(1), 3-19. doi:10.1177/1468797611412007

Moeahu, K. (2019). Indigenous stories are embedded in the land. Paper presented at the Naenae Residents Association

Mulholland, M., \& Tawhai, V. M. H. (Eds.). (2010). Weeping waters : the Treaty of Waitangi and constitutional change. Wellington, N.Z: Huia Publishers.

Murchison, J. M. (2010). Ethnography essentials : designing, conducting, and presenting your research (1st ed.). San Francisco: Jossey-Bass.

Nakata, M. (2004). Indigenous Australian Studies and Higher Education. Paper presented at the The Wentworth Lectures.

Nakata, M. (2012). Pathways for Indigenous Education in the Australian Curriculum Framework. The Australian Journal of Indigenous Education, 40, 1-8. doi:10.1375/ajie.40.1

The Ngai Tahu Atlas. (2019). Retrieved from http://www.kahurumanu.co.nz/cultural-mappingstory/the-ngai-tahu-atlas

O'Malley, V. (2019a). The New Zealand Wars: Ngā Pakanga o Aotearoa. Wellington: Bridget Williams Books.

O'Malley, V. (2019b). Vincent O'Malley - The New Zealand Wars/ Nga Pakanga o Aotearoa. Retrieved from https://www.rnz.co.nz/national/programmes/saturday/audio/2018696717/vincent-omalley-the-new-zealand-wars-nga-pakanga-o-aotearoa

O'Regan, T. (2014). New myths and old politics: the Waitangi Tribunal and the challenge of tradition. Wellington: Bridget Williams Books.

O'Sullivan, D. (2007). Beyond biculturalism : the politics of an indigenous minority. Wellington: Huia.

O'Malley, V. (2016). 'Don't mention the war' became a kind of agreement. Retrieved from https://e-tangata.co.nz/history/vincent-omalley-dont-mention-the-war-became-a-kind-ofagreement/

Oliver, P. (2006). The Sage dictionary of social research methods. In V. Jupp (Ed.), Dictionary of social research methods. London: SAGE Publications.

Orange, C. (2004). An illustrated history of the Treaty of Waitangi. Wellington: Bridget Williams Books.

Ormond, B. M. (2017). Curriculum decisions - the challenges of teacher autonomy over knowledge selection for history. Journal of Curriculum Studies, 49(5), 599-619. doi:10.1080/00220272.2016.1149225

Paperson, L. (2014). A ghetto land pedagogy: an antidote for settler environmentalism. Environmental Education Research, 20(1), 115-130. doi:10.1080/13504622.2013.865115

Park, G. (1995). The groves of life - Nga uruora : ecology and history in a New Zealand landscape. Wellington, N.Z.: Victoria University Press. 
Parkhouse, H. (2018). Pedagogies of Naming, Questioning, and Demystification: A Study of Two Critical U.S. History Classrooms. Theory \& Research in Social Education, 46(2), 277-317. doi:10.1080/00933104.2017.1389327

Patterson, B., Hill, R. S., \& Patterson, K. (Eds.). (2016). After the Treaty : the settler state, race relations and the exercise of power in colonial New Zealand: essays in honour of lan McLean Wards. Wellington, New Zealand: Steele Roberts Publishers.

Paulson, J. (2015). "Whether and how?" History education about recent and ongoing conflict: A review of research Journal on Education in Emergencies, 1(1), 14-47.

Peck, C. L. (2017). Intersections of Students' Ethnic Identifications and Undersatndings of History. In C. L. Peck \& T. Epstein (Eds.), Teaching and Learning Difficult Histories in International Contexts: A Critical Sociocultural Approach. New York: Routledge.

Penetito, W. (2009). Place-based education: Catering for curriculum, culture and community. New Zealand Annual Review of Education, 18, 5-29.

Pihama, L., Reynolds, P., Smith, C., Reid, J., Smith, L. T., \& Nana, R. T. (2014). Positioning Historical Trauma Theory within Aotearoa new Zealand. AlterNative: An International Journal of Indigenous Peoples, 10(3), 248-262. doi:10.1177/117718011401000304

Pitt, A., \& Britzman, D. (2003). Speculations on qualities of difficult knowledge in teaching and learning: an experiment in psychoanalytic research. International Journal of Qualitative Studies in Education, 16(6), 755-776. doi:10.1080/09518390310001632135

Port, A. I. (2015). History from Below, the History of Everyday Life, and Microhistory. In J. D. Wright (Ed.), International Encyclopedia of the Social \& Behavioral Sciences (Second Edition) (pp. 108-113). Oxford: Elsevier.

Prasad, P. (2005). Crafting qualitative research : working in the postpositivist traditions. Armonk, N.Y: M.E. Sharpe.

Priestley, M., \& Sinnema, C. (2014). Downgraded curriculum? An analysis of knowledge in new curricula in Scotland and New Zealand. Curriculum Journal, 25(1), 50-75. doi:10.1080/09585176.2013.872047

Psaltis, C., Carretero, M., \& Čehajić-Clancy, S. (2017). History Education and Conflict Transformation Social Psychological Theories, History Teaching and Reconciliation / edited by Charis Psaltis, Mario Carretero, Sabina Čehajić-Clancy: Cham : Springer International Publishing : Imprint: Palgrave Macmillan.

Quijano, A., \& Ennis, M. (2000). Coloniality of Power, Eurocentrism, and Latin America. Nepantla: Views from South, 1(3), 533-580.

Rata, E. (2012). The politics of knowledge in education. British Educational Research Journal, 38(1), 103-124. doi:10.1080/01411926.2011.615388

Rey, J., \& Harrison, N. (2018). Sydney as an Indigenous place: "Goanna walking" brings people together. AlterNative: An International Journal of Indigenous Peoples, 14(1), 81-89. doi:10.1177/1177180117751930

Rose, J. (2016). Interpreting difficult history at museums and historic sites. Lanham: Maryland: Rowman \& Littlefield.

Ross, M. H. (2009). Cultural Contestation and the Symbolic Landscape: Politics by Other Means? In M. H. Ross (Ed.), Culture and Belonging in Divided Societies : Contestation and Symbolic Landscapes. Philadelphia: University of Pennsylvania Press.

Rudolph, S., Sriprakash, A., \& Gerrard, J. (2018). Knowledge and racial violence: the shine and shadow of 'powerful knowledge'. Ethics and Education, 13(1), 22-38. doi:10.1080/17449642.2018.1428719

Salinas, C., Blevins, B., \& Sullivan, C. C. (2012). Critical Historical Thinking: When Official Narratives Collide With Other Narratives. Multicultural Perspectives, 14(1), 18-27. doi:10.1080/15210960.2012.646640

Salmond, A. (2012). Ontological quarrels: Indigeneity, exclusion and citizenship in a relational world. Anthropological Theory, 12(2), 115-141. doi:10.1177/1463499612454119 
Salmond, A. (2017). Tears of Rangi: experiments across worlds. Auckland, New Zealand: Auckland University Press.

Santos, B. d. S. (2007). Beyond Abyssal Thinking: From Global Lines to Ecologies of Knowledges. Review (Fernand Braudel Center), 30(1), 45-89.

Santos, B. d. S. (2014). Epistemologies of the South : Justice Against Epistemicide. Herndon: Herndon: Routledge.

Sarah, P. (2007). Doing Visual Ethnography (Second Edition ed.). London: SAGE Publications, Ltd.

Savenije, G. M., van Boxtel, C., \& Grever, M. (2014). Learning About Sensitive History: "Heritage" of Slavery as a Resource. Theory \& Research in Social Education, 42(4), 516-547. doi:10.1080/00933104.2014.966877

Schaefli, L. M., Godlewska, A. M. C., \& Rose, J. (2018). Coming to know Indigeneity: Epistemologies of ignorance in the 2003-2015 Ontario Canadian and World Studies Curriculum. Curriculum Inquiry, 48(4), 475-498. doi:10.1080/03626784.2018.1518113

Schick, C. (2012). White resentment in settler society. Race Ethnicity and Education, 17(1), 88-102. doi:10.1080/13613324.2012.733688

Schramm, K. (2011). Introduction: landscapes of violence: memory and sacred space. History and Memory: Studies in Representation of the Past, 23(1), 5. doi:10.1353/ham.2011.0001

Schweber, S. (2019). A Foreword on Inheritance: Difficult History in Difficult Times. In M. H. Gross \& L. Terra (Eds.), Teaching and Learning the difficult past: Comparative perspectives. New York: Routledge.

Segall, A., Trofanenko, B. M., \& Schmitt, A. J. (2018). Critical Theory and History Education. In S. A. Metzger \& L. M. Harris (Eds.), The Wiley International Handbook of History Teaching and Learning: John Wiley \& Sons.

Seidman, I. (2013). Interviewing as qualitative research: a guide for researchers in education and the social sciences (4th ed.). New York: Teachers College Press.

Seixas, P. (2012). Indigenous Historical Consciousness: An Oxymoron or a Dialogue? In M. Carretero, M. Asensio, \& M. Rodríguez-Moneo (Eds.), History Education and the Construction of National Identities. Charlotte: NC: Information Age Publishing Inc.

Seixas, P. (2017a). Historical Consciousness and Historical Thinking. In M. Carretero, S. Berger, \& M. Grever (Eds.), Palgrave Handbook of Research in Historical Culture and Education. London: Palgrave Macmillan UK.

Seixas, P. (2017b). A Model of Historical Thinking. Educational Philosophy and Theory, 49(6), 593605. doi:10.1080/00131857.2015.1101363

Seixas, P., \& Morton, T. (2013). The big six: historical thinking concepts. Toronto: Nelson Education.

Sensoy, O. z., \& DiAngelo, R. (2012). Is everyone really equal? : an introduction to key concepts in social justice education. New York: Teachers College Press.

Shaw, W. S., Herman, R. D. K., \& Dobbs, G. R. (2006). 'Encountering Indigeneity: Re-Imagining and Decolonizing Geography'. Geografiska Annale, 88(3), 267-276.

Shear, S. (2018). Transforming Teaching and Learning about American Indians. Retrieved from https://www.youtube.com/watch?v=7GxPbYfVnu0\&t=155s

Shear, S. B., Knowles, R. T., Soden, G. J., \& Castro, A. J. (2015). Manifesting Destiny: Re/presentations of Indigenous Peoples in K-12 U.S. History Standards. Theory \& Research in Social Education, 43(1), 68-101. doi:10.1080/00933104.2014.999849

Shear, S. B., \& Krutka, D. G. (2019). Confronting settler colonialism: Theoretical and methodological questions about social studies research. Theory and Research in Social Education, 47(1), 2951. doi:10.1080/00933104.2018.1541428

Sheehan, M. (2010). The place of 'New Zealand' in the New Zealand history curriculum. Journal of Curriculum Studies, 42(5), 671-691. doi:10.1080/00220272.2010.485247

Sheehan, M. (2017). A matter of choice: Controversial histories, citizenship, and the challenge of a high-autonomy curriculum. Curriculum Matters, 13, 103-114. doi:10.18296/cm.0023 
Sheehan, M., Epstein, T., \& Harcourt, M. (2018). "People are still grieving": Maori and non Maori Adolescents' Perceptions of the Treaty of Waitangi. In T. Epstein \& C. Peck (Eds.), Teaching and Learning Difficult Histories in International Contexts: A Critical Sociocultural Approach. New York: Routledge.

Sheppard, M., Katz, D., \& Grosland, T. (2015). Conceptualizing Emotions in Social Studies Education. Theory \& Research in Social Education, 43(2), 147-178. doi:10.1080/00933104.2015.1034391

Sheppard, M. G. (2010). Difficult histories in an urban classroom (Doctoral dissertation). University of Minnesota, Minneapolis, MN.

Shuster, K. (2018). Teaching Hard History: American Slavery. Montgomery: Southern Poverty Law Center.

Sibley, C. G., \& Liu, J. H. (2004). Attitudes towards biculturalism in New Zealand: Social dominance and Pakeha attitudes towards the general principles and resource-specific aspects of bicultural policy. New Zealand Journal of Psychology, 33(2), 88-99.

Simon, R. I., \& Dippo, D. (1986). On Critical Ethnographic Work. Anthropology \& Education Quarterly, 17(4), 195-202. doi:10.1525/aeq.1986.17.4.04x0613o

Sinnema, C. (2015). The Ebb and Flow of Curricular Autonomy: Balance Between Local Freedom and National Prescription in Curricula The SAGE Handbook of Curriculum, Pedagogy and Assessment: Two Volume Set (pp. 965-983).

Smith, G. H. (2017). Kaupapa Māori Theory: Indigenous Transforming of Education. In T. K. Hoskins \& A. Jones (Eds.), Critical conversations in kaupapa Māori. Wellington, New Zealand: Huia Publishers.

Smith, J. (2019). Curriculum coherence and teachers' decision-making in Scottish high school history syllabi. Curriculum Journal, <xocs:firstpage xmlns:xocs=""/>. doi:10.1080/09585176.2019.1647861

Smith, L. T. (1999). Decolonizing Methodologies: research and Indigenous peoples. London: Zed Books Ltd.

Smith, M., Davidson, J., Cameron, L., \& Bondi, L. (2009). Introduction: Geography and Emotins Emerging Constellations. In M. Smith, J. Davidson, L. Cameron, \& L. Bondi (Eds.), Emotion, Place and Culture. Surrey: Ashgate Publishing Limited.

Somerville, M. (2007). Place literacies. Australian Journal of Language and Literacy, 30, 149+.

Somerville, M., \& Perkins, T. (2010). Border work in the contact zone: thinking indigenous/nonindigenous collaboration spatially. Journal of Intercultural Studies, 24(3), 253-266. doi:10.1080/0725686032000172597

Somerville, M. (2010). A Place Pedagogy for 'Global Contemporaneity'. Educational Philosophy and Theory, 42(3), 326-344. doi:10.1111/j.1469-5812.2008.00423.x

Spalding, N. (2011). Learning to remember slavery: school field trips and the representation of difficult histories in English museums. Journal of Educational Memory, Media, and Society, 3(2), 155.

Spoonley, P. (2015). New diversity, old anxieties in New Zealand: the complex identity politics and engagement of a settler society. Ethnic and Racial Studies, 38(4), 650-661. doi:10.1080/01419870.2015.980292

Stanton, C. R. (2012). "Hearing" the Story: Critical Indigenous Curriculum Inquiry and Primary Source Representation in Social Studies Education. Theory and Research in Social Education, 40(4), 339-370. doi:10.1080/00933104.2012.723242

Stastny, A. (2018). Settler-Indigenous relationships and the emotional regime of empathy in Australian History school teaxtbooks in times of reconciliation. In L. Smith, M. Wetherell, \& G. Campbell (Eds.), Emotion, Affective Practices and the Past in the Present. New York: Routledge.

Statistics NZ: Major ethnic groups in New Zealand. (2015). Retrieved from https://www.stats.govt.nz/infographics/major-ethnic-groups-in-new-zealand 
Stephen, S. (2000). Handbook for culturally responsive science education. Fairbanks: Alaska Native Knowledge Network.

Stoddard, J., Marcus, A. S., \& Hicks, D. (Eds.). (2017). Teaching Difficult History Through Film. New York: Routledge.

Sundberg, J. (2014). Decolonizing posthumanist geographies. cultural geographies, 21(1), 33-47. doi:10.1177/1474474013486067

Tapasā: Cultural competencies framework for teachers of Pacific learners (2018). Wellington: Ministry of Education.

Tau, T. M. (2001). Matauranga Maori as an epistemology. In A. Sharp \& P. G. McHugh (Eds.), Histories, Power and Loss: Uses of the Past - A New Zealand Commentary. Wellington: Bridget Williams Books.

Taylor, T., \& Guyver, R. (2011). History wars and the classroom : global perspectives / edited by Tony Taylor, Robert Guyver. Charlotte, NC: Charlotte, NC : Information Age Pub.

Teeger, C. (2019). "Apartheid is boring": The Politics of Disinterest in South African History Classrooms. Paper presented at the Conflict and Identity: Confronting the past through education, University of Oxford.

Thornton, S. J. (2005). Teaching social studies that matters: Curriculum for Active Learning. New York: Teachers College Press.

Tinkham, J. (2018). "That's Not My History": The reconceptualization of Canadian Histroy Education in Nova Scotia Schools. In T. Epstein \& C. L. Peck (Eds.), Teaching and Learning Difficult Histories in International Contexts. New York: Routledge.

Todd, S. (2003). Learning from the other : Levinas, psychoanalysis, and ethical possibilities in education Albany: State University of New York Press.

Tomlins-Jahnke, H. (2019). Contested Spaces: Indigeneity and Epistemologies of Ignorance. In H. Tomlins-Jahnke, M. K. Hohepa, S. Styres, \& S. Lilley (Eds.), Indigenous Education : New Directions in Theory and Practice. Edmonton: University of Alberta Press.

Tooth, R., \& Renshaw, P. (2009). Reflections on Pedagogy and Place: A Journey into Learning For Sustainability through Environmental Narrative and Deep Attentive Reflection. Australian Journal of Environmental Education, 25, 95-104.

Traille, K. (2007). "You should be proud about your history. They make me feel ashamed": Teaching history hurts. Teaching History, 127, 31-37.

Trofanenko, B. M. (2011). On difficult history displayed: the pedagogical challenges of interminable learning. Museum Management and Curatorship, 26(5), 481-495. doi:10.1080/09647775.2011.621733

Tuck, E., \& Gaztambide-Fernandez, R. (2013). Curriculum, Replacement, and Settler Futurity.

Tuck, E., \& McKenzie, M. (2015). Place in research: theory, methodology, and methods. New York: Routledge.

Tuck, E., McKenzie, M., \& McCoy, K. (2014). Land education: Indigenous, post-colonial, and decolonizing perspectives on place and environmental education research. Environmental Education Research, 20(1), 1-23. doi:10.1080/13504622.2013.877708

Tuck, E., \& Yang, K. W. (2012). Decolonization is not a metaphor. Decolonization: Indigeneity, Education \& Society, 1(1), 1-40.

Tupper, J. (2014). The Possibilities for Reconciliation Through Difficult Dialogues: Treaty Education as Peacebuilding. Curriculum Inquiry, 44(4), 469-488. doi:10.1111/curi.12060

Tupper, J., \& Cappello, M. (2008). Teaching Treaties as (Un)Usual Narratives: Disrupting the Curricular Commonsense. Curriculum Inquiry, 38(5), 559-578. doi:10.1111/j.1467873X.2008.00436.x

Tupper, J. A. (2011). Disrupting ignorance and settler identities: The challenges of preparing beginning teachers for treaty education. in education, 17(3), 28-55. 
Turner, S. (1999). Settlement as forgetting. In K. Neumann, N. Thomas, \& H. Ericksen (Eds.), Quicksands : foundational histories in Australia and Aotearoa New Zealand. Sydney: UNSW Press.

Van Maanen, J. (2011). Tales of the field : on writing ethnography (2nd ed.). Chicago: University of Chicago Press.

Van Straaten, D., Wilschut, A., \& Oostdam, R. (2016). Making history relevant to students by connecting past, present and future: a framework for research. Journal of Curriculum Studies, 48(4), 479-502. doi:10.1080/00220272.2015.1089938

VanSledright, B. (2010). The challenge of rethinking history education: on practices, theories, and policy. New York: Routledge.

Veracini, L. (2008). Settler Collective, Founding Violence and Disavowal: The Settler Colonial Situation. Journal of Intercultural Studies, 29(4), 363-379. doi:10.1080/07256860802372246

Veracini, L. (2015). The Settler Colonial Present. London: London: Palgrave Macmillan UK.

Walker, R. (2004). Ka whawhai tonu mātou: Struggle without end. Auckland, N.Z.: Penguin.

Ward, A. (1999). An unsettled history: Treaty claims in New Zealand today. Wellington, N.Z: Bridget Williams Books.

Webber, M. (2008). Walking the space between : identity and Māori/Pākehā Wellington: NZCER Press.

Webber, M., \& O'Connor, K. (2019). A Fire in the Belly of Hineāmaru: Using Whakapapa as a Pedagogical Tool in Education. Genealogy, 3(3), 41. doi:10.3390/genealogy3030041

Weuffen, S. L., Cahir, F., \& Pickford, A. M. (2016). The centrality of Aboriginal cultural workshops and experiential learning in a pre-service teacher education course: a regional Victorian University case study. Higher Education Research \& Development, 36(4), 838-851. doi:10.1080/07294360.2016.1242557

Wheelahan, L. (2010). Why knowledge matters in curriculum : a social realist argument. Abingdon, United Kingdom: Routledge.

Williams, M. M. (2014). Panguru and the city: Kāinga Tahi, Kāinga Rua: an urban migration history (1st edition. ed.). Wellington: Bridget Williams Books.

Wills, J. S. (2019). "Daniel was racist": Individualizing racism when teaching about the Civil Rights Movement. Theory \& Research in Social Education, 47(3), 396-425. doi:10.1080/00933104.2019.1583620

Wolfe, P. (1998). Settler colonialism and the transformation of anthropology: the politics and poetics of an ethnographic event. London: Cassell.

Wolfe, P. (2006). Settler colonialism and the elimination of the native. Journal of Genocide Research, 8(4), 387-409. doi:10.1080/14623520601056240

Wood, B. (2011). Citizenship in our place: exploring New Zealand young people's everyday, placebased perspectives on participation in society: A thesis submitted to the Victoria University of Wellington in fulfilment of the requirements for the degree of Doctor of Philosophy [in Education]. Victoria University of Wellington, Wellington.

Yin, R. K. (2009). Case study research: design and methods (4th ed.). Los Angeles: Sage Publications.

Young, M., \& Lambert, D. (2014). Knowledge and the future school : curriculum and social justice. London: Bloomsbury Academic.

Zembylas, M. (2007). Theory and methodology in researching emotions in education. International Journal of Research \& Method in Education, 30(1), 57-72. doi:10.1080/17437270701207785

Zembylas, M. (2011). Investigating the emotional geographies of exclusion at a multicultural school. Emotion, Space and Society, 4(3), 151-159. doi:10.1016/j.emospa.2010.03.003

Zembylas, M. (2012). Pedagogies of strategic empathy: navigating through the emotional complexities of anti-racism in higher education. Teaching in Higher Education, 17(2), 113125. doi:10.1080/13562517.2011.611869 
Zembylas, M. (2013a). Affective, political and ethical sensibilities in pedagogies of critical hope: Exploring the notion of 'critical emotional praxis'. In B. L. Vivienne Bozalek, Ronelle Carolissen, Megan Boler (Ed.), Discerning Critical Hope in Educational Practices: Routledge.

Zembylas, M. (2013b). The "Crisis of Pity" and the Radicalization of Solidarity: Toward Critical Pedagogies of Compassion. Educational Studies, 49(6), 504-521. doi:10.1080/00131946.2013.844148

Zembylas, M. (2013c). Critical pedagogy and emotion: working through 'troubled knowledge' in posttraumatic contexts. Critical Studies in Education, 54(2), 176-189. doi:10.1080/17508487.2012.743468

Zembylas, M. (2013d). The Emotional Complexities of "Our" and "Their" Loss: The Vicissitudes of Teaching about/for Empathy in a Conflicting Society. Anthropology \& Education Quarterly, 44(1), 19-37. doi:10.1111/j.1548-1492.2012.01175.x

Zembylas, M. (2014a). Affective, political, and ethical sensibilities in pedagogies of critical hope. In B. L. V. Bozalek, R. Carolissen, \& M. Boler (Ed.), Discerning critical hope in educational practices. London, UK: Routledge.

Zembylas, M. (2014b). Theorizing "Difficult Knowledge" in the Aftermath of the "Affective Turn": Implications for Curriculum and Pedagogy in Handling Traumatic Representations. Curriculum Inquiry, 44(3), 390-412. doi:10.1111/curi.12051

Zembylas, M. (2014c). Unmasking the Entanglements of Violence, Difficult Knowledge, and Schooling. Religious Education, 109(3), 258-262. doi:10.1080/00344087.2014.911622

Zembylas, M. (2015). 'Pedagogy of discomfort' and its ethical implications: the tensions of ethical violence in social justice education. Ethics and Education, 10(2), 163-174. doi:10.1080/17449642.2015.1039274

Zembylas, M. (2017a). The quest for cognitive justice: towards a pluriversal human rights education. Globalisation, Societies and Education, 15(4), 397-409. doi:10.1080/14767724.2017.1357462

Zembylas, M. (2017b). Teacher resistance to engage with 'alternative' perspectives of difficult histories: the limits and prospects of affective disruption. Discourse: Studies in the Cultural Politics of Education, 38(5), 659-675. doi:10.1080/01596306.2015.1132680

Zembylas, M. (2017c). Teacher resistance to engage with 'alternative' perspectives of difficult histories: the limits and prospects of affective disruption. Discourse: Studies in the Cultural Politics of Education, 38(5), 659-675. doi:10.1080/01596306.2015.1132680

Zembylas, M. (2017d). Wilful Ignorance and the Emotional Regime of Schools. British Journal of Educational Studies, 65(4), 499-515. doi:10.1080/00071005.2017.1290785

Zembylas, M. (2018). Hannah Arendt's political thinking on emotions and education: implications for democratic education. Discourse, <xocs:firstpage xmlns:xocs="'/>. doi:10.1080/01596306.2018.1508423

Zembylas, M., \& McGlynn, C. (2012). Discomforting pedagogies: emotional tensions, ethical dilemmas and transformative possibilities. British Educational Research Journal, 38(1), 41-59. doi:10.1080/01411926.2010.523779

Zembylas, M., \& Papamichael, E. (2017). Pedagogies of discomfort and empathy in multicultural teacher education. Intercultural Education, 28(1), 1-19. doi:10.1080/14675986.2017.1288448 


\section{Appendices}

\section{Appendix 1 - Teacher survey}

Pilot surveys for teachers and students

\section{Teaching about colonisation in New Zealand}

\section{Questionnaire for secondary school teachers of social studies and history}

The purpose of this survey is to gather information about history and social studies teachers' perceptions and experiences of teaching about colonisation in New Zealand. The results from this survey will be presented at conferences and published in journals.

Colonisation is an idea that applies to many parts of history but in this survey it refers to the influence of European settlers and their governments on New Zealand and the consequences this had for Māori and non-Māori.

This questionnaire is anonymous. You will not be identified. You can skip questions, choose not to comment, and you do not have to complete it once you have started. You do not have to do this questionnaire. If you do, the findings will be used to help us understand more about how to teach about colonisation in history and social studies classes. Because it is anonymous, once you submit the electronic form, you cannot withdraw your response.

The survey will take approximately 8-12 minutes to complete.

Thank you!

Michael Harcourt

PhD candidate

Victoria University of Wellington

The Victoria University of Wellington Human Ethics Committee has approved this research [HEC 25337].

Q1 How many years have you taught in the social sciences?

$0-2$

3-5

6-10

$11+$

$20+$ 
Q2 If you have taken social sciences papers at or above 300 level at University, what was/were your major discipline(s)?

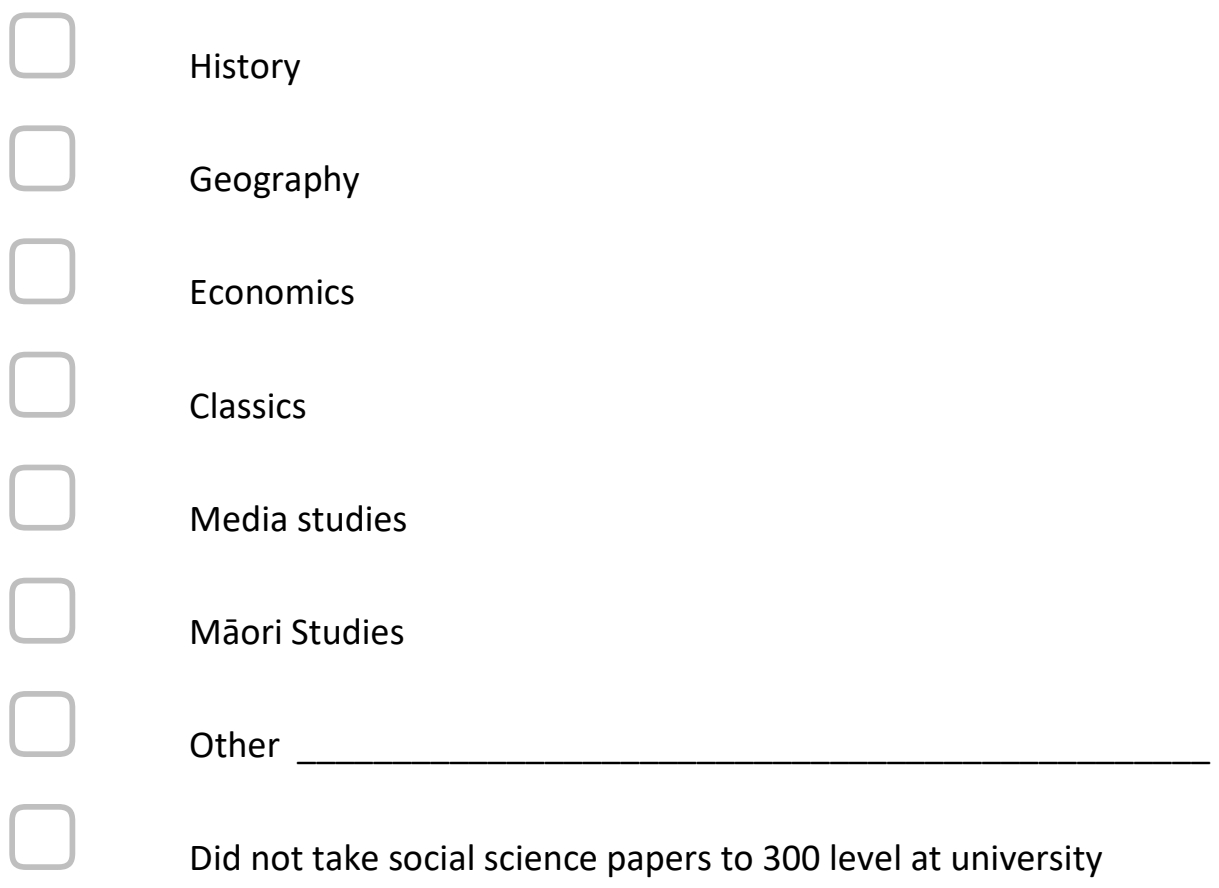

Q3 Which gender or genders do you identify with?

Male

Female

Other

Prefer not to answer 
Q4 What ethnicity or which ethnicities do you identify with?

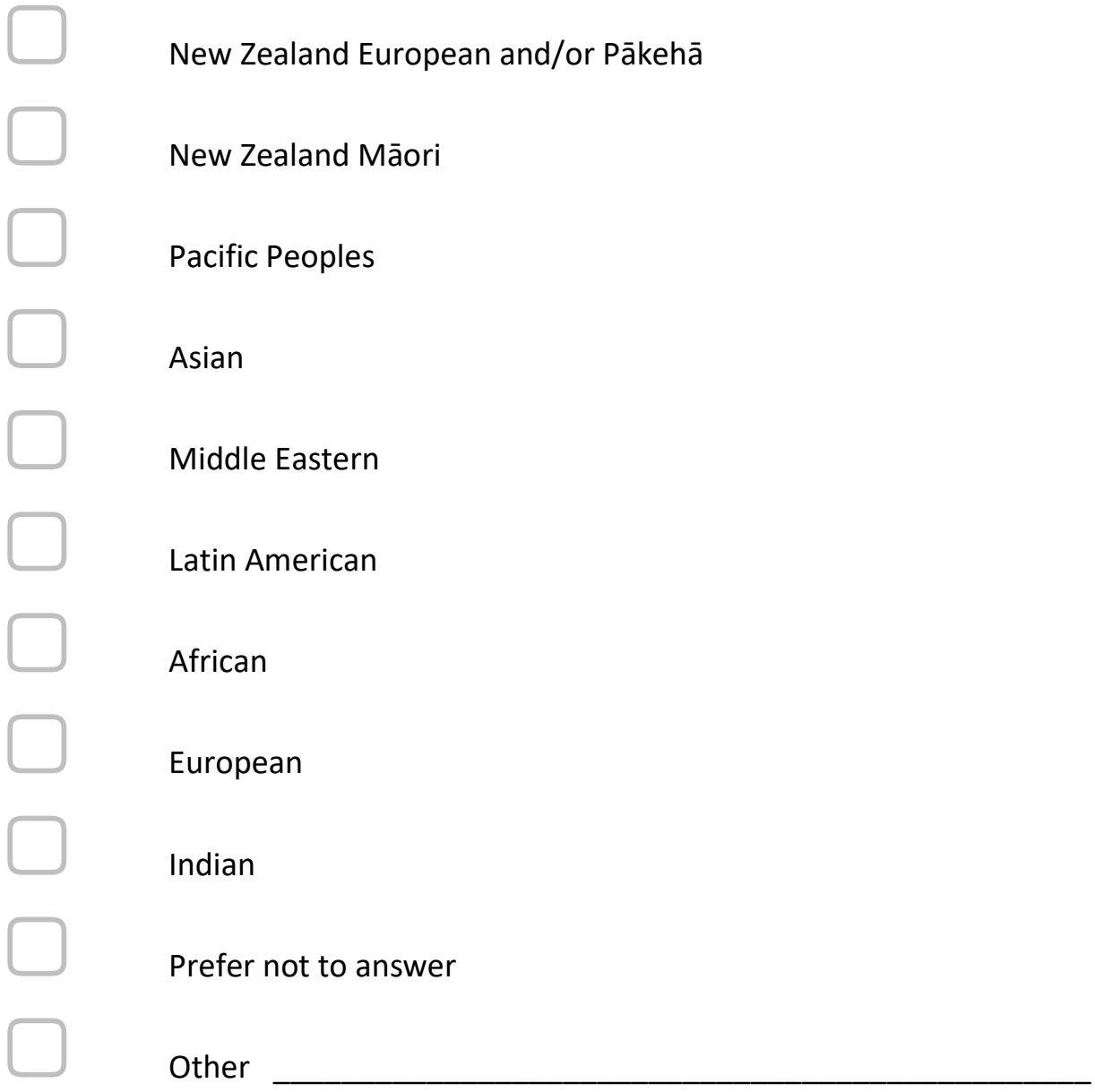

Q5 Which region do you currently teach in?

Northland

Auckland

Waikato

Bay of Plenty

Gisborne

Hawke's Bay

Taranaki

Manawatū-Whanganui

Wairarapa

Wellington 
Nelson region

Marlborough

West Coast

Canterbury

Otago

Southland

Other

Q6 Please choose the statement that best characterises the ethnic composition of your school's student body.

Majority NZ European/Pākehā

Majority NZ Māori

Majority Pacific Peoples

Majority Asian

Roughly the same NZ European/Pākehā and NZ Māori as the majority

Roughly the same NZ European/Pākehā and Asian as the majority

Roughly the same NZ European/Pākehā, NZ Māori and Asian as the majority

Roughly the same NZ Māori and Pacific Peoples as the majority

Other 
Q7 Which decile is your school?
1
2
3
4
5
6
7
8
9
10

Q8 Are you currently the Head of Department or Teacher in Charge of history or social studies in your school?

Yes

No

Q9 Do history and social studies departments in this country give enough priority to topics or issues relevant to colonisation in New Zealand?

Almost all of them do

Many of them do

Some of them do

Few of them do

Very few of them do

Q9a Comment 
Q10 Colonisation in New Zealand was a benign (good, kindly, humane) process. (Please comment if you like).

Strongly agree

Agree

Disagree

Strongly disagree

Q10a Comment

Q11 Colonisation has consequences for people in New Zealand today (Please comment if you like).

Strongly agree

Agree

Disagree

Strongly disagree

\section{Q11a Comment}

Q12 Building and maintaining a positive relationship between Māori and non-Māori is not helped by learning about the history of violence and conflict between them (Please comment if you like).

Strongly agree

Agree

Disagree

Strongly disagree

Q12a Comment

Q13 This is a memorial to Colonel Nixon in Ōtāhuhu, Auckland. Nixon died from wounds he received during an attack in 1864 on the village of Rangiaowhia during the invasion of the Waikato. There is 
currently a debate over whether this memorial should be taken down, put in a museum, left alone, reinterpreted, or another memorial added to the site [Photo credit: NZhistory].

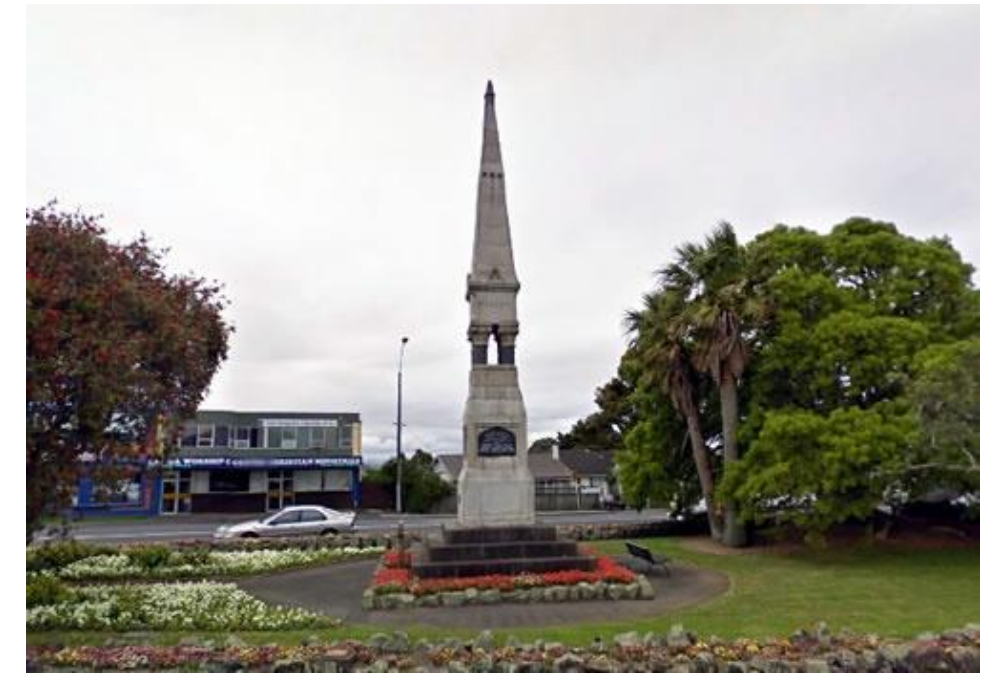

Q13a Should memorials like this one to New Zealand's colonial past be taken down?
Yes
No
Not sure
It depends

Q13b Please give a short explanation for your answer.

Q14 During the previous year, have you taught a unit (a sequence of at least 8 lessons) on some aspect of colonisation in New Zealand?

Yes

No

Skip To: Q15 If During the previous year, have you taught a unit (a sequence of at least 8 lessons) on some

aspec... = Yes

Skip To: Q25 If During the previous year, have you taught a unit (a sequence of at least 8 lessons) on some aspec... = No 
Q15 To which year level(s) did you teach unit(s) about colonisation in New Zealand? (Please indicate all that apply).

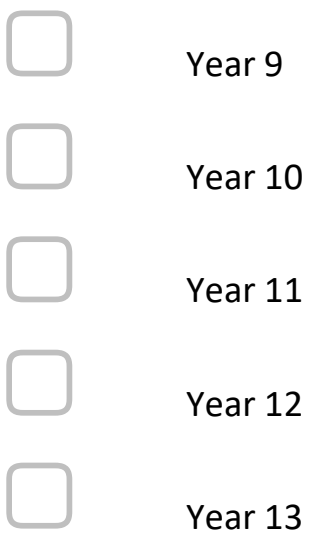

Q16 Please list the topic(s) (a sequence of at least 8 lessons) relevant to colonisation in New Zealand that you have taught in the previous year:

Q17 When teaching about New Zealand's colonial past, it is important to connect this history to issues affecting New Zealand today (Please comment if you like).

Strongly agree

Agree

Disagree

Strongly disagree

Q17a Comment

Q18 It is important to teach students about colonisation in New Zealand (Please comment if you like).

Strongly agree

Agree

Disagree

Strongly disagree

\section{Q18a Comment}


Q19 Do you take students to places outside the classroom when teaching about colonisation in New Zealand? (Please comment if you like).

Almost never

Sometimes

Often

Almost all of the time

Q19a Comment

Q20 Is teaching about colonisation in New Zealand controversial in your classes?

Almost never

Sometimes

Often

Almost all of the time

Skip To: Q21 If Is teaching about colonisation in New Zealand controversial in your classes? = Almost all of the time

Q21 What is it about colonisation in New Zealand that you think makes it controversial for your students? 
Q22 When I am teaching about controversial aspects of colonisation I prioritise the following strategies (tick those that are relevant and comment if you want to):

Classroom discussion

Avoid classroom discussion

Ask for students' personal opinions

Avoid asking for students' personal opinions

Keep to the text book

Use primary sources

Emphasise teacher-centred instruction

Show students different historians' views

Ask students not to be too emotive

Explore colonisation through student-led investigation

Focus on colonisation in places beyond NZ

Focus on multiple historical causes and perspectives of events in NZ

Highlight European supporters/allies of Māori

Move through controversial content quickly

Emphasise the benefits of colonisation to New Zealand (17)

Discuss how students' personal backgrounds may shape their attitudes toward the past

Connect the past to the present

Avoid connecting the past to the present

Other 
Q23 Comment 
Q24 Please rate the significance of each of the following challenges in relation to teaching about colonisation in New Zealand in your school

\begin{tabular}{|c|c|c|c|c|}
\hline & Not significant & Slightly significant & $\begin{array}{l}\text { Somewhat } \\
\text { significant }\end{array}$ & Highly significant \\
\hline $\begin{array}{l}\text { The topic is under } \\
\text { resourced }\end{array}$ & & & & \\
\hline $\begin{array}{c}\text { My historical } \\
\text { content knowledge } \\
\text { needs } \\
\text { development }\end{array}$ & & ) & & 0 \\
\hline $\begin{array}{l}\text { Students do not } \\
\text { find the topic } \\
\text { interesting }\end{array}$ & & & & \\
\hline $\begin{array}{c}\text { It's a controversial } \\
\text { topic }\end{array}$ & & 0 & & ) \\
\hline $\begin{array}{l}\text { My school's } \\
\text { community is not } \\
\text { supportive of it } \\
\text { being taught }\end{array}$ & & & & \\
\hline $\begin{array}{l}\text { I don't have access } \\
\text { to iwi and hapū } \\
\text { who could help me }\end{array}$ & & & & \\
\hline $\begin{array}{l}\text { Senior colleagues } \\
\text { are not supportive } \\
\text { of it being taught }\end{array}$ & & & & \\
\hline $\begin{array}{l}\text { Other topics have a } \\
\text { higher priority }\end{array}$ & O & $\bigcirc$ & & 0 \\
\hline $\begin{array}{l}\text { The history of } \\
\text { colonisation where }\end{array}$ & & & & \\
\hline $\begin{array}{l}\text { I teach is very raw } \\
\text { for local } \\
\text { communities }\end{array}$ & 0 & & & \\
\hline $\begin{array}{l}\text { Students will be } \\
\text { more successful in } \\
\text { NCEA if they focus } \\
\text { on non-NZ topics }\end{array}$ & & & & \\
\hline
\end{tabular}


Q24a Any other comments on the challenges of teaching about colonisation.

Skip To: End of Survey If Any other comments on the challenges of teaching about colonisation. =

Page Break

Q25 Why have you not been able to teach a unit (a sequence of at least 8 lessons) on colonisation in either history or social studies? 


\begin{tabular}{|c|c|c|c|c|}
\hline & Strongly agree & Agree & Disagree & Strongly disagree \\
\hline $\begin{array}{c}\text { Other teachers in the } \\
\text { department do it } \\
\text { already }\end{array}$ & C & & & \\
\hline $\begin{array}{l}\text { It is a topic not well } \\
\text { resourced at my school }\end{array}$ & 0 & & & \\
\hline $\begin{array}{l}\text { My historical content } \\
\text { knowledge of } \\
\text { colonisation is not } \\
\text { strong }\end{array}$ & & & & \\
\hline $\begin{array}{l}\text { It doesn't interest the } \\
\text { students at my school }\end{array}$ & 0 & & & \\
\hline $\begin{array}{l}\text { I'd like to, but it isn't } \\
\text { part of my department's } \\
\text { programme }\end{array}$ & ( & & & \\
\hline $\begin{array}{l}\text { Senior colleagues are } \\
\text { not supportive }\end{array}$ & 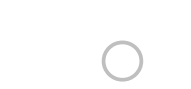 & & & \\
\hline $\begin{array}{l}\text { The wider community in } \\
\text { which I teach is not } \\
\text { supportive }\end{array}$ & ( & & & \\
\hline $\begin{array}{l}\text { I don't have connections } \\
\text { with iwi or hapū who } \\
\text { can help me }\end{array}$ & ( & & & \\
\hline $\begin{array}{l}\text { I feel uncomfortable } \\
\text { teaching about New } \\
\text { Zealand's colonial past }\end{array}$ & & & & \\
\hline $\begin{array}{l}\text { Other topics have a } \\
\text { higher priority }\end{array}$ & 0 & & & \\
\hline $\begin{array}{l}\text { The history of } \\
\text { colonisation where I } \\
\text { teach is very raw for } \\
\text { local communities }\end{array}$ & C & & & \\
\hline $\begin{array}{l}\text { Students will be } \\
\text { more successful in } \\
\text { NCEA if they focus } \\
\text { on non-NZ topics }\end{array}$ & & & & \\
\hline
\end{tabular}

Q25a Additional reasons for not teaching about colonisation and/or any comments on the challenges of teaching about colonisation. 


\section{Learning about colonisation in New Zealand}

I am a university student and I am interested in what you and other young people from around this country think about colonisation in Aotearoa/New Zealand. In this questionnaire, colonisation refers to the influence of European settlers and their governments in New Zealand. It also refers to the consequences of colonisation for Māori and non-Māori.

You are invited to take part in this questionnaire. You do not have to do it or give a reason for not doing it. If you do, it will help us find out more about how to teach some important aspects of Aotearoa/New Zealand's history. Please be aware: This questionnaire is anonymous which means you will not be identified. You can skip questions and you do not have to complete it once you have started. Because it is anonymous, once you submit the electronic version or return the paper version to your teacher, you cannot withdraw your response. You should not write your name if you are doing it on paper.

You will be able to find out about the project's results because I will provide a summary to your teacher. Please INDIVIDUALLY answer the questions below as best you can. The survey will take approximately 15-20 minutes to complete.

Thank you for helping!

Michael Harcourt

Victoria University of Wellington.

\section{Section 1 - Background information}

1. Which school do you attend? 
2. In which region of New Zealand is your school?

Northland

Auckland region

Waikato

Bay of Plenty

Gisborne

Hawke's Bay

Taranaki

Manawatū-Whanganui

Wairarapa

Nelson region

Marlborough

West Coast

Canterbury

Otago

Southland

Wellington

Other (please specify)

3. Which year level are you in?

Year 9

Year 10

Year 11

Year 12

Year 13 
4. Which gender(s) do you identify with? (Please indicate any that apply)

Male

Female

Other

Prefer not to say 
5. Which ethnicity or ethnicities do you identify with? (Please indicate any that apply)

New Zealand European/Pākehā

New Zealand Māori

Pacific Peoples

European

Asian

Middle Eastern

Latin American

African

Indian

Other

Prefer not to say 
6. Below are some examples of several broad topics relevant to the colonisation of New Zealand that you may have studied in history or social studies. Please mark which ones you have learned about in school so far. Leave it blank if you haven't learned about the topic or if you are not sure.

I learned this in primary or intermediate school
I learned this in secondary school
Answer 1 (1)

Māori responses to the arrival of explorers, traders, guns, Christian missionaries. (1)

Te Tiriti o Waitangi/The Treaty of Waitangi. (2)

Wars between the British and Māori iwi/tribes. (3)

Recent Māori protest and resistance (for example, Bastion Point, the 1975 Land March, Māori language revival, Seabed and Foreshore Act) (4)

The Waitangi Tribunal and the return of land and assets to Māori tribes. (5)
Answer 1 (1)
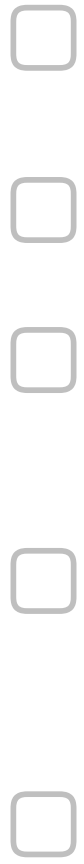
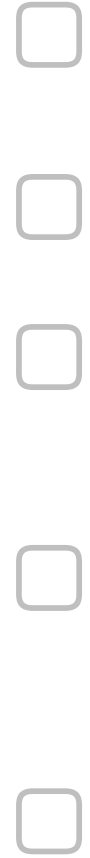

6a. Are there other topics relevant to colonisation in New Zealand that you have learned in school that are not covered in the examples above? Please write them below, otherwise go to the next question. 
Read the short piece of text below and complete three brief questions about it. There is space at the end of each question if you would like to write any comments.

Introduction: Owning our history

Following the Waikato War of July 1863 to April 1864, the once flourishing Waikato Māori economy stood in ruins - with villages destroyed, crops razed [pulled up/wrecked] and livestock [cows, pigs etc] looted. An area that just a few years earlier had been a hub of colonial commerce, exporting produce [food] to New South Wales, Victoria and even California, lay waste. Worse still, hundreds of Waikato Māori had been killed, and many more were left crippled or wounded.

O'Malley, V. (2016). The Great War for New Zealand: Waikato 1800-2000, Bridget Williams Press: Wellington, pp.9-10.

7. Indicate which ONE word MOST describes your feelings after reading the text above:

Shame

Anger

Sadness

Grief

Guilt

Frustration

Resentment

Other

7a. Why did you choose this word? 
8. Which ONE word LEAST describes your feelings after reading the text above:

Shame

Anger

Sadness

Grief

Guilt

Frustration

Resentment

Other

8a. Why did you choose this word?

9. Past conflict and violence between Māori and non-Māori still has an effect on life in New Zealand today

Strongly agree

Agree

Disagree

Strongly disagree

9a. Please tell me why you agree or disagree 
10. When people learn about the history of conflict and violence between Māori and non-Māori it makes it harder for them to get along today.

Strongly agree

Agree

Disagree

Strongly disagree

10a. Please tell me why you agree or disagree:

11. The New Zealand government should say sorry to Mãori tribes/iwi for not honouring Te Tiriti o Waitangi/The Treaty of Waitangi.

Strongly agree

Agree

Disagree

Strongly disagree

11a. Please tell me why you agree or disagree:

12. The New Zealand government should give money and/or return land to Māori tribes who suffered loss of their land during the process of colonisation

Strongly agree

Agree

Disagree

Strongly disagree

12a. Please tell me why you agree or disagree:

Section 3 - Your thoughts on learning about colonisation 
13. Talking about European colonisation of Aotearoa/New Zealand causes disagreements in my class

Almost always (1)

Often (2)

Sometimes (3)

Almost never (4)

13a. Please tell me why you chose this option:

14. Please indicate the ONE statement that BEST describes your personal feelings about learning New Zealand's history of colonisation.

It is interesting to me (1)

It is boring to me (2)

It is frustrating to me (3)

It is exciting to me (4)

It is meaningful to me (5)

It is meaningless to me (6)

It is disturbing to me (7)

It is important to me (8)

It is uncomfortable for me (9)

Other (10)

14a. Please tell me why you chose this option: 
Section 4 - Images of colonisation (Hang in there! This is the last section of the survey).

Look at the image below carefully. Please write down any questions or thoughts you have about it.

This photo is of a member of the armed constabulary (police) guarding a Māori prisoner, sometime in the 1870s in Taranaki [Photo credit: Puke Ariki museum].

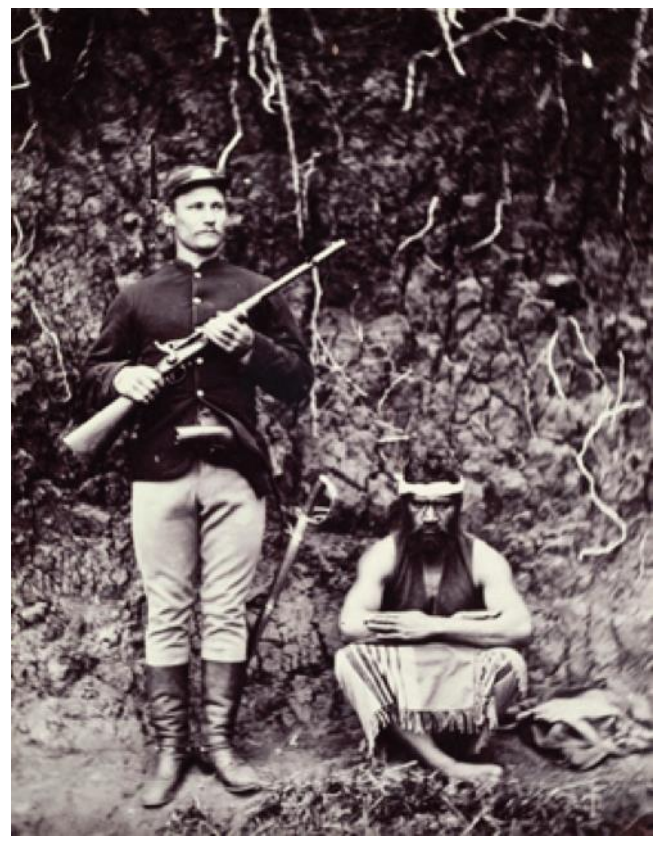

15. Any questions or thoughts you have about this photo: 
Look at the image below carefully. Please write down any questions or thoughts you have about it.

This map shows the extent of Māori land loss in the North Island. In 1860 (top left) most of the land in the North is controlled by Māori, by 1939 (bottom right) most of the land has been transferred to European control. The South Island showed a similar pattern. [Photo credit: Te Ara].

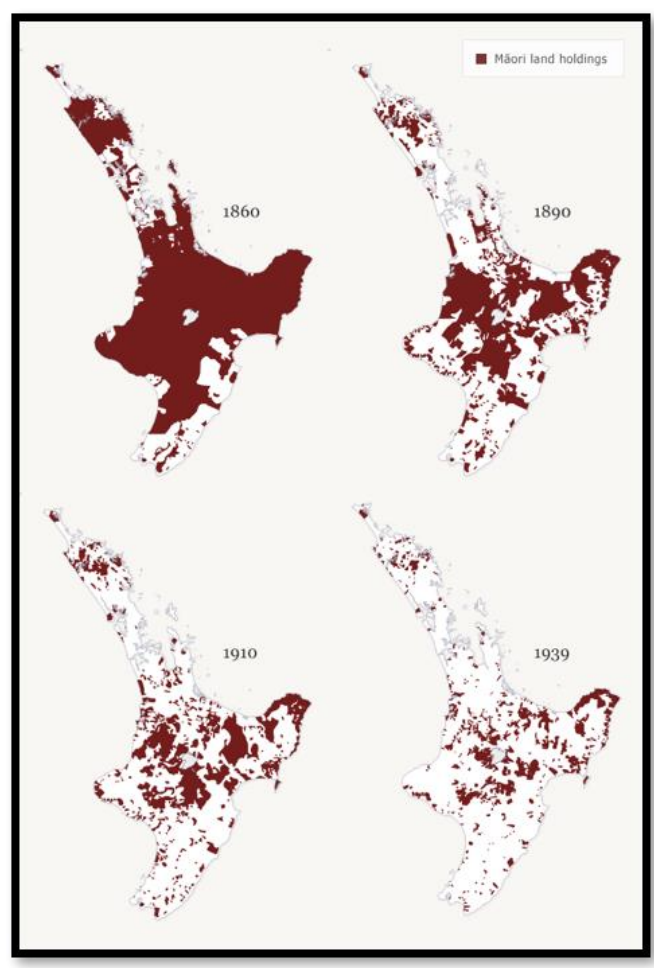

16. Any questions or thoughts you have about this map:

Look at the image below carefully. Please write down any questions or thoughts you have about it.

This is a European family farming in 1902 on land that had recently belonged to Māori [Photo credit: Te Ara]. 


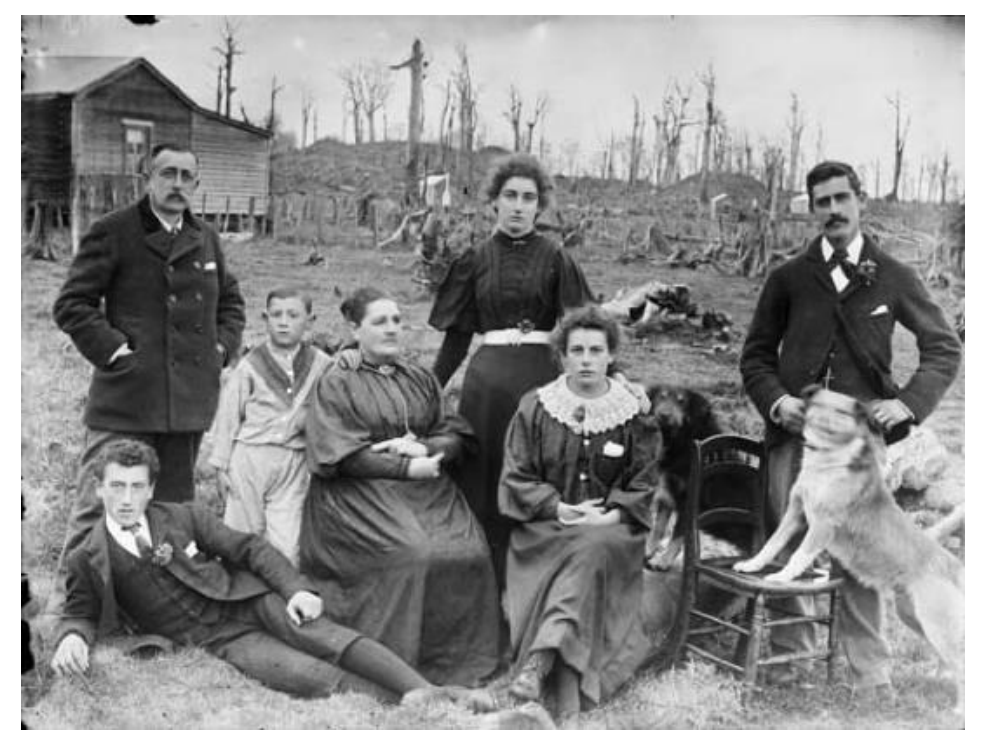

\section{Any questions or thoughts you have about this photo:}

Look at the image below carefully. Please write down any questions or thoughts you have about it.

This is a memorial to a British officer who led an attack on a Mãori village in 1864 during the invasion of the Waikato. Women, children, the elderly and some British soldiers were killed or wounded in this attack. The memorial was recently the subject of a debate. Some people argued it should be removed, others that it should remain, and others that it needed to be added to with a Māori perspective [Photo credit: Nzhistory.net]. 


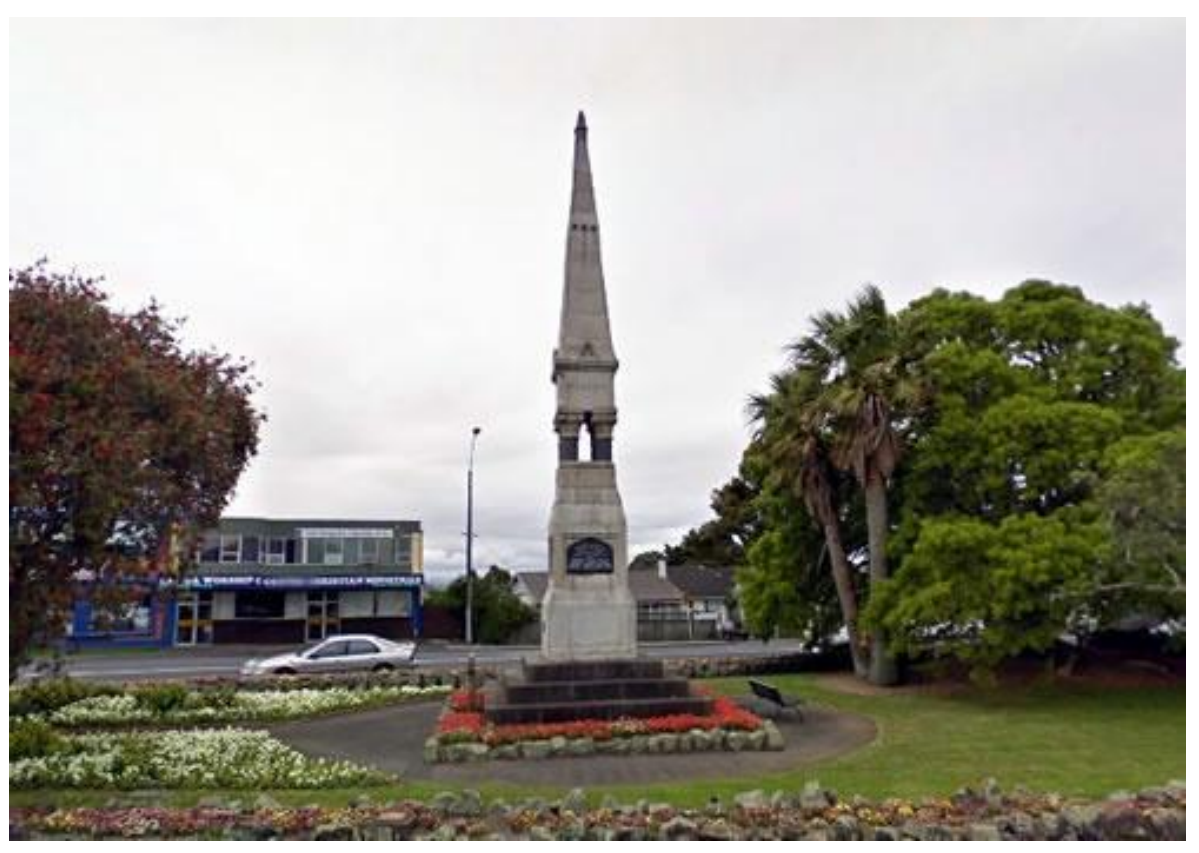

18. Any questions or thoughts you have about this memorial: 


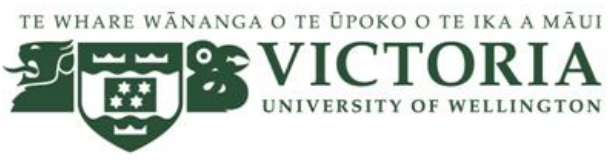

\section{Teaching and learning about colonisation in New Zealand secondary schools}

\section{Consent Sheet for Questionnaire: Principals}

This consent form will be held for 5 years.

Researcher: Michael Harcourt, Faculty of Education, Victoria University of Wellington.

- I have read the Information Sheet and the project has been explained to me. My questions have been answered to my satisfaction. I understand that I can ask further questions at any time.

- I consent for Michael Harcourt to approach the Head of Social Sciences in my school to invite them or any of their staff to administer a short, anonymous online or paper questionnaire.

I understand that:

- $\quad$ The anonymous nature of the questionnaire being administered means that I will not be able to withdraw students' questionnaire data from this study once it has been completed by students.

- I understand that data provided in this study will be stored in a locked cabinet or on a passwordprotected computer to ensure that it is safe, and that it is all completely anonymous.

- I would like to receive a summary of the final report and have added my email address below.

Yes

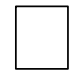

No

Signature of participant:

Name of participant:

Date:

Contact details: 


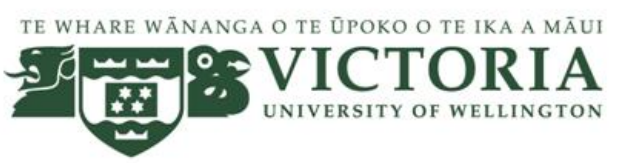

Teaching and learning about colonisation in New Zealand secondary schools

\section{Consent Sheet Case Study Research: Principals CONSENT TO CARRY OUT RESEARCH IN A SCHOOL}

This consent form will be held for 5 years.

Researcher: Michael Harcourt, Faculty of Education, Victoria University of Wellington.

- I have read the Information Sheet and the project has been explained to me. My questions have been answered to my satisfaction. I understand that I can ask further questions at any time.

- I consent for Michael Harcourt to approach a teacher and some of their students in my school to invite them to participate in the research.

I understand that:

- I may withdraw my school from this study at any point before September 30, 2018 and any information that my school has provided will be destroyed.

- I understand that data provided in this study will be stored in a locked cabinet or on a passwordprotected computer to ensure that it is safe.

- My school will not be named and will receive a pseudonym for the research and that no students or teachers will be named or identified in the research.

- $\quad$ The researcher (at no expense to the school) will attend the teacher's field trip.

- The researcher is a fully registered teacher and holds a current practicing certificate (registration number 243682) but will strictly remain in the role of researcher.

- I would like to receive a summary of the final report
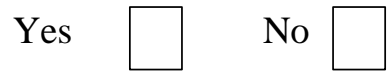

- I would like to receive a summary of findings for my school

Yes

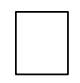

No and have added my email address below.

Signature of participant:

Name of participant:

Date: 
Contact details: 


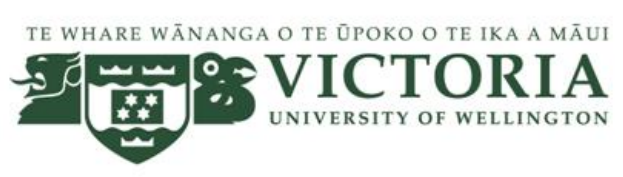

Teaching and learning about colonisation in New Zealand secondary schools:

\section{Consent sheet: Teachers}

\section{CONSENT TO INTERVIEW}

This consent form will be held for 5 years.

Researcher: Michael Harcourt, Faculty of Education, Victoria University of Wellington.

- I have read the Information Sheet and the project has been explained to me. My questions have been answered to my satisfaction. I understand that I can ask further questions at any time.

- $\quad$ I give my consent to be involved in a focus group in this research.

I understand that:

- I may withdraw the information I provide from this study at any point before September 30, 2018 [TBC] and any information provided will be destroyed.

- I understand that data provided in this study will be stored in a locked cabinet or on a password-protected computer to ensure that it is safe.

- I won't be named or identified in the research and I can give a pseudonym for myself.

- $\quad$ Any information I provide will be kept confidential to the researcher and his supervisors.

- I understand that the results will be used for a $\mathrm{PhD}$ dissertation and academic publications and presented to conferences.

- My name will not be used in reports, nor will any information be used that would identify me.

- I would like a copy of the transcript of my interview

Yes
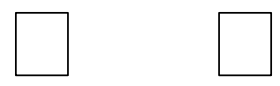

- $\quad$ I would like a summary of the final report

Yes

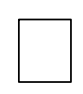

No

and have added my email address below.

Signature of participant:

Name of participant: 
Date:

Contact details: 


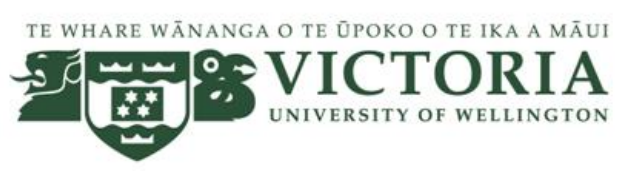

\section{Teaching and learning about colonisation in New Zealand secondary schools \\ Consent Sheet: Students \\ CONSENT TO FOCUS GROUP INTERVIEW}

This consent form will be held for 5 years.

Researcher: Michael Harcourt, Faculty of Education, Victoria University of Wellington.

- I have read the Information Sheet and the project has been explained to me. My questions have been answered to my satisfaction. I understand that I can ask further questions at any time.

- I give my consent to be involved in a focus group in this research.

I understand that:

- Due to the nature of a focus group interview (which involves lots of discussion where the voices of individuals may not be clear from the recording) it will be difficult or impossible to withdraw my contribution to the discussion.

- I can choose to leave the focus group interview at any time and do not have to give reasons why.

- I understand that data provided in this study will be stored in a locked cabinet or on a password-protected computer to ensure that it is safe.

- I won't be named or identified in the research and I can give a pretend name for myself.

- $\quad$ Any information I provide will be kept confidential to the researcher and his supervisors.

- I understand that the results will be used for a final report and academic publications and presented to conferences.

- I would like to receive a summary of findings for my school Yes and have added my email address below.

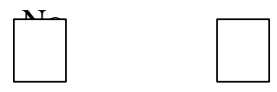

Signature of participant:

Name of participant:

Date:

Contact details: 


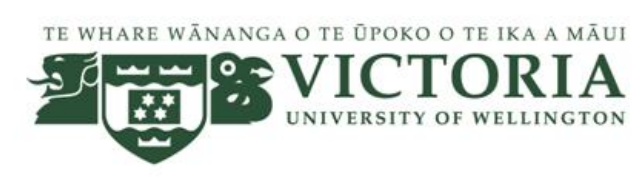

Teaching and learning about colonisation in New Zealand secondary schools

\section{Consent Sheet: Students \\ CONSENT TO PHOTOGRAPHY ACTIVITY}

This consent form will be held for 5 years.

Researcher: Michael Harcourt, Faculty of Education, Victoria University of Wellington.

- I have read the Information Sheet and the project has been explained to me. My questions have been answered to my satisfaction. I understand that I can ask further questions at any time.

- I give my consent to be involved in a photography activity in this research.

I understand that:

- I may withdraw the information I provide from this study before September 30, 2018 [TBC] and any information provided will be destroyed.

- The data provided in this study will be stored in a locked cabinet or on a password-protected computer to ensure that it is safe.

- I won't be named or identified in the research and I can give a pretend name for myself.

- No identifiable images of people will be used in any reporting of this research.

- $\quad$ Any information I provide will be kept confidential to the researcher and his supervisors.

- The results, including potentially some of my photographs, will be used for a final report and academic publications and presented to conferences.

- $\quad$ The images I take belong to me and I have the right to decide which ones, if any, are used by the researcher. If I change my mind about wanting all or some of my photographs used in this research before September 30,2018 , I can contact the researcher through my teacher and they will not be used.

- I may participate in the focus group interviews even if I decide not to participate in the photography activity or share any photos I may have taken during the field trip

- I would like to receive a summary of findings for my school Yes and have added my email address below.

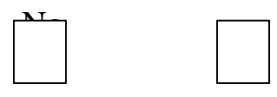


Signature of participant:

Name of participant:

Contact details:

Date: 


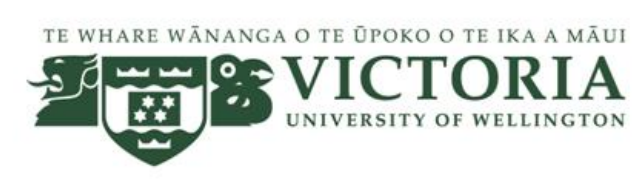

\section{Teaching and learning about colonisation in New Zealand secondary schools Consent Sheet: Parents/Caregivers CONSENT TO FOCUS GROUP INTERVIEW/PHOTOGRAPHY ACTIVITY}

This consent form will be held for 5 years.

Researcher: Michael Harcourt, Faculty of Education, Victoria University of Wellington.

- I have read the Information Sheet and the project has been explained to me. My questions have been answered to my satisfaction. I understand that I can ask further questions at any time.

- I give my consent for my son/daughter to be involved in

- A focus group interview and a photography activity

I understand that:

- My young person may withdraw the information provided for this study at any point before September 30, 2018 [TBC]. If this is happens any information provided will be destroyed.

- Data provided for this study will be stored in a locked cabinet or on a password-protected computer to ensure that it is safe.

- My young person won't be named or identified in the research and s/he can give a pseudonym for him/herself.

- The photograph activity protocols will be clearly explained and no identifiable images of people will be used in the final research.

- $\quad$ Any information s/he provides will be kept confidential to the researcher and his supervisors.

- $\quad$ The results will be used for a final report and academic publications and presented to conferences.

- $\quad$ Any images taken by my young person belong to them and they have the right to decide which ones, if any, are used by the researcher.

- My young person may participate in the focus group interviews even if they decide not to participate in, or share any photos they may have taken during the field trip.

- I would like to receive a summary of findings for my school Yes and have added my email address below.

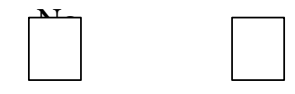

Signature of parent/caregiver: 
Name of participant:

Contact details:

Date: 


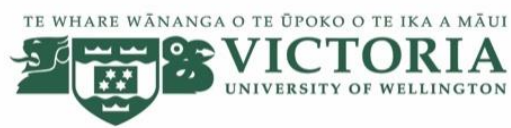

\section{Information sheet for Principals: Questionnaire}

\section{Teaching and learning about colonisation in New Zealand secondary schools}

Principal Investigator: Michael Harcourt: Faculty of Education Victoria University.

Tēnā koe

My name is Michael Harcourt and I am a PhD student at Victoria University of Wellington. I am currently researching how teachers and students engage with New Zealand's colonial past in history and social studies classrooms.

I would like your permission to invite the head of Social Sciences in your school to help me administer a short, anonymous questionnaire to four to six classes of year 9-13 history and social studies students. The questionnaire asks students' about their thoughts and beliefs concerning New Zealand's colonial past and their learning of this historical process. The questionnaire is in either digital or paper format depending on what is easiest for the teacher(s) to administer.

The Victoria University ethics committee has approved this research [HEC 25337]. Because the questionnaire is anonymous, students of all ages can give their consent simply by agreeing to complete the questionnaire. However, no student should feel compelled to complete the questionnaire and this will be made clear to students should you give permission for it to be administered.

None of the data generated will identify your students in any way and I will make the findings of the research available by sending a summary to the Head of Department to distribute to all classes once I have completed my analysis. In the questionnaire, students will be asked to name their school but the school's identity will remain confidential and not reported in any way. 
If you have any questions or points that you would like me to clarify, please do not hesitate to contact me. Please could you let me know if you are happy for me to invite the Social Sciences Head of Faculty to participate in this research by completing the attached consent form or simply by emailing me. Alternatively, if on reflection you do not wish your school to participate just let me know (you do not need to provide a reason) and thank you for considering our request.

Ngā mihi

\section{Michael Harcourt}

If you have any questions or points that you would like me to clarify, please do not hesitate to contact me or my Supervisor:

\section{Contact details}

\begin{tabular}{|l|l|}
\hline Michael Harcourt & Supervisor: Mark Sheehan \\
Faculty of Education & Faculty of Education \\
Victoria University of Wellington & Ph 044639687 \\
Email: Michael.harcourt@ vuw.ac.nz & Email: mark.sheehan@vuw.ac.nz \\
\hline
\end{tabular}

\section{Human Ethics Committee information}

If you have any concerns about the ethical conduct of the research you may contact the Victoria University HEC Convenor: Associate Professor Susan Corbett. Email susan.corbett@vuw.ac.nz or telephone +64-4-463 5480. 
Information sheet for Heads of Faculty, Heads of Department or TiCs: Questionnaire

\section{Teaching and learning about colonisation in New Zealand secondary schools}

Principal Investigator: Michael Harcourt: Faculty of Education Victoria University,

Tēnā koe

My name is Michael Harcourt and I am a PhD student at Victoria University of Wellington. I am currently researching how teachers and students engage with New Zealand's colonial past in history and social studies classrooms. Your principal has given me permission to inquire into your interest in helping me with a section of my research.

In recent months there has been considerable media and political attention focussed on the importance of New Zealanders knowing this country's colonial history. Some of this attention has been directed at teachers and at the social sciences curriculum, with several commentators calling for some topics (such as the New Zealand Land Wars) to be made mandatory. My research intends to examine teachers and students' experiences of teaching and learning about colonisation. I would like to invite you or any of your staff to help me administer a short, anonymous questionnaire to four to six classes of history and social studies students in years 9-13. The questionnaire is in either digital or paper format depending on what is easiest for your school.

The Victoria University Ethics Committee has approved this research [HEC 25337]. Because the questionnaire is anonymous, students of all ages can give their consent simply by agreeing to complete the questionnaire. However, no student should feel compelled to complete it and this will be made clear to students on the questionnaire and on an information sheet, should you and/or your staff be willing to participate in my study.

None of the data generated will identify your students in any way and I will make the findings of the research available by sending a summary of findings to the school to distribute 
to all classes once I have completed my analysis. The information from my research will be used in my $\mathrm{PhD}$ thesis and for publication in academic journals and conference presentations. Please could you let me know if you are willing to be involved in this study at the email below and we can talk further about me sending you a link to the survey or hard copies in a pre-paid return envelope. Alternatively, if on reflection you do not wish your Faculty or Department to participate just let me know (you do not need to provide a reason) and thank you for considering my request.

Ngā mihi

Michael Harcourt

If you have any questions or points that you would like me to clarify, please do not hesitate to contact me or my Supervisor:

\section{Contact details}

\begin{tabular}{|l|l|}
\hline Michael Harcourt & Supervisor: Mark Sheehan \\
Faculty of Education & Faculty of Education \\
Victoria University of Wellington & Ph 044639687 \\
Email: Michael.harcourt@ vuw.ac.nz & Email: mark.sheehan@vuw.ac.nz \\
\hline
\end{tabular}

\section{Human Ethics Committee information}

If you have any concerns about the ethical conduct of the research you may contact the Victoria University HEC Convenor: Associate Professor Susan Corbett. Email susan.corbett@vuw.ac.nz or telephone +64-4-463 5480. 


\title{
Teaching and learning about colonisation in New Zealand secondary schools
}

\author{
Kia ora \\ My name is Michael Harcourt and I am a doctoral student from the Faculty of Education at Victoria \\ University, Wellington. I am carrying out research in classrooms around New \\ Zealand to see what and how students are learning about colonisation, or the period in which \\ Europeans established control over New Zealand.
}

This research has the approval of Victoria University Human Ethics Committee [HEC No. 25337] and your school principal.

I am inviting you to complete a survey either in digital or paper format, depending on what your teacher decides. Taking part in this study is voluntary. If you do not want to take part, you do not have to do so and you do not need to provide a reason.

If you fill out this questionnaire, it will be taken that you agree to take part. It will take you about 10-12 minutes to complete.

If you decide to participate, thank you. If you decide not to take part, thank you for considering my request.

\section{What will happen to the information you give?}

This research is anonymous. This means that nobody, including me, will be aware of your identity. The questionnaire will ask you to name your school, but I will not know who you are. You will be able to find out about the project findings as I will email a summary to your teacher to share with you. Once you submit the survey, it will be impossible to retract your answer. Please do not include any personal identifiable information in your responses.

What will the project produce? 
The information from my research will be used in my $\mathrm{PhD}$ thesis and for publication in academic journals and conference presentations.

Ngā mihi

Michael Harcourt

If you have any questions, either now or in the future, please feel free to contact either myself or my Supervisor:

\section{Contact details}

\begin{tabular}{|l|l|}
\hline Michael Harcourt & Supervisor: Mark Sheehan \\
Faculty of Education & Faculty of Education \\
Victoria University of Wellington & Ph 044639687 \\
Email: Michael.harcourt@ vuw.ac.nz & Email: mark.sheehan@ vuw.ac.nz \\
\hline
\end{tabular}

\section{Human Ethics Committee information}

If you have any concerns about the ethical conduct of the research you may contact the Victoria University HEC Convenor: Associate Professor Susan Corbett. Email susan.corbett@vuw.ac.nz or telephone +64-4-463 5480. 


\title{
Appendix 5 - Information sheets for multiple site study
}

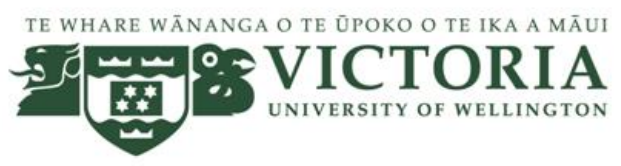

\author{
Teaching and learning about colonisation in New Zealand secondary schools \\ Principal Investigator: Michael Harcourt: Faculty of Education Victoria University of \\ Wellington.
}

\section{Research Information Sheet for School Case Study Research: Principals}

\section{Dear XXX,}

My name is Michael Harcourt and I am a PhD student at the Faculty of Education at Victoria University of Wellington. I am currently researching how teachers and students engage with New Zealand's colonial past in history and social studies classrooms.

\section{What is the aim of the research?}

In recent months there has been considerable media and political attention focussed on the importance of New Zealanders knowing this country's colonial history. Some of this attention has been directed at teachers in the social sciences and at the social sciences curriculum, with several commentators calling for some topics (such as the New Zealand Land Wars) to be made mandatory.

My study aims to gain a deeper, more nuanced understanding of young peoples' and teachers' engagement with the history of colonisation by working closely with a teacher and his/her class as they study a historical New Zealand context. It is for this reason that I am writing to you.

I would like to invite your school to be part of my research because I am particularly interested in working with XXXX. She/he has a reputation in the history teaching community for being an active and committed member of the profession who is dedicated to the critical teaching of colonisation in New Zealand. XX has indicated s/he is interested in my project and happy to work with me.

What is involved with the research? 
My research would involve observing some of XXX's lessons in the lead up to your school's field trip to a site associated with the colonial era. It would also include going on the field trip (at no extra cost to the school) and I can pay the equivalent of one student's field trip fee. The research would also involve carrying out an interview with the teacher and running two focus groups with a selection of 8-10 students before and after the field trip.

I have received ethical permission for this research from the Victoria University Human Ethics Committee [HEC 25337] and the findings will be written up in a final report, in academic journals and in conference presentations.

The students invited to participate in a focus group interview will also be invited to take part in a photography activity during the field trip to capture their impressions in pictures. They will be loaned a digital camera during the field trip. Following the trip they will discuss their photos with me. Students will receive guidance about how to take photos which are sensitive to the wāhi tapu of sites and to the confidentiality of others. No identifiable photos will be used in any reporting of the research

\section{Privacy and confidentiality}

I will not name any schools involved in the research but will attribute a pseudonym to the school when I report findings.

All data collected will be stored in a locked filing cabinet and all electronic information will be password protected. All data will be destroyed five years after completion of the research. You may withdraw your school (or any information you have provided) from this project at any stage before data analysis is complete (by September 30,2018), without having to give a reason.

I will be very happy to provide a summary of the findings of the research to you or interested staff in the school and you can request a copy of the summary of findings on the consent sheet attached.

I am happy to answer any questions about this research. Please feel free to contact me or my supervisor using the contact details below.

I appreciate you taking time to consider this request.

Warm regards,

Michael Harcourt

PhD student 


\section{Contact details}

\begin{tabular}{|l|l|}
\hline Michael Harcourt & Supervisor: Mark Sheehan \\
Faculty of Education & Faculty of Education \\
Victoria University of Wellington & Ph 044639687 \\
Email: Michael.harcourt@ vuw.ac.nz & Email: mark.sheehan@vuw.ac.nz \\
\hline
\end{tabular}

If at any time you have any ethical concerns about this study, contact Dr. Susan Corbett, Chair of the Victoria University of Wellington Human Ethics Committee (telephone: +644 463 5480; email: susan.corbett@vuw.ac.nz). 


\author{
Teaching and learning about colonisation in New Zealand secondary schools \\ Principal Investigator: Michael Harcourt: Faculty of Education Victoria University of \\ Wellington
}

\title{
Research Information Sheet for School Case Study Research: Teachers
}

Tēnā koe

You are invited to take part in this research. Please read this information before deciding whether or not to take part. If you decide to participate, thank you. If you decide not to participate, thank you for considering this request.

\section{Who am I?}

My name is Michael Harcourt and I am a PhD candidate in Education at Victoria University of Wellington. This research project is work towards my thesis.

\section{What is the aim of the project?}

This project explores how young people and teachers engage with New Zealand's history of colonisation during history and social studies lessons. This research has been approved by the Victoria University of Wellington Human Ethics Committee [HEC 25337].

\section{How can you help?}

You have been invited to participate because you have a reputation for developing in your students critical understanding of aspects of colonisation in New Zealand. You also take students on field trips to sites associated this aspect of New Zealand's history, which is a particular interest of my thesis. If you agree to take part, I will observe as much of your teaching of a topic about colonisation that you are willing to allow me and interview you at your school after the field trip. In the interview I will ask you questions about the challenges and opportunities you experience when teaching about colonisation, both during classroombased lessons and during the field trip. The interview will take 45 minutes. I will audio record the interview with your permission and write it up later. You can choose to not answer any question or stop the interview at any time, without giving a reason. You can withdraw from the study by contacting me at any time up September 20, 2018 [TBC]. If you withdraw, the information you provided will be destroyed or returned to you.

I also intend to invite some of your students to join a focus group with the aim of gaining a deeper understanding of how they engage with New Zealand's colonial past. If it is OK with you and the school I hope to join in your planned field trip (at no cost to the school - I would cover all my own expenses). During the field trip I would like to loan a digital camera to the students I have interviewed earlier so they can take photos of things that particularly interest them or that they would like to reflect on further with me following the field trip. As a way of 
contributing to the school and to say thank you for allowing me to join in, I would like to cover the costs of one students' field trip expenses. All of these details would be discussed to make sure the research works for everyone involved.

\section{What will happen to the information you give?}

This research is confidential. This means that I and my supervisors will be aware of your identity but your identity will not be revealed in any reports, presentations, or public documentation. However, you should be aware that in small projects your identity might be obvious to some people in your community (especially your immediate colleagues).

Only my supervisors and I will read the notes or transcript of the interview. The interview transcripts, summaries and any recordings will be kept securely and destroyed five years after the end of the research.

\section{What will the project produce?}

The information from my research will be used in my $\mathrm{PhD}$ dissertation and academic publications and conferences.

\section{If you accept this invitation, what are your rights as a research participant?}

You do not have to accept this invitation if you don't want to. If you do decide to participate, you have the right to:

- choose not to answer any question

- ask for the recorder to be turned off at any time during the interview

- withdraw from the study by September 30, 2018 [TBC].

- ask any questions about the study at any time

- receive a copy of your interview recording

- receive a copy of your interview transcript

- be able to read any reports of this research by emailing the researcher to request a copy

- expect a small koha in acknowledgement of the time taken from your day to be interviewed

- say if you would rather not have me observe your lesson on a particular day.

I appreciate you taking time to consider this request.

Nga mihi,

\section{Michael Harcourt}

If you have any questions or problems, who can you contact?

If you have any questions, either now or in the future, please feel free to contact either:

\section{Student:}

Name: Michael Harcourt

\section{Supervisor:}

Name: Mark Sheehan

Role: Primary supervisor 
University email address:

michael.harcourt@vuw.ac.nz
School: School of Education

Phone: 4639687

mark.sheehan@vuw.ac.nz

\section{Human Ethics Committee information}

If you have any concerns about the ethical conduct of the research you may contact the Victoria University HEC Convenor: Associate Professor Susan Corbett. Email susan.corbett@vuw.ac.nz or telephone +64-4-463 5480. 


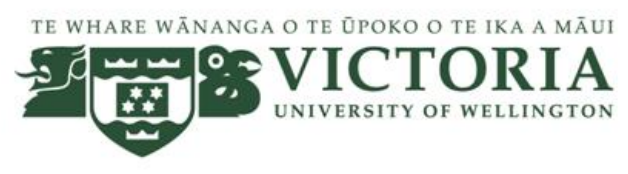

\author{
Teaching and learning about colonisation in New Zealand secondary schools \\ Principal Investigator: Michael Harcourt: Faculty of Education Victoria University of \\ Wellington.
}

\title{
Research Information Sheet for School Case Study Research: Students
}

\section{Kia ora}

My name is Michael Harcourt and I am a PhD student at the Faculty of Education at Victoria University of Wellington.

\section{What is the aim of the research?}

In recent months there has been lots of interest in the importance of New Zealanders, and especially young people, knowing this country's colonial history. However, often it is the voices and experiences of people like you that is missing.

I want to hear more about your own experiences of learning an important part of New Zealand's history.

This research is of interest to many people and the findings will be written up in a final report and also written up in journals and shared at conferences. The Victoria University Human Ethics Committee [HEC 25337] has given me permission to do this study.

\section{How can you help?}

I will be observing some of your history lessons in the lead up to your history field trip. I would like to invite you to participate in a one-hour focus group interview before and after your field trip with 3-4 other members of your class.

If you agree to take part, in the first focus group interview I will ask you some questions and audio record your discussion. This discussion will be at a time that suits your teacher and you and doesn't distract from your learning.

During the field trip I will also invite you to take some photos about your experiences, photographing the things that capture your interest, or which you have further questions about. This would involve being loaned a digital camera for the field trip. This is an activity you would do individually since each of you will notice different things. I will print your photos for you and ask you to select some to discuss during the second interview after the field trip. I won't use or report any photos which can identify people in my research or name your school.

\section{What will happen to the information you give?}

I will not name you or your school, but I will give your school a code name and you can choose a name for yourself so you can't be identified.

All data collected will be stored in a locked filing cabinet and all electronic information will be password protected. All data will be destroyed five years after completion of the research.

If you accept this invitation, what are your rights as a research participant?

You do not have to be involved in the research and it will make no difference to your grades if you choose to participate or not. 
If you do decide to participate, you have the right to:

- choose not to answer any question;

- ask for the recorder to be turned off at any time during the interview;

- withdraw from the study before 30 September, 2018 without giving a reason;

- ask any questions about the study at any time.

- participate in the focus group but not take or share any photos from the field trip

If you are under 16 years, I will need your parent's consent for you to participate in this research. If you are willing to be involved, can you please sign the form below and get your parent's consent as well. Your parents are very welcome to contact me if they require further information - my details are supplied below.

I will be very happy to provide a summary of the findings of the research to you/your parents and you can request a copy of the final report or a summary document on the consent sheet attached.

I appreciate you taking time to consider this request.

Nga mihi,

Michael Harcourt

Contact details

\begin{tabular}{|l|l}
\hline Michael Harcourt & Supervisor: Mark Sheehan \\
Faculty of Education & Faculty of Education \\
Victoria University of Wellington & Ph 4639687 \\
Email: Michael.harcourt@ vuw.ac.nz & Email: mark.sheehan@ vuw.ac.nz
\end{tabular}

If at any time you have any ethical concerns about this study, contact Dr. Susan Corbett, Chair of the Victoria University of Wellington Human Ethics Committee (telephone: +64 4 463 5480; email: susan.corbett@ vuw.ac.nz). 


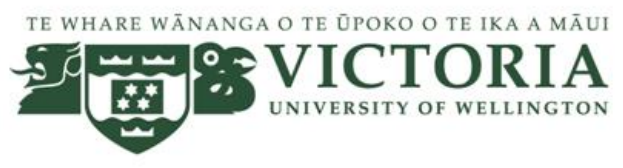

\author{
Teaching and learning about colonisation in New Zealand secondary schools \\ Principal Investigator: Michael Harcourt: Faculty of Education Victoria University of \\ Wellington
}

Research Information Sheet for School Case Study Research: Parents and Caregivers

Tēnā koe

My name is Michael Harcourt and I am a PhD student at the Faculty of Education at Victoria University of Wellington.

\title{
What is the aim of the research?
}

In recent months there has been considerable media attention focussed on the importance of New Zealanders, and especially young people, knowing this country's colonial history.

However, often it is the voices and experiences of young people that are missing from these conversations. My research aims to hear more about your child's experiences of learning an important aspect of New Zealand's history.

This research is of interest to many people and the findings will be written up in a final report, in academic journals and in conference presentations. I have received ethical permission for this research from the Victoria University Human Ethics Committee [HEC 25337].

\section{How can you help?}

As your child is under 16 , s/he requires parental consent to participate. This letter explains the project which s/he is interested in being involved in.

Your young person has been studying about colonisation in his or her history class. I would like to invite him/her to participate in two focus group interviews with 3-4 other students. The timing of these will be before and after your child's history field trip and either during class time or lunch (approx. 60 mins), in a school classroom according to what works best for the students and teacher and results in the least amount of disruption to their learning.

I would also like to invite your child to participate in a photo activity during the field trip, capturing images of things that interest them or which they have further questions about. I will provide a digital camera for this task and it will not get in the way of the teacher's activities and teaching during the trip. The images will be printed for your child and I will ask them to choose a selection to discuss during the final focus group interview. For example, I will ask 'why did you take this photo? What does it mean to you? Before distributing the cameras we will discuss protocols for taking photos, especially at places closely associated with the violence and suffering associated with colonial conflict. I won't use or report any photos which can identify people in the research.

\section{What will happen to the information your young person gives?}

I will not name the school or the young person at any time but will allocate a pseudonym to the school and young person so that they can't be identified.

All data collected will be stored in a locked filing cabinet and all electronic information will be password protected. All data will be destroyed five years after completion of the research. 


\section{If you accept this invitation, what are the rights of your young person?}

There is no obligation to be involved in the research and there are no implications for your young person's learning or grades if s/he doesn't participate.

If $\mathrm{s} / \mathrm{he}$ does decide to participate, $\mathrm{s} / \mathrm{he}$ has the right to:

- $\quad$ choose not to answer any question;

- $\quad$ not take photos during the field trip

- $\quad$ ask for the recorder to be turned off at any time during the interview;

- $\quad$ withdraw from the study before September 30, 2018 without giving a reason;

- $\quad$ ask any questions about the study at any time.

- $\quad$ participate in the focus group but not share any photos they may have taken on the field trip

If you are willing for your son/daughter to be involved, please sign the consent form provided and return to (teacher). As an alternative, you can email your consent (including your son/daughter's name/class) to me at Michael.harcourt@vuw.ac.nz.

If you would like a copy of the final report or a summary of findings please indicate on the consent sheet attached or in an email to me.

I appreciate you taking time to consider this request.

Ngā mihi,

Michael Harcourt

Contact details

\begin{tabular}{|l|l|}
\hline Michael Harcourt & Supervisor: Mark Sheehan \\
Faculty of Education & Faculty of Education \\
Victoria University of Wellington & Ph 4639687 \\
Email: Michael.harcourt@ vuw.ac.nz & Email: mark.sheehan@vuw.ac.nz \\
\hline
\end{tabular}

If at any time you have any ethical concerns about this study, contact Dr. Susan Corbett, Chair of the Victoria University of Wellington Human Ethics Committee (telephone: +64 4 463 5480; email: susan.corbett@ vuw.ac.nz). 


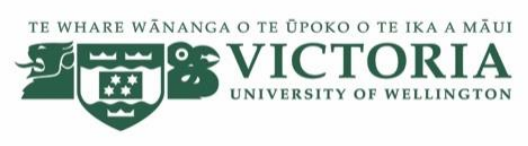

Field trip photo task

Kia ora

I would like to learn more about how you connect to historical sites and the kind of impact they have on you.

During your field trip please could you try and take photos that respond to these questions:

- which aspects of this place make you think the most about New Zealand's history of colonisation?

- what parts of the site are the most challenging or difficult to deal with?

- what aspects of the site make you feel something? (For example, shame, anger, grief, sadness, guilt, frustration, resentment, happiness, boredom etc).

I have some digital cameras for you to use during the trip and this activity will work well groups of 23. The questions above will also be in the bags of the cameras on a laminated card.

I will print all of the photographs you want to share and you can keep a copy of these, and I can send you a link to the digital files.

Look after these cameras carefully and let me know if it needs recharging.

Please listen carefully to what your teachers and others helping with this trip say about photographs. There may be some places where you are asked to only take photos at certain times, and you'll need to respect this.

If you take a photo(s) using your phone or another device and you would like to include these you can email it to me at michael.harcourt@ vuw.ac.nz so I can print them for you.

I'll collect the cameras on the last day of the field trip and we will debrief back at school.

Thank you!

Michael Harcourt 


\section{CONSENT TO PHOTOGRAPHY ACTIVITY}

This consent form will be held for 5 years.

Researcher: Michael Harcourt, Faculty of Education, Victoria University of Wellington.

- I have read the Information Sheet and the project has been explained to me. My questions have been answered to my satisfaction. I understand that I can ask further questions at any time.

- I give my consent to be involved in a photography activity in this research.

I understand that:

- I may withdraw the information I provide from this study before September 30, 2018 and any information provided will be destroyed.

- The photographs provided in this study will be stored in a locked cabinet or on a passwordprotected computer to ensure that it is safe and no photos of identifiable people will be used

- I won't be named or identified in the research and I can give a pretend name for myself.

- $\quad$ No identifiable images of people will be used in any reporting of this research.

- $\quad$ Any information I provide will be kept confidential to the researcher and his supervisors.

- The results, including potentially some of my photographs, will be used for a final report and academic publications and presented to conferences.

- I may participate in the focus group interviews even if I decide not to participate in the photography activity.

- I would like to receive a summary of findings for my school

Yes

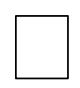

No and have added my email address below.

Signature of participant:

Name of participant:

Contact details:

Date:

Thank you!!

Michael

P.S - Let me know if the $\$ 40$ Tussock voucher runs out 


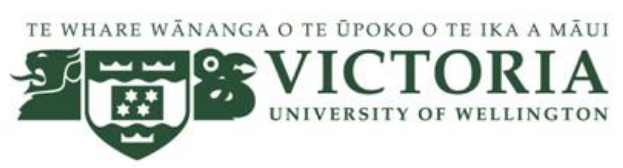

\section{Teaching and learning about colonisation in New Zealand secondary schools \\ Consent Sheet: Students \\ CONSENT TO FOCUS GROUP INTERVIEW}

This consent form will be held for 5 years.

- I would like to be involved in a group discussion

Yes $\square$ No $\square$

I understand that:

- The information provided in this study will be stored in a locked cabinet or on a password-protected computer to ensure that it is safe.

- $\quad$ Because the group interview involves lots of discussion (where the voices of individuals may not be clear from the recording) it will be difficult or impossible to withdraw my contribution to the discussion. However, I can ask for as much as possible of my contribution to be withdrawn up until September $30^{\text {th }}, 2018$.

- I can choose to leave the focus group interview at any time and do not have to give reasons why.

- I won't be named or identified in the research and I can give a pretend name for myself.

- Any information I provide will be kept confidential to the researcher and his supervisors.

- I understand that the results will be used for a final report and academic publications and presented to conferences.

- I would like to receive a summary of findings for my school Yes and have added my email address below.

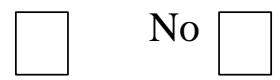


Signature of participant:

Name of participant:

Date:

Contact details: 


\title{
Learning the history of colonisation in Aotearoa/New Zealand
}

\author{
A comparative summary of key quantitative findings \\ for XXXXX College, May, 2019.
}

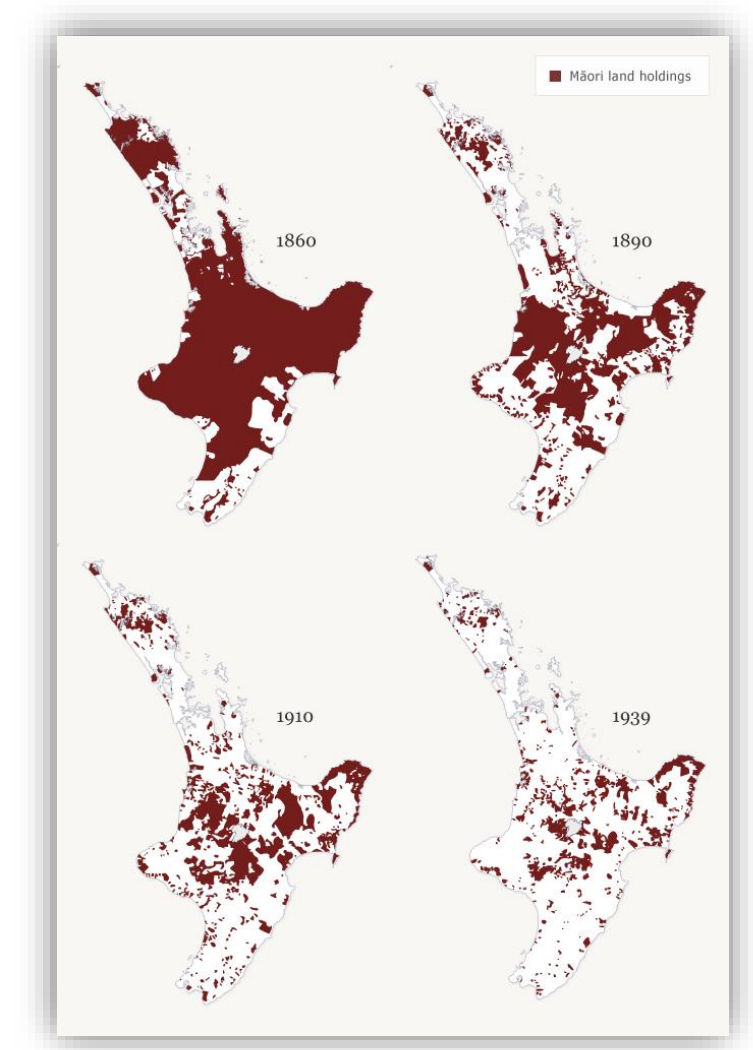

Michael Harcourt

PhD candidate, Victoria University of Wellington

michael.harcourt@vuw.ac.nz 
Past conflict and violence between Māori and non-Māori still has an effect on life in New Zealand today
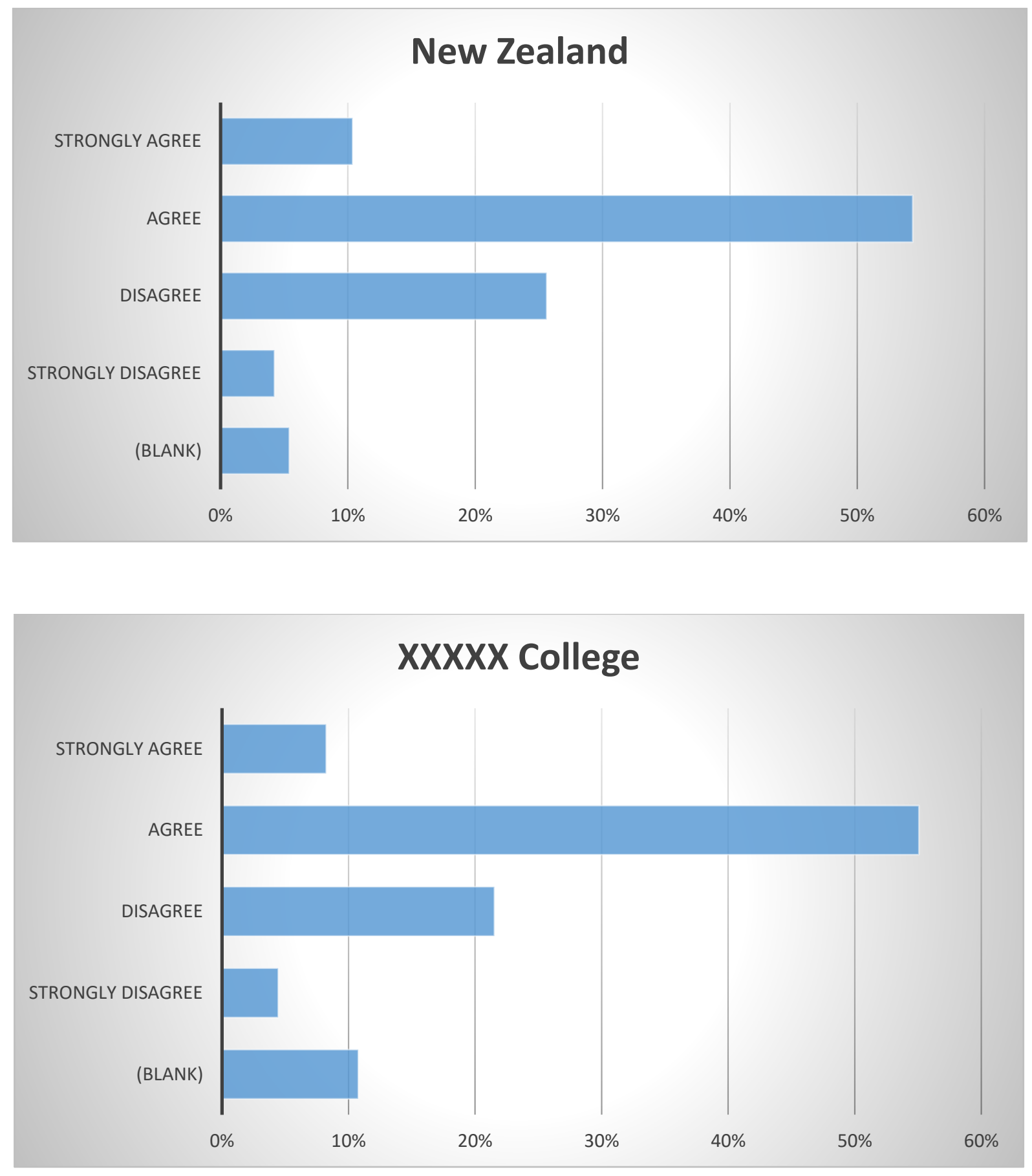
The New Zealand government should say sorry to Māori tribes/iwi for not honouring Te Tiriti o Waitangi/The Treaty of Waitangi
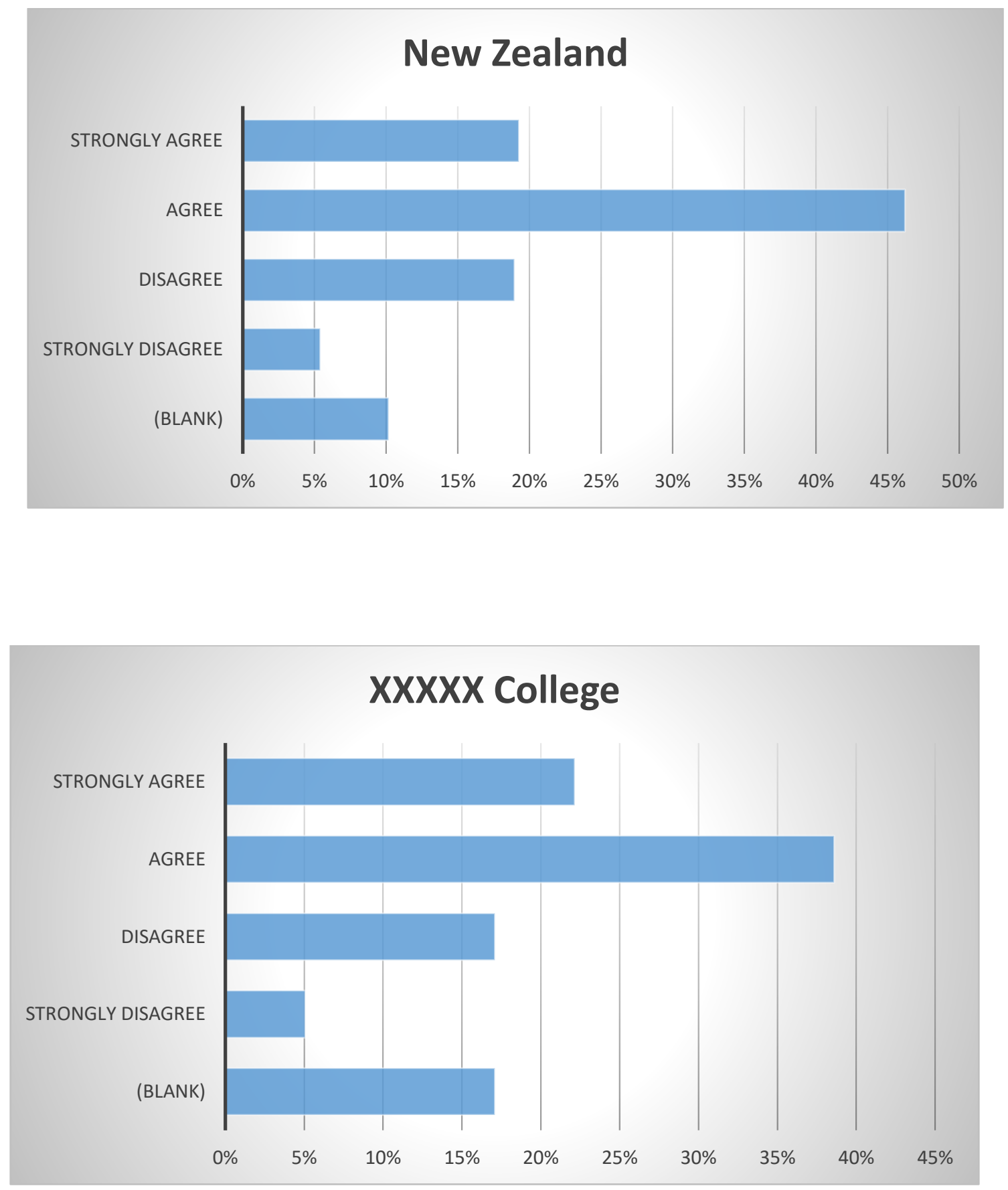
The New Zealand government should give money and/or return land to

Māori tribes who suffered loss of their land during the process of colonisation
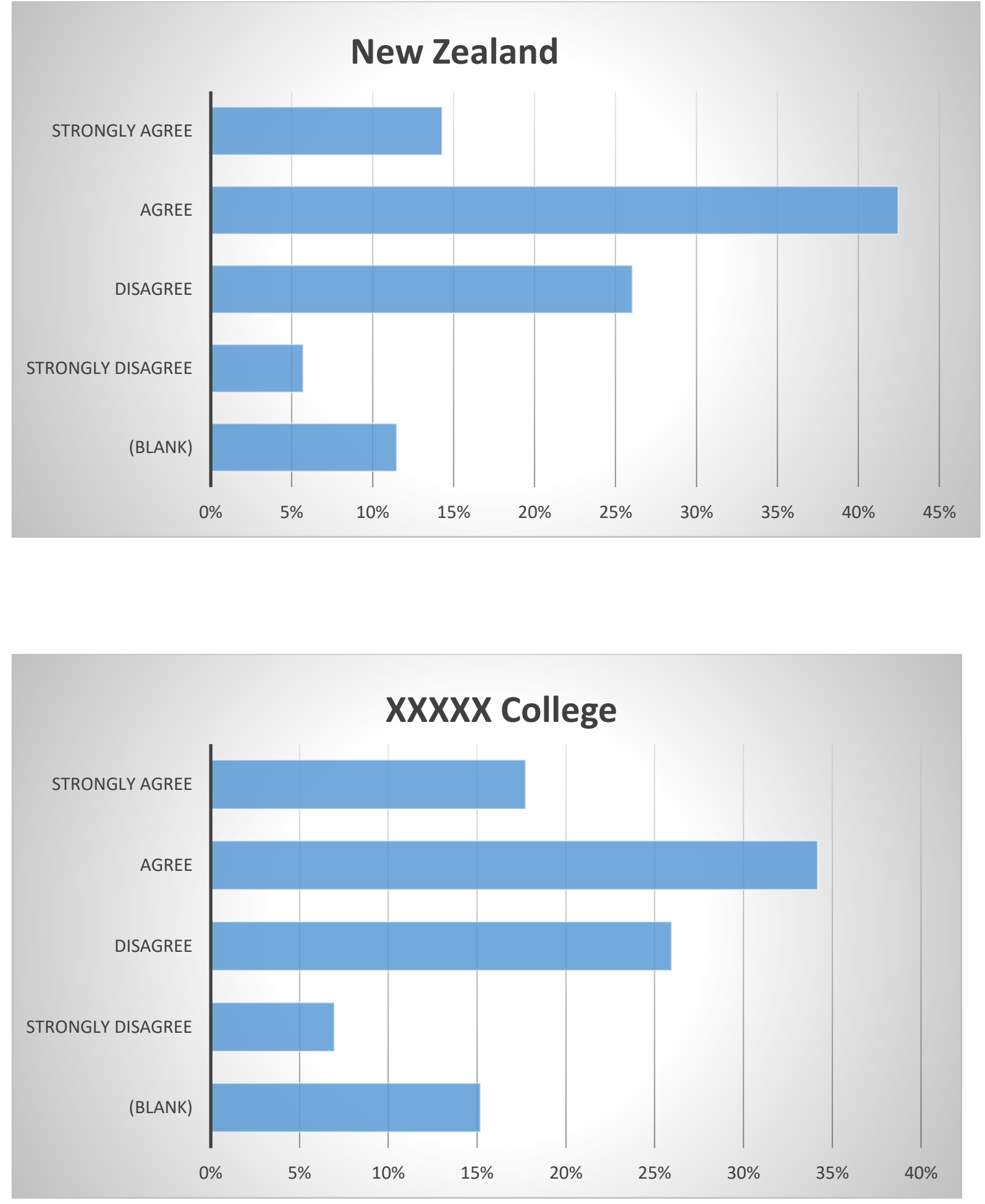
When people learn about the history of conflict and violence between Māori and non-Māori it makes it harder for them to get along today
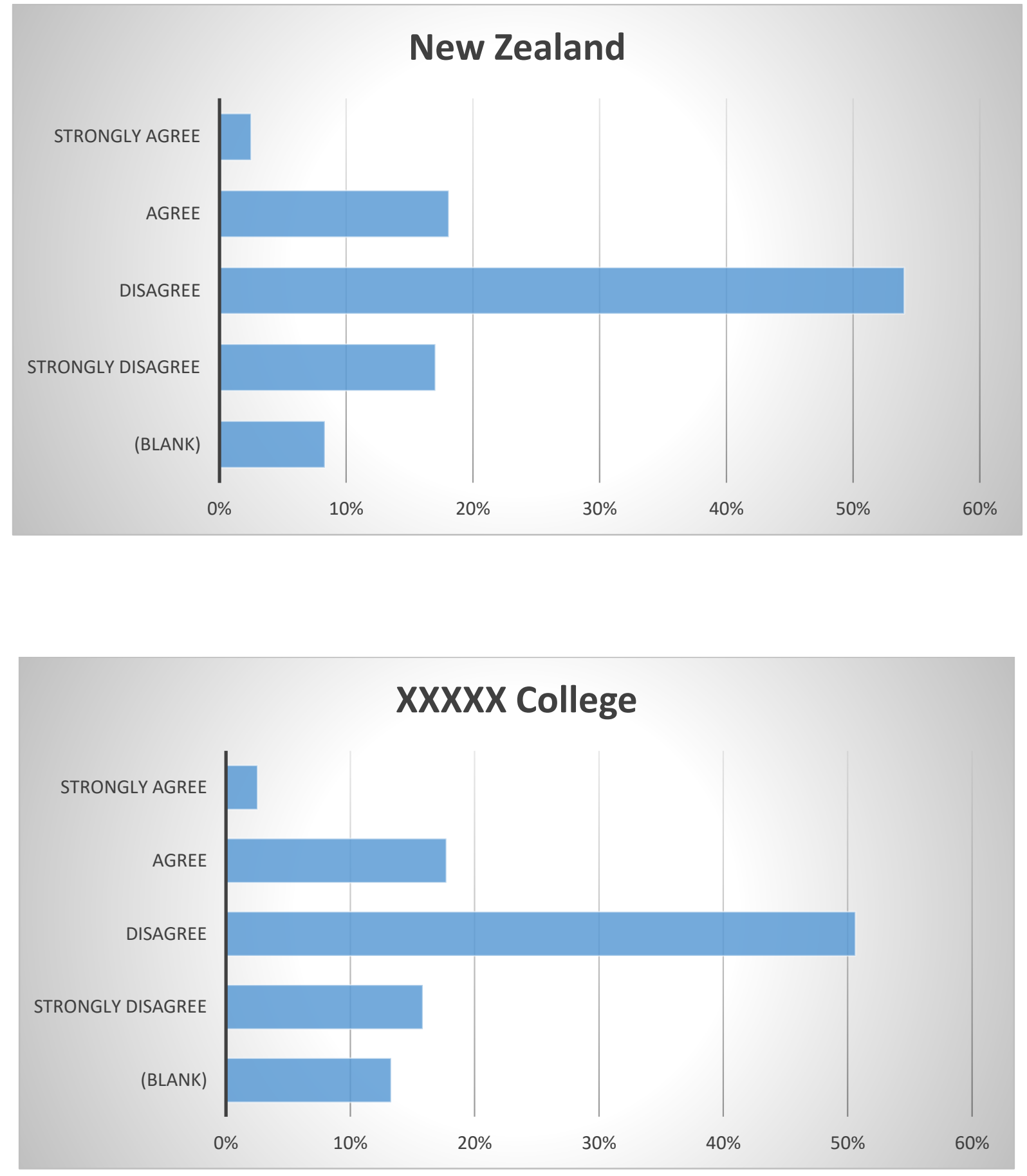
Talking about European colonisation of Aotearoa/New Zealand causes disagreements in my class

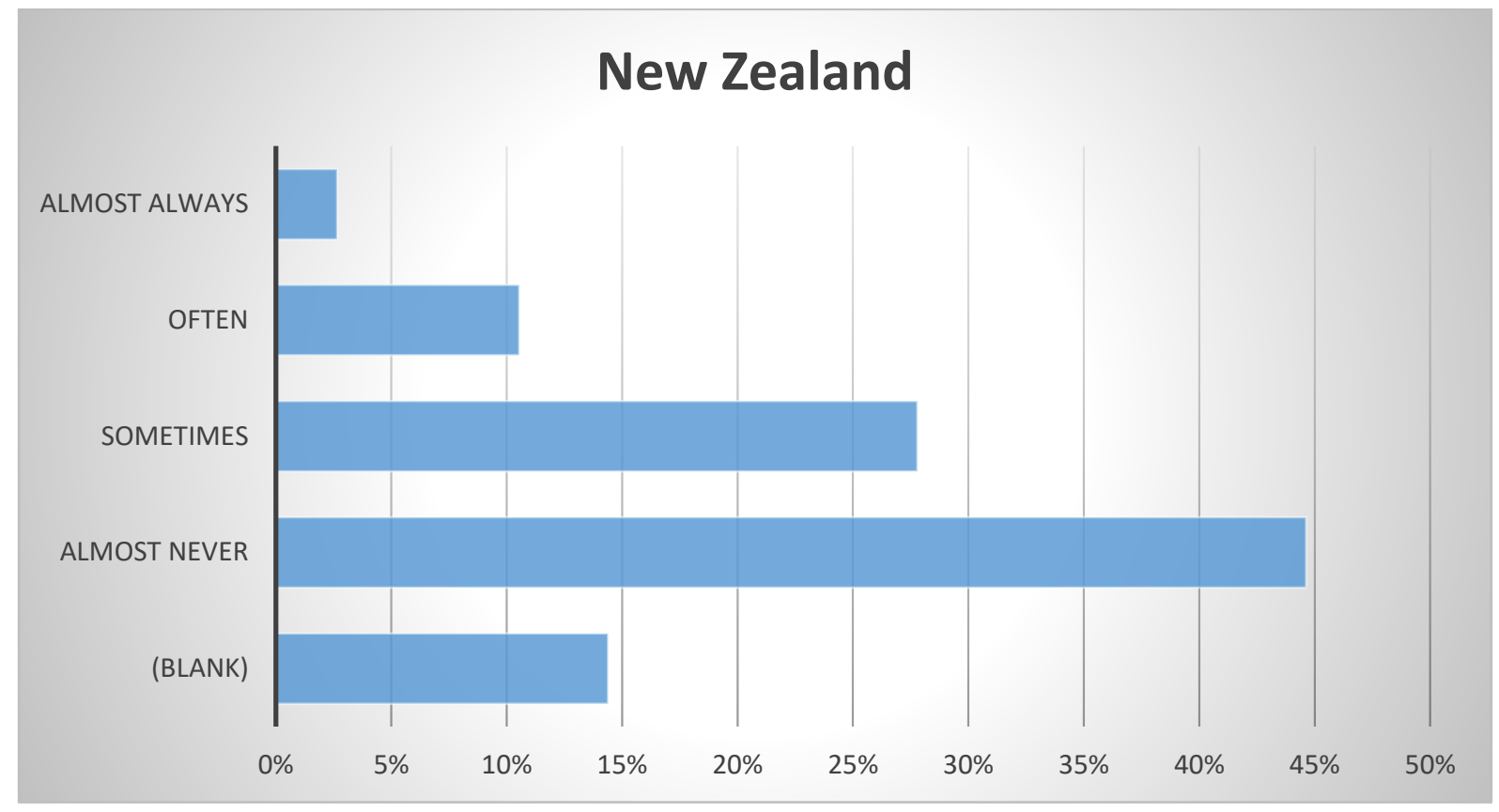

XXXXX College

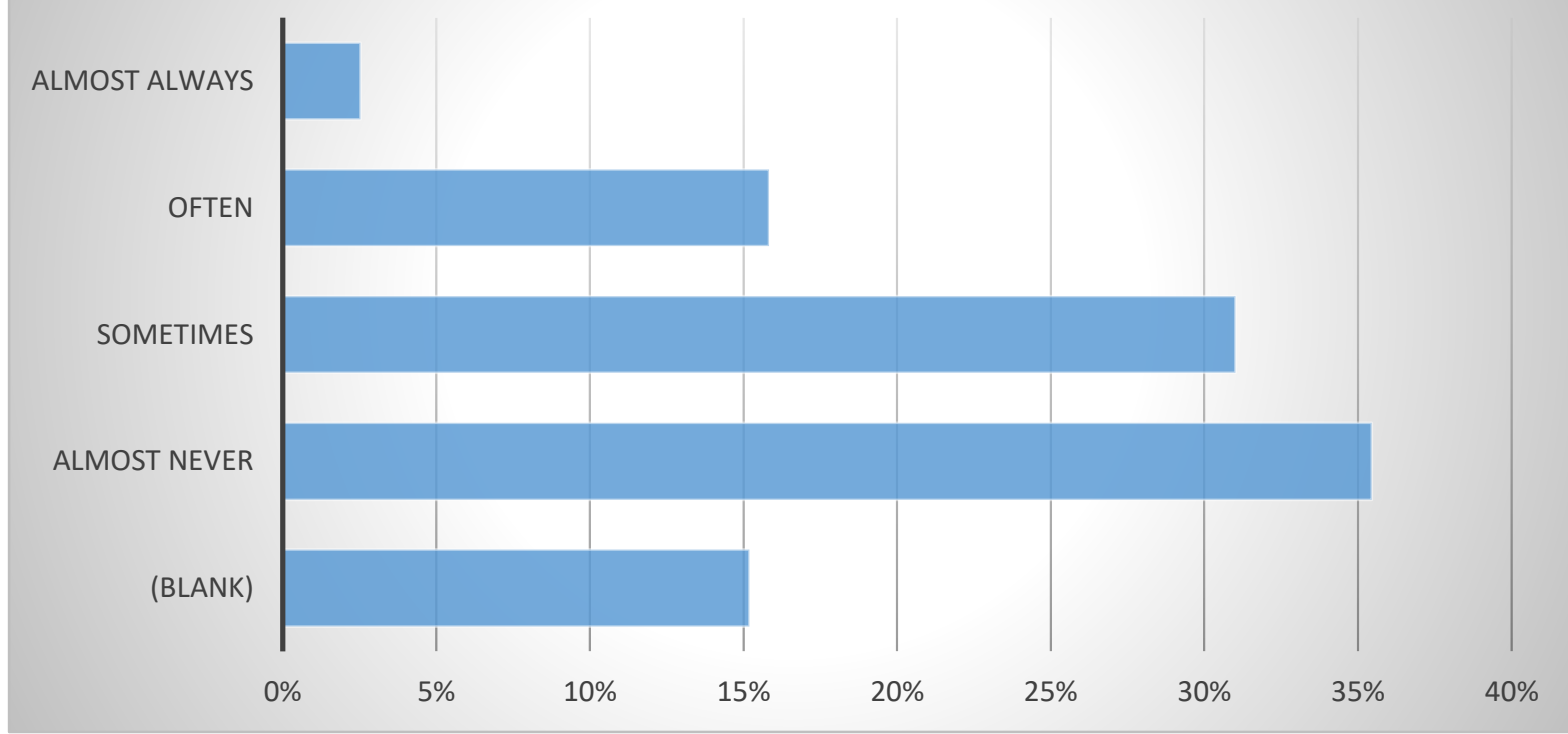


Please indicate the ONE statement that BEST describes your personal feelings about learning New Zealand's history of colonisation

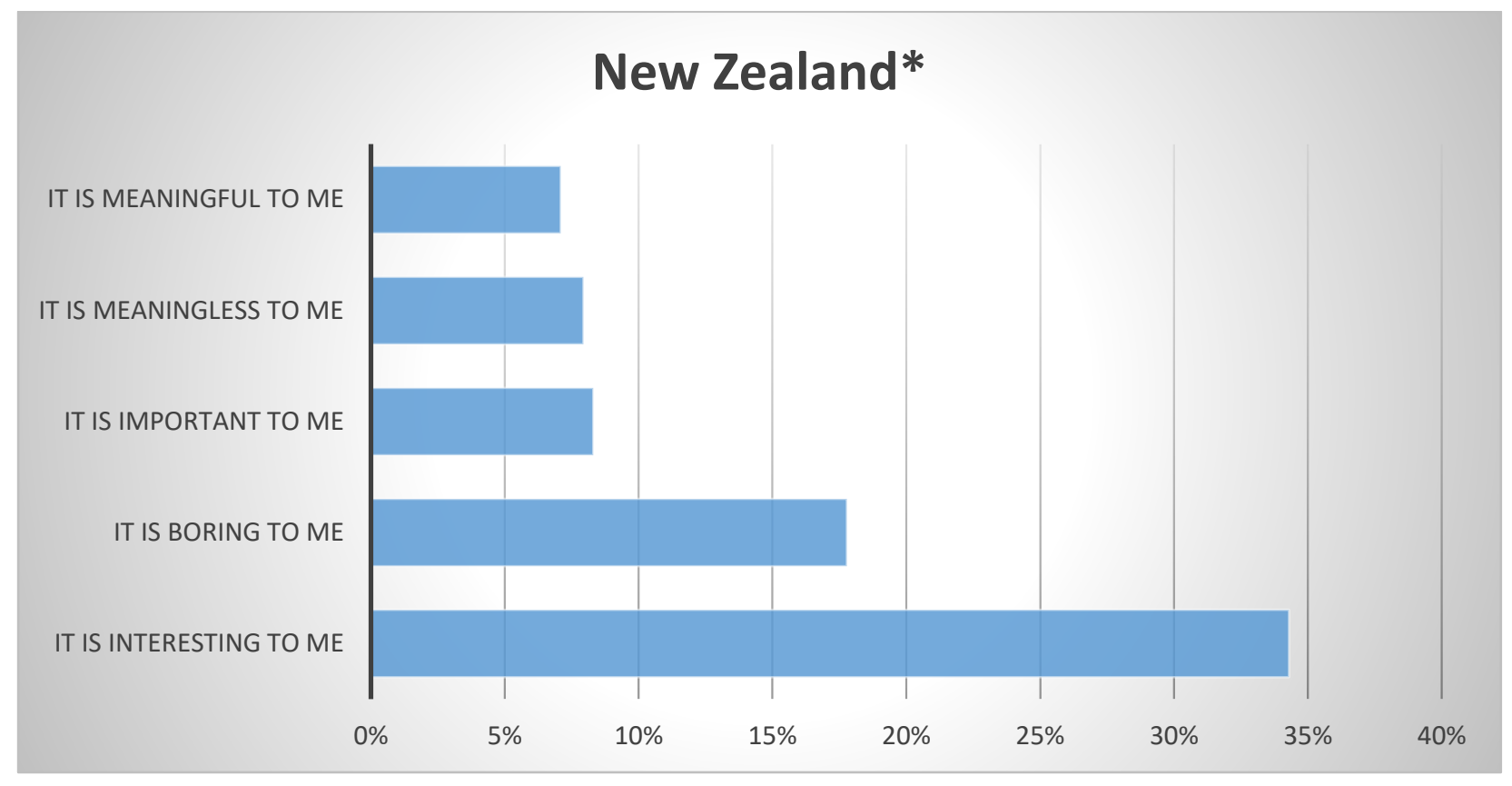

*These are the top five judgements. Nearly $10 \%$ chose 'other' and these responses were often ambiguous. For example, students might have written "it depends", "half and half" or "a bit boring, interesting sometimes".

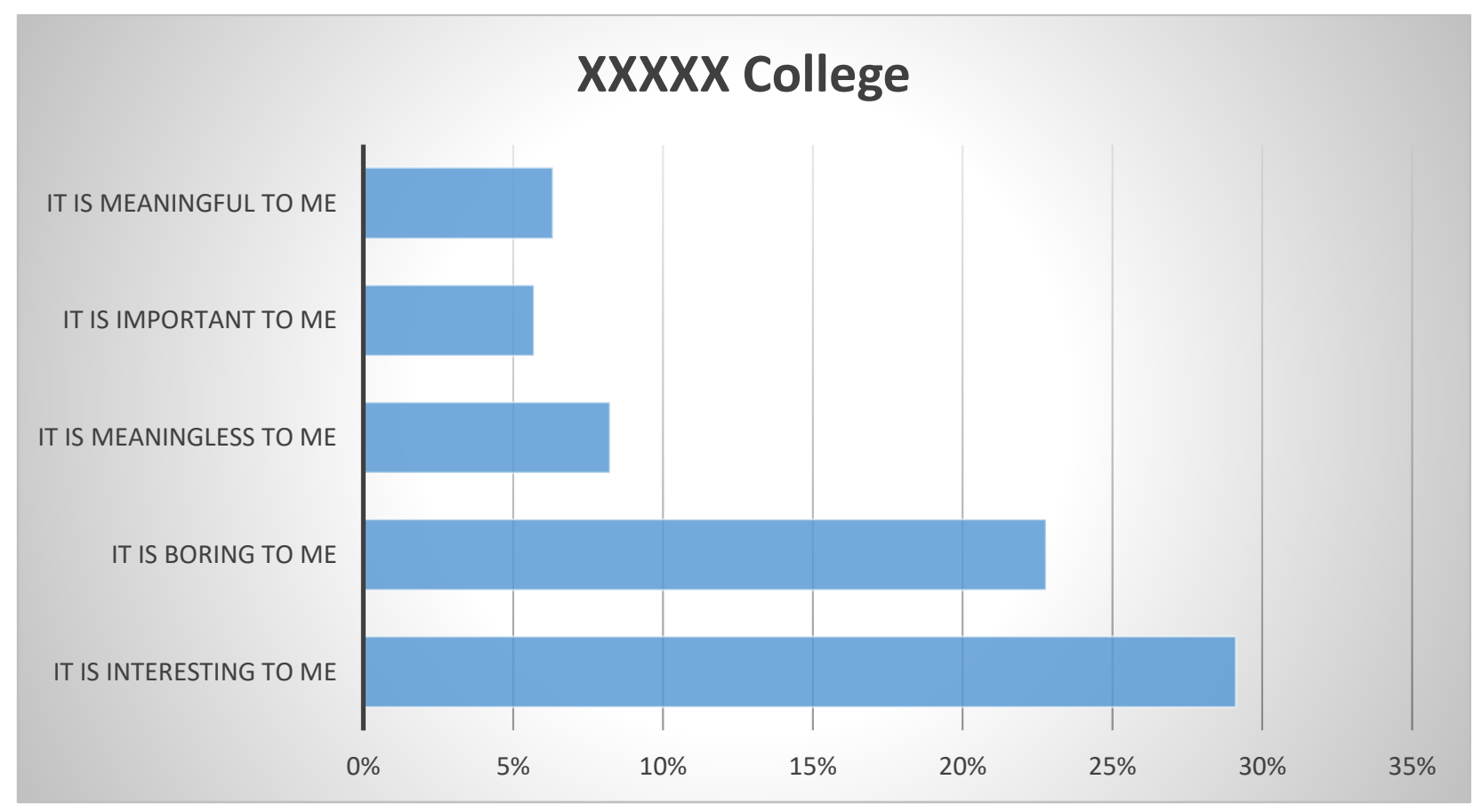




\section{Recommendations}

- Students express a variety of different opinions about colonisation in New Zealand and to varying degrees of intensity. Surprisingly, this does not tend to translate into classroom disagreements. Rationally dealing with disagreement about social issues is arguably one of the social sciences' key contributions to education. The range of perspectives evident in the survey responses from students across New Zealand could be more explicitly drawn upon by teachers as a pedagogical resource through structured, discussion-type pedagogies such as Socratic Seminars or Structured Academic Controversies [https://www.facinghistory.org/resource-library/teachingstrategies/socratic-seminar].

- At a national level, a surprising number of students could not see an historical relationship between past conflict and violence between Māori and non-Māori and New Zealand society today. Other data in my study shows this historical understanding changing over time and students in Year 13 are more likely to recognise that historical events have consequences today than students in Year 9. To deepen students' historical consciousness from a younger age social studies teachers could consider drawing more explicit past and present connections through linking their teaching of the colonial past to contemporary issues and exploring in greater depth the historical thinking concepts of continuity and change.

- Students across all schools tend to find New Zealand's history of colonisation interesting, meaningful and important. A significant percentage, however, struggle to see its significance. The school-specific data in this report could serve as a topic of discussion with your social sciences department. Depending on your school's findings, it could validate what is already being done or be used as a conversation starter for developing new approaches to teaching. 